\title{
Biodegradable Hydrogels by Physical and Enzymatic Crosslinking of Biomacromolecules
}

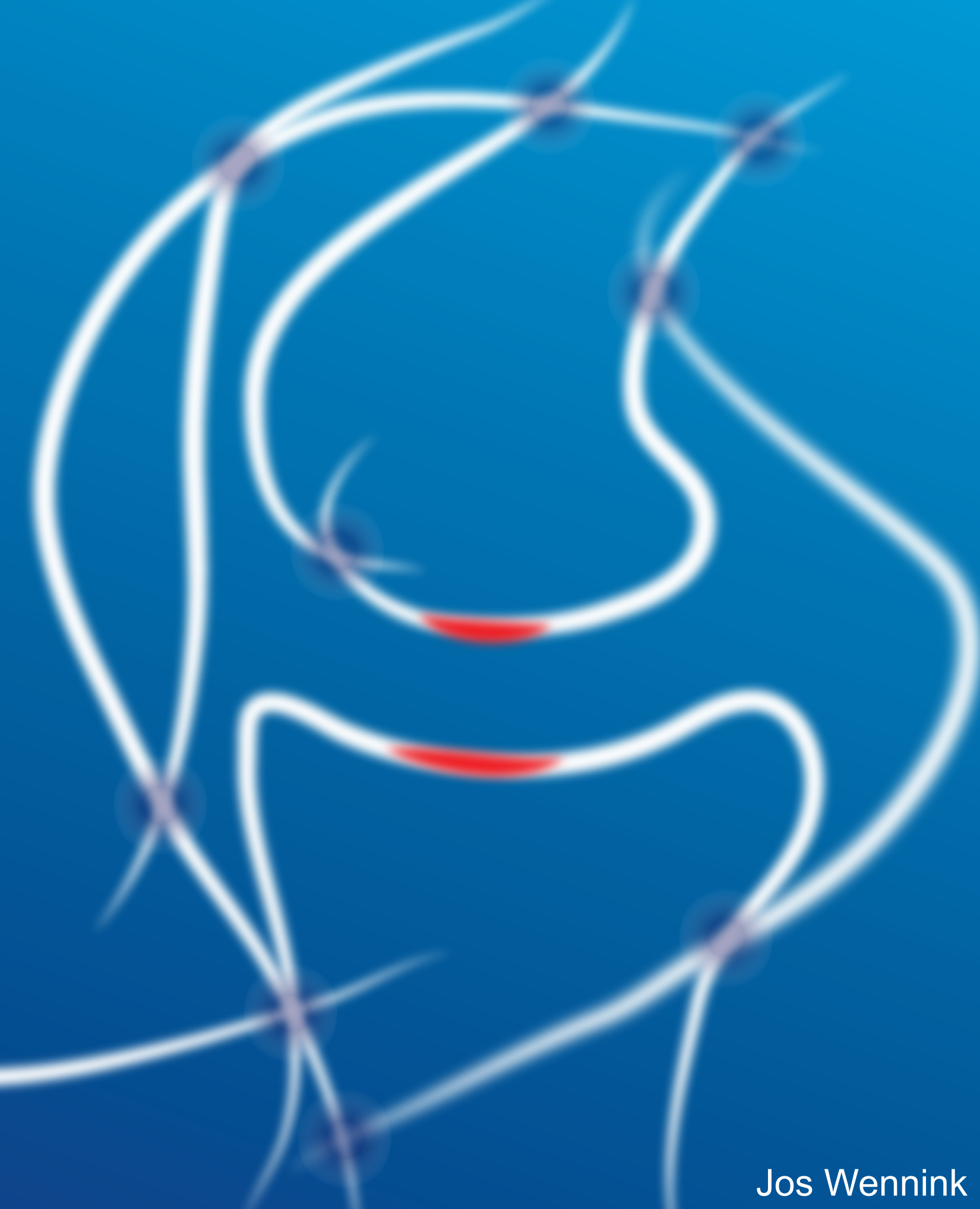




\title{
Biodegradable Hydrogels by Physical and
}

\section{Enzymatic Crosslinking of Biomacromolecules}

\author{
Jos Wennink \\ 2013
}


The research described was financially supported by the BioMedical Materials institute and forms part of the project P2.02 OAcontrol.

Biodegradable hydrogels by physical and enzymatic crosslinking of biomacromolecules Jos Wennink

$\mathrm{PhD}$ thesis with references and summaries in English and Dutch University of Twente, Enschede, The Netherlands.

ISBN: 978-90-365-3503-8

DOI: $10.3990 / 1.9789036535038$

Copyright (C) 2013 by Jos Wennink. All rights reserved

Printed by Ipskamp Drukkers B.V.

Cover design by Jos wennink Artistic drawing of crosslinked biomarcomolecules in the shape of a knee joint. 


\title{
BIODEGRADABLE HYDROGELS BY PHYSICAL AND
}

\section{ENZYMATIC CROSSLINKING OF BIOMACROMOLECULES}

\section{PROEFSCHRIFT}

\author{
ter verkrijging van \\ de graad van Doctor aan de Universiteit Twente, \\ op gezag van de rector magnificus, \\ Prof. Dr. H. Brinksma \\ volgens besluit van het College van Promoties \\ in het openbaar te verdedigen \\ op woensdag 27 maart 2013 om 12.45 uur
}

door

\section{Johannes Wilhelmus Hendrikus Wennink}

Geboren op 28 september 1984

te Hengelo-ov- 
Dit proefschrift is goedgekeurd door de promotoren:

Prof. Dr. J. Feijen

Prof. Dr. P.J. Dijkstra

(C) 2013 Jos Wennink

ISBN: 978-90-365-3503-8 
Samenstelling van de commissie:

Voorzitter Prof. Dr. G. van der Steenhoven

Promotor Prof. Dr. J. Feijen

Universiteit Twente

Promotor Prof. Dr. P.J. Dijkstra

Soochow University

Leden Prof. Dr. Ir. W.E. Hennink

Universiteit Utrecht

Prof. Dr. Ir. J.C.M. van Hest

Radboud Universiteit Nijmegen

Prof. Dr. J.A. Loontjes

Rijksuniversiteit Groningen

Prof. Dr. J.F.J. Engbersen

Universiteit Twente

Prof. Dr. Ir. J. Huskens

Universiteit Twente

Prof. Dr. H.B.J. Karperien

Universiteit Twente

Prof. Dr. Ir. R.G.H. Lammertink

Universiteit Twente 


\section{Table of Contents}

Chapter 1

1

General Introduction

Chapter 2

9

Injectable Hydrogels for Articular Cartilage Tissue Engineering

Chapter 3

43

Aggregation Behavior of Thermo-Responsive and

$\mathrm{pH}$-sensitive four-armed PLLA-PEG copolymers

Chapter 4 69

Aggregation and gelation behavior of

stereocomplexed four-arm PLA-PEG copolymers

Chapter 5

Aggregation and gelation behavior of

hyperbranched PEI-PLLA-PEG copolymers

Chapter 6

PLLA block length dependent aggregation behavior and

enzymatic crosslinking of star-shaped PEG-(PLLA-Tyramine) ${ }_{8}$ copolymers

Chapter 7 135

Injectable Hydrogels by Enzymatic Co-Crosslinking of

Dextran and Hyaluronic Acid Tyramine Conjugates

\section{Chapter 8}

Injectable In-Situ Forming Hydrogels by Enzymatic Co-Crosslinking of

Dextran, Heparin and Hyaluronic Acid Tyramine Conjugates for

Cartilage Tissue Engineering

Summary 179

Samenvatting 182 
(7) Non ses

(x) 1 .

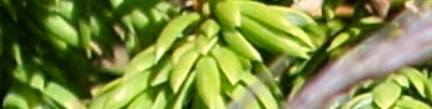

V10. 1.

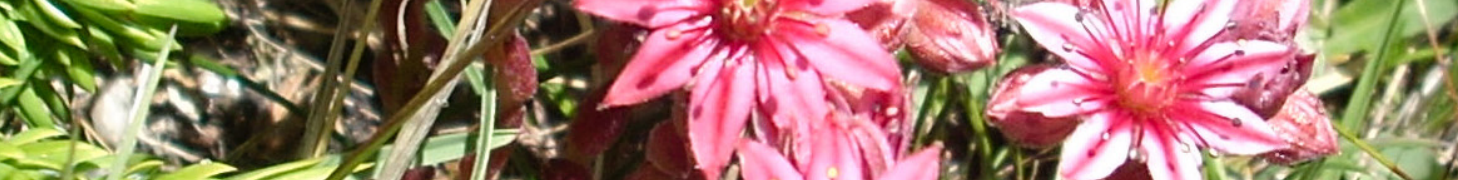

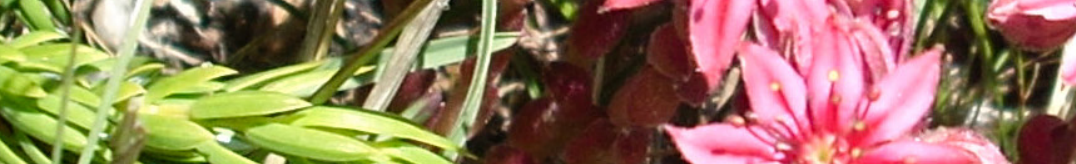
s.

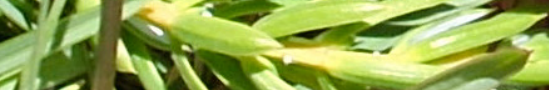

(1)

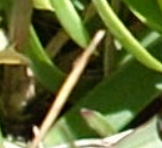

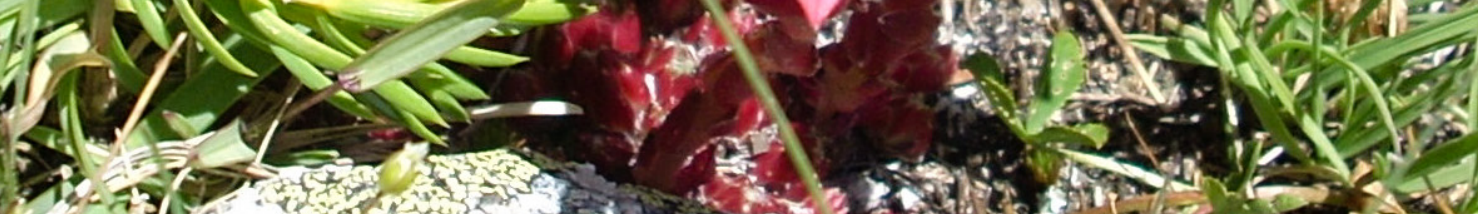

1

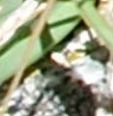

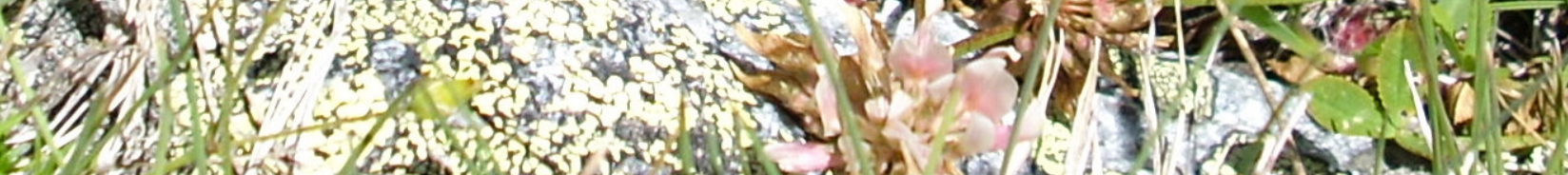
it

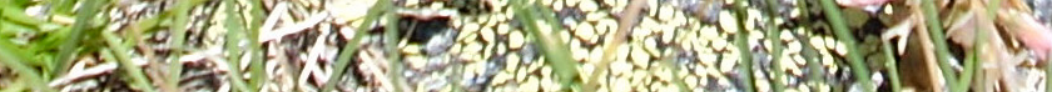
5. 26. $x^{2}$,

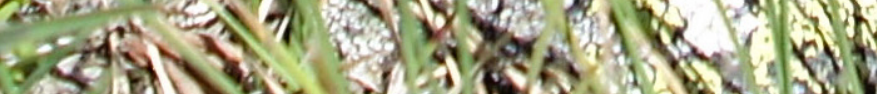
(1)

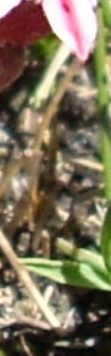
Tion.

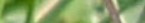
(6), $10,5,2$ (1)

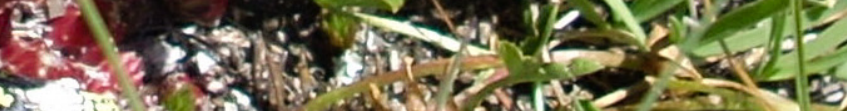
$4 x=50$. (2) 


\section{Chapter 1 General Introduction}

"If we consult the standard chirurgical writers from Hippocrates down to the present age, we shall find, that an ulcerated cartilage is universally allowed to be a very troublesome disease; that it admits of a cure with more difficulty than carious bone; and that, when destroyed, it is not recovered" 


\section{Introduction}

Hydrogels are hydrophilic polymer networks that can retain large amounts of water ${ }^{1}$. Well known examples in everyday use are contact lenses and cosmetics like hair gels. In the past decades hydrogels for biomedical and pharmaceutical applications gained increasing interest. There hydrophilic nature resembles that of soft tissues and potential applications are their use as tissue engineering scaffolds or as drug delivery vehicles. Moreover, due to their high water content hydrogels don't evoke serious immune reactions and show good cytocompatibility ${ }^{2}$.

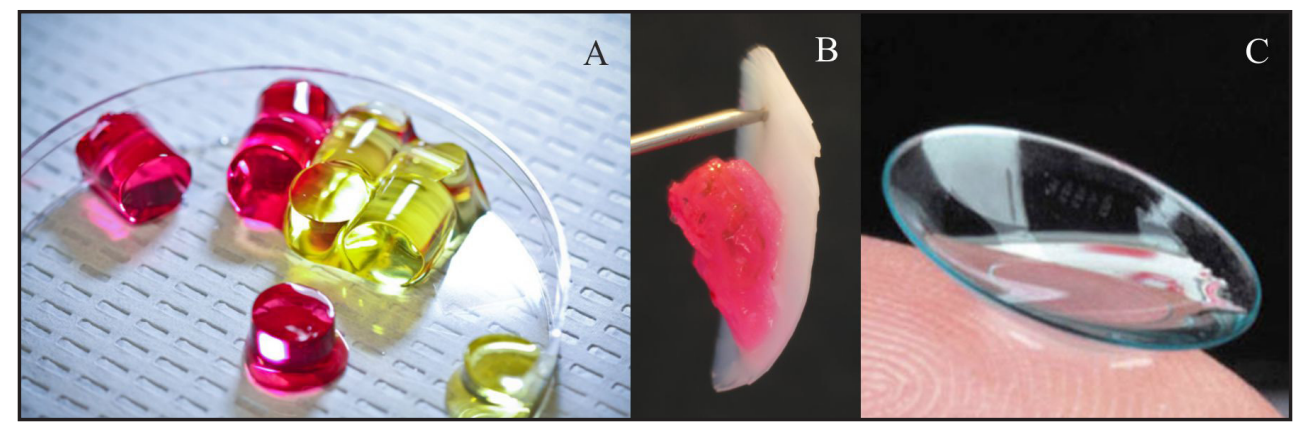

Figure 1. Examples of hydrogels for biomedical and pharmaceutical applications. A) cylindrical hydrogel loaded with a model drug, in this case a yellow or red dye. B) synthetic poly(lactide)-poly(ethylene glycol)-poly(lactide) hydrogel (colored red) placed on cartilage, a natural hydrogel and C) a poly(2-hydroxyethylmethacrylate) soft contact lens.

Hydrogels can be classified either by type of polymer, synthetic ${ }^{3}$ or natural ${ }^{4}$, or by the method of crosslinking, physical or chemical ${ }^{5}$. Natural polymers, like polysaccharides and proteins have inherent macromolecular properties similar to the natural extracellular matrix and can induce specific cell-material interactions. Synthetic materials have the advantage that mechanical properties can be tailored and a much broader range of materials with specific properties can be prepared. However, cell-material interactions and biocompatibility may be an issue and have to be taken into account in the design of these materials. Physically crosslinked hydrogels maintain a network structure by the formation of non-covalent crosslinks through e.g. hydrophobic or ionic interactions. Especially physically crosslinked gels that exhibit a reversible sol-gel transition depending on temperature contributed to a large extend to the development of these materials for biomedical and pharmaceutical applications. Typical examples of these materials are amphiphilic block copolymers of aliphatic polyesters and poly(ethylene glycol) ${ }^{6}$. Depending on type of polymer and hydrophilic to hydrophobic weight ratio a transition from the sol to the gel phase or gel to sol phase takes place when the temperature is elevated. From a biomedical perspective this means that locally in the body a gel can be formed by injection of a polymer solution that will gel by an increase in temperature. 
Chemical crosslinking can be achieved by numerous methods, but always involves the formation of covalent bonds between polymer chains. Recent advances in polymer chemistry made it possible to develop injectable in situ forming chemically crosslinked hydrogels ${ }^{7}$. The formation of the gel at the site of injection also in this case ensures a proper shape filling of a defect (Figure 2) or may be used to induce a local release when a drug is incorporated. The use of polymer precursor solutions also allows for easy incorporation of cells and biologically active compounds before injection. Articular cartilage is a connective tissue that is located at the extremities of articulating bones like the hips, knees, elbows and shoulders. It allows for easy movement by cushioning the impact forces during articulation ${ }^{8,9}$. Articular cartilage resembles to a certain extend a hydrogel for it consists of $65-80 \mathrm{wt} \%$ of water. Cartilage consists also of $20-35 \%$ of an extracellular matrix (ECM). Of the ECM $60 \%$ are collagens, $10 \%$ other proteins and $30 \%$ are proteoglycans. Articular cartilage can be damaged due to trauma, wear or disease. Since cartilage is avascular it has a very limited self-healing capacity and trauma and diseases like osteoarthritis are frequently the cause of disabling symptoms such as pain and limited articulation of the affected joint ${ }^{10,11}$.

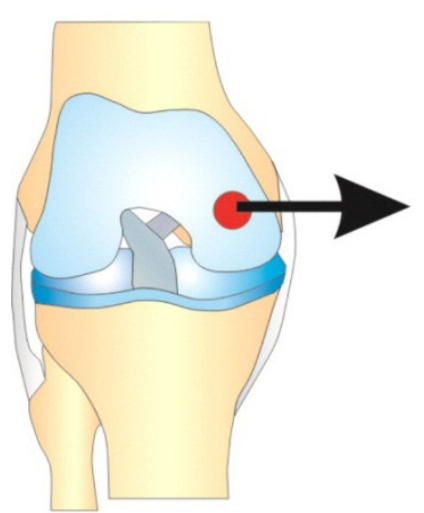

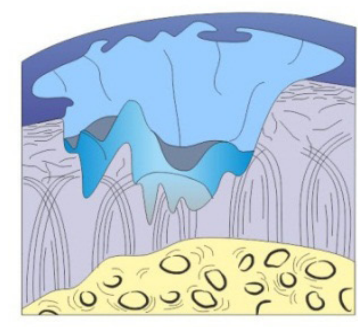

Cartilage defect

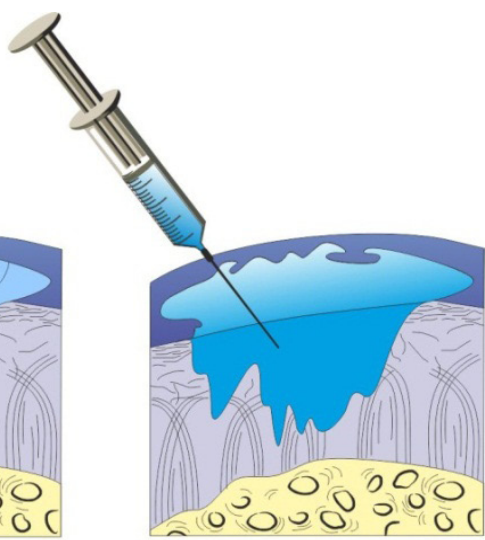

Gel filled defect

Figure 2. Principle of minimally invasive procedure for an in-situ forming injectable hydrogel

Nowadays, treatments for articular cartilage repair include: microfacture mosaicplasty, autologous chondrocyte transplantation and osteochondral allograft transplantation 12, 13 . Although these techniques do relieve pain and improve joint function the repaired tissue often lacks the structure of native cartilage and shows signs of deterioration after 1 year. Recent studies conducted towards in-situ chemically crosslinked hydrogels as scaffolds for articular cartilage repair offer a promising alternative ${ }^{14,15}$. As mentioned above they can 
fill irregularly shaped defects and allow a homogeneous cell distribution (Figure 2). They also introduce the possibility of implantation by arthroscopic techniques thus removing the necessity for open procedures which are costly and have a higher risk of infections.

\section{Aim of the research}

The aims of the work described in the thesis were:

- To study the effect of incorporating positively charged moieties on the aggregation and (thermo-reversible) gelation behavior of amphiphilic block copolymers. The objective is to increase the adhesion of physically crosslinked hydrogels to soft tissues like cartilage that have an ECM that is negatively charged.

- To study the influence of the chemical structure and aggregation behavior of tyramine substituted synthetic and natural polymers on their enzymatic crosslinking. Research was aimed at developing injectable and biodegradable scaffolds with controlled degradation times that support chondrocyte survival and matrix production.

\section{Outline of the thesis}

This thesis is divided into three parts. The introductory part, Chapter 2, provides a literature overview of injectable in situ forming hydrogels currently studied for cartilage tissue engineering. The review summarizes the methods applied and associated problems. Finally an overview of state of the art injectable in situ forming hydrogels and their advantages and disadvantages is presented.

The second part of this thesis focuses on the preparation and properties of amphiphilic block and hyperbranched copolymers comprising cationic groups.

In Chapter 3 we describe the use of PEG-PLLA triblock copolymers comprising a central N-hydroxy-succinimide active ester for the preparation of four-armed (PEG-PLLA) ${ }_{2}^{-}$ $\mathrm{R}$-(PLLA-PEG) $)_{2}$ copolymers with central $\alpha, \omega$-diamide groups (R). When $\mathrm{R}$ comprises secondary amine groups large differences were observed in the aggregation behavior of these polymers. Chapter 4 reports on four-arm stereocomplexed (PEG-PLA) $)_{2}$ R-(PLA-PEG) hydrogels as described in Chapter 3. Upon mixing PBS solutions of enantiomeric 4-armed copolymers gelation readily occurs. Aggregation and gelation studies were performed to elucidate the gelation mechanism for both neutral four-armed stereocomplexed hydrogels and four-armed stereocomplexed (PEG-PLA) $)_{2}$-R-(PLA-PEG) ${ }_{2}$ hydrogels with cationic charges. In Chapter 5 we describe hyperbranched poly(ethylene imine)-poly(L-lactide)-poly(ethylene glycol) $(\alpha-\text { HPEI- } \gamma \text {-(PLLA-PEG) })_{2}$ ) copolymers synthesized by coupling of NHS-(PLLA- 
PEG) $)_{2}$ to the primary amine groups of HPEI with molecular weights $(\alpha)$ of $600,1200,1800$, 5000 or $10000 \mathrm{~g} / \mathrm{mol}$, respectively. The aggregation and gelation behavior was studied. It was found that 1200-HPEI-5.5-(PLLA-PEG) $)_{2}$ and 1800-HPEI-8.2-(PLLA-PEG) formed stable hydrogels while all other hyperbranched copolymers afforded solutions. Based on high resolution magic angle spinning ${ }^{1} \mathrm{H}-\mathrm{NMR}$ studies it was found that the formation of immobile PLLA aggregates is essential for gelation. These results were used to create a model for the aggregation and gelation behavior of the $\alpha$-HPEI- $\gamma$-(PLLA-PEG) $)_{2}$ copolymers.

The third part of this thesis describes a study on the enzymatic crosslinking of tyramine conjugated amphiphilic synthetic block polymers and tyramine grafted natural polymers. In Chapter 6 we describe the synthesis and characterization of eight arm star shaped poly(ethylene glycol)-poly(L-lactide)-tyramine (PEG-PLLA-TA) 8 copolymers. These copolymers were enzymatically crosslinked with horseradish peroxidase and hydrogen peroxide. This study revealed that depending on the PLLA block length the enzymatic crosslinking either afforded hydrogels or crosslinked nanoparticles. In Chapter 7, the horseradish peroxidase mediated co-crosslinking of dextrantyramine (Dex-TA) and hyaluronic acid-tyramine (HA-TA) conjugates is described. Co-crosslinking of Dex-TA and HA-TA afforded hydrogels which can be degraded by hyaluronidase. Furthermore, cytocompatibility studies were performed and chondrocytes incorporated in the gels showed good viability after 28 days of culturing. Chapter 8 reports the chondrogenic potential of dextran-tyramine (Dex-TA), heparintyramine (Hep-TA) and/or hyaluronic acid-tyramine (HA-TA) crosslinked by horseradish peroxidase and hydrogen peroxide. Gelation times, gel content, water uptake, rheological properties and enzymatic degradation times were determined. Chondrocyes were incorporated in hydrogels and the cell-hydrogel constructs were evaluated for cell survival and cartilage specific deposition of extracellular matrix.

\section{References}

1. Hoffman, A. S., Hydrogels for biomedical applications. Advanced Drug Delivery Reviews 2002, 54, (1), 3-12.

2. Lee, K. Y.; Mooney, D. J., Hydrogels for tissue engineering. Chemical Reviews 2001, 101, (7), 1869-1879.

3. Lutolf, M. P.; Hubbell, J. A., Synthetic biomaterials as instructive extracellular microenvironments for morphogenesis in tissue engineering. Nature Biotechnology 2005, 23, (1), 47-55.

4. Augst, A. D.; Kong, H. J.; Mooney, D. J., Alginate hydrogels as biomaterials. Macromolecular Bioscience 2006, 6, (8), 623-633.

5. Hennink, W. E.; van Nostrum, C. F., Novel crosslinking methods to design hydrogels. Advanced Drug Delivery Reviews 2002, 54, (1), 13-36. 
6. Tan, H. P.; DeFail, A. J.; Rubin, J. P.; Chu, C. R.; Marra, K. G., Novel multiarm PEG-based hydrogels for tissue engineering. Journal of Biomedical Materials Research Part A 2010, 92A, (3), 979-987.

7. Van Tomme, S. R.; Storm, G.; Hennink, W. E., In situ gelling hydrogels for pharmaceutical and biomedical applications. International Journal of Pharmaceutics 2008, $355,(1-2), 1-18$.

8. Chiang, H. S.; Jiang, C. C., Repair of Articular Cartilage Defects: Review and Perspectives. Journal of the Formosan Medical Association 2009, 108, (2), 87-101.

9. Buckwalter, J. A., Articular cartilage injuries. Clinical Orthopaedics and Related Research 2002, (402), 21-37.

10. Beris, A. E.; Lykissas, M. G.; Papageorgiou, C. D.; Georgoulis, A. D., Advances in articular cartilage repair. Injury-International Journal of the Care of the Injured 2005, 36, S14-S23.

11. Coutts, R. D.; Healey, R. M.; Ostrander, R.; Sah, R. L.; Goomer, R.; Amiel, D., Matrices for cartilage repair. Clinical Orthopaedics and Related Research 2001, (391), S271-S279.

12. Marlovits, S.; Zeller, P.; Singer, P.; Resinger, C.; Vecsei, V., Cartilage repair:

Generations of autologous chondrocyte transplantation. Eur. J. Radiol. 2006, 57, (1), 24-31.

13. Minas, T.; Nehrer, S., Current concepts in the treatment of articular cartilage defects. Orthopedics 1997, 20, (6), 525-538.

14. Jin, R.; Teixeira, L. S. M.; Dijkstra, P. J.; van Blitterswijk, C. A.; Karperien, M.; Feijen, J., Enzymatically-crosslinked injectable hydrogels based on biomimetic dextranhyaluronic acid conjugates for cartilage tissue engineering. Biomaterials 2010, 31, (11), 3103-3113.

15. Hu, X. H.; Zhu, Y.; Gao, C. Y., Hydrogels for Cartilage Regeneration. Progress in Chemistry 2009, 21, (10), 2164-2175. 


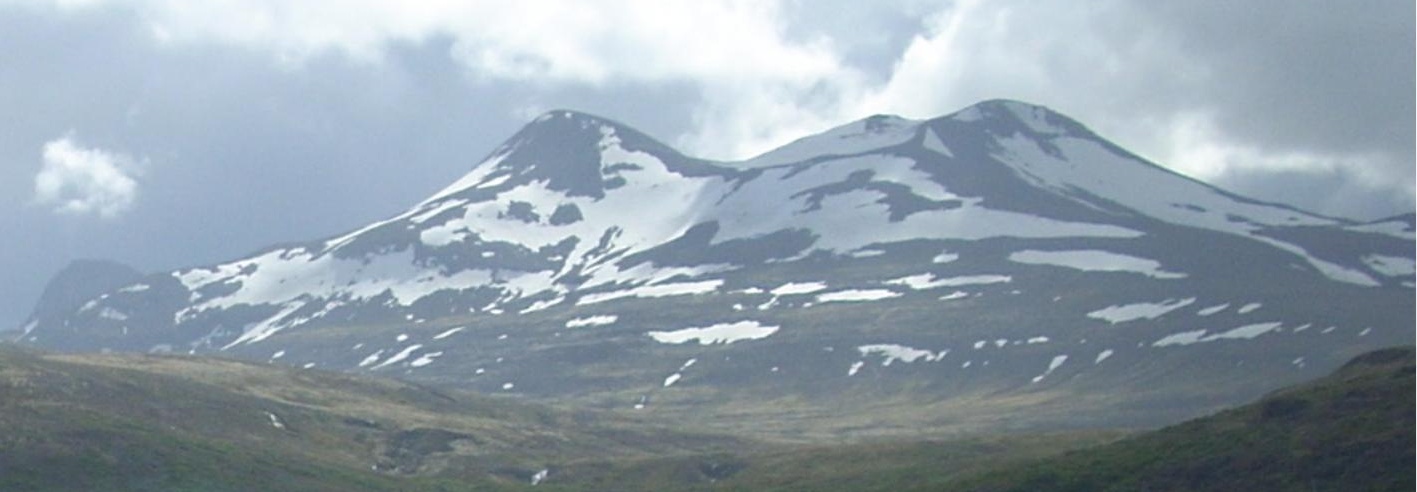

ind

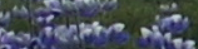

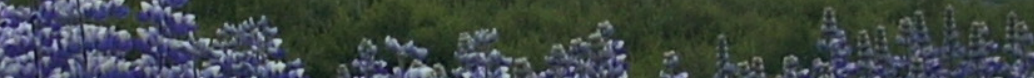
An

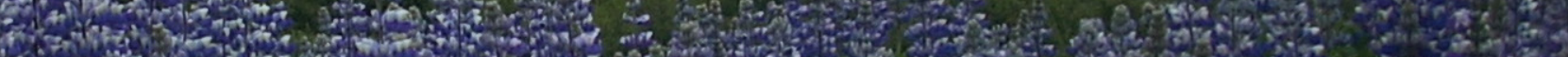

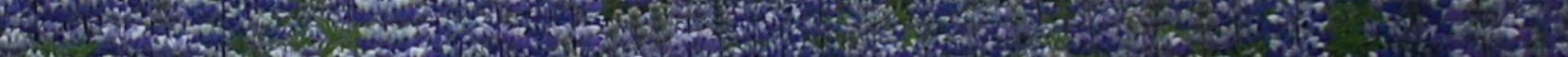
Then

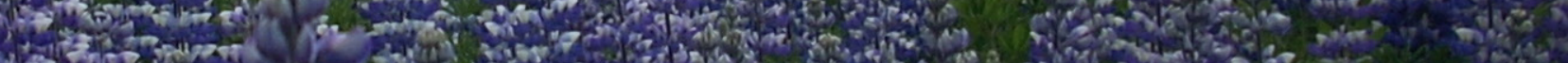

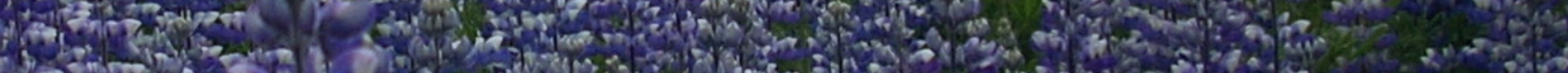

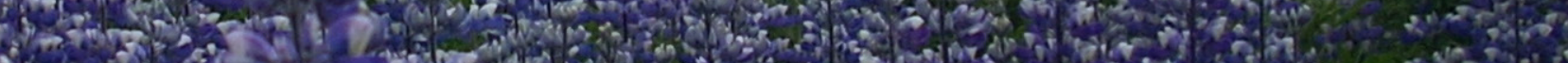

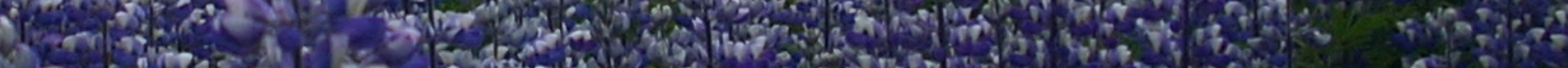
3.t.

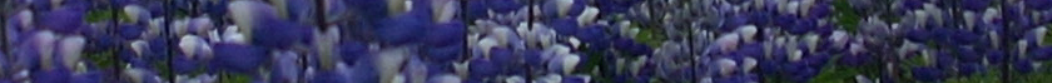

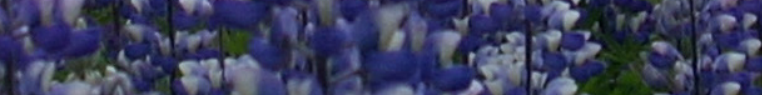

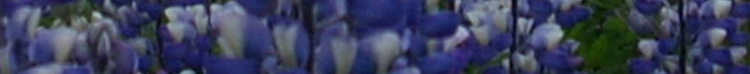

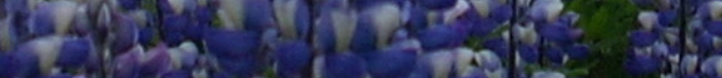

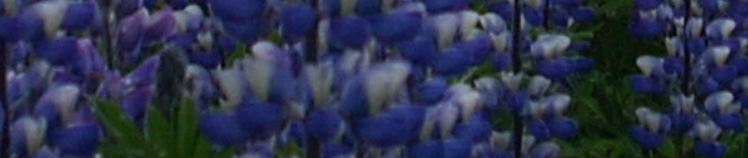

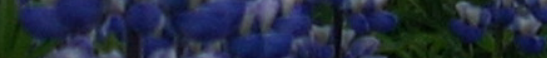

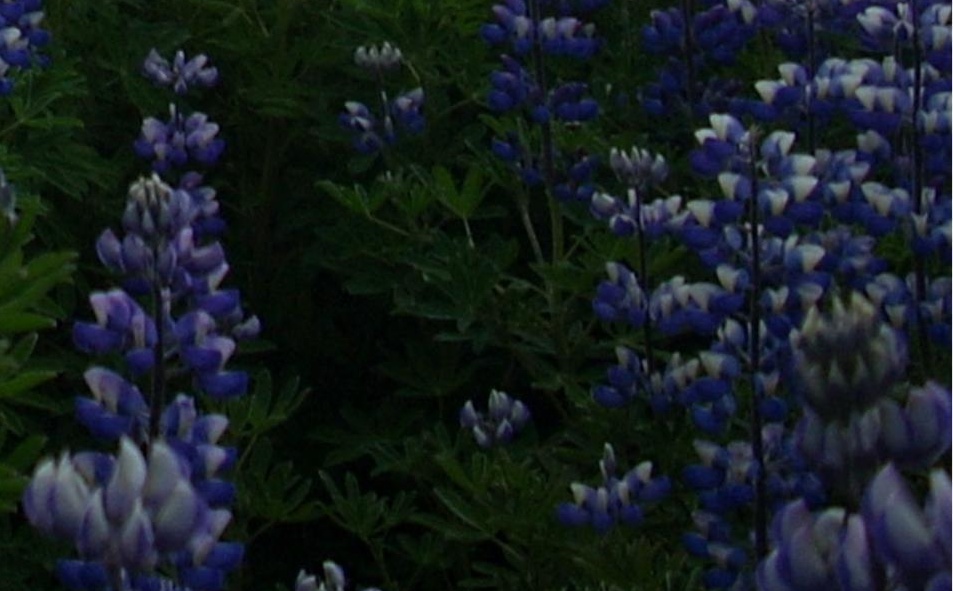




\section{Chapter 2 Injectable Hydrogels for Articular Cartilage Tissue Engineering}

Jos W.H. Wennink, Jan Feijen, Pieter J. Dijkstra and Marcel Karperien 


\begin{abstract}
Articular cartilage is a highly resilient tissue that exhibits a very limited capacity to repair itself once damaged. Current procedures to restore this tissue, such as debridement, microfracture, mosaicplasty and autologous chondrocyte transfer vary largely in success rate and the average long-term results are unsatisfactory. The current long term outlook for patients is the replacement of the biological joint with an artificial prosthesis. In the past decade, as an alternative approach, research has focused on cartilage tissue engineering. In this approach polymeric materials are generally used for the preparation of scaffolds and combined with chondrocytes to provide a temporary matrix that may regenerate into cartilage. Since cartilage is a highly hydrated soft tissue, hydrogels are regarded suitable temporary scaffold materials for cartilage tissue engineering. Especially in-situ forming hydrogels that can be applied by minimally invasive procedures are widely investigated. The current status of cartilage tissue engineering technology using in-situ forming hydrogels is presented in this review. Crosslinking methods to prepare networks, gelation times, scaffold mechanical properties, degradation times and in vitro and in vivo performance of cell-scaffold constructs, all key factors in the regeneration of cartilage tissue, are highlighted.
\end{abstract}




\section{Introduction}

In synovial joints like the hip, knee, elbow and shoulder hyaline cartilage covers the articulating surface of the bones. Hyaline cartilage is a highly resilient tissue and allows articulation of joints without pain. With a population that becomes increasingly active and older articular cartilage injuries and wear are expected to boom in the coming years. Cartilage tissue is not able to repair itself because it is an aneural, avascular and alymphatic tissue. Nowadays an increasing number of patients suffers from joint pain and more than 250.000 knee and hip replacements are carried out in the United States alone each year ${ }^{1}$. Knee and hip implants have a limited life span and revision operations are relatively complicated or not possible at all. Therefore, in the past decades several alternative treatments to restore articular cartilage tissue have been developed. The most common techniques are: microfracture, mosaicplasty and autologous chondrocyte transplantation (ACT). Especially ACT introduced in 1994 can be regarded a breakthrough since it is based on cartilage regeneration using the patients own cartilage cells ${ }^{2}$. In the ACT procedure chondrocytes are isolated from healthy cartilage tissue by a biopsy and cultured to obtain sufficient cells for implantation. After cleaning and covering the defect with a piece of periosteum from bone the cultured chondrocytes are injected under the periosteum filling the damaged area. Ideally the injected chondrocytes produce new cartilage at the damaged area and new healthy tissue is generated. Although this technique is less radical than total knee or hip replacement and improves joint function it is also plagued with several disadvantages. The main limitation of ACT is the low number of cells obtained through the biopsy. Also the rather difficult surgical procedure and the high costs remain drawbacks. A major problem is that fibrocartilage is formed which is mechanically inferior to hyaline cartilage. Due to the mismatch in mechanical properties the long term viability of the regenerated cartilage is limited ${ }^{3}$. Because ACT showed promising results as a methodology to regenerate cartilage tissue scientists started to investigate tissue engineering as an alternative approach. The basic approach to tissue engineering generally involves a combination of cells, scaffolds and biological factors to induce generation of tissues. Since articular cartilage is a soft tissue with a high water content hydrogels have attracted a lot of attention to function as temporary scaffolds for chondrocytes. Especially, physically crosslinked thermo-reversible hydrogels, polymer solutions that form gels upon a change in temperature, and covalently crosslinked in-situ forming hydrogels are currently widely investigated. In both cases polymer solutions can be injected which form a hydrogel at the location site. Such injectable insitu forming hydrogels are highly attractive because they can be applied using minimally invasive techniques ${ }^{4-6}$. Moreover, polymer solutions can be combined with cells to provide a homogeneous cell matrix construct at the defect site which may develop into new cartilage. 
The minimally invasive procedure eliminates drawbacks of open surgical procedures like risk of infections and high operating costs. This review provides an overview of the emerging trends in in-situ forming hydrogels for cartilage tissue engineering.

\section{Composition and structure of articular cartilage}

Articular cartilage present in synovial joints is a specialized connective tissue located at the extremities of long bones. Healthy articular cartilage appears white and slightly translucent and its main role is to absorb, transmit and distribute the forces during articulation in a frictionless way. Articular cartilage is a connective tissues consisting of water (65$80 \%)$, an extracellular matrix (ECM) $(20-35 \%)$ and less than $2 \%$ of cells ${ }^{7,8}$. The ECM consists of $60 \%$ collagen, $30 \%$ proteoglycans and about $10 \%$ of other proteins. The main role of the fibrillar collagen is to provide resistance to shear stresses and compression forces, while the highly hydrated proteoglycan rich matrix acts as a shock absorber ${ }^{7-9}$. Chondrocytes, the cells present in cartilage produce the ECM ${ }^{7,10}$. Their interaction with the ECM is critical for both development and maintenance of the tissue ${ }^{7}$. The immediate microenvironment of the chondrocyte is the chondron which main function is to insulate and physically separate the chondrocyte from direct interaction with the bulk of the load bearing matrix ${ }^{7}$. In articular cartilage different zones can be distinguished which have different functions and compositions. These zones are called the superficial zone, transitional zone, radial zone and calcified cartilage zone. The chondrocytes in these zones have a different size, shape and metabolic activity. The collagen fibrils, a major component of cartilage, are aligned differently in the four zones. In the superficial zone they are oriented horizontally and are thereby resisting the shear forces resulting from the movement of the joint. In the transitional and radial zone the fibrils are oriented randomly and with a high concentration of aggrecan present create a structure that is perfectly suited for shock absorption. In the calcified cartilage zone the fibrils are oriented perpendicular to the bone surface. This orientation is important in the resistance against compression forces. The fibrils are attached to the subchondral bone tissue in order to relay any remaining forces to the underlying bone ${ }^{8}$. 


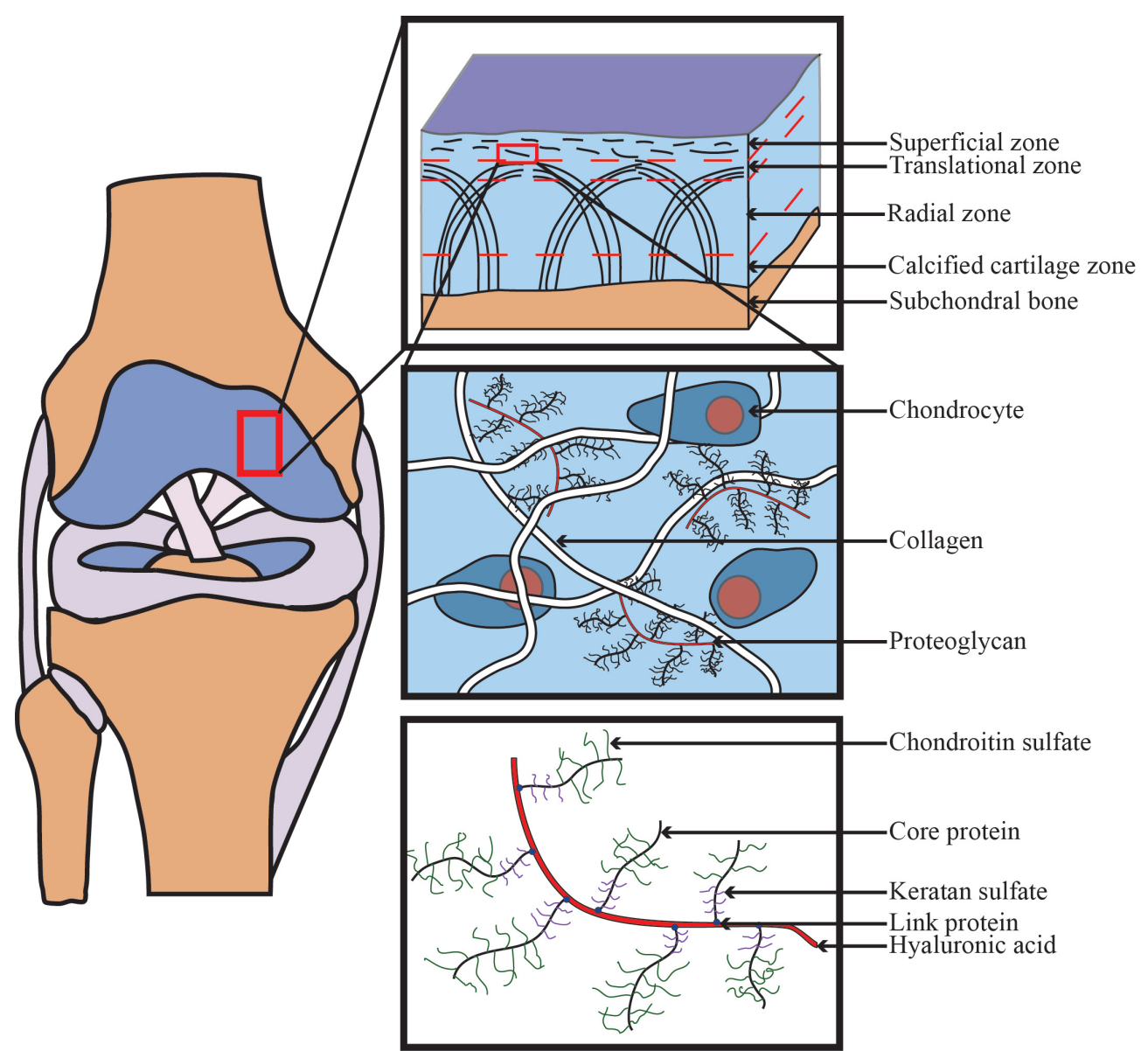

Figure 1. At the top a sectional view of articular cartilage showing the 4 different zones. In the middle a schematic representation of the cartilage macromolecular environment and at the bottom the structure of a proteoglycan aggregate.

Other important components of articular cartilage are the proteoglycans. Two major classes of proteoglycans are found in articular cartilage, large proteoglycans called aggrecans and small proteoglycans including decorin, biglycan and fibromodulin. Proteoglycans are comb like molecules composed of glucosaminoglycans (e.g. chondroitin sulfate and keratan sulfate) linked to a core protein ${ }^{7,9}$. With hyaluronic acid they form large complexes, the aggrecan aggregates, having very high molecular weights. Upon articulation a compressive force is applied to the cartilage and a small amount of fluid is released. After articulation the balance is restored. 


\section{Classification of articular cartilage defects.}

Articular cartilage defects can be due to trauma or diseases. These defects cause many disabling symptoms such as pain and limited articulation of the joint. The International Cartilage Repair Society (ICRS) introduced a classification of cartilage defects based on the Outerbridge classification defined in 1961 (Figure 2) ${ }^{11,12}$. This classification, which ranges from grade 0 to grade 4 , gives a macroscopic description of articular cartilage defects.

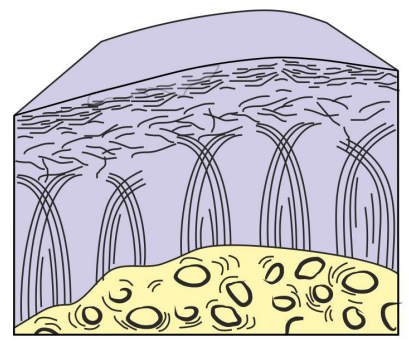

Grade 0

Normal

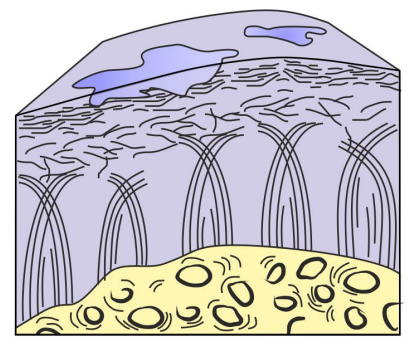

Grade 1 Superficial defects

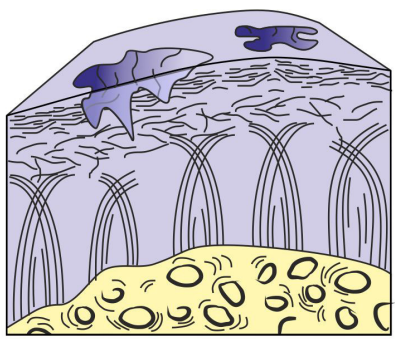

Grade 2

Abnormal

Defect $<50 \%$ of cartilage depth

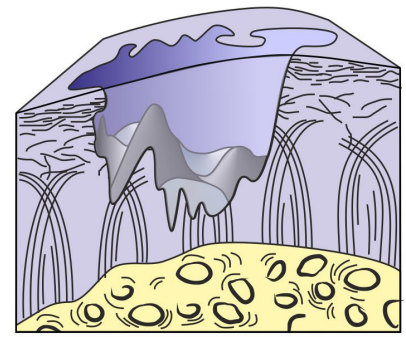

Grade 3

Severely abnormal defects $>50 \%$ of cartilage depth

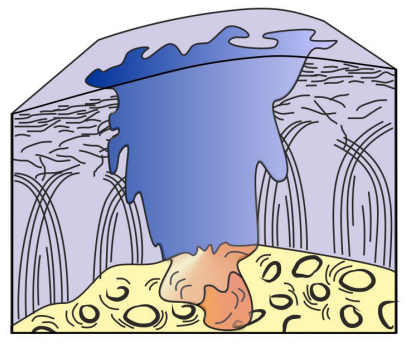

Grade 4

Severely abnormal defects extend through the subchondral bone

Figure 2. International Cartilage Repair Society (ICRS) classification of cartilage defects ${ }^{11}$.

Grade 0 corresponds to normal healthy cartilage. A grade 1 classification is given when the cartilage remains intact but shows increased swelling due to degradation of proteoglycans, which are changes at the macromolecular level. Since the patient is generally not aware of the damage, progressive deterioration leads to further degeneration of the tissue up to grade 2 or even grade $3^{13}$. Grades 2 and 3 classify interruptions in the articular cartilage. These defects are accompanied with an increased proliferation of the chondrocytes and an increased synthesis of matrix molecules. However, the newly formed matrix does not fill the defect and soon cell activity and proliferation cease ${ }^{14}$. The defect becomes permanent, which alters the mechanical function of the joint, thereby increasing the risk of further cartilage degeneration surrounding the defect. A grade 4 defect is an injury that passes through the subchondral bone 
and reaches the bone marrow. This triggers the formation of a blood clot that fills the defect site ${ }^{15}$. After the formation of a dense fibrin network, blood vessels invade the fibrin network and scar tissue is formed ${ }^{16}$. In the following months, a repair tissue intermediate between hyaline cartilage and fibrocartilage is formed ${ }^{17,18}$. This tissue has inferior mechanical properties with less proteoglycans and collagen type II as present in healthy articular cartilage. After 1 year, this repair tissue often shows signs of deterioration such as, fibrillation, fragmentation and irregularities, which promotes degeneration of the surrounding healthy cartilage ${ }^{15}$.

\section{Strategies for cartilage repair.}

Current clinical treatments for articular cartilage repair include: abrasion, microfracture, mosaicplasty and ACT ${ }^{19}$. Abrasion is an arthroscopic procedure that debrides the cartilage defect (Figure 3A). Subsequently, a hole is drilled up to the osteochondral bone in order to attract stem cells from the underlying bone marrow to trigger a repair response. This procedure is typically applied in case of small $(\sim 1 \mathrm{~mm})$ cartilage defects. For larger cartilage defects the microfracture technique can be used (Figure 3B). This technique is similar to abrasion and also relies on activation of the underlying bone marrow. The method can be applied to treat larger defects and involves drilling of small holes in the osteochondral bone that are placed 3-5 mm apart and approximately $3 \mathrm{~mm}$ in depth. Initially, a blood clot is formed which is followed by a repair process. Long term follow ups of 41 months have led to the conclusion that abrasion and microfracture provide effective short term functional improvement but show shortcomings including poor hyaline cartilage formation and degradation and deterioration of tissue in the defect site.

In mosaicplasty or osteochondral autograft/allograft transfer (Figure 3C) plugs (cartilage and the underlying subchondral bone) are removed from a non-weight bearing unaffected area of the knee. The plugs are used as autograft implants and placed in the defect. Several problems are encountered with osteochondral autograft transfer, the main one being that the structure and composition of the cartilage donor site does not match with the defect site which results in a mismatch in biomechanics. This mismatch can be solved with osteochondral allograft transfer. In this case the plug is harvested from donor tissue at a similar place providing a similar structure and composition of the cartilage. Drawbacks of this technique are chances of rejection, transmission of viral diseases and limited donor availability. 
A) Abrasion
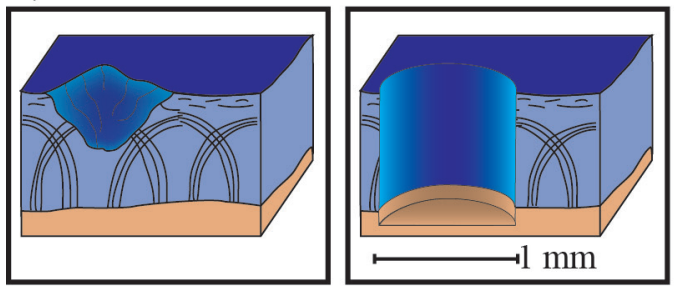

B) Microfracture
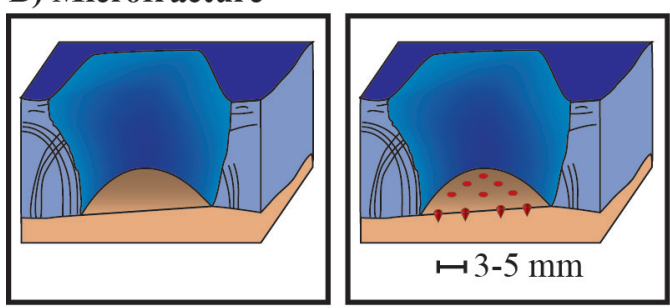

\section{C) Mosaicplasty}
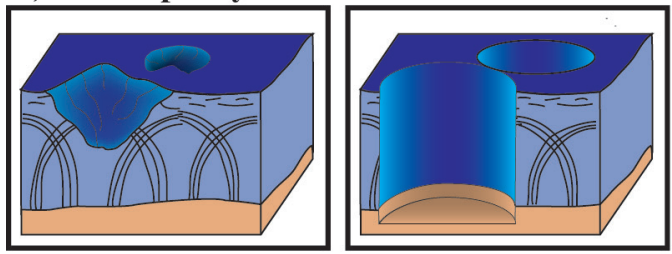
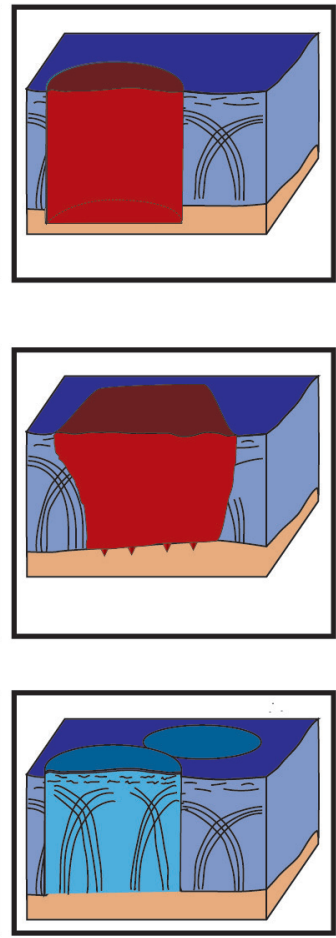

\section{D) Autologous Chondrocyte Transplantation}

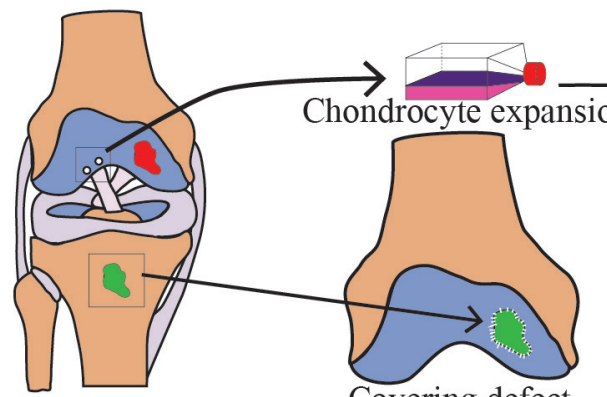

Covering defect

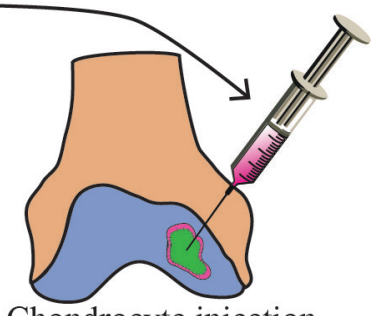

Chondrocyte injection

with periosteal flap under the periosteal flap

Figure 3. Schematic representation of A) abrasion; left panel cartilage defect; middle panel after drilling to the subchondral bone; right panel formation of a blood clot, B) microfracture; left panel cartilage defect; middle panel after puncturing; right panel formation of a blood clot, C) mosaicplasty; left panel cartilage defect; middle panel after drilling a hole to the subchondral bone; right panel insertion of autologous cartilage plug, D) ACT procedure. 
ACT was described in 1994 by Brittberg and coworkers in treating grade 4 defects in the human knee (Figure 3D) ${ }^{20}$. In the first stage chondrocytes are isolated from a biopsy of healthy cartilage at a non-load bearing area. Within a period of 4-6 weeks culturing, 5 to 10 million chondrocytes can be obtained. Stage two involves debridement of the defect site and covering the defect with a periosteal flap. The chondrocytes are subsequently injected under the periosteal flap. The surgical procedure is rather complex and expensive. The fibrocartilage formed in time is biomechanically inferior to native articular cartilage.

New strategies to generate articular cartilage have emerged from the rapidly developing field of tissue engineering ${ }^{21,22}$. For the fabrication of new cartilage tissue three different approaches are generally chosen, (I) guided tissue regeneration using engineered matrices, (II) injection of cells or (III) cells seeded within matrices ${ }^{23}$. In the most frequently used approach cells are seeded on a scaffold and grown in vitro. The resulting tissue engineered material is implanted in the appropriate location. For cartilage engineering a great deal of progress has been made using solid scaffolds ${ }^{22,24}$. Scaffold materials must be biocompatible whereas the construct should be mechanically stable and permeable to allow cell seeding and migration. Ideally, the material is biodegradable and primarily serves as a temporary construct which is in time replaced by newly synthesized ECM. A wide variety of materials have been explored to construct scaffolds that suffice the above mentioned requisites, such as poly(lactide-co-glycolic acid) (PLGA) ${ }^{25}$ or poly(ethylene glycol terephthalate)/ poly(butylene terephthalate) (PEO/PBT) scaffolds ${ }^{26}$. Despite the large progress made several limitations have been encountered. It is often difficult to achieve a homogeneous distribution of cells within a 3-dimensional construct. Additionally, bulky scaffolds necessitate invasive implantation procedures which are costly and have a higher risk of infections than minimally invasive procedures.

\section{Hydrogels}

Recent studies conducted using hydrogels as scaffolds for articular cartilage repair show that hydrogels offer a promising alternative for solid scaffolds ${ }^{27-30}$. The high water content of hydrogels mimics that of native cartilage tissue and creates a protective environment for chondrocytes. In addition, nutrients, waste products, growth factors and cell-signaling molecules can diffuse freely throughout the gel. Applying in-situ gelation, the formation of a gel from precursor solutions at the site of implantation, allows an accurate and complete filling of irregularly shaped cartilage defects. Moreover, the formation of hydrogels in-situ also allows the use of arthroscopic procedures. 


\section{Hydrogels: Material considerations for cartilage tissue engineering}

\section{Physical versus chemical crosslinking}

Several methods can be applied for in situ formation of hydrogels. These methods can be classified by the nature of network formation: by physical or chemical crosslinking. In physically crosslinked hydrogels the crosslinks are formed by e.g. hydrophobic interactions, ionic interactions, hydrogen bonds, supramolecular self-assembly or inclusion complexes. Especially, temperature dependent gelation induced by hydrophobic interactions in amphiphilic block copolymers has been extensively studied. Depending on the composition, concentration and architecture of the block-copolymer, the phase transition from a solution to a gel can take place by increasing or decreasing the temperature. When the transition temperature is close to body temperature hydrogels can be formed in-situ ${ }^{31,32}$. The mechanical strength of physically crosslinked hydrogels is generally low and gels easily deform under stress without regaining their former shape. During articulation cartilage tissue is subjected to high mechanical stresses and therefore in general physically crosslinked hydrogels are not suitable as scaffold materials for cartilage repair. In the past decade in-situ forming chemically crosslinked hydrogels have been developed. Such gels, which have much higher strength, can be prepared from soluble precursors having complementary reactive groups. These reactive groups are introduced in the polymer chains by conjugation or end group functionalization. Alternatively, conjugated groups may be used to form covalent bonds between adjacent polymer chains by the action of e.g. radical initiators or enzymes. For any application, it is desirable that chemical reactions take place with minimal unwanted side reactions to nearby tissue. Unlike preformed scaffolds, crosslinking agents and noncrosslinked material remain in an injectable gel, so all reactants must be non-cytotoxic at the concentrations they are employed.

\section{Mechanical properties}

Cartilage can experience forces up to six times the body weight and compressive stresses approaching $10 \mathrm{MPa}{ }^{33}$. The kinetic coefficient of friction of cartilage is lower than 0.005 ${ }^{34}$. The nearly frictionless properties of cartilage result from a complex combination of fluid film lubrication, boundary lubrication and synovial fluid pressurization. Because articular cartilage is a load-bearing tissue, hydrogels filling up defects should not collapse under the compressive and shear stresses of the joint. Ideally, the hydrogel should have mechanical properties matching those of the native tissue, maintaining its structural integrity during use and adequately transmitting physiological forces during its replacement by regenerated tissue. 


\section{Crosslink density}

The crosslink density of a hydrogel is an important parameter for controlling its mechanical behavior, the diffusion of several important chemical compounds in the gel and the rate of degradation and therefore this parameter will also have a significant effect on the behavior of cells incorporated in hydrogels ${ }^{35,36}$. Less densely crosslinked hydrogels have a larger mesh size, which allows better diffusion of nutrients and waste products to and from the chondrocytes ${ }^{37}$. It has been shown that chondrocytes produce more cartilage ECM components when encapsulated in PEG hydrogels with lower crosslink densities. It has also been noted that the mesh size of the hydrogels should be larger than the size of proteoglycan aggregates to ensure sufficient diffusion and thereby better assembly of newly formed tissue 38 .

\section{Degradation}

Degradable hydrogels allow initial mechanical support that is gradually transferred to the evolving cartilage matrix over time. The degradation rate of scaffolds should proceed on the time scale of tissue formation so that the chondrocytes are provided with a constant stable platform for cartilage development ${ }^{36,39}$. If the scaffold degrades prematurely, the injury site will also be subjected to compressive stresses that will cause further inflammation and degradation of cartilage tissue. If the scaffolding degrades too slowly, it will prohibit new tissue formation. To couple the kinetics of hydrogel degradation to cartilage formation, PEGbased hydrogels have been modified with peptide sequences that can be cleaved by matrix metalloproteinases (MMP) produced by cells ${ }^{40-43}$. In this way the cell activity determines the rate of degradation of the hydrogel.

\section{Hydrogels: Biological considerations for cartilage tissue engineering}

\section{Zonal organization}

Articular cartilage is organized into zones (Figure 1), which have different physical, mechanical and biological functions and properties. The non-calcified region is organized into three zones: superficial, middle and deep. The chondrocytes in each zone have different morphologies and exhibit different responses to environmental stimuli. Importantly chondrocytes isolated and cultured from the different zones have been reported to retain different biosynthetic activities. By isolating chondrocytes from the different zones the "zonal memory" of these cells has been used to influence the regeneration process by placing them in separate layers. A recent review on the approaches followed has been reported by the group of Hutmacher ${ }^{44}$. As an example, when chondrocytes harvested from the different zones are embedded 
in separate layers of photo-crosslinkable PEG hydrogels it was shown that bi-layered constructs with a top layer containing chondrocytes form the superficial zone and bottom layer with chondrocytes from the radial zone had better shear, $8.63 \mathrm{kPa}$, and compressive properties, $30.60 \mathrm{kPa}$, than hydrogels containing a random mixture of isolated and cultured chondrocytes that had a shear of $3.25 \mathrm{kPa}$ and compressive properties of $16.00 \mathrm{kPa}{ }^{45,46}$. In other studies bi- or multilayered hydrogels, in which each layer has different mechanical properties, were used to investigate this zonal organization on the regeneration of cartilage ${ }^{47}$. Immature bovine chondrocytes from different zonal regions have been seeded into bilayered constructs composed of 2 and $3 \%$ agarose having different mechanical properties. After several weeks of culturing, a zonal chondrocyte organization and depth-dependent biochemical content similar to native cartilage were obtained. A different approach to induce zonal organization is based on the application of mechanical loading of cell gel constructs. Kock et al. developed a bioreactor that indents constructs with a bar, which moves over the construct without relieving the indentation strain ${ }^{48}$. The sliding indentation induced depth dependent ECM deposition and the highest GAG content was found in the top half of the construct. Computing methods may also be a valuable addition to experimental studies. Results from a numerical study suggest that sliding indentation stimulates the formation of a superficial zone with parallel fibers ${ }^{49}$. Lateral compression, on the other hand may induce the formation of vertical fibers in the deep zone. These results reveal that proper application of mechanical stimuli may improve the formation of cartilage with a zonal organization.

\section{Adhesion}

An implant should adhere well to the surrounding tissue in order to transfer loads effectively and to prevent that no new defects will form around its circumference. This is a major challenge to the success of regenerative strategies and must be addressed to achieve successful cartilage regeneration. Hydrogel adhesion to adjacent cartilage has been rarely reported ${ }^{50-}$ ${ }^{52}$. Elisseeff and coworkers have investigated the chemical attachment of PEG hydrogels to surrounding cartilage tissue through tissue initiated photo-polymerization ${ }^{52}$. In this method tyrosyl radicals are generated on collagen exposed at the defect surface by photo-oxidation of tyrosine groups. A PEG-diacrylate macromer solution is subsequently injected into the defect and polymerized by tyrosyl radical initiation and UV excitation. The method results in good adhesion of the in-situ formed hydrogel to cartilage. 


\section{Growth factors}

Incorporation of growth factors into hydrogels has been applied to stimulate cartilage tissue formation. Growth factors like IGF1, TGF- $\beta 1$, TGF- $\beta 2$, TGF- $\beta 3$ and BMP-2 can have a positive effect on the production of ECM, or guiding stem cells to differentiate into chondrocytes. It has been shown that fibrin hydrogels implanted in osteochondral defects in horses and loaded with IGF1facilitate chondrogenisis in the stem cell pool of the subchondral bone ${ }^{53}$. Mikos and coworkers have reported that the use of hydrogels in which IGF1and TGF- $\beta 1$ have been incorporated improves cartilage regeneration in vitro and in vivo ${ }^{54,55}$. Moreover, they have shown that application of an OPF hydrogel with incorporated TGF- $\beta 3$ (section: radical polymerization) stimulates chondrogenic differentiation ${ }^{56}$. In a study by Elisseeff and coworkers it was shown that incorporation of TGF- $\beta 3$ and hyaluronic acid in a PEG hydrogel for culture of cartilage enhanced proteoglycan production ${ }^{46}$. When used independently, TGF- $\beta 3$ and hyaluronic acid induced cartilagespecific gene expression and collagen type II production. When used in combination enhanced proteoglycan production and reduced expression and production of collagen type I was observed compared to hydrogels with only TGF- $\beta 3$ or hyaluronic acid. Vacanti and coworkers showed that a chondrocyte culture with a PEG- poly(N-isopropylacrylamide) (PNIPAAM) hydrogel loaded with TGF- $\beta 2$ showed an increased synthesis of collagen type II compared to PEG-PNIPAAM hydrogel cultured without TGF- $\beta 2{ }^{57}$. Chondrocytes are prone to de-differentiate into fibroblast-like cells during their culture in vitro. In the presence of BMP-2 these fibroblast-like cells re-differentiate into chondrocytes ${ }^{58}$. It was shown that these chondrocytes had the ability to produce collagen type II and aggrecans when embedded in alginate hydrogels. 
Table 1. Effect of different parameters on cartilage regeneration using hydrogels as scaffold materials.

\begin{tabular}{|c|c|c|c|}
\hline Parameter & $\begin{array}{l}\text { Type of } \\
\text { hydrogel }\end{array}$ & Observation & Refs. \\
\hline $\begin{array}{l}\text { Hydrogel } \\
\text { crosslinking } \\
\text { density }\end{array}$ & $\begin{array}{l}\text { PEG- } \\
\text { based }\end{array}$ & $\begin{array}{l}\text { A less densely crosslinked network results in } \\
\text { enhanced production of ECM components which } \\
\text { are more homogeneously dispersed. }\end{array}$ & $36-39$ \\
\hline $\begin{array}{l}\text { Mechanical } \\
\text { stimulation }\end{array}$ & Agarose & $\begin{array}{l}\text { Dynamic compression in combination with the } \\
\text { incorporation of TGF- } \beta 3 \text { results in neocartilage } \\
\text { formation possessing a similar compressive } \\
\text { modulus as native cartilage. } \\
\text { Shear mechanical stimulation in combination } \\
\text { with the incorporation of TGF- } \beta 1 \text { results in lower } \\
\text { coefficients of friction. } \\
\text { Mechanical stimulation and incorporation } \\
\text { of TGF- } \beta 1 \text { increases the tensile modulus of } \\
\text { engineered cartilage. }\end{array}$ & $\begin{array}{l}59 \\
60 \\
61\end{array}$ \\
\hline $\begin{array}{l}\text { Zonal } \\
\text { organization }\end{array}$ & $\begin{array}{l}\text { PEG- } \\
\text { based } \\
\text { Agarose }\end{array}$ & $\begin{array}{l}\text { Harvested chondrocytes from different zones } \\
\text { resulted in better mechanical properties and zonal } \\
\text { organization in bi layered hydrogels. } \\
\text { Varying the crosslink density can result in zonal } \\
\text { organization }\end{array}$ & $\begin{array}{l}45,46 \\
47\end{array}$ \\
\hline $\begin{array}{l}\text { Degradation } \\
\text { rate }\end{array}$ & $\begin{array}{l}\text { PEG- } \\
\text { based }\end{array}$ & $\begin{array}{l}\text { A degradation rate that complements formation of } \\
\text { ECM results in increased ECM production. }\end{array}$ & $\begin{array}{l}37-40, \\
43,62\end{array}$ \\
\hline $\begin{array}{l}\text { Hydrogel } \\
\text { tissue adhesion }\end{array}$ & $\begin{array}{l}\text { PEG- } \\
\text { based } \\
\text { Dextran- } \\
\text { based }\end{array}$ & $\begin{array}{l}\text { Strategies that aim to covalently attach gels at the } \\
\text { interface. }\end{array}$ & $50-52$ \\
\hline $\begin{array}{l}\text { Incorporation } \\
\text { of IGF1 }\end{array}$ & $\begin{array}{l}\text { PEG- } \\
\text { based } \\
\text { Fibrin }\end{array}$ & Increased ECM synthesis. & $\begin{array}{l}51,53 \\
57,63\end{array}$ \\
\hline $\begin{array}{l}\text { Incorporation } \\
\text { of TGF- } \beta 1\end{array}$ & $\begin{array}{l}\text { PEG- } \\
\text { based } \\
\text { Fibrin } \\
\text { Peptide- } \\
\text { based }\end{array}$ & $\begin{array}{l}\text { Induced differentiation of MSC to chondrocytes } \\
\text { results in increased chondrogenesis. }\end{array}$ & $64-69$ \\
\hline $\begin{array}{l}\text { Incorporation } \\
\text { of TGF- } \beta 2\end{array}$ & $\begin{array}{l}\text { PEG- } \\
\text { based }\end{array}$ & Increased collagen synthesis & 57 \\
\hline $\begin{array}{l}\text { Incorporation } \\
\text { of TGF- } \beta 3\end{array}$ & $\begin{array}{l}\text { PEG- } \\
\text { based }\end{array}$ & Increased ECM synthesis & $\begin{array}{l}46,70, \\
71\end{array}$ \\
\hline $\begin{array}{l}\text { Incorporation } \\
\text { of BMP-2 }\end{array}$ & $\begin{array}{l}\text { Alginate- } \\
\text { based }\end{array}$ & $\begin{array}{l}\text { Re-differentiation of fibroblast-like cells in } \\
\text { chondrocytes }\end{array}$ & 58 \\
\hline
\end{tabular}




\section{Injectable hydrogels for cartilage tissue engineering}

Current approaches in regenerative medicine are directed towards using less invasive surgical techniques with the objective of reducing tissue morbidity and duration of hospitalization. Insitu forming hydrogels that can be applied using arthroscopic techniques largely contribute to this development. In the following section we summarize injectable in situ forming hydrogels investigated as temporary scaffolds in cartilage tissue regeneration. Crosslinking methods, gelation times, storage moduli, degradation times and in vitro and in vivo performance are key parameters taken into account.

\section{Injectable hydrogels for cartilage engineering: chemistry and material properties}

\section{Michael addition}

A promising method that can be applied to covalently crosslink hydrophilic polymer conjugates into hydrogels is the Michael type addition between thiols and acrylates or vinyl sulfones (Figure 4) ${ }^{72-74}$. The reaction can be performed under physiological conditions and proceeds with a much higher reaction rate than that of naturally present primary amines with the corresponding unsaturated groups making this type of crosslinking very well suited for in-situ hydrogel formation. Dextran conjugated with vinylsulfone alkanoic acids and subsequently mixed with thiol end-functionalized linear or 4-arm PEGs form hydrogels via a Michael-type addition reaction at physiological conditions ${ }^{72}$. The gelation time can be controlled between 30 seconds and 7.5 minutes depending on the degree of substitution (DS = number of groups per 100 anhydroglucose rings) of vinyl sulfone groups to dextran, the concentration, dextran molecular weight and PEG-SH functionality. Rheological analyses show that highly elastic hydrogels are formed with storage moduli ranging from 3 to $46 \mathrm{kPa}$. The degradation time of the gels can be adjusted from 3 to 21 days by varying the DS, concentration, dextran molecular weight, PEG-SH functionality and type of alkanoic acid used. Similarly, Jin et al. used thiolated hyaluronic acid (HA$\mathrm{SH}$ ) and PEG vinyl sulfones (PEG-VS) to prepare injectable hydrogels ${ }^{74}$. Gelation times varied from 14 to less than 1 minute depending on the molecular weights of HA-SH and PEG-VS, degree of substitution of HA-SH and total polymer concentration. Elastic hydrogels with storage moduli up to $1.6 \mathrm{kPa}$ were obtained. In the presence of hyaluronidase the gels degraded within 3 to 15 days depending on the initial polymer concentration. Compared to vinyl sulfones the Michael addition reaction of acrylates and thiols is much slower. PEG-tetra-acrylate was first reacted with a thiol containing collagen mimetic peptide to yield solutions of PEG that were partially conjugated with the collagen mimetic peptide ${ }^{75}$. The resulting PEG derivatives were further crosslinked to form hydrogels after subsequent 
Michael reaction with tetra sulfhydryl PEG. Depending on the $\mathrm{pH}$ and concentration of the precursor solution gelation times were between 8 and 30 minutes. The obtained hydrogels have storage moduli between 3.7 and $5.5 \mathrm{kPa}$. Incorporation of the collagen mimetic peptide showed enhanced hMSCs viability and activation of cartilage specific genes that enhanced ECM production.
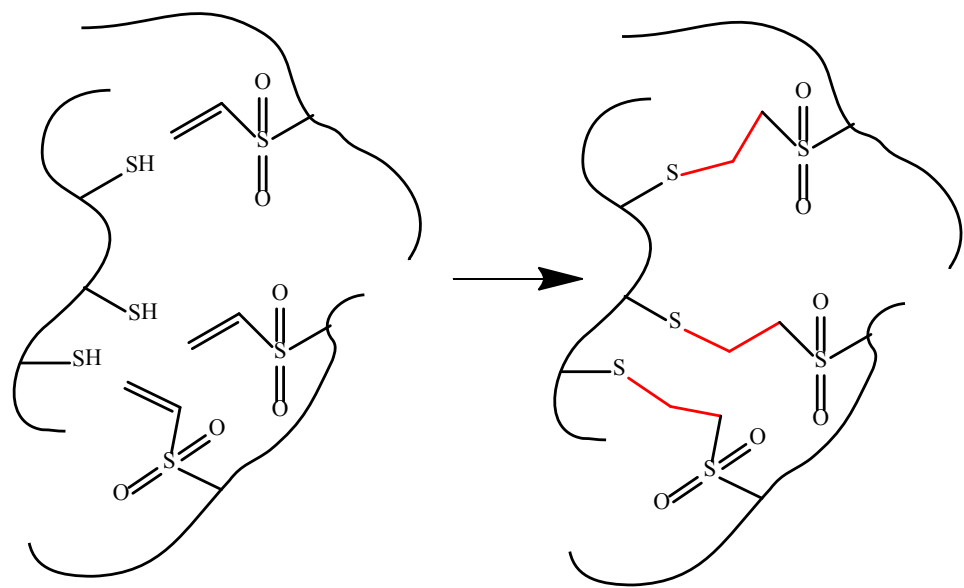

Figure 4. Schematic representation of the Michael addition between vinyl sulfone and thiol conjugated polymers.

\section{Enzymatic crosslinking ${ }^{76}$}

A versatile method to generate in-situ covalently crosslinked hydrogels is the radical coupling of phenols by the enzyme horseradish peroxidase (HRP) in the presence of hydrogen peroxide $\left(\mathrm{H}_{2} \mathrm{O}_{2}\right)$ (Figure 5). The principle has been described by Kaplan et al. for the formation of hydrogels from poly(aspartic acid) conjugated with tyramine (TA), tyrosine or aminophenol groups ${ }^{77}$. Fast gelation (e.g. 1 min) takes place at pH 6.5 using a HRP concentration of $2 \mathrm{mg} / \mathrm{mL}$ and a molar ratio of $\mathrm{H}_{2} \mathrm{O}_{2}$ to TA of 0.5 . Kurisawa et al. were the first to use the HRP catalyzed crosslinking of hyaluronic acid tyramine conjugates to produce in-situ forming hydrogels. Fast gelation of these conjugates at low concentrations takes place in between 20 and $400 \mathrm{~s}$ depending on the $\mathrm{HRP}$ and $\mathrm{H}_{2} \mathrm{O}_{2}$ concentrations applied. The hydrogels degrade in the presence of $10 \mathrm{U} / \mathrm{mL}$ hyaluronidase in approximately $10 \mathrm{~h}$ ${ }^{78}$. With the aim to prolong the degradation times, and thus to obtain hydrogels that will be more suitable for long term implantation as in the regeneration of cartilage, Jin et al. have synthesized dextran tyramine conjugates that can be crosslinked in-situ in the presence of $\mathrm{HRP}$ and $\mathrm{H}_{2} \mathrm{O}_{2}$. Gelation times range from $5 \mathrm{~s}$ to $9 \mathrm{~min}$, depending on the polymer concentration and enzyme or $\mathrm{H}_{2} \mathrm{O}_{2} /$ tyramine ratios ${ }^{79}$. Degradation of the gels takes several months and has been ascribed to the slow hydrolysis of the carbamate bonds between the 
tyramine groups and the dextran backbone. Co-crosslinking of dextran-tyramine conjugates with tyramine conjugated polysaccharides like heparin ${ }^{80}$ or hyaluronic acid ${ }^{81}$ has also been carried out. Co-crosslinking with tyramine conjugated hyaluronic acid results in hydrogels with a controlled disintegration time of 55 days. The hydrogel architecture can also be modified by end functionalization of a dextran-tyramine conjugate and subsequent coupling to hyaluronic acid providing a branched system resembling the structure of a proteoglycan ${ }^{82}$. Elastic gels are rapidly formed in the presence of $\mathrm{HRP}$ and $\mathrm{H}_{2} \mathrm{O}_{2}$ with gelation times of $10 \mathrm{~s}$ to 2 min and elastic moduli up to $18 \mathrm{kPa}$ depending on the degree of substitution of tyramine groups to the dextran and polymer concentration. Depending on the crosslink density these gels degrade in the presence of $100 \mathrm{U} / \mathrm{mL}$ hyaluronidase in between 4 and 21 days. The use of chitosan as a material for in-situ forming hydrogels for cartilage engineering has been widely investigated. Chitosan is a biopolymer consisting of $\beta-(1-4)$-linked D-glucosamine and $\mathrm{N}$-acetyl-D-glucosamine units and is obtained by partial deacetylation of chitin ${ }^{83-90}$. It is poorly soluble at physiological $\mathrm{pH}$ and in order to couple phenol groups to chitosan, first glycolic acid has been grafted to chitosan to render it soluble at $\mathrm{pH} 7.4$, followed by conjugation with phloretic acid ${ }^{91}$. These conjugated polysaccharides show gelation times of $250 \mathrm{~s}$ at $1 \mathrm{wt}$ $\%$ and $10 \mathrm{~s}$ at $3 \mathrm{wt} \%$ polymer concentration. The obtained hydrogels have good mechanical properties with storage moduli of $1.3 \mathrm{kPa}$ for $1 \mathrm{wt} \%$ hydrogels and $5.5 \mathrm{kPa}$ for $2 \mathrm{wt} \%$ hydrogels. In the presence of $1 \mathrm{mg} / \mathrm{mL}$ lysozyme these hydrogels degrade and after 3 weeks the $1 \mathrm{wt} \%$ hydrogel had lost $40 \%$ of its initial weight and the $3 \mathrm{wt} \%$ hydrogel $20 \%$ of its initial weight. Tyramine alginate conjugates have been prepared by first EDC/NHS activation of the carboxyl groups of the alginate and subsequent reaction with the tyramine amino groups ${ }^{92,93}$. In the presence of $\mathrm{HRP}$ and $\mathrm{H}_{2} \mathrm{O}_{2}$ hydrogels are formed in less than $1 \mathrm{~min}$. It has been recently shown that tyramine conjugated chondroitin sulfate can be crosslinked by tyrosinase ${ }^{94}$. Gelation times of $3 \mathrm{~min}$ and gels with a storage modulus of $1 \mathrm{kPa}$ were obtained for $10 \mathrm{wt} \%$ chondroitin sulfate-tyramine. By changing the tyrosinase concentration, polymer concentration or substitution degree gelation times and mechanical properties could be tuned. In the presence of $0.05 \mathrm{mg} / \mathrm{mL}$ chondroitinase these gels degrade between 7 days and 11 weeks depending on the degree of substitution of tyramine units. 


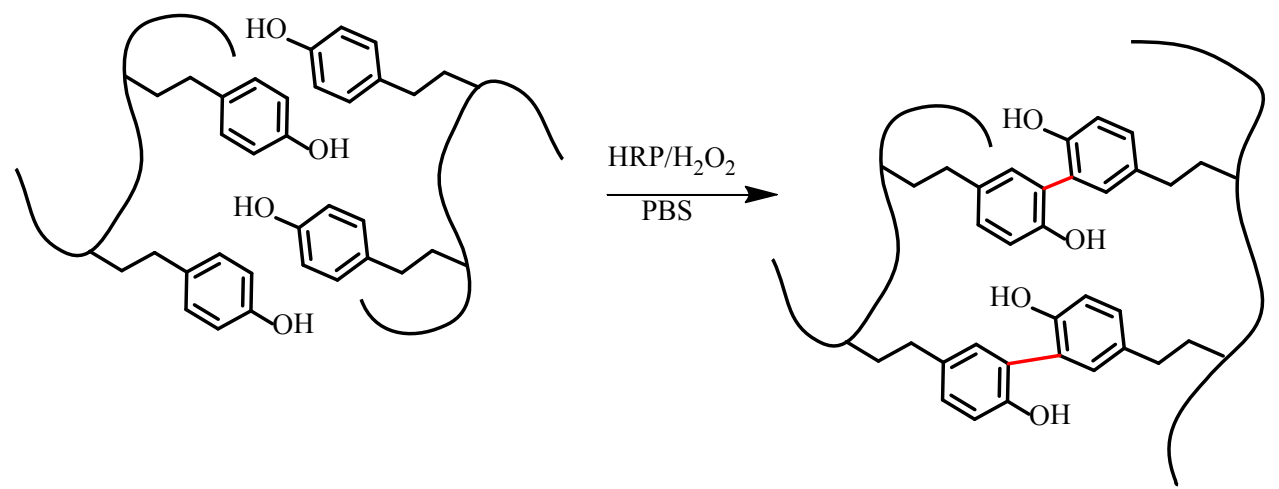

Figure 5. In situ formation of a polymeric hydrogel by an enzyme-catalyzed oxidation reaction of polymer-tyramine conjugates.

Fibrin hydrogels can be prepared from fibrinogen in the presence of thrombin and transglutaminase (Figure 6). Since the components can be isolated from a patient's own blood the risks of foreign body reactions are reduced. Fibrin hydrogels generally exhibit excellent adhesion to surrounding tissue ${ }^{95,96}$. Depending on the concentration of thrombin, gelation times vary from 1 to $10 \mathrm{~min}$. Fibrin hydrogels generally have poor mechanical properties and start degrading after 1 week when injected subcutaneously in nude mice which is relatively fast for cartilage engineering purposes ${ }^{97}$.

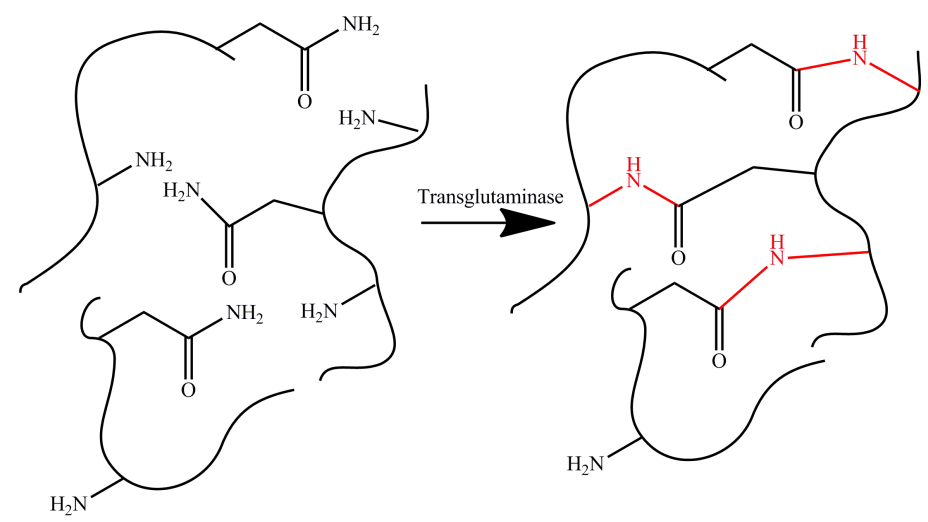

Figure 6. Schematic representation of a transglutaminase crosslinking reaction.

\section{Radical polymerization}

Acrylic groups can be polymerized using photo, thermal or redox initiation (Figure 7). Since photo (UV light) and thermal initiation might bring unwanted side effects redox initiation has been studied as an alternative method. Mikos and coworkers have prepared oligo(poly(ethylene glycol) fumarate) (OPF) polymers that can be in-situ crosslinked using 
ascorbic acid and ammonium persulfate ${ }^{98-100}$. These hydrogels degrade by hydrolysis of the fumarate ester bonds.
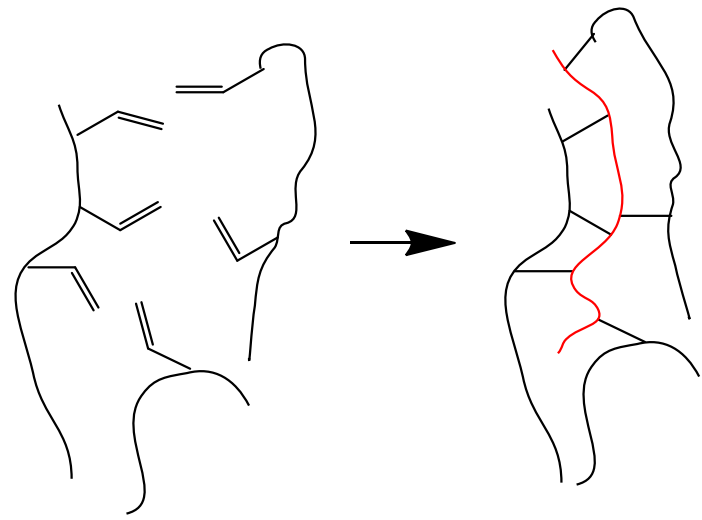

Figure 7. Schematic representation of radical initiated crosslinking of acrylate functionalized polymers.

Elisseeff and coworkers have developed a bio-adhesive hydrogel based on chondroitin sulfate and PEG ${ }^{51,52}$. Chondroitin sulfate was modified with both methacrylate groups and aldehyde groups. After application of the conjugate at the defect site the aldehyde groups react with the free amine groups present in collagen. Subsequently, the defect site is filled with PEG diacrylate and co-crosslinked to the modified chondroitin sulfate by photo initiation. In vitro studies reveal that this approach leads to the formation of mechanically stable hydrogels at the defect site inducing the repair of cartilage tissue. Adhesion of the gel to articular cartilage is 10 times stronger than that of fibrin glue and mechanical testing has shown that rupture of the hydrogel-cartilage construct takes place in the bulk of the hydrogel and not at the interface.

\section{Hydrophobic interaction}

Pluronics (block copolymers of poly(ethylene oxide) and poly(propylene oxide)) and poly(Nisopropylacrylamide) (PNIPAAM) are well known materials that provide thermo-sensitive hydrogels ${ }^{66,101}$. These physically crosslinked hydrogels are generally too weak to function in the environment of synovial joints. They have been combined with chitosan, hyaluronic acid or gelatin and studied as potential materials for cartilage tissue regeneration ${ }^{102,103}$. As an example a thermo-sensitive chitosan/pluronic hydrogel was synthesized by grafting pluronics onto chitosan using EDC/NHS chemistry ${ }^{103}$. The resulting polymer has a sol-gel transition at $25^{\circ} \mathrm{C}$ and a storage modulus of $10 \mathrm{kPa}$.

In a similar approach PNIPAAM end-capped with a carboxyl group was grafted to chitosan (Chitosan-PNIPAAM) ${ }^{104}$. Chitosan-PNIPAAM was subsequently grafted to hyaluronic acid. 
The resulting polymer forms hydrogels at $5 \mathrm{wt} \%$ above $30{ }^{\circ} \mathrm{C}$. The storage modulus of a 10 wt $\%$ hydrogel at $37^{\circ} \mathrm{C}$ is $5 \mathrm{kPa}$.

Chitosan mixed with glycerol-phosphate disodium salt affords thermo-reversible hydrogels 105, 106 . The system remains liquid at room temperature, but quickly gels at body temperature. The temperature at which the sol-gel transition takes place decreases with increasing deacetylation degree of the chitosan. The obtained hydrogels have storage moduli of 30 to $50 \mathrm{kPa}$.

Gelatin can also be modified with PNIPAAM which reverses the gelation window of gelatin, that forms a gel at lower temperatures. Gelatin grafted with poly(N-isopropylacrylamide) forms hydrogels at $37{ }^{\circ} \mathrm{C}$ due to hydrophobic interactions ${ }^{107}$. In vitro culture experiments with these hydrogels and rabbit chondrocytes for 12 weeks show a good production of cartilage matrix. 
Table 2. Overview of injectable hydrogels for cartilage tissue engineering and their material properties.

\begin{tabular}{|c|c|c|c|c|c|}
\hline $\begin{array}{l}\text { In-situ forming } \\
\text { hydrogels }\end{array}$ & $\begin{array}{l}\text { Crosslinking } \\
\text { method }\end{array}$ & $\begin{array}{l}\text { Gelation } \\
\text { time }\end{array}$ & $\begin{array}{l}\text { Storage } \\
\text { modulus } \\
(\mathrm{kPa})\end{array}$ & $\begin{array}{l}\text { Degradation } \\
\text { time/ } \\
\text { conditions }\end{array}$ & Refs. \\
\hline $\begin{array}{l}\text { Dextran thiols and } \\
\text { PEG vinyl sulfone }\end{array}$ & $\begin{array}{l}\text { Michael } \\
\text { addition }\end{array}$ & $\begin{array}{l}0.2-6 \\
\min \end{array}$ & $3-46$ & $\begin{array}{l}3-21 \text { weeks } \\
\text { HEPES } \\
\text { buffered saline, } \\
\text { pH } 7,37^{\circ} \mathrm{C}\end{array}$ & $\begin{array}{l}72,73, \\
108\end{array}$ \\
\hline $\begin{array}{l}\text { Hyaluronic acid } \\
\text { thiols and PEG vinyl } \\
\text { sulfones }\end{array}$ & $\begin{array}{l}\text { Michael } \\
\text { addition }\end{array}$ & $1-15 \mathrm{~min}$ & $0.7-1.6$ & $\begin{array}{l}\text { 3-15 days } \\
\text { Chondrocyte } \\
\text { expansion } \\
\text { medium, } 100 \\
\text { units/mL } \\
\text { hyaluronidase, } \\
37^{\circ} \mathrm{C}\end{array}$ & 74 \\
\hline $\begin{array}{l}\text { PEG tetra-acrylate } \\
\text { and PEG thiols }\end{array}$ & $\begin{array}{l}\text { Michael } \\
\text { addition }\end{array}$ & $30 \mathrm{~min}$ & $3.7-5.5$ & - & 75 \\
\hline $\begin{array}{l}\text { Hyaluronic acid } \\
\text { tyramine }\end{array}$ & Enzymatic & $\begin{array}{l}0.2-7 \\
\min \end{array}$ & - & $\begin{array}{l}10 \text { hours } \\
\text { PBS, } 10 \\
\text { units } / \mathrm{mL} \\
\text { hyaluronidase, } \\
37^{\circ} \mathrm{C}\end{array}$ & 78 \\
\hline $\begin{array}{l}\text { Dextran tyramine } \\
\text { conjugates }\end{array}$ & Enzymatic & $\begin{array}{l}0.2-9 \\
\min \end{array}$ & $2.4-41$ & $\begin{array}{l}4-10 \text { days } \\
\text { Dex-Diglycolic } \\
\text {-Tyramine, } \\
\text { PBS, } 37^{\circ} \mathrm{C} \\
>5 \text { months } \\
\text { Dex-tyramine, } \\
\text { PBS, } \\
37^{\circ} \mathrm{C}\end{array}$ & 79 \\
\hline $\begin{array}{l}\text { Dextran tyramine } \\
\text { and heparin tyramine }\end{array}$ & Enzymatic & $\begin{array}{l}0.2-9 \\
\min \end{array}$ & $3.6-48$ & - & 80 \\
\hline $\begin{array}{l}\text { Dextran tyramine } \\
\text { and hyaluronic acid } \\
\text { tyramine }\end{array}$ & Enzymatic & $1 \mathrm{~min}$ & 15 & $\begin{array}{l}55 \text { days } \\
\mathrm{PBS}, 20 \\
\text { units } / \mathrm{mL} \\
\text { hyalyronidase, } \\
37^{\circ} \mathrm{C}\end{array}$ & 81 \\
\hline
\end{tabular}




\begin{tabular}{|c|c|c|c|c|c|}
\hline $\begin{array}{l}\text { In-situ forming } \\
\text { hydrogels }\end{array}$ & $\begin{array}{l}\text { Crosslinking } \\
\text { method }\end{array}$ & $\begin{array}{l}\text { Gelation } \\
\text { time }\end{array}$ & $\begin{array}{l}\text { Storage } \\
\text { modulus } \\
(\mathrm{kPa})\end{array}$ & $\begin{array}{l}\text { Degradation } \\
\text { time/ } \\
\text { conditions }\end{array}$ & Refs. \\
\hline $\begin{array}{l}\text { Dextran tyramine } \\
\text { grafted to hyaluronic } \\
\text { acid }\end{array}$ & Enzymatic & $\begin{array}{l}0.3-2 \\
\min \end{array}$ & $0.37-18$ & $\begin{array}{l}\text { 4-21 days } \\
\text { PBS, } 100 \\
\text { units/mL } \\
\text { hyaluronidase, } \\
37^{\circ} \mathrm{C}\end{array}$ & 82 \\
\hline Chitosan tyramine & Enzymatic & $\begin{array}{l}0.2-4 \\
\min \end{array}$ & $1.3-5.5$ & $\begin{array}{l}>21 \text { days } \\
\text { PBS, } 1 \mathrm{mg} / \\
\mathrm{mL} \text { lysozyme, } \\
37^{\circ} \mathrm{C}\end{array}$ & 91 \\
\hline Alginate tyramine & Enzymatic & $1 \mathrm{~min}$ & - & - & 92,93 \\
\hline $\begin{array}{l}\text { Chondroitin sulfate } \\
\text { tyramine }\end{array}$ & Enzymatic & $<3 \min$ & 1 & $\begin{array}{l}7 \text { days- } 11 \\
\text { weeks } \\
\text { Tris buffer, } \\
0.05 \mathrm{mg} / \mathrm{mL} \\
\text { chondroitinase } \\
\text { ABC, } \\
37^{\circ} \mathrm{C}\end{array}$ & 94 \\
\hline Fibrin & Enzymatic & $1-10 \mathrm{~min}$ & - & $\begin{array}{l}5-6 \text { weeks } \\
\text { placed } \\
\text { subcutaneously } \\
\text { in nude mice }\end{array}$ & $95-97$ \\
\hline $\begin{array}{l}\text { Oligo(poly(ethylene } \\
\text { glycol)fumarate }\end{array}$ & $\begin{array}{l}\text { Radical } \\
\text { initiation }\end{array}$ & $3.6 \mathrm{~min}$ & - & $\begin{array}{l}>12 \text { weeks } \\
\text { PBS, } 37^{\circ} \mathrm{C}\end{array}$ & $98-100$ \\
\hline PEG-dimethacrylate & $\begin{array}{l}\text { Radical } \\
\text { initiation }\end{array}$ & $10 \mathrm{~min}$ & - & $\begin{array}{l}7 \text { days } \\
\text { PBS, } 37^{\circ} \mathrm{C}\end{array}$ & 38 \\
\hline $\begin{array}{l}\text { Pluronic grafted to } \\
\text { chitosan }\end{array}$ & $\begin{array}{l}\text { Hydrophobic } \\
\text { interaction }\end{array}$ & - & $10-40$ & - & 103 \\
\hline $\begin{array}{l}\text { Hyaluronic acid- } \\
\text { chitosan-PNIPAAM }\end{array}$ & $\begin{array}{l}\text { Hydrophobic } \\
\text { interaction }\end{array}$ & - & 0.2 & - & 104 \\
\hline $\begin{array}{l}\text { Chitosan-glycerol } \\
\text { phosphate }\end{array}$ & $\begin{array}{l}\text { Hydrophobic } \\
\text { interaction }\end{array}$ & - & 5 & - & 105,106 \\
\hline Articular cartilage & & & 10000 & & 109 \\
\hline
\end{tabular}




\section{Injectable hydrogels for cartilage engineering: in vitro and in vivo performance}

\section{Cells or no cells}

In-situ forming hydrogels are mostly combined with cells and bioactive components to generate cartilage tissue formation at the implant site. Cells need to be harvested preferably from the patient's own tissue and cultured, which is a costly and time consuming procedure. Also the availability of an appropriate cell type in elderly people is not always guaranteed. Another option is to recruit cells from the surrounding tissue. Up to now only preliminary studies have been performed. Moreira Teixeira and coworkers have shown that in vitro chondrocytes can migrate into injectable dextran-tyramine and heparin-tyramine hydrogels and subsequently start with the deposition of hyaline cartilage matrix ${ }^{50}$. It has also been shown by Chevrier and coworkers that chitosan hydrogels injected in rabbit osteochondral defects recruit neutrophils but did not recruit chondrocytes ${ }^{110}$.

\section{In vitro performance of injectable hydrogels}

Once the chondrocytes are located in the hydrogel, either by migration or by incorporation in the precursor solution of the hydrogel, they have to produce hyaline type cartilage. Typical components of hyaline type cartilage are collagen type II and aggrecans. All injectable hydrogels listed in Table 2 have been tested in vitro using culture experiments with chondrocytes showing an increased production of collagen type II and synthesis of aggrecans as compared to their controls or when stem cells are used an increased chondrogenesis. Currently, the main approaches to increase the production of hyaline type cartilage are the addition of growth factors, i.e. IGF1, TGF- $\beta 1$, TGF- $\beta 2$, TGF- $\beta 3$ and BMP-2, the use of certain polysaccharides, i.e. hyaluronic acid or chitosan that interact with receptors on the chondrocytes to produce hyaline type cartilage.

\section{In vivo performance of injectable hydrogels}

Many injectable hydrogels for cartilage tissue engineering have been prepared and studied in vitro, however, only a few reports have appeared on their performance in vivo in the repair of cartilage defects. In vivo experiments have been conducted with pluronic/hyaluronic acid physically crosslinked hydrogels containing human adipose stem cells and TGF- $\beta 1$, which have been placed in osteochondral defects (grade 4) of rabbits. After 4-weeks in vivo adipose stem cells differentiated into chondrogenic cells. However, the hydrogel filling the defect area was significantly eroded and the defect sites poorly covered ${ }^{66}$. OPF hydrogels have been applied in rabbit osteochondraldefects. Cell-freeOPF hydrogels allow migration and fibrocartilage formation by host $\mathrm{MSCs}^{70,111}$, whereas the quality of the repaired 
tissue improves when MSCs are encapsulated in the hydrogels. These hydrogels have also been used to evaluate the effect of the release of TGF- $\beta$ and IGF1 on the formation of cartilage tissue in osteochondral defects. Release of TGF- $\beta$ induces differentiation of MSCs in chondrocytes and increased chondrogenesis, resulting in an enhanced repair of the rabbit osteochondral defect. Application of IGF1 leads to a more effective repair of the rabbit osteochondral defect ${ }^{112}$. After performing their in vitro experiments on the adhesion and chondrogenesis of PEGdimethacrylate and methacrylated chondroitin sulfate Elisseeff and coworkers have also tested their materials in an in vivo chondral defect goat model ${ }^{51}$. Defects treated with methacrylated chondroitin sulfate and subsequently PEG dimethacrylate show improved cartilage repair compared to an empty, untreated defect after 6 months. These hydrogels are currently being investigated in phase II clinical trials (ChonDux, Cartilix). MSCs differentiate into chondrocytes and produce more cartilage tissue when incorporated in fibrin hydrogels than when placed in alginate hydrogels. Currently, fibrin hydrogels are investigated as carriers in autologous chondrocyte transplantation in clinical trials in Europe (Tissucol) ${ }^{113}$. Hoemann and coworkers have tested the residence time of injectable chitosan/glycerol phosphate hydrogels in osteochondral defects in rabbit joints and have shown that their gels can reside at least 1 day in a full-thickness chondral defect, and at least 1 week in a mobile osteochondral defect ${ }^{85}$. Non weight bearing defects in sheep can be repaired with good integration within the surrounding tissue using chondrocytes incorporated in injectable chitosan hydrogels ${ }^{114}$. Furthermore, these hydrogels have the potential to repair weight bearing cartilage defects in sheep with more hyaline cartilage formation than obtained with microfracture controls ${ }^{115}$. This strategy is currently in phase II clinical trials (BST-Cargel). 


\section{Conclusions and future perspectives}

When the field of tissue engineering emerged it was predicted that tissue engineering of articular cartilage would be one of the first success stories. Research in the past 20 years on articular cartilage has provided a deeper understanding on the behavior of this apparently relatively simple but actually very complex tissue and has led to the current research area of injectable hydrogels for articular cartilage tissue engineering. A multitude of injectable gels for the repair of articular cartilage defects has been investigated. This has culminated in the design of several injectable hydrogels that are currently in phase 2 clinical trials. It has to be mentioned that the current approaches do not lead to full repair of the cartilage defect with new naturally organized hyaline cartilage. One of the reasons can be the mismatch in mechanical properties of the injectable hydrogels currently used with those of hyaline cartilage. Engineered cartilage still lacks the mechanical properties of hyaline cartilage due to lack of zonal organization of collagen fibers. Therefore, future research should focus on creating an injectable hydrogel with mechanical properties that initially resembles that of the articular cartilage at the defect site, proper adhesion of the hydrogel to the surrounding tissue and strategies to induce the zonal organization of collagen fibers in the ECM.

\section{References}

1. Elisseeff, J., Injectable cartilage tissue engineering. Expert Opinion on Biological Therapy 2004, 4, (12), 1849-1859.

2. Marlovits, S.; Zeller, P.; Singer, P.; Resinger, C.; Vecsei, V., Cartilage repair: Generations of autologous chondrocyte transplantation. European Journal of Radiology 2006, 57, (1), 24-31.

3. Ge, Z. G.; Li, C.; Heng, B. C.; Cao, G. X.; Yang, Z., Functional biomaterials for cartilage regeneration. Journal of Biomedical Materials Research Part A 2012, 100A, (9), 2526-2536.

4. $\quad$ Fong, E. L. S.; Watson, B. M.; Kasper, F. K.; Mikos, A. G., Building Bridges: Leveraging Interdisciplinary Collaborations in the Development of Biomaterials to Meet Clinical Needs. Advanced Materials 2012, 24, (36), 4995-5013.

5. Li, Y. L.; Rodrigues, J.; Tomas, H., Injectable and biodegradable hydrogels: gelation, biodegradation and biomedical applications. Chemical Society Reviews 2012, 41, (6), 2193-2221.

6. Overstreet, D. J.; Dutta, D.; Stabenfeldt, S. E.; Vernon, B. L., Injectable hydrogels. Journal of Polymer Science Part B-Polymer Physics 2012, 50, (13), 881-903.

7. Buckwalter, J. A.; Mankin, H. J., Instructional Course Lectures, The American Academy of Orthopaedic Surgeons - Articular Cartilage. Part I: Tissue Design and Chondrocyte-Matrix Interactions* $\{$ dagger\}\}. J Bone Joint Surg Am 1997, 79, (4), 600-11. 8. Bhosale, A. M.; Richardson, J. B., Articular cartilage: structure, injuries and review of management. British Medical Bulletin 2008, 87, (1), 77-95.

9. Knudson, C. B.; Knudson, W., Cartilage proteoglycans. Seminars in Cell \& Developmental Biology 2001, 12, (2), 69-78. 
10. Chung, C.; Burdick, J. A., Engineering cartilage tissue. Advanced Drug Delivery Reviews 2008, 60, (2), 243-262.

11. Mainil-Varlet, P.; Aigner, T.; Brittberg, M.; Bullough, P.; Hollander, A.; Hunziker, E.; Kandel, R.; Nehrer, S.; Pritzker, K.; Roberts, S.; Stauffer, E., Histological assessment of cartilage repair: A report by the Histology Endpoint Committee of the International Cartilage Repair Society (ICRS). Journal of Bone and Joint Surgery - Series A 2003, 85, (SUPPL. 1), 45-57.

12. Outerbridge, R. E., The Etiology of Chondromalacia Patellae. Journal of Bone and Joint Surgery-British Volume 1961, 43, (4), 752-757.

13. Buckwalter, J. A.; Brown, T. D., Joint injury, repair, and remodeling. Clinical Orthopaedics and Related Research 2004, (423), 7-16.

14. Buckwalter, J. A., Articular cartilage: Injuries and potential for healing. Journal of Orthopaedic \& Sports Physical Therapy 1998, 28, (4), 192-202.

15. Jackson, D. W.; Lalor, P. A.; Aberman, H. M.; Simon, T. M., Spontaneous repair of full-thickness defects of articular cartilage in a goat model - A preliminary study. Journal of Bone and Joint Surgery-American Volume 2001, 83A, (1), 53-64.

16. Tyyni, A.; Karlsson, J., Biological treatment of joint cartilage damage.

Scandinavian Journal of Medicine \& Science in Sports 2000, 10, (5), 249-265.

17. Shapiro, F.; Koide, S.; Glimcher, M. J., Cell Origin And Differentiation In The Repair Of Full-Thickness Defects Of Articular-Cartilage. Journal of Bone and Joint Surgery-American Volume 1993, 75A, (4), 532-553.

18. Mankin, H. J., The Response Of Articular-Cartilage To Mechanical Injury. Journal of Bone and Joint Surgery-American Volume 1982, 64, (3), 460-466.

19. Minas, T.; Nehrer, S., Current concepts in the treatment of articular cartilage defects. Orthopedics 1997, 20, (6), 525-538.

20. Brittberg, M.; Lindahl, A.; Nilsson, A.; Ohlsson, C.; Isaksson, O.; Peterson, L., Treatment Of Deep Cartilage Defects In The Knee With Autologous Chondrocyte Transplantation. New England Journal of Medicine 1994, 331, (14), 889-895.

21. Hoffman, A. S., Hydrogels for biomedical applications. Advanced Drug Delivery Reviews 2002, 54, (1), 3-12.

22. Hutmacher, D. W., Scaffolds in tissue engineering bone and cartilage. Biomaterials 2000, 21, (24), 2529-2543.

23. Fuchs, J. R.; Nasseri, B. A.; Vacanti, J. P., Tissue engineering: a 21 st century solution to surgical reconstruction. The Annals of Thoracic Surgery 2001, 72, (2), 577-591.

24. Kerker, J. T.; Leo, A. J.; Sgaglione, N. A., Cartilage Repair: Synthetics and Scaffolds Basic Science, Surgical Techniques, and Clinical Outcomes. Sports Medicine and Arthroscopy Review 2008, 16, (4), 208-216.

25. Sherwood, J. K.; Riley, S. L.; Palazzolo, R.; Brown, S. C.; Monkhouse, D. C.; Coates, M.; Griffith, L. G.; Landeen, L. K.; Ratcliffe, A., A three-dimensional osteochondral composite scaffold for articular cartilage repair. Biomaterials 2002, 23, (24), 4739-4751.

26. Malda, J.; Woodfield, T. B. F.; van der Vloodt, F.; Kooy, F. K.; Martens, D. E.; Tramper, J.; van Blitterswijk, C. A.; Riesle, J., The effect of PEGT/PBT scaffold architecture on oxygen gradients in tissue engineered cartilaginous constructs. Biomaterials 2004, 25, (26), 5773-5780.

27. Biancamaria, B., Hydrogels for tissue engineering and delivery of tissue-inducing substances. Journal of Pharmaceutical Sciences 2007, 96, (9), 2197-2223. 
28. Drury, J. L.; Mooney, D. J., Hydrogels for tissue engineering: scaffold design variables and applications. Biomaterials 2003, 24, (24), 4337-4351.

29. Kessler, M. W.; Ackerman, G.; Dines, J. S.; Grande, D., Emerging Technologies and Fourth Generation Issues in Cartilage Repair. Sports Medicine and Arthroscopy Review 2008, 16, (4), 246-254.

30. Stoop, R., Smart biomaterials for tissue engineering of cartilage. Injury 2008, 39, (1, Supplement 1), 77-87.

31. Ruel-Gariepy, E.; Leroux, J. C., In situ-forming hydrogels - review of temperaturesensitive systems. European Journal of Pharmaceutics and Biopharmaceutics 2004, 58, (2), 409-426.

32. Hennink, W. E.; van Nostrum, C. F., Novel crosslinking methods to design hydrogels. Advanced Drug Delivery Reviews 2002, 54, (1), 13-36.

33. Brand, R., Joint contact stress: a reasonable surrogate for biological processes? Iowa Orthop J. 2005, 25, 82-94.

34. McNary, S. M.; Athanasiou, K. A.; Reddi, A. H., Engineering Lubrication in Articular Cartilage. Tissue Engineering Part B-Reviews 2012, 18, (2), 88-100.

35. Bryant, S. J.; Anseth, K. S.; Lee, D. A.; Bader, D. L., Crosslinking density influences the morphology of chondrocytes photoencapsulated in PEG hydrogels during the application of compressive strain. Journal of Orthopaedic Research 2004, 22, (5), 1143 1149.

36. Bryant, S. J.; Chowdhury, T. T.; Lee, D. A.; Bader, D. L.; Anseth, K. S., Crosslinking density influences chondrocyte metabolism in dynamically loaded photocrosslinked poly(ethylene glycol) hydrogels. Annals of Biomedical Engineering 2004, 32, (3), 407-417.

37. Bryant, S. J.; Bender, R. J.; Durand, K. L.; Anseth, K. S., Encapsulating Chondrocytes in degrading PEG hydrogels with high modulus: Engineering gel structural changes to facilitate cartilaginous tissue production. Biotechnology and Bioengineering 2004, 86, (7), 747-755.

38. Bryant, S. J.; Anseth, K. S., Hydrogel properties influence ECM production by chondrocytes photoencapsulated in poly(ethylene glycol) hydrogels. Journal of Biomedical Materials Research 2002, 59, (1), 63-72.

39. Bryant, S. J.; Anseth, K. S., Controlling the spatial distribution of ECM components in degradable PEG hydrogels for tissue engineering cartilage. Journal of Biomedical Materials Research Part A 2003, 64A, (1), 70-79.

40. Lutolf, M. P.; Lauer-Fields, J. L.; Schmoekel, H. G.; Metters, A. T.; Weber, F. E.; Fields, G. B.; Hubbell, J. A., Synthetic matrix metalloproteinase-sensitive hydrogels for the conduction of tissue regeneration: Engineering cell-invasion characteristics. Proceedings of the National Academy of Sciences of the United States of America 2003, 100, (9), 54135418.

41. Lutolf, M. P.; Raeber, G. P.; Zisch, A. H.; Tirelli, N.; Hubbell, J. A., Cellresponsive synthetic hydrogels. Advanced Materials 2003, 15, (11), 888-+.

42. West, J. L.; Hubbell, J. A., Polymeric biomaterials with degradation sites for proteases involved in cell migration. Macromolecules 1999, 32, (1), 241-244.

43. Park, Y.; Lutolf, M. P.; Hubbell, J. A.; Hunziker, E. B.; Wong, M., Bovine primary chondrocyte culture in synthetic matrix metalloproteinase-sensitive poly(ethylene glycol)based hydrogels as a scaffold for cartilage repair. Tissue Engineering 2004, 10, (3-4), 515- 
522.

44. Klein, T. J.; Rizzi, S. C.; Reichert, J. C.; Georgi, N.; Malda, J.; Schuurman, W.; Crawford, R. W.; Hutmacher, D. W., Strategies for Zonal Cartilage Repair using Hydrogels. Macromolecular Bioscience 2009, 9, (11), 1049-1058.

45. Kim, T. K.; Sharma, B.; Williams, C. G.; Ruffner, M. A.; Malik, A.; McFarland, E. G.; Elisseeff, J. H., Experimental model for cartilage tissue engineering to regenerate the zonal organization of articular cartilage. Osteoarthritis and Cartilage 2003, 11, (9), 653664.

46. Sharma, B.; Williams, C. G.; Khan, M.; Manson, P.; Elisseeff, J. H., In vivo chondrogenesis of mesenchymal stem cells in a photopolymerized hydrogel. Plastic and Reconstructive Surgery 2007, 119, (1), 112-120.

47. Ng, K. W.; Ateshian, G. A.; Hung, C. T., Zonal Chondrocytes Seeded in a Layered Agarose Hydrogel Create Engineered Cartilage with Depth-Dependent Cellular and Mechanical Inhomogeneity. Tissue Engineering Part A 2009, 15, (9), 2315-2324.

48. Kock, L. M.; Ravetto, A.; van Donkelaar, C. C.; Foolen, J.; Emans, P. J.; Ito, $\mathrm{K}$., Tuning the differentiation of periosteum-derived cartilage using biochemical and mechanical stimulations. Osteoarthritis and Cartilage 2010, 18, (11), 1528-1535.

49. Khoshgoftar, M.; van Donkelaar, C. C.; Ito, K., Mechanical stimulation to stimulate formation of a physiological collagen architecture in tissue-engineered cartilage: a numerical study. Computer Methods in Biomechanics and Biomedical Engineering 2011, $14,(2), 135-144$.

50. Teixeira, L. S. M.; Bijl, S.; Pully, V. V.; Otto, C.; Rong, J.; Feijen, J.; van Blitterswijk, C. A.; Dijkstra, P. J.; Karperien, M., Self-attaching and cell-attracting insitu forming dextran-tyramine conjugates hydrogels for arthroscopic cartilage repair. Biomaterials 2012, 33, (11), 3164-3174.

51. Wang, D. A.; Varghese, S.; Sharma, B.; Strehin, I.; Fermanian, S.; Gorham, J.; Fairbrother, D. H.; Cascio, B.; Elisseeff, J. H., Multifunctional chondroitin sulphate for cartilage tissue-biomaterial integration. Nature Materials 2007, 6, (5), 385-392.

52. Wang, D. A.; Williams, C. G.; Yang, F.; Elisseeff, J. H., Enhancing the tissuebiomaterial interface: Tissue-initiated integration of biomaterials. Advanced Functional Materials 2004, 14, (12), 1152-1159.

53. Nixon, A. J.; Fortier, L. A.; Williams, J.; Mohammed, H., Enhanced repair of extensive articular defects by insulin-like growth factor-I-laden fibrin composites. Journal of Orthopaedic Research 1999, 17, (4), 475-487.

54. Holland, T. A.; Bodde, E. W. H.; Cuijpers, V.; Baggett, L. S.; Tabata, Y.; Mikos, A. G.; Jansen, J. A., Degradable hydrogel scaffolds for in vivo delivery of single and dual growth factors in cartilage repair. Osteoarthritis and Cartilage 2007, 15, (2), 187-197. 55. Holland, T. A.; Tabata, Y.; Mikos, A. G., Dual growth factor delivery from degradable oligo(poly(ethylene glycol) fumarate) hydrogel scaffolds for cartilage tissue engineering. Journal of Controlled Release 2005, 101, (1-3), 111-125.

56. Guo, X.; Liao, J.; Park, H.; Saraf, A.; Raphael, R. M.; Tabata, Y.; Kasper, F. K.; Mikos, A. G., Effects of TGF-beta 3 and preculture period of osteogenic cells on the chondrogenic differentiation of rabbit marrow mesenchymal stem cells encapsulated in a bilayered hydrogel composite. Acta Biomaterialia 2010, 6, (8), 2920-2931.

57. Yasuda, A.; Kojima, K.; Tinsley, K. W.; Yoshioka, H.; Mori, Y.; Vacanti, C. A., In vitro culture of chondrocytes in a novel thermoreversible gelation polymer scaffold 
containing growth factors. Tissue Engineering 2006, 12, (5), 1237-1245.

58. Grunder, T.; Gaissmaier, C.; Fritz, J.; Stoop, R.; Hortschansky, P.; Mollenhauer, J.; Aicher, W. K., Bone morphogenetic protein (BMP)-2 enhances the expression of type II collagen and aggrecan in chondrocytes embedded in alginate beads. Osteoarthritis and Cartilage 2004, 12, (7), 559-567.

59. Lima, E. G.; Bian, L.; Ng, K. W.; Mauck, R. L.; Byers, B. A.; Tuan, R. S.; Ateshian, G. A.; Hung, C. T., The beneficial effect of delayed compressive loading on tissue-engineered cartilage constructs cultured with TGF-beta 3. Osteoarthritis and Cartilage 2007, 15, (9), 1025-1033.

60. DuRaine, G.; Neu, C. P.; Chan, S. M. T.; Komvopoulos, K.; June, R. K.; Reddi, A. H., Regulation of the friction coefficient of articular cartilage by TGF- $\beta 1$ and IL- $1 \beta$. Journal of Orthopaedic Research 2009, 27, (2), 249-256.

61. Elder, B. D.; Athanasiou, K. A., Synergistic and Additive Effects of Hydrostatic Pressure and Growth Factors on Tissue Formation. PLoS ONE 2008, 3, (6), e2341.

62. Chung, C.; Beecham, M.; Mauck, R. L.; Burdick, J. A., The influence of degradation characteristics of hyaluronic acid hydrogels on in vitro neocartilage formation by mesenchymal stem cells. Biomaterials 2009, 30, (26), 4287-4296.

63. Fortier, L. A.; Mohammed, H. O.; Lust, G.; Nixon, A. J., Insulin-like growth factor-I enhances cell-based repair of articular cartilage. Journal of Bone and Joint SurgeryBritish Volume 2002, 84B, (2), 276-288.

64. Park, H.; Temenoff, J. S.; Holland, T. A.; Tabata, Y.; Mikos, A. G., Delivery of TGF-beta 1 and chondrocytes via injectable, biodegradable hydrogels for cartilage tissue engineering applications. Biomaterials 2005, 26, (34), 7095-7103.

65. Shah, R. N.; Shah, N. A.; Lim, M. M. D.; Hsieh, C.; Nuber, G.; Stupp, S. I., Supramolecular design of self-assembling nanofibers for cartilage regeneration. Proceedings of the National Academy of Sciences of the United States of America 2010, 107, (8), 3293-3298.

66. Jung, H. H.; Park, K.; Han, D. K., Preparation of TGF-beta 1-conjugated biodegradable pluronic F127 hydrogel and its application with adipose-derived stem cells. Journal of Controlled Release 2010, 147, (1), 84-91.

67. Huang, Q.; Hutmacher, D. W.; Lee, E. H., In vivo mesenchymal cell recruitment by a scaffold loaded with transforming growth factor beta 1 and the potential for in situ chondrogenesis. Tissue Engineering 2002, 8, (3), 469-482.

68. Kopesky, P. W.; Vanderploeg, E. J.; Kisiday, J. D.; Frisbie, D. D.; Sandy, J. D.; Grodzinsky, A. J., Controlled Delivery of Transforming Growth Factor beta 1 by SelfAssembling Peptide Hydrogels Induces Chondrogenesis of Bone Marrow Stromal Cells and Modulates Smad2/3 Signaling. Tissue Engineering Part A 2011, 17, (1-2), 83-92.

69. Zheng, L.; Fan, H. S.; Sun, J.; Chen, X. N.; Wang, G.; Zhang, L.; Fan, Y. J.; Zhang, X. D., Chondrogenic differentiation of mesenchymal stem cells induced by collagen-based hydrogel: An in vivo study. Journal of Biomedical Materials Research Part A 2010, 93A, (2), 783-792.

70. Guo, X.; Park, H.; Young, S.; Kretlow, J. D.; van den Beucken, J. J.; Baggett, L. S.; Tabata, Y.; Kasper, F. K.; Mikos, A. G.; Jansen, J. A., Repair of osteochondral defects with biodegradable hydrogel composites encapsulating marrow mesenchymal stem cells in a rabbit model. Acta Biomaterialia 2010, 6, (1), 39-47.

71. Park, J. S.; Woo, D. G.; Yang, H. N.; Na, K.; Park, K. H., Transforming growth 
factor beta-3 bound with sulfate polysaccharide in synthetic extracellular matrix enhanced the biological activities for neocartilage formation in vivo. Journal of Biomedical Materials Research Part A 2009, 91A, (2), 408-415.

72. Hiemstra, C.; van der Aa, L. J.; Zhong, Z. Y.; Dijkstra, P. J.; Feijen, J., Novel in situ forming, degradable dextran hydrogels by Michael addition chemistry: Synthesis, rheology, and degradation. Macromolecules 2007, 40, (4), 1165-1173.

73. Hiemstra, C.; van der Aa, L. J.; Zhong, Z. Y.; Dijkstra, P. J.; Feijen, J., Rapidly in situ-forming degradable hydrogels from dextran thiols through michael addition.

Biomacromolecules 2007, 8, (5), 1548-1556.

74. Jin, R.; Teixeira, L. S. M.; Krouwels, A.; Dijkstra, P. J.; van Blitterswijk, C. A.; Karperien, M.; Feijen, J., Synthesis and characterization of hyaluronic acid-poly(ethylene glycol) hydrogels via Michael addition: An injectable biomaterial for cartilage repair. Acta Biomaterialia 2010, 6, (6), 1968-1977.

75. Liu, S. Q.; Tian, Q. A.; Hedrick, J. L.; Hui, J. H. P.; Ee, P. L. R.; Yang, Y. Y., Biomimetic hydrogels for chondrogenic differentiation of human mesenchymal stem cells to neocartilage. Biomaterials 2010, 31, (28), 7298-7307.

76. Teixeira, L. S. M.; Feijen, J.; van Blitterswijk, C. A.; Dijkstra, P. J.; Karperien, M., Enzyme-catalyzed crosslinkable hydrogels: Emerging strategies for tissue engineering. Biomaterials 2012, 33, (5), 1281-1290.

77. Sofia, S. J.; Singh, A.; Kaplan, D. L. In Peroxidase-catalyzed crosslinking of functionalized polyaspartic acid polymers, 2002; Marcel Dekker Inc: 2002; pp 1151-1181.

78. Kurisawa, M.; Chung, J. E.; Yang, Y. Y.; Gao, S. J.; Uyama, H., Injectable biodegradable hydrogels composed of hyaluronic acid-tyramine conjugates for drug delivery and tissue engineering. Chemical Communications 2005, (34), 4312-4314.

79. Jin, R.; Hiemstra, C.; Zhong, Z.; Feijen, J., Enzyme-mediated fast in situ formation of hydrogels from dextran-tyramine conjugates. Biomaterials 2007, 28, (18), 2791-2800.

80. Jin, R.; Moreira Teixeira, L. S.; Dijkstra, P. J.; Van Blitterswijk, C. A.; Karperien, M.; Feijen, J., Chondrogenesis in injectable enzymatically crosslinked heparin/dextran hydrogels. Journal of Controlled Release 2011, 152, (1), 186-195.

81. Wennink, J. W. H.; Niederer, K.; Bochynska, A. I.; Teixeira, L. S. M.; Karperien, M.; Feijen, J.; Dijkstra, P. J., Injectable Hydrogels by Enzymatic Co-Crosslinking of Dextran and Hyaluronic Acid Tyramine Conjugates. In Advanced Polymers in Medicine, Lendlein, A.; Grijpma, D. W., Eds. 2011; Vol. 309-310, pp 213-221.

82. Jin, R.; Teixeira, L. S. M.; Dijkstra, P. J.; van Blitterswijk, C. A.; Karperien, M.; Feijen, J., Enzymatically-crosslinked injectable hydrogels based on biomimetic dextranhyaluronic acid conjugates for cartilage tissue engineering. Biomaterials 2010, 31, (11), 3103-3113.

83. Berger, J.; Reist, M.; Mayer, J. M.; Felt, O.; Peppas, N. A.; Gurny, R., Structure and interactions in covalently and ionically crosslinked chitosan hydrogels for biomedical applications. European Journal of Pharmaceutics and Biopharmaceutics 2004, 57, (1), 1934.

84. Ganji, F.; Abdekhodaie, M. J., Synthesis and characterization of a new thermosensitive chitosan-PEG diblock copolymer. Carbohydrate Polymers 2008, 74, (3), 435-441.

85. Hoemann, C. D.; Sun, J.; Legare, A.; McKee, M. D.; Buschmann, M. D., Tissue engineering of cartilage using an injectable and adhesive chitosan-based cell-delivery 
vehicle. Osteoarthritis and Cartilage 2005, 13, (4), 318-329.

86. Kim, I.-Y.; Seo, S.-J.; Moon, H.-S.; Yoo, M.-K.; Park, I.-Y.; Kim, B.-C.; Cho, C.S., Chitosan and its derivatives for tissue engineering applications. Biotechnology Advances 2008, 26, (1), 1-21.

87. Shang, J.; Shao, Z.; Chen, X., Chitosan-based electroactive hydrogel. Polymer 2008, 49, (25), 5520-5525.

88. Silva, S. S.; Motta, A.; Rodrigues, M. r. T.; Pinheiro, A. F. M.; Gomes, M. E.; Mano, J. F.; Reis, R. L.; Migliaresi, C., Novel Genipin-Cross-Linked Chitosan/Silk Fibroin Sponges for Cartilage Engineering Strategies. Biomacromolecules 2008, 9, (10), 27642774.

89. Sokker, H. H.; Ghaffar, A. M. A.; Gad, Y. H.; Aly, A. S., Synthesis and characterization of hydrogels based on grafted chitosan for the controlled drug release. Carbohydrate Polymers 2009, 75, (2), 222-229.

90. Chenite, A.; Chaput, C.; Wang, D.; Combes, C.; Buschmann, M. D.; Hoemann, C. D.; Leroux, J. C.; Atkinson, B. L.; Binette, F.; Selmani, A., Novel injectable neutral solutions of chitosan form biodegradable gels in situ. Biomaterials 2000, 21, (21), 2155 2161.

91. Jin, R.; Teixeira, L. S. M.; Dijkstra, P. J.; Karperien, M.; van Blitterswijk, C. A.; Zhong, Z. Y.; Feijen, J., Injectable chitosan-based hydrogels for cartilage tissue engineering. Biomaterials 2009, 30, (13), 2544-2551.

92. Sakai, S.; Kawakami, K., Synthesis and characterization of both ionically and enzymatically cross-linkable alginate. Acta Biomaterialia 2007, 3, (4), 495-501.

93. Sakai, S.; Kawakami, K., Development of porous alginate-based scaffolds covalently cross-linked through a peroxidase-catalyzed reaction. Journal of Biomaterials Science, Polymer Edition 2011, 22, (18), 2407-2416.

94. Jin, R.; Lou, B.; Lin, C., Tyrosinase-mediated in situ forming hydrogels from biodegradable chondroitin sulfate-tyramine conjugates. Polymer International 2012. 95. Dare, E. V.; Griffith, M.; Poitras, P.; Wang, T.; Dervin, G. F.; Giulivi, A.; Hincke, M. T., Fibrin Sealants from Fresh or Fresh/Frozen Plasma as Scaffolds for In Vitro Articular Cartilage Regeneration. Tissue Engineering Part A 2009, 15, (8), 2285-2297.

96. Chang, F.; Ishii, T.; Yanai, T.; Mishima, H.; Akaogi, H.; Ogawa, T.; Ochiai, N., Repair of large full-thickness articular cartilage defects by transplantation of autologous uncultured bone-marrow-derived mononuclear cells. Journal of Orthopaedic Research 2008, 26, (1), 18-26.

97. Silverman, R. P.; Passaretti, D.; Huang, W.; Randolph, M. A.; Yaremchuk, M., Injectable tissue-engineered cartilage using a fibrin glue polymer. Plastic and Reconstructive Surgery 1999, 103, (7), 1809-1818.

98. Temenoff, J. S.; Athanasiou, K. A.; LeBaron, R. G.; Mikos, A. G., Effect of poly(ethylene glycol) molecular weight on tensile and swelling properties of oligo(poly(ethylene glycol) fumarate) hydrogels for cartilage tissue engineering. Journal of Biomedical Materials Research 2002, 59, (3), 429-437.

99. Temenoff, J. S.; Park, H.; Jabbari, E.; Conway, D. E.; Sheffield, T. L.; Ambrose, C. G.; Mikos, A. G., Thermally cross-linked oligo(poly(ethylene glycol) fumarate) hydrogels support osteogenic differentiation of encapsulated marrow stromal cells in vitro. Biomacromolecules 2004, 5, (1), 5-10.

100. Shin, H.; Ruhe, P. Q.; Mikos, A. G.; Jansen, J. A., In vivo bone and soft tissue 
response to injectable, biodegradable oligo(poly(ethylene glycol) fumarate) hydrogels. Biomaterials 2003, 24, (19), 3201-3211.

101. Cohn, D.; Sosnik, A.; Garty, S., Smart hydrogels for in situ generated implants. Biomacromolecules 2005, 6, (3), 1168-1175.

102. Park, K. M.; Joung, Y. K.; Park, K. D.; Lee, S. Y.; Lee, M. C., RGD-conjugated chitosan-Pluronic hydrogels as a cell supported scaffold for articular cartilage regeneration. Macromolecular Research 2008, 16, (6), 517-523.

103. Park, K. M.; Lee, S. Y.; Joung, Y. K.; Na, J. S.; Lee, M. C.; Park, K. D., Thermosensitive chitosan-Pluronic hydrogel as an injectable cell delivery carrier for cartilage regeneration. Acta Biomaterialia 2009, 5, (6), 1956-1965.

104. Chen, J. P.; Cheng, T. H., Preparation and evaluation of thermo-reversible copolymer hydrogels containing chitosan and hyaluronic acid as injectable cell carriers. Polymer 2009, 50, (1), 107-116.

105. Chenite, A.; Buschmann, M.; Wang, D.; Chaput, C.; Kandani, N., Rheological characterisation of thermogelling chitosan/glycerol-phosphate solutions. Carbohydrate Polymers 2001, 46, (1), 39-47.

106. Iliescu, M.; Hoemann, C. D.; Shive, M. S.; Chenite, A.; Buschmann, M. D., Ultrastructure of hybrid chitosan-glycerol phosphate blood clots by environmental scanning electron Microscopy. Microscopy Research and Technique 2008, 71, (3), 236-247.

107. Ibusuki, S.; Fujii, Y.; Iwamoto, Y.; Matsuda, T., Tissue-engineered cartilage using an injectable and in situ gelable thermoresponsive gelatin: Fabrication and in vitro performance. Tissue Engineering 2003, 9, (2), 371-384.

108. Jukes, J. M.; van der Aa, L. J.; Hiemstra, C.; van Veen, T.; Dijkstra, P. J.; Zhong, Z. Y.; Feijen, J.; van Blitterswijk, C. A.; de Boer, J., A Newly Developed Chemically Crosslinked Dextran-Poly(Ethylene Glycol) Hydrogel for Cartilage Tissue Engineering. Tissue Engineering Part A 2010, 16, (2), 565-573.

109. Elisseeff, J.; McIntosh, W.; Anseth, K.; Riley, S.; Ragan, P.; Langer, R., Photoencapsulation of chondrocytes in poly(ethylene oxide)-based semi-interpenetrating networks. Journal of Biomedical Materials Research 2000, 51, (2), 164-171.

110. Chevrier, A.; Hoemann, C. D.; Sun, J.; Buschmann, M. D., Chitosan-glycerol phosphate/blood implants increase cell recruitment, transient vascularization and subchondral bone remodeling in drilled cartilage defects. Osteoarthritis and Cartilage 2007, 15, (3), 316-327.

111. Holland, T. A.; Bodde, E. W. H.; Baggett, L. S.; Tabata, Y.; Mikos, A. G.; Jansen, J. A., Osteochondral repair in the rabbit model utilizing bilayered, degradable oligo(poly(ethylene glycol) fumarate) hydrogel scaffolds. Journal of Biomedical Materials Research Part A 2005, 75A, (1), 156-167.

112. Park, H.; Temenoff, J. S.; Tabata, Y.; Caplan, A. I.; Mikos, A. G., Injectable biodegradable hydrogel composites for rabbit marrow mesenchymal stem cell and growth factor delivery for cartilage tissue engineering. Biomaterials 2007, 28, (21), 3217-3227. 113. Visna, P.; Pasa, L.; Cizmar, I.; Hart, R.; Hoch, J., Treatment of deep cartilage defects of the knee using autologous chondrograft transplantation and by abrasive techniques - A randomized controlled study. Acta Chirurgica Belgica 2004, 104, (6), 709714.

114. Hao, T.; Wen, N.; Cao, J. K.; Wang, H. B.; Lu, S. H.; Liu, T.; Lin, Q. X.; Duan, C. M.; Wang, C. Y., The support of matrix accumulation and the promotion of sheep articular 
cartilage defects repair in vivo by chitosan hydrogels. Osteoarthritis and Cartilage 2010, $18,(2), 257-265$.

115. Hoemann, C. D.; Hurtig, M.; Rossomacha, E.; Sun, J.; Chevrier, A.; Shive, M. S.; Buschmann, M. D., Chitosan-glycerol phosphate/blood implants improve hyaline cartilage repair in ovine microfracture defects. Journal of Bone and Joint Surgery-American Volume 2005, 87A, (12), 2671-2686. 


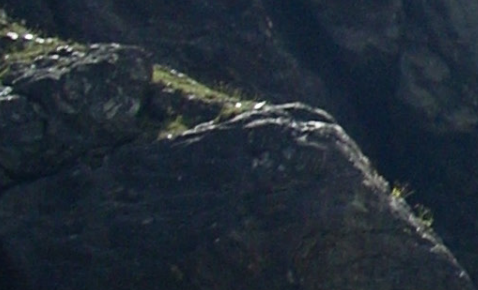




\section{Chapter 3 Aggregation Behavior of Thermo-Responsive and $\mathrm{pH}$-sensitive 4-armed PLLA-PEG copolymers}

Jos W.H. Wennink, Francesca Signori, Marcel Karperien, Jan Feijen and Pieter J. Dijkstra

"The most exciting phrase to hear in science, the one that heralds new discoveries, is not Eureka! But rather, 'hmm... that's funny...”, 


\begin{abstract}
Starting from bis-MPA, PEG-PLLA triblock copolymers (bis-MPA-(PLLA-PEG) $)_{2}$, comprising a central N-hydroxy succinimide active ester were synthesized. Reacting the corresponding active ester with $\alpha, \omega$-diamines afforded four-armed (PEG-PLLA) 2 -R-(PLLA$\mathrm{PEG})_{2}$ copolymers with central $\alpha, \omega$-diamide groups (R). Applying $\alpha, \omega$-diamines like spermine, norspermidine or diethylenenetriamine, triethylenetetramine or tetraethylenepentamine secondary amines were introduced. Whereas a copolymer containing no secondary amine groups showed fully thermo-reversible gelation behavior, copolymers comprising a central moiety containing secondary amine groups form initially gels in PBS but after repeated heating to $75{ }^{\circ} \mathrm{C}$ and cooling to $20{ }^{\circ} \mathrm{C}$ retained the 'sol' state. Dynamic light scattering revealed large differences in the aggregation behavior of the four-armed PEG-PLLA-PEG block copolymers in PBS at different temperatures. A copolymer containing no secondary amine groups showed a thermo-reversible shift in the size of micelles and micellar aggregates (57 and $877 \mathrm{~nm}$ at $25^{\circ} \mathrm{C}$ and 40 and $152 \mathrm{~nm}$ at $50^{\circ} \mathrm{C}$ ). Conversely, copolymers comprising a central moiety containing secondary amine groups show a temperature independent distribution mainly consisting of micelles. It is proposed that the protonated amine groups preferably are located at the corona of the micelles and micellar aggregates and/or shielded by the PEG blocks, hindering the formation of hydrogels by PEG entanglements upon a change in temperature.
\end{abstract}




\section{Introduction}

Thermo-responsive hydrogels have been widely investigated for pharmaceutical and biomedical applications such as drug delivery systems and tissue engineering ${ }^{1,2}$. Upon injection of a thermo-responsive polymer solution into the body, a temperature shift can cause a transition from the fluid state, the sol, to the immobile state, the gel. A well-known class of polymers with a thermo-responsive behavior are the Pluronics or Poloxamers (poly(ethylene oxide)-poly(propylene oxide)-poly(ethylene oxide) block copolymers) ${ }^{3}$. Pluronic F108 $\left(\mathrm{PEO}_{133} \mathrm{PPO}_{50} \mathrm{PEO}_{133}\right)$ polymers in water assemble in micelles to minimize the interfacial free energy and at elevated temperatures dehydration of poly(propylene oxide) segments occurs with a gain in entropy. When reaching a high micellar volume fraction the micelles pack into a hard sphere crystal like structure and gelation occurs. At even higher temperatures a gel-sol transition can occur by further dehydration of the PEG chains, triggering a loss of interaction among the micelles. A general drawback in the use of these materials for biomedical applications is that they are non-biodegradable.

This prompted investigators to design and evaluate thermo-responsive hydrogels based on block copolymers of PEG (A-block) and biodegradable polyesters (B-block). In the past decade, many $\mathrm{AB}, \mathrm{ABA}$ and $\mathrm{BAB}$ type block copolymers, including star block copolymers comprising different polyester or polycarbonate blocks have been investigated for their thermo-responsive behavior ${ }^{4-6}$. The thermal phase transitions of these copolymers in an aqueous environment depend on the molecular weight of the blocks, the hydrophilic/ hydrophobic ratio and copolymer architecture.

This can be illustrated by a few examples for typical ABA systems ${ }^{7-10}$. ABA triblock copolymers have been prepared by ring opening copolymerization of lactide and glycolide, using methoxy-hydroxy PEG as the initiator and subsequent coupling of the diblock copolymer using hexamethylenediisocyanate. Using low molecular weight PEG $\left(M_{n} \leq 3000\right.$ $\mathrm{g} / \mathrm{mol}$ ) and a hydrophobic to hydrophilic ratio of $<30 \mathrm{wt} \%$ the resulting triblock copolymers are water soluble at low temperatures and transformed into the gel state at elevated temperatures. Further increase of the temperature leads to phase separation, and this sol-gelsol phase behavior is comparable to that of Pluronics. However, PLGA is more hydrophobic than PPO and already micelles are present in the sol state at ambient temperatures ${ }^{11}$. For these PEG-PLGA-PEG triblock copolymers the gelation mechanism is suggested to be a result of an increase in the aggregation number and size of the micelles upon an increase in temperature ${ }^{10,12}$. A sol-gel transition occurs when the total volume fraction of micelles is higher than the maximum packing fraction. Whereas copolymers with short PEG blocks show a similar behavior as the Pluronics, copolymers with larger PEG blocks $\left(M_{n} \geq 5000 \mathrm{~g} /\right.$ mol) and a hydrophilic to hydrophobic ratio of $>70 \mathrm{wt} \%$ afford thermo-sensitive hydrogels 
with a gel to sol transition at elevated temperatures ${ }^{8}$. Gelation is believed to occur by close packing of micelles and formation of PEG entanglements. The gel-sol transition is caused by disruption of the micellar packing due to shrinkage of the PEG corona by partial dehydration at higher temperatures ${ }^{8}$. The gel-sol transitions of these block copolymers are influenced by the hydrophilic/hydrophobic balance of the copolymer, block length, hydrophobicity, and in case of PLA block-copolymers, stereoregularity of the hydrophobic block of the copolymer. Due to its high hydrophilicity PEG shows hardly any interactions with proteins ${ }^{13}$. This may be regarded a disadvantage when the hydrogel needs to properly attach to tissue in case of intended tissue regeneration or drug release in a certain area. In recent years, cationic $\mathrm{pH}$ responsive polymers have become of interest due to their ability to form ionic complexes with anionically charged biomacromolecules. Lee et al. have developed several cationically charged copolymer hydrogels based on poly(amino urethane)s and poly(amido amine)s ${ }^{14}$, ${ }^{15}$. These hydrogels exhibited a sol-gel-sol transition at relatively high $\mathrm{pH}$ values. However, the bioadhesive properties of these copolymers have not been reported. Recent work was focused on a triblock copolymer composed of central PEG block (A) and biocompatible poly(ß-amino ester) blocks (B) ${ }^{16}$. This material easily dissolves in aqueous solutions at relatively low $\mathrm{pH}$. At $\mathrm{pH}$ values above 6.4 the copolymer showed a gel-sol transition with an increase in temperature. Gelation occurred as a result of bridging of micelles by the BAB block-copolymer similarly as observed with PLA-PEG-PLA blockcopolymers. In addition, hydrogels based on the former copolymer had bioadhesive properties.

In this paper we describe the synthesis of bis-MPA based ABA type PLLA-PEG copolymers and their properties in an aqueous environment. Coupling of two of these ABA type copolymers via their residual activated ester groups with a central linking unit comprising secondary amines provided four-arm PLLA-PEG copolymers with positive charges at the appropriate $\mathrm{pH}$ in the linking unit. These polymers were compared with polymers containing a neutral linking unit. The temperature and $\mathrm{pH}$ dependent aggregation of the copolymers in an aqueous environment were studied with dynamic light scattering. The results were related to the temperature dependent gelation of these copolymers at higher concentrations as measured by rheology.

\section{Materials and methods}

\section{Materials}

L-lactide (L-LA) was purchased from Purac (Gorinchem, the Netherlands). 2,2-Bis(hydroxymethyl)propionic acid (bis-MPA) was obtained from Acros (Geel, Belgium). Tin (II) 2-ethylhexanoate $\left(\mathrm{Sn}(\mathrm{Oct})_{2}\right)$, succinic anhydride, N-hydroxysuccinimide (NHS), N,N'-dicyclohexylcarbodiimide (DCC), mesyl chloride, deuterated chloroform $\left(\mathrm{CDCl}_{3}\right)$, 
aqueous ammonia (25\%), glacial acetic acid, 1,6-diphenyl-1,3,5-hexatriene (DPH), 1,7-diaminoheptane, norspermidine, spermine, diethylenetriamine, triethylenetetramine and tetraethylenepentamine were obtained from Sigma-Aldrich (Zwijndrecht, the Netherlands). Methoxy-hydroxy poly(ethylene glycol) with a Mw of $5000 \mathrm{~g} / \mathrm{mol}$ (mPEG5000-OH) was purchased from Fluka (Buchs, Switzerland). Triethylamine and 4-dimethylaminopyridine (DMAP) were acquired from Merck (Darmstadt, Germany). All additional solvents were from Biosolve (Valkenswaard, the Netherlands). Dichloromethane and toluene were dried over calcium hydride (Aldrich) and sodium wire, respectively, and distilled prior to use. All other chemicals were used as received.

\section{Synthesis}

bis-MPA-(PLLA10): $)_{2}$ The macromonomer was prepared by adding L-lactide (50.0 g, 348.0 $\mathrm{mmol})$ to a reaction vessel, which contained bis-MPA $(2.3 \mathrm{~g}, 17.4 \mathrm{mmol})$ as the initiator and $\mathrm{Sn}(\mathrm{Oct})_{2}(0.2 \mathrm{~g}, 0.5 \mathrm{mmol})$ as the catalyst. The mixture was allowed to react overnight at $130^{\circ} \mathrm{C}$ under an argon atmosphere. The product was subsequently cooled to room temperature and dissolved in $50 \mathrm{~mL}$ of dichloromethane containing a small amount of glacial acetic acid. The product was precipitated in an excess of cold diethyl ether and collected by filtration and dried in vacuo to give a white powder (yield: $96 \%)$. ${ }^{1} \mathrm{H} \mathrm{NMR}\left(\mathrm{CDCl}_{3}\right): \delta=5.15\left(\mathrm{~m}, \mathrm{CHCH}_{3}\right)$, 4.50-4.20 (m, $\left.\mathrm{CCH}_{2}, \mathrm{CH}_{3} \mathrm{CHOH}\right), 1.57$ (d, $\mathrm{CHCH}_{3}$ ), 1.48 (d, $\left.\mathrm{CHCH}_{3}, \mathrm{CH}_{3} \mathrm{CHOH}\right), 1.22$ (s, $\mathrm{CCH}_{3}$ ).

bis-MPA-(PLLA10-COOH), bis-MPA-(PLLA10), (30.0 g, $9.9 \mathrm{mmol})$, succinic anhydride (2.4 g, $23.9 \mathrm{mmol})$, DMAP (1.5 g, $12.0 \mathrm{mmol})$, and TEA (2.0 g, $19.8 \mathrm{mmol})$ were dissolved in $200 \mathrm{~mL}$ of dichloromethane and stirred for $24 \mathrm{~h}$ under an argon atmosphere at room temperature. The solvent was partially evaporated under reduced pressure and the polymer was precipitated in a diethyl ether: methanol (10:1 v:v) mixture, filtrated and dried in vacuo overnight. The product was obtained as a white powder (yield: $93 \%) .{ }^{1} \mathrm{H} \mathrm{NMR}\left(\mathrm{CDCl}_{3}\right)$ : $\delta=$ $5.15\left(\mathrm{~m}, \mathrm{CHCH}_{3}\right), 4.50-4.20\left(\mathrm{~m}, \mathrm{CCH}_{2}\right), 2.55\left(\mathrm{~m}, \mathrm{OCOCH}_{2} \mathrm{CH}_{2} \mathrm{COOH}\right), 1.57\left(\mathrm{~d}, \mathrm{CHCH}_{3}\right)$, $1.48\left(\mathrm{~d}, \mathrm{CHCH}_{3}\right), 1.22\left(\mathrm{~s}, \mathrm{CCH}_{3}\right)$.

bis-MPA(NHS)-(PLLA10-NHS) : bis-MPA-(PLLA10-COOH) ${ }_{2}(25.0 \mathrm{~g}, 8.1 \mathrm{mmol})$ was dissolved in $200 \mathrm{~mL}$ of dichloromethane. To the resulting solution, NHS (3.7 g, $32.5 \mathrm{mmol})$ and DCC (7.2 g, $35.0 \mathrm{mmol})$ were added. Subsequently, the reaction mixture was allowed to react for $24 \mathrm{~h}$ at room temperature under an argon atmosphere. After the reaction, the formed dicyclohexylurea was removed by filtration. The clear solution was concentrated by partially evaporating the dichloromethane, and the polymer was precipitated in an excess of cold diethyl ether: methanol (10:1 v:v). The product was dried in vacuo overnight and was obtained as a white powder (yield: $94 \%$ ). ${ }^{1} \mathrm{H} \mathrm{NMR}\left(\mathrm{CDCl}_{3}\right): \delta=5.15\left(\mathrm{~m}, \mathrm{CHCH}_{3}\right), 4.50-4.20$ $\left(\mathrm{m}, \mathrm{CCH}_{2}\right), 2.90-2.70\left(\mathrm{~m}, \mathrm{OCOCH}_{2}\right), 2.78\left(\mathrm{~s}, \mathrm{CH}_{2} \mathrm{CH}_{2}\right), 1.57\left(\mathrm{~d}, \mathrm{CHCH}_{3}\right), 1.48\left(\mathrm{~d}, \mathrm{CHCH}_{3}\right)$, 
$1.44\left(\mathrm{~s}, \mathrm{CCH}_{3}\right)$.

mPEG-NH $:$ mPEG-NH $\mathrm{N}_{2}$ was synthesized according the procedure outlined by Elbert and Hubbell ${ }^{17}$. In a typical procedure mPEG5000-OH (50.0 g, $10 \mathrm{mmol}$ ) was dissolved in 700 $\mathrm{mL}$ of dry toluene and dried by the removal of $350 \mathrm{~mL}$ of solvent by azeotropic distillation. After the solution was cooled in an ice-bath, $25 \mathrm{~mL}$ of dichloromethane and TEA $(5.3 \mathrm{ml}$, $37.5 \mathrm{mmol})$ were added. Subsequently, mesyl chloride $(2.9 \mathrm{ml}, 37.5 \mathrm{mmol})$ was added dropwise under stirring and allowed to react overnight at room temperature. The solution was filtered and the product was precipitated in a large excess of cold diethyl ether. After drying, the formed mPEG5000-mesylate was reacted with $100 \mathrm{~mL}$ of an aqueous ammonia solution ( $25 \%$ ) for 4 days at room temperature. Subsequently, the ammonia was allowed to evaporate and the $\mathrm{pH}$ of the solution was raised to 13 , using $1 \mathrm{M} \mathrm{NaOH}$. The solution was extracted 3 times with $200 \mathrm{~mL}$ of dichloromethane. The dichloromethane extracts were combined, dried with $\mathrm{MgSO}_{4}$, filtered and the solution was concentrated. mPEG5000- $\mathrm{NH}_{2}$ was isolated by precipitation in cold diethyl ether, and drying in vacuo (yield: $76 \%$ ). ${ }^{1} \mathrm{H} \mathrm{NMR}\left(\mathrm{CDCl}_{3}\right): \delta=$ 3.65 (m, PEG protons), 3.37 ( $\mathrm{s}, \mathrm{CH}_{2} \mathrm{OCH}_{3}$ ), 2.94 ( $\mathrm{t}, \mathrm{CH}_{2} \mathrm{CH}_{2} \mathrm{NH}_{2}$ ).

bis-MPA(NHS)-(PLLA10-mPEG5000) : $\quad$ bis-MPA(NHS)-(PLLA10-NHS) $)_{2}\left(\begin{array}{lll}8.0 & \mathrm{~g}, & 1.9\end{array}\right.$ $\mathrm{mmol})$ and $\mathrm{mPEG} 5000-\mathrm{NH}_{2}(19.2 \mathrm{~g}, 3.8 \mathrm{mmol})$ were dissolved in $80 \mathrm{ml}$ of dichloromethane, and stirred for $24 \mathrm{~h}$ at room temperature under an argon atmosphere. The resulting solution was concentrated by partially evaporating the solvent, and the polymer was precipitated in an excess of cold diethyl ether: methanol (10:1 v:v). The product was dried in vacuo and was obtained as a white powder (yield: $87 \%) .{ }^{1} \mathrm{H} \mathrm{NMR}\left(\mathrm{CDCl}_{3}\right): \delta=6.40\left(\mathrm{~s}, \mathrm{CH}_{2} \mathrm{NHCO}\right)$ $5.15\left(\mathrm{~m}, \mathrm{CHCH}_{3}\right), 4.50-4.20\left(\mathrm{~m}, \mathrm{CCH}_{2}\right), 3.65$ (m, PEG protons), 3.55 (m, $\mathrm{NHCH}_{2}$ ), 3.37 (s, $\left.\mathrm{CH}_{2} \mathrm{OCH}_{3}\right), 2.85\left(\mathrm{~s}, \mathrm{CH}_{2} \mathrm{CH}_{2}\right), 2.75-2.50\left(\mathrm{~m}, \mathrm{OCOCH}_{2}\right), 1.57\left(\mathrm{~d}, \mathrm{CHCH}_{3}\right), 1.44\left(\mathrm{~s}, \mathrm{CCH}_{3}\right)$.

General procedure for the synthesis of 4-armed PLLA10-PEG5000: In a typical experiment, bis-MPA(NHS)-(PLLA10-MPEG5000) $)_{2}(4.0 \mathrm{~g}, 0.3 \mathrm{mmol})$ and spermine (30 $\mathrm{mg}, 0.15 \mathrm{mmol}$ ) were dissolved in $20 \mathrm{~mL}$ of DMF, and stirred for $24 \mathrm{~h}$ at room temperature under an argon atmosphere. The resulting polymer was precipitated in an excess of cold diethyl ether and the product was dried in vacuo. To remove residual DMF, the product was dissolved again in dichloromethane and precipitated in an excess of cold diethyl ether. The product was dried in vacuo and obtained as a white powder (yields ranged from $89 \%$ to $97 \%$ ). I: ${ }^{1} \mathrm{H} \mathrm{NMR}\left(\mathrm{CDCl}_{3}\right): \delta=6.40,\left(\mathrm{~s}, \mathrm{CH}_{2} \mathrm{NHCO}\right) 5.15\left(\mathrm{~m}, \mathrm{CHCH}_{3}\right), 4.40-4.10\left(\mathrm{~m}, \mathrm{CCH}_{2}\right), 3.65$ (m, PEG protons), 3.55 (m, $\left.\mathrm{NHCH}_{2}\right), 3.37\left(\mathrm{~s}, \mathrm{CH}_{2} \mathrm{OCH}_{3}\right), 2.75-2.50$ (m, $\left.\mathrm{OCOCH}_{2}\right), 1.57$ (d, $\left.\mathrm{CHCH}_{3}\right), 1.22\left(\mathrm{~s}, \mathrm{CCH}_{3}\right)$.

II: ${ }^{1} \mathrm{H}$ NMR $\left(\mathrm{CDCl}_{3}\right): \delta=6.40,\left(\mathrm{~s}, \mathrm{CH}_{2} \mathrm{NHCO}\right) 5.15\left(\mathrm{~m}, \mathrm{CHCH}_{3}\right), 4.40-4.10\left(\mathrm{~m}, \mathrm{CCH}_{2}\right), 3.65$ (m, PEG protons), 3.55 (m, $\left.\mathrm{NHCH}_{2}\right), 3.37\left(\mathrm{~s}, \mathrm{CH}_{2} \mathrm{OCH}_{3}\right), 2.75-2.50\left(\mathrm{~m}, \mathrm{OCOCH}_{2}\right), 2.62$ (s, $\left.\mathrm{CH}_{2} \mathrm{NHCH}_{2}\right), 1.57\left(\mathrm{~d}, \mathrm{CHCH}_{3}\right), 1.22\left(\mathrm{~s}, \mathrm{CCH}_{3}\right)$.

III: ${ }^{1} \mathrm{H} \mathrm{NMR}\left(\mathrm{CDCl}_{3}\right): \delta=6.40,\left(\mathrm{~s}, \mathrm{CH}_{2} \mathrm{NHCO}\right) 5.15\left(\mathrm{~m}, \mathrm{CHCH}_{3}\right), 4.40-4.10\left(\mathrm{~m}, \mathrm{CCH}_{2}\right), 3.65$ 
(m, PEG protons), 3.55 (m, $\left.\mathrm{NHCH}_{2}\right), 3.37\left(\mathrm{~s}, \mathrm{CH}_{2} \mathrm{OCH}_{3}\right), 2.75-2.50\left(\mathrm{~m}, \mathrm{OCOCH}_{2}\right), 2.62$ (s, $\left.\mathrm{CH}_{2} \mathrm{NHCH}_{2}\right), 1.57$ (d, $\left.\mathrm{CHCH}_{3}, \mathrm{CH}_{2} \mathrm{CH}_{2} \mathrm{CH}_{2}\right), 1.22\left(\mathrm{~s}, \mathrm{CCH}_{3}\right)$.

IV: ${ }^{1} \mathrm{H}$ NMR $\left(\mathrm{CDCl}_{3}\right): \delta=6.40,\left(\mathrm{~s}, \mathrm{CH}_{2} \mathrm{NHCO}\right) 5.15\left(\mathrm{~m}, \mathrm{CHCH}_{3}\right), 4.40-4.10\left(\mathrm{~m}, \mathrm{CCH}_{2}\right), 3.65$ (m, PEG protons), 3.55 (m, $\left.\mathrm{NHCH}_{2}\right), 3.37\left(\mathrm{~s}, \mathrm{CH}_{2} \mathrm{OCH}_{3}\right), 2.75-2.50\left(\mathrm{~m}, \mathrm{OCOCH}_{2}\right), 2.62$ (s, $\left.\mathrm{CH}_{2} \mathrm{NHCH}_{2}\right), 1.57\left(\mathrm{~d}, \mathrm{CHCH}_{3}\right), 1.22\left(\mathrm{~s}, \mathrm{CCH}_{3}\right)$.

V: ${ }^{1} \mathrm{H}$ NMR $\left(\mathrm{CDCl}_{3}\right): \delta=6.40,\left(\mathrm{~s}, \mathrm{CH}_{2} \mathrm{NHCO}\right) 5.15\left(\mathrm{~m}, \mathrm{CHCH}_{3}\right), 4.40-4.10\left(\mathrm{~m}, \mathrm{CCH}_{2}\right), 3.65$ (m, PEG protons), 3.55 (m, $\left.\mathrm{NHCH}_{2}\right), 3.37\left(\mathrm{~s}, \mathrm{CH}_{2} \mathrm{OCH}_{3}\right), 2.75-2.50$ (m, $\left.\mathrm{OCOCH}_{2}\right), 2.62$ (s, $\left.\mathrm{CH}_{2} \mathrm{NHCH}_{2}\right), 1.57\left(\mathrm{~d}, \mathrm{CHCH}_{3}\right), 1.22\left(\mathrm{~s}, \mathrm{CCH}_{3}\right)$.

VI: ${ }^{1} \mathrm{H}$ NMR $\left(\mathrm{CDCl}_{3}\right): \delta=6.40,\left(\mathrm{~s}, \mathrm{CH}_{2} \mathrm{NHCO}\right) 5.15\left(\mathrm{~m}, \mathrm{CHCH}_{3}\right), 4.40-4.10\left(\mathrm{~m}, \mathrm{CCH}_{2}\right), 3.65$ (m, PEG protons), 3.55 (m, $\left.\mathrm{NHCH}_{2}\right), 3.37\left(\mathrm{~s}, \mathrm{CH}_{2} \mathrm{OCH}_{3}\right), 2.75-2.50\left(\mathrm{~m}, \mathrm{OCOCH}_{2}\right), 2.62$ (s, $\left.\mathrm{CH}_{2} \mathrm{NHCH}_{2}\right), 1.57\left(\mathrm{~d}, \mathrm{CHCH}_{3}\right), 1.22\left(\mathrm{~s}, \mathrm{CCH}_{3}\right)$.

\section{Characterization}

${ }^{1}$ H-NMR: ${ }^{1} \mathrm{H}(300 \mathrm{MHz}) \mathrm{NMR}$ spectra were recorded using a Varian Inova NMR spectrometer. Polymers were dissolved in $\mathrm{CDCl}_{3}$ at a concentration of $0.015 \mathrm{~g} / \mathrm{mL}$. Peak multiplicity was denoted as s (singlet), d (doublet), dd (double doublet), t (triplet), q (quartet), m (multiplet), and $b$ (broad signal).

DSC: Thermal analysis of the macromonomers and the copolymers was carried out using a Pyris 1 differential scanning calorimeter, calibrated with indium and gallium. During a measurement, the polymer $(5-15 \mathrm{mg})$ was cooled to $-50{ }^{\circ} \mathrm{C}$ and kept at this temperature for $1 \mathrm{~min}$. The sample was then heated to $200^{\circ} \mathrm{C}$, annealed for $1 \mathrm{~min}$ and subsequently cooled to $-50{ }^{\circ} \mathrm{C}$. Finally, the sample was kept at $-50{ }^{\circ} \mathrm{C}$ for $5 \mathrm{~min}$ and heated to $200{ }^{\circ} \mathrm{C}$. The heating and cooling rates were $20^{\circ} \mathrm{C} / \mathrm{min}$. Melting $\left(\mathrm{T}_{\mathrm{m}}\right)$ temperatures were obtained from the peak maxima in the second scan. The melt $\left(\Delta \mathrm{H}_{\mathrm{m}}\right)$ enthalpies were determined from the area under the curve. The glass transition temperature $\left(\mathrm{T}_{\mathrm{g}}\right)$ was taken at the inflection point. The crystallization temperature $\left(\mathrm{T}_{c}\right)$ and enthalpy $\left(\Delta \mathrm{H}_{\mathrm{c}}\right)$ were obtained from the peak maximum and the area under the curve in the cooling scan, respectively.

Vial tilting method: The phase behavior of aqueous polymer solutions was investigated by the vial tilting method. Block copolymers were dissolved in PBS (10-40 wt \%) in tightly capped $5 \mathrm{~mL}$ vials by repeatedly heating to $60{ }^{\circ} \mathrm{C}$ for $2 \mathrm{~min}$ and stirring while cooling. The block copolymer solutions were kept at $4{ }^{\circ} \mathrm{C}$ overnight prior to measurement. The temperature was increased step-wise with 2 or $4{ }^{\circ} \mathrm{C}$ and the samples were kept at the measuring temperature for $10 \mathrm{~min}$ to equilibrate. The gel-sol transition temperature was determined by tilting the vials $90^{\circ}$ for $1 \mathrm{~min}$. If there was no flow, the sample was regarded as a gel. In other cases it was regarded as a sol.

Rheology: Rheology experiments were performed with an Anton Paar Physica MCR 301 rheometer with flat plate geometry $(20 \mathrm{~mm}$ diameter, $0.3 \mathrm{~mm}$ gap) in oscillating mode. 
Solutions of the polymers in PBS were prepared by dissolving the appropriate amount of polymer as described above. The gels were kept at $4{ }^{\circ} \mathrm{C}$ overnight prior to measurement. The gels were then applied to the rheometer. To prevent evaporation of water a solvent trap was placed over the geometry. A pre-shear was applied for $10 \mathrm{~s}$, after which the polymer solution was allowed to equilibrate for $10 \mathrm{~min}$. Subsequently, the polymer solution was heated to 75 ${ }^{\circ} \mathrm{C}$ at $1{ }^{\circ} \mathrm{C} / \mathrm{min}$, and then cooled to $20{ }^{\circ} \mathrm{C}$ at $1{ }^{\circ} \mathrm{C} / \mathrm{min}$. Sol to gel transitions were monitored by measuring the storage modulus $\mathrm{G}^{\prime}$ and the loss modulus $\mathrm{G}$ ”. A frequency $\omega$ of $1 \mathrm{~Hz}$ and a strain $\gamma$ of $1 \%$ were applied to minimize the influence of deformation on the hydrogels. After heating and cooling cycles, a frequency and amplitude sweep were performed at $\omega$ 0.01-10 $\mathrm{Hz}(\gamma=1 \%)$ and $\gamma 0.01-10 \%(\omega=1 \mathrm{~Hz})$ at $20^{\circ} \mathrm{C}$, to confirm that the applied frequency of 1 $\mathrm{Hz}$ and a strain of $1 \%$ was within the linear viscoelastic range.

UV-VIS: The critical association concentration of the copolymers in PBS at $20{ }^{\circ} \mathrm{C}$ was determined by the dye solubilization method. To $1.0 \mathrm{~mL}$ of copolymer solutions with concentrations ranging from 0.0001 to $1 \mathrm{wt} \%, 10 \mu \mathrm{L}$ of a $0.5 \mathrm{mM}$ DPH solution in methanol was added. The resulting mixture was stored in the dark and equilibrated overnight. UV-Vis absorption spectra of the solutions were recorded in the 300 to $500 \mathrm{~nm}$ range. The difference in the absorption at $378 \mathrm{~nm}$ relative to $403 \mathrm{~nm}$ was plotted against the polymer concentration and the intercept of the extrapolated straight lines was defined as the critical association concentration of the copolymer.

DLS: Dynamic light scattering experiments were performed on $0.3 \mathrm{wt} \%$ solutions using a Malvern zetasizer 4000 (Malvern Corp., Malvern, UK), using a laser wavelength of 633 nm. The CONTIN method was applied for data processing. The diameter of micelles or aggregates of copolymers in PBS was determined as a function of temperature in between 20 and $50{ }^{\circ} \mathrm{C}$. All solutions were allowed to equilibrate at each measuring temperature for $15 \mathrm{~min}$. 


\section{Results and discussion}

By a convergent synthetic approach 4-armed PLLA-PEG block copolymers, comprising a central moiety containing $0,1,2$ or 3 secondary amine groups, were prepared. A key compound is the PLLA-PEG block copolymer having a single activated carboxylic acid group, which was synthesized starting from bis-MPA (Scheme 1).

First, using bis-MPA as the initiator in the $\mathrm{Sn}(\mathrm{Oct})_{2}$ catalyzed ring opening polymerization of L-lactide, PLLA macromonomers were prepared. The monomer to initiator ratio was chosen such that the degree of polymerization (DP) per arm was 10 lactide units and a high conversion was reached within $16 \mathrm{~h}$ of reaction (98-99\%). From the integral ratio of the $\mathrm{CH}$ protons of the lactide repeating units $(5.15 \mathrm{ppm})$ to the $\mathrm{CH}_{3}$ protons of the bis-MPA moiety (1.24 ppm) in the ${ }^{1} \mathrm{H}-\mathrm{NMR}$ spectra of the purified bis-MPA-(PLLA10) ${ }_{2}$ macromonomers, the average DP per arm was calculated (Figure 1A). The results obtained were in good agreement with theoretical values, based on the monomer to initiator ratio. 

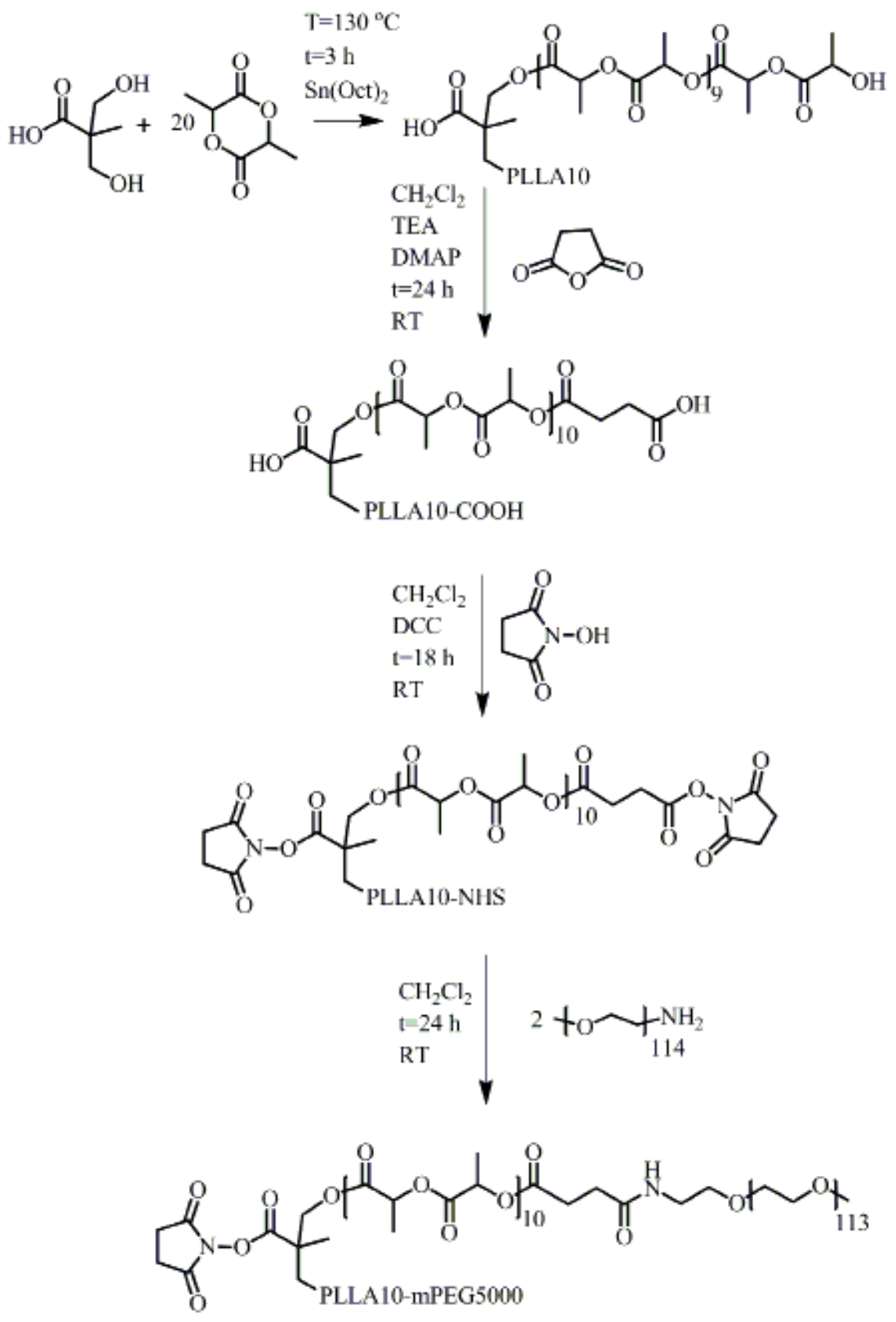

Scheme 1. Synthetic route for the preparation of bis-MPA(NHS)-(PLLA10-mPEG5000). 
The hydroxyl end groups of bis-MPA-(PLLA10) ${ }_{2}$ were subsequently reacted with succinic anhydride to yield carboxylic acid end groups. The ${ }^{1} \mathrm{H}-\mathrm{NMR}$ spectrum of the macromer (Figure 1B) shows the disappearance of the signals c' (4.40 ppm) and d' (1.50 ppm), belonging to the protons of the terminal lactic acid units, and the appearance of a new signal at 2.70 ppm (e), corresponding to the methylene protons of the succinic ester groups. Furthermore, the integral ratio of signals $\mathrm{b}$ and e was $1: 2$, revealing a high conversion of the hydroxyl end groups.

All three carboxylic acid groups were then converted into their NHS active esters by reaction with NHS in the presence of DCC. The ${ }^{1} \mathrm{H}-\mathrm{NMR}$ spectrum (Figure 1C) showed the appearance of a new signal originating from the methylene protons of the succinimide ring at $2.82 \mathrm{ppm}$. Furthermore, the signal corresponding to the methyl protons of the bis-MPA moiety shifted from 1.24 to $1.44 \mathrm{ppm}$. The ${ }^{1} \mathrm{H}-\mathrm{NMR}$ spectra revealed that high conversions were obtained based on the integral ratio of signals $a, b$, e and $f$.

In preliminary experiments on the coupling of bis-MPA(NHS)-(PLLA10-NHS) ${ }_{2}$ and mPEG5000- $\mathrm{NH}_{2}$, it was observed that the primary activated carboxylic ester groups react selectively at room temperature and only by applying elevated temperatures the tertiary active ester reacts with the amine end functionalized PEG. This observation opened the opportunity to macromolecular engineer materials by selectively introducing different end functionalized macromonomers or polymer blocks. Thus, reacting bis-MPA(NHS)-(PLLA10-NHS) ${ }_{2}$ and mPEG5000- $\mathrm{NH}_{2}$ at a 1:2 ratio in dichloromethane at room temperature, the bis-MPA(NHS)(PLLA10-mPEG5000), copolymer was obtained. The ${ }^{1} \mathrm{H}-\mathrm{NMR}$ spectrum (Figure 1D) showed that peaks originating from the methylene protons of the succinic ester (e) at 2.83 ppm and $3.00 \mathrm{ppm}$ shifted to $2.50 \mathrm{ppm}$ and $2.70 \mathrm{ppm}$, respectively. Additionally, NH protons of the formed amide bonds were found at $6.50 \mathrm{ppm}$. Furthermore, the integral ratio of the remaining NHS methylene protons (f) and the methoxy group (j) was 2:3, indicating that selective coupling was successful.

The thermal properties of the different PLLA macromonomers (Table 1) show a $T_{g}$ at $\sim 57$ ${ }^{\circ} \mathrm{C}$ and $\mathrm{a} \mathrm{T}_{\mathrm{m}}$ at $\sim 124{ }^{\circ} \mathrm{C}$. A melting peak was found for the PEG and PLLA rich phases in the block copolymer. The melting transitions at $74.5{ }^{\circ} \mathrm{C}$ of the PLLA rich phase and at $57.2^{\circ} \mathrm{C}$ of the PEG phase in the copolymer were lower than those of their corresponding macromonomers, likely due to partial phase mixing. 


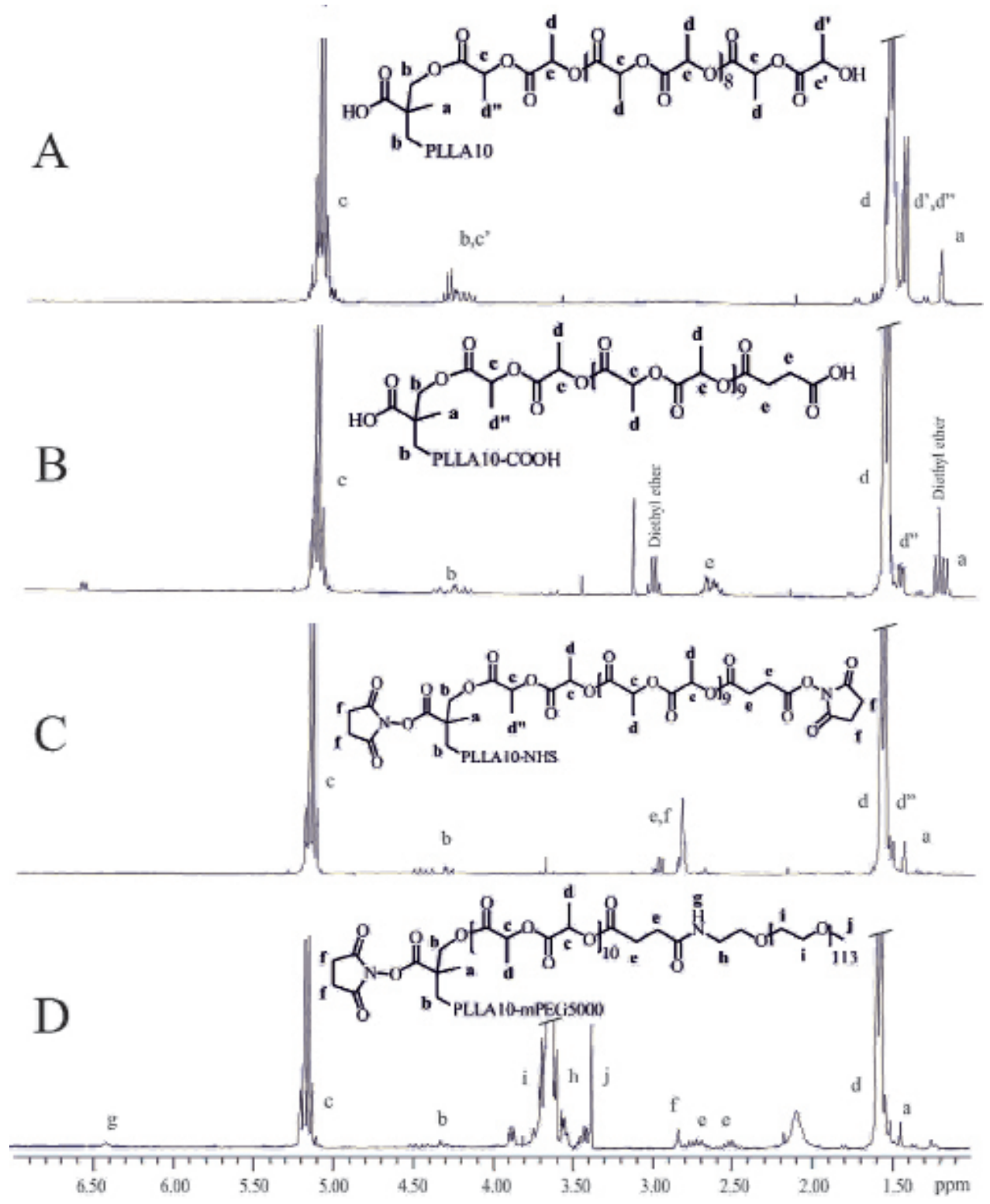

Figure 1. ${ }^{1} \mathrm{H}-\mathrm{NMR}$ spectra of (A) bis-MPA-(PLLA10), (B) bis-MPA-(PLLA10-COOH) $)_{2}$, (C) bis-MPA(NHS)(PLLA10-NHS) $)_{2}$, (D) bis-MPA(NHS)-(PLLA10-mPEG5000). Solvent: $\mathrm{CDCl}_{3}$. 
Table 1. Thermal properties of macromonomers mPEG5000-NH ${ }_{2}$, bis-MPA-(PLLA10), bis-MPA-(PLLA10$\mathrm{COOH})_{2}$, bis-MPA(NHS)-(PLLA10-NHS), and copolymer bis-MPA(NHS)-(PLLA10-mPEG5000).

\begin{tabular}{|c|c|c|c|c|c|c|c|c|c|}
\hline & \multicolumn{5}{|c|}{ PLLA } & \multicolumn{4}{|l|}{ PEG } \\
\hline & $\begin{array}{l}\mathrm{T}_{\mathrm{g}} \\
\left({ }^{\circ} \mathrm{C}\right)\end{array}$ & $\begin{array}{l}\mathrm{T}_{\mathrm{m}} \\
\left({ }^{\circ} \mathrm{C}\right)\end{array}$ & $\begin{array}{l}\Delta H_{m} \\
(J / g)\end{array}$ & $\begin{array}{l}\mathrm{T}_{\mathrm{c}} \\
\left({ }^{\circ} \mathrm{C}\right)\end{array}$ & $\begin{array}{l}\Delta H_{c} \\
(J / g)\end{array}$ & $\begin{array}{l}\mathrm{T}_{\mathrm{m}} \\
\left({ }^{\circ} \mathrm{C}\right)\end{array}$ & $\begin{array}{l}\Delta \mathbf{H}_{\mathrm{m}} \\
(\mathrm{J} / \mathrm{g})\end{array}$ & $\begin{array}{l}\mathrm{T}_{c} \\
\left({ }^{\circ} \mathrm{C}\right)\end{array}$ & $\begin{array}{l}\Delta \mathbf{H}_{\mathrm{c}} \\
(\mathrm{J} / \mathrm{g})\end{array}$ \\
\hline mPEG5000- $\mathrm{NH}_{2}$ & - & - & - & - & - & 60.1 & 158.6 & 29.8 & 160.7 \\
\hline bis-MPA-(PLLA10) & 58.3 & 124.7 & 5.6 & - & - & - & - & - & - \\
\hline $\begin{array}{l}\text { bis-MPA-(PLLA10- } \\
\mathrm{COOH})_{2}\end{array}$ & 56.7 & 126.5 & 5.2 & - & - & - & - & - & - \\
\hline $\begin{array}{l}\text { bis-MPA(NHS)- } \\
\text { (PLLA10-NHS) }\end{array}$ & 56.3 & 121.2 & 3.3 & - & - & - & - & - & - \\
\hline $\begin{array}{l}\text { bis-MPA(NHS)- } \\
\text { (PLLA10-mPEG5000) }\end{array}$ & - & 74.5 & 1.7 & 36.3 & 5.3 & 57.2 & 74.3 & 17.7 & 69.0 \\
\hline
\end{tabular}

A range of four armed PLLA-mPEG copolymers were conveniently prepared by reacting different $\alpha, \omega$-bis-amines with the bis-MPA(NHS)-(PLLA10-mPEG5000) ${ }_{2}$ macromer in DMF at room temperature for $24 \mathrm{~h}$ in high conversion and yield (Figure 2). As a typical example, the ${ }^{1} \mathrm{H}$-NMR spectrum of the product obtained upon reaction of the macromer with norspermidine (II) showed the disappearance of the NHS methylene protons (Figure 3). Additionally, the $\mathrm{CH}_{3}$ protons of the bis-MPA (a) shifted from $1.44 \mathrm{ppm}$ to $1.20 \mathrm{ppm}$. From this shift and the integral ratios of protons $\mathrm{a}, \mathrm{b}$ and $\mathrm{g}$ it was concluded that the coupling reaction of the $\alpha, \omega$-bis-amine with bis-MPA(NHS)-(PLLA10-mPEG5000), to provide the four armed PLLA-mPEG copolymer was quantitative. 


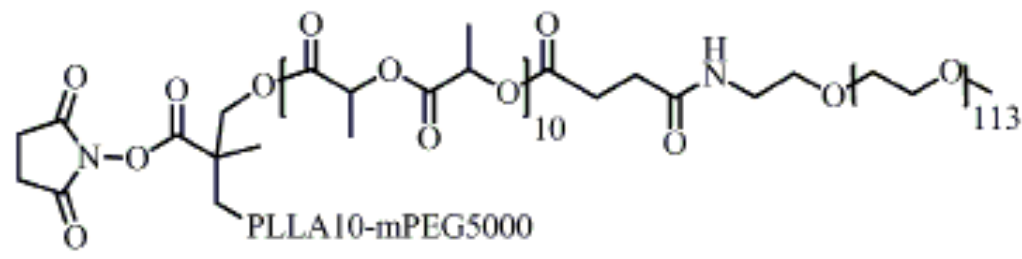

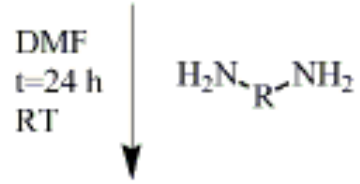

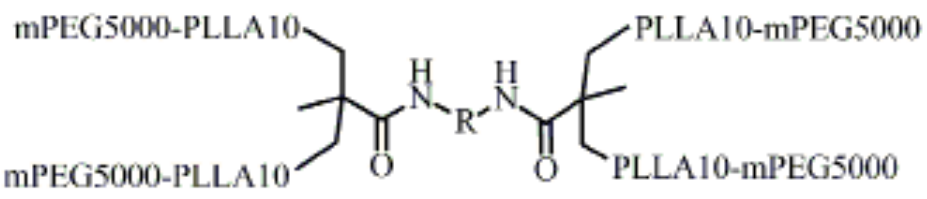

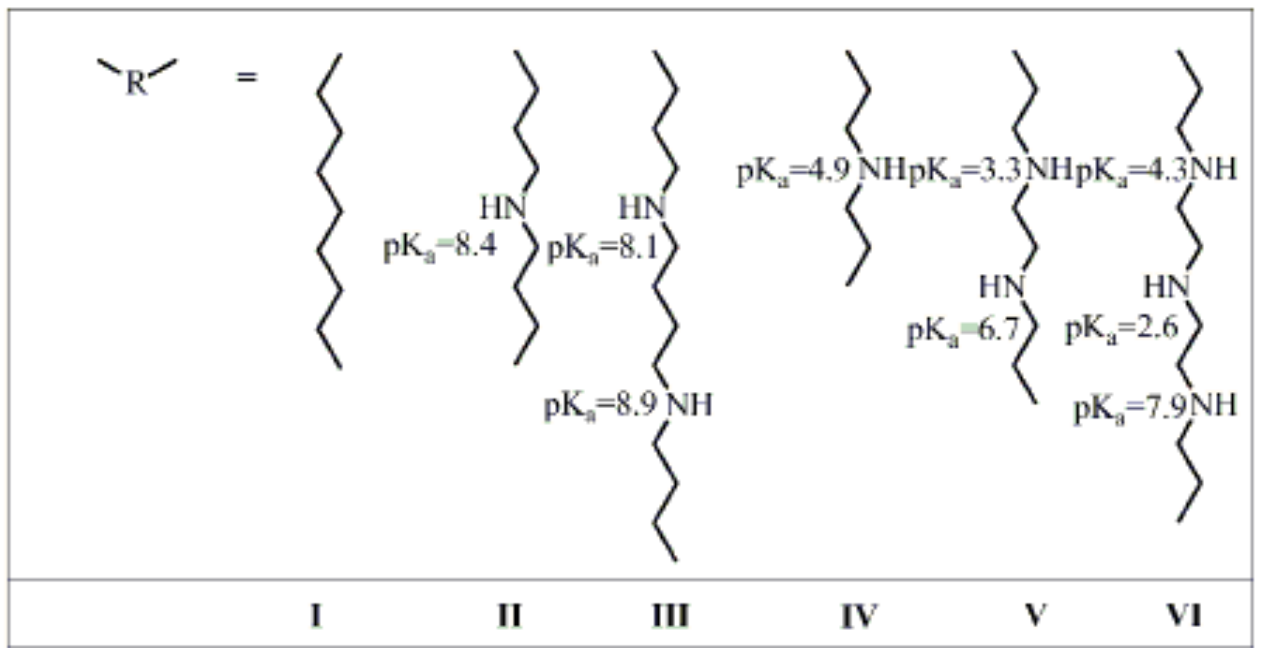

Figure 2. Schematic synthetic route for the preparation of four armed PLLA-mPEG copolymers with different central moieties. pKa values indicated are the values for the corresponding protonated alkylamines. 


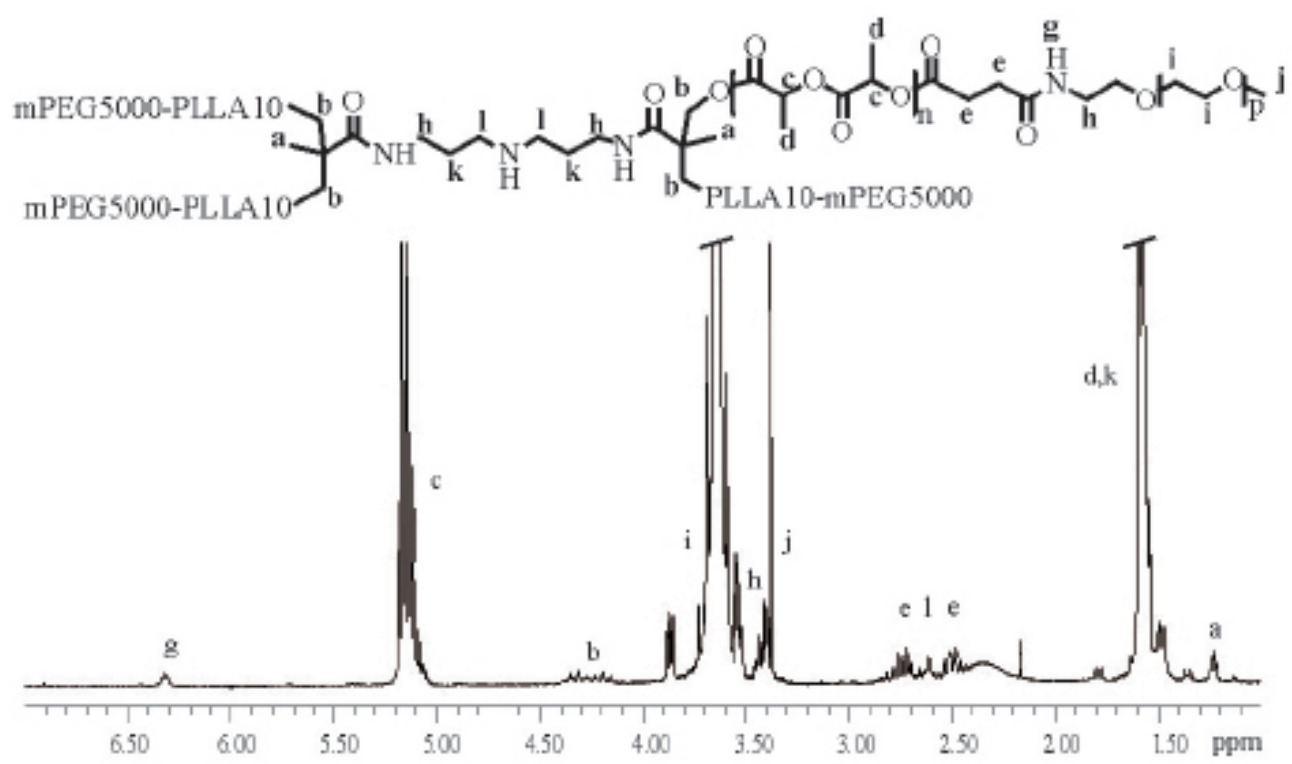

Figure 3. ${ }^{1} \mathrm{H}-\mathrm{NMR}$ spectrum of copolymer II. Solvent $\mathrm{CDCl}_{3}$

The thermal properties of the PLLA-mPEG four armed polymers with different $\alpha, \omega$-bisamide moieties are presented in Table 2. It was found that the melting and crystallization temperatures only slightly increased compared to those of the precursor compound bisMPA(NHS)-(PLLA10-mPEG5000), and have similar values.

Table 2. Thermal properties of copolymers I-VI.

\begin{tabular}{|l|l|l|l|l|l|l|l|l|}
\hline & \multicolumn{9}{l}{ PLLA } & \multicolumn{3}{l|}{ PEG } \\
\hline & $\begin{array}{l}\mathbf{T}_{\mathbf{m}} \\
\left({ }^{\circ} \mathbf{C}\right)\end{array}$ & $\begin{array}{l}\Delta \mathbf{H}_{\mathrm{m}} \\
(\mathbf{J} / \mathbf{g})\end{array}$ & $\begin{array}{l}\mathbf{T}_{\mathbf{c}} \\
\left({ }^{\circ} \mathbf{C}\right)\end{array}$ & $\begin{array}{l}\Delta \mathbf{H}_{\mathbf{c}} \\
(\mathbf{J} / \mathbf{g})\end{array}$ & $\begin{array}{l}\mathbf{T}_{\mathbf{m}} \\
\left({ }^{\circ} \mathbf{C}\right)\end{array}$ & $\begin{array}{l}\Delta \mathbf{H}_{\mathrm{m}} \\
(\mathbf{J} / \mathbf{g})\end{array}$ & $\begin{array}{l}\mathbf{T}_{\mathbf{c}} \\
\left({ }^{\circ} \mathbf{C}\right)\end{array}$ & $\begin{array}{l}\Delta \mathbf{H}_{\mathbf{c}} \\
(\mathbf{J} / \mathbf{g})\end{array}$ \\
\hline $\mathbf{I}$ & 79.1 & 2.1 & 38.8 & 4.8 & 57.8 & 75.2 & 19.1 & 70.9 \\
\hline $\mathbf{I I}$ & 77.5 & 1.9 & 39.0 & 4.7 & 57.6 & 75.5 & 18.8 & 71.2 \\
\hline III & 78.5 & 1.7 & 39.3 & 4.3 & 58.6 & 76.8 & 19.7 & 73.3 \\
\hline IV & 77.9 & 2.2 & 39.1 & 4.3 & 58.3 & 75.3 & 18.8 & 72.1 \\
\hline V & 78.2 & 1.9 & 39.4 & 5.0 & 59.0 & 76.3 & 19.0 & 71.0 \\
\hline VI & 78.5 & 2.0 & 39.6 & 5.1 & 57.9 & 75.4 & 18.7 & 71.2 \\
\hline
\end{tabular}


All PLLA-mPEG four armed copolymers prepared afforded transparent solutions in PBS at pH 7.4 at low concentrations. It was observed that the introduction of different $\alpha, \omega$-bis-amide moieties comprising secondary amine groups increased the aqueous solubility compared to the four armed copolymer I. This could also be illustrated by coupling of the mono amine functionalized N,N-dimethyl-dipropylene triamine to the bis-MPA(NHS)-(PLLA10mPEG5000) (data not shown) resulting in a two armed copolymer. The resulting copolymer with a moiety containing one secondary and one tertiary amine group coupled to the central bis-MPA unit appeared highly soluble in PBS at pH 7.4, even at high concentrations (40 wt $\%$ ) and independent of the temperature $\left(25-75^{\circ} \mathrm{C}\right)$.

All polymers (I-IV) provided in most cases gels upon mixing the solid polymeric materials with PBS at concentrations of 10 to $30 \mathrm{wt} \%$, heating the mixture to $60{ }^{\circ} \mathrm{C}$ and subsequent cooling to room temperature. Following, a number of experiments were performed to study the reversibility of gel to sol transitions of these initially formed gels as a function of temperature and $\mathrm{pH}$.

Copolymer I afforded a thermo-reversible hydrogel of which the gel-sol transition temperature increased with increasing concentration (see Figure 4 for a concentration of 10 wt \%). Conversely, the initially formed hydrogels from copolymers II-VI were not thermoreversible. After bringing the hydrogels to the sol-state by heating, and equilibration for several hours, no gels were formed anymore upon cooling, and only highly viscous solutions were obtained. This took place independent of concentration (10-40 wt \%) and pH (5-8).
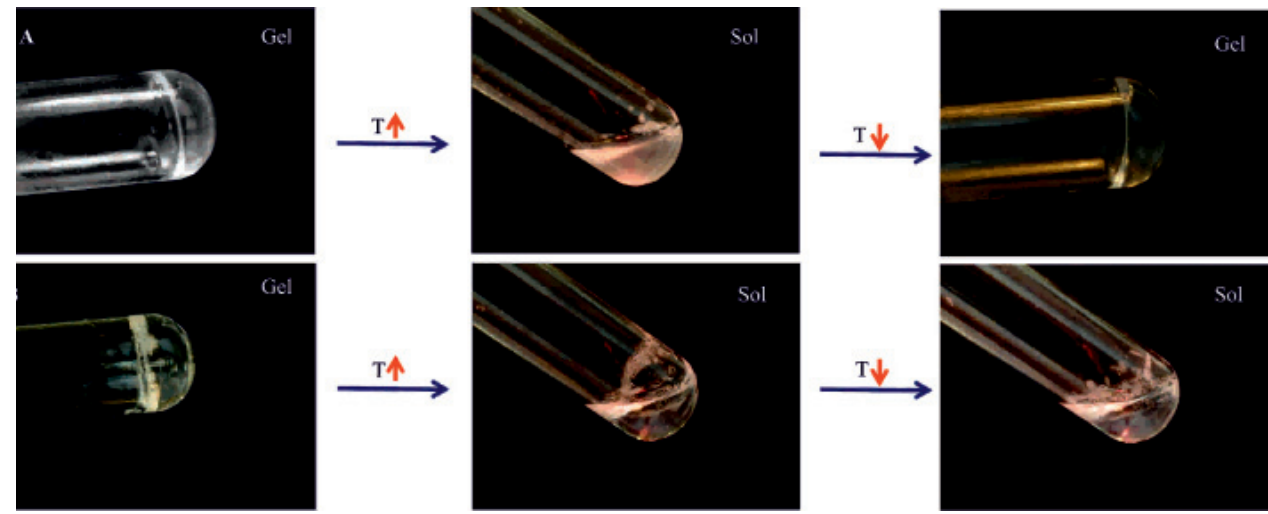

PBS, pH 7.4, 10 wt \%, and B) II, PBS, pH 7.4, 20 wt \%. 
The increased hydrophilicity of the copolymers containing a central moiety with secondary amine groups (II-VI) as compared to I at pH 7.4 may account for the observed shift in the gel to sol transition. Polymers prepared by coupling of norspermidine (II) or spermine (III) have a propylene spacer between the amide and secondary amine groups. The pKa values of the secondary amines in these linking units are approximately 8.5 (Figure 2). This means that at the $\mathrm{pH}$ values applied the secondary amines in II and III are mostly present in the protonated form, and especially copolymer III becomes well soluble in PBS (pH 7.4) up to concentrations of at least $40 \mathrm{wt} \%$. For copolymers (IV-VI), which have an ethylene spacer between the amide and secondary amine groups, the successive amine groups are protonated in two steps with a distinctive gauche-anti conformational transition ${ }^{18,19}$. Although this lowers the effective charge in the central moiety at $\mathrm{pH} 7.4$, also in this case no clear sol-gel transition was observed.

Oscillatory rheology experiments confirmed the observations from the vial tilting experiments. The storage (G') and loss (G') moduli of copolymer I (10 wt \% in PBS) upon repeated heating and cooling cycles revealed gel-sol-gel transitions at $65-70{ }^{\circ} \mathrm{C}$ (Figure $5 \mathrm{~A}$ ). It should be noted that the difference between the storage and loss modulus is rather small, and thus only weak and non-elastic hydrogels are formed. Similar experiments performed on copolymers II- VI (a typical example is presented in Figure 5B) revealed that upon several heating and cooling cycles the sol to gel transition temperature gradually decreased from $68^{\circ} \mathrm{C}$ (first cycle) to 54 ${ }^{\circ} \mathrm{C}$ (second cycle) to $39{ }^{\circ} \mathrm{C}$ (third cycle). From the fourth cycle on no gel to sol transition is observed anymore. In order to exclude degradation of the copolymers during the heating and cooling cycles, ${ }^{1} \mathrm{H}-\mathrm{NMR}$ analysis of copolymer samples after heating and cooling cycles was carried out and it revealed that within the limits of ${ }^{1} \mathrm{H}-\mathrm{NMR}$ spectroscopy no degradation of the copolymers had taken place. 

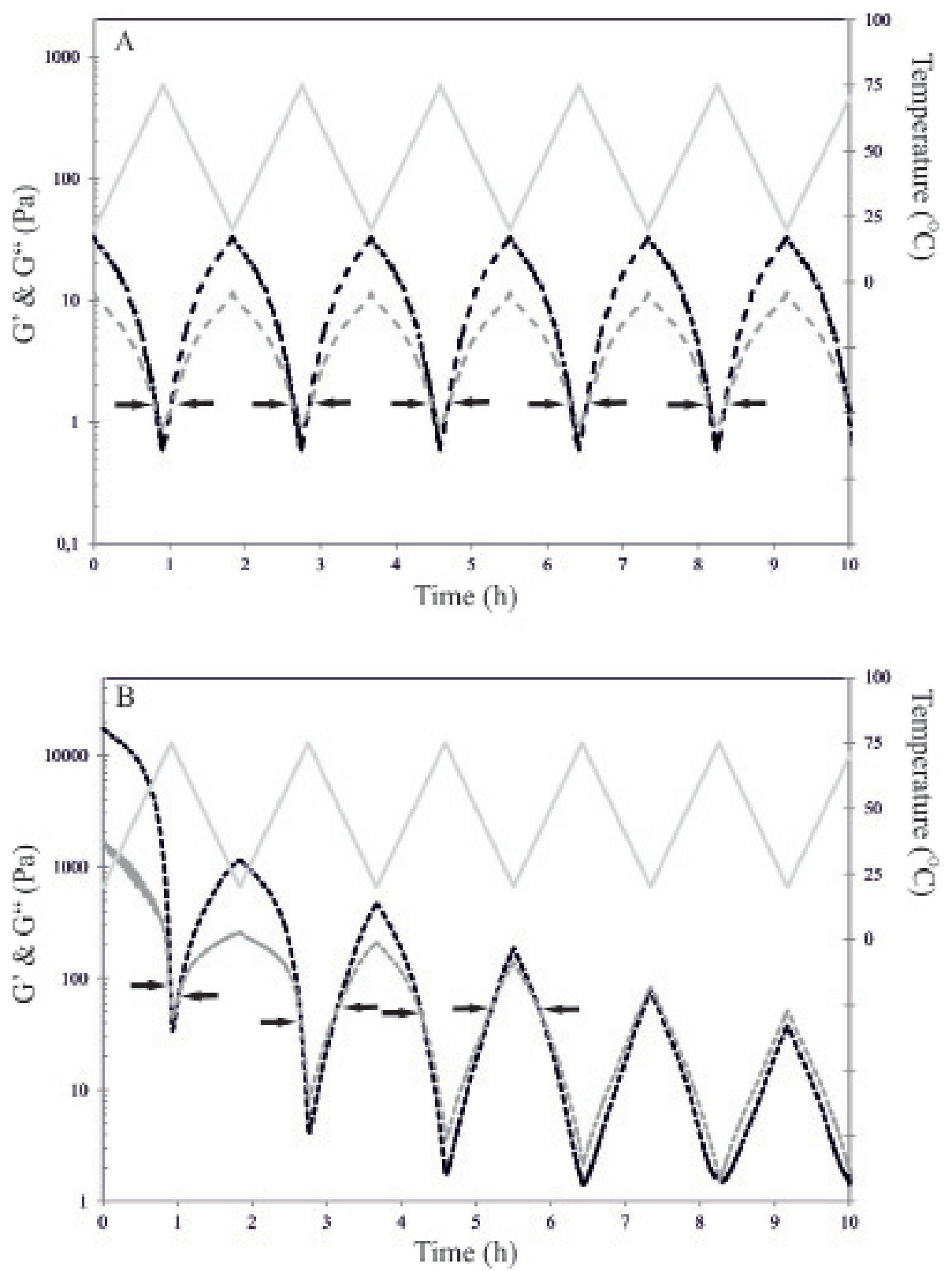

Figure 5. The storage (G', - - ), loss (G”, $\longrightarrow$ ) modulus and temperature profile $(\longrightarrow)$ of copolymers I (A, $10 \mathrm{wt} \%$ ) and II (B, $30 \mathrm{wt} \%$ ), upon repeated heating from 20 to $75^{\circ} \mathrm{C}$ and cooling from 75 to 20 ${ }^{\circ} \mathrm{C}$. The arrows indicate the sol-gel or gel-sol transition (PBS, pH7.4). 
The results described above reveal a profound effect on the gel properties when a cationic group is incorporated in the four-armed copolymers. To further elucidate the possible mechanisms involved in the sol-gel transitions, critical association concentrations and also aggregate size and aggregate size distributions of the copolymers in aqueous surroundings at low concentrations as a function of temperature and $\mathrm{pH}$ were determined.

The critical association concentration (CAC) values of the four armed PLLA-PEG copolymers (PBS, pH 7.4) were 0.039 for copolymer I and in between 0.052 and $0.058 \mathrm{wt} \%$ for II, III, IV, V and VI (Figure 6) with slightly higher values with increasing numbers of secondary amine groups in the central unit.

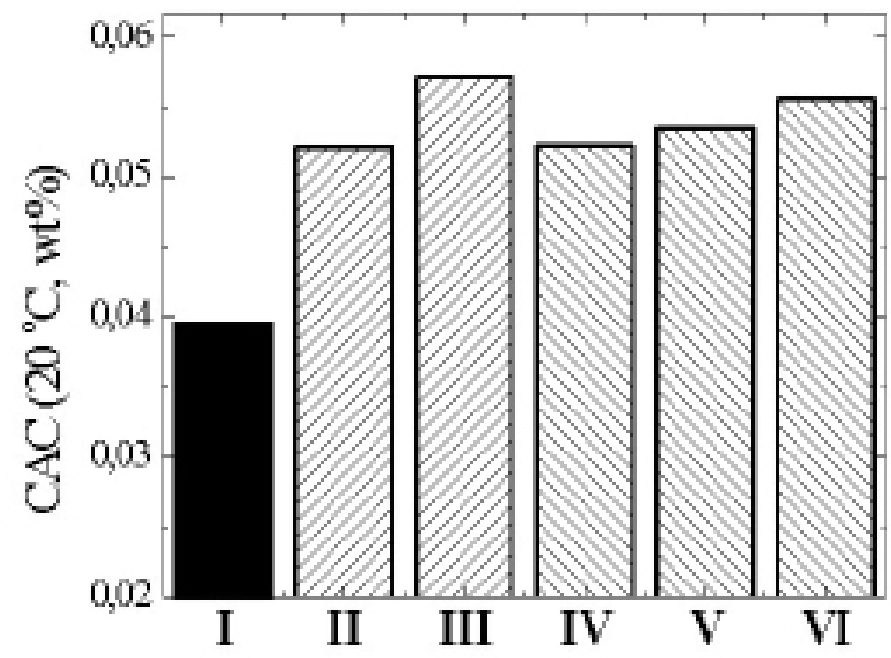

Figure 6. Critical association concentration (wt \%) of copolymers I-VI (PBS, pH 7.4).

The aggregate size and aggregate size distribution of the copolymers at a concentration of 0.3 wt \% in PBS were determined using dynamic light scattering (DLS). The influence of the type of linker, temperature and $\mathrm{pH}$ are presented in Figures 7-9. At $\mathrm{pH} 6.0$ an aqueous solution of the 4-armed copolymer I contains 'micellar' type aggregates at $57 \mathrm{~nm}$ as well as larger aggregates with size distributions at $877 \mathrm{~nm}$ (Figure 7). Incorporating a central moiety with one secondary amine group (II) resulted in a single aggregate size distribution at $83 \mathrm{~nm}$. The aggregate size decreases to $45 \mathrm{~nm}$ for copolymer III containing a central moiety with two secondary amine groups. Also the 4-armed copolymers IV, V and VI show single size distributions at 88,80 and $71 \mathrm{~nm}$ respectively (data not shown). Increasing the $\mathrm{pH}$ of the 
solutions to 7.4 decreases the degree of protonation and for copolymers II and III (Figure 7), a second distribution between $300-800 \mathrm{~nm}$ is observed.
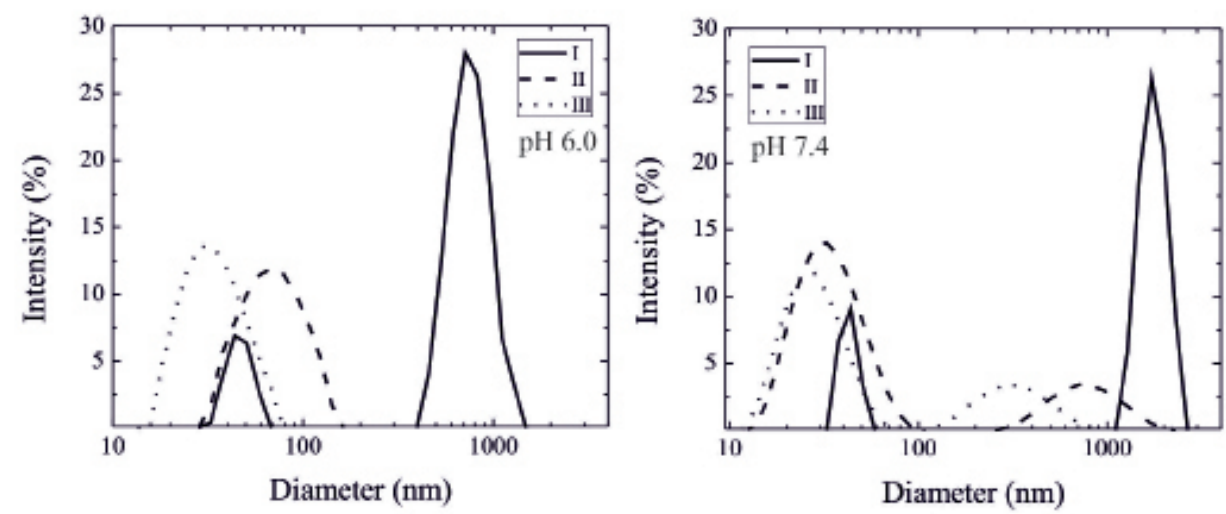

Figure 7. DLS intensity plots of copolymers I, II and III at pH 6.0 and 7.4 (PBS, 0.3 wt \%, $25{ }^{\circ} \mathrm{C}$ ).

These results show that incorporation of partially or almost fully protonated secondary amine groups diminish aggregation of the copolymers. Upon an increase in temperature it was observed that the micelles and aggregates of copolymer I became smaller. For example, the intensity plots reveal distributions at 54 and $218 \mathrm{~nm}$ at $37^{\circ} \mathrm{C}$ and 40 and $152 \mathrm{~nm}$ at $50^{\circ} \mathrm{C}$ both at pH 6.0 (Figure 8). A similar phenomenon was observed at pH 7.4 and these results may be related to dehydration and shrinking of the PEG chains present in the micelles and aggregates ${ }^{6}$. The entanglements of the PEG chains will decrease and smaller aggregates will be formed. Copolymers containing a positively charged central moiety (II- VI) retain a single aggregate size distribution at $\mathrm{pH} 6.0$ in the temperature range from $25-50{ }^{\circ} \mathrm{C}$. A typical example of the size distribution determined with DLS of copolymer III is presented in Figure 8. The size distribution is similar for copolymer II $\left(54 \mathrm{~nm}\right.$ at $25^{\circ} \mathrm{C}$ and $56 \mathrm{~nm}$ at $50{ }^{\circ} \mathrm{C}$ ) and increases slightly for copolymer IV $\left(98 \mathrm{~nm}\right.$ at $25^{\circ} \mathrm{C}$ and $107 \mathrm{~nm}$ at $\left.50{ }^{\circ} \mathrm{C}\right), \mathbf{V}\left(82 \mathrm{~nm}\right.$ at $25^{\circ} \mathrm{C}$ and 104 $\mathrm{nm}$ at $\left.50{ }^{\circ} \mathrm{C}\right)$ and $\mathrm{VI}\left(72 \mathrm{~nm}\right.$ at $25^{\circ} \mathrm{C}$ and $104 \mathrm{~nm}$ at $\left.50{ }^{\circ} \mathrm{C}\right)$, data not shown. These results may be rationalized when the cationic groups are located near the surface of the aggregates or that the PEG blocks are turned inward to shield the charges near the center. In the first case the cationic moiety creates charge repulsion among the micellar type aggregates, thus preventing aggregation towards larger aggregates. Zeta potential measurements did not give evidence for this hypothesis, but it has to be emphasized that the overall charge of the micelles is low. At pH 7.4, solutions of copolymer III also contain larger aggregates with an average dimension of $300 \mathrm{~nm}$ almost independent from the temperature (Figure 8). 

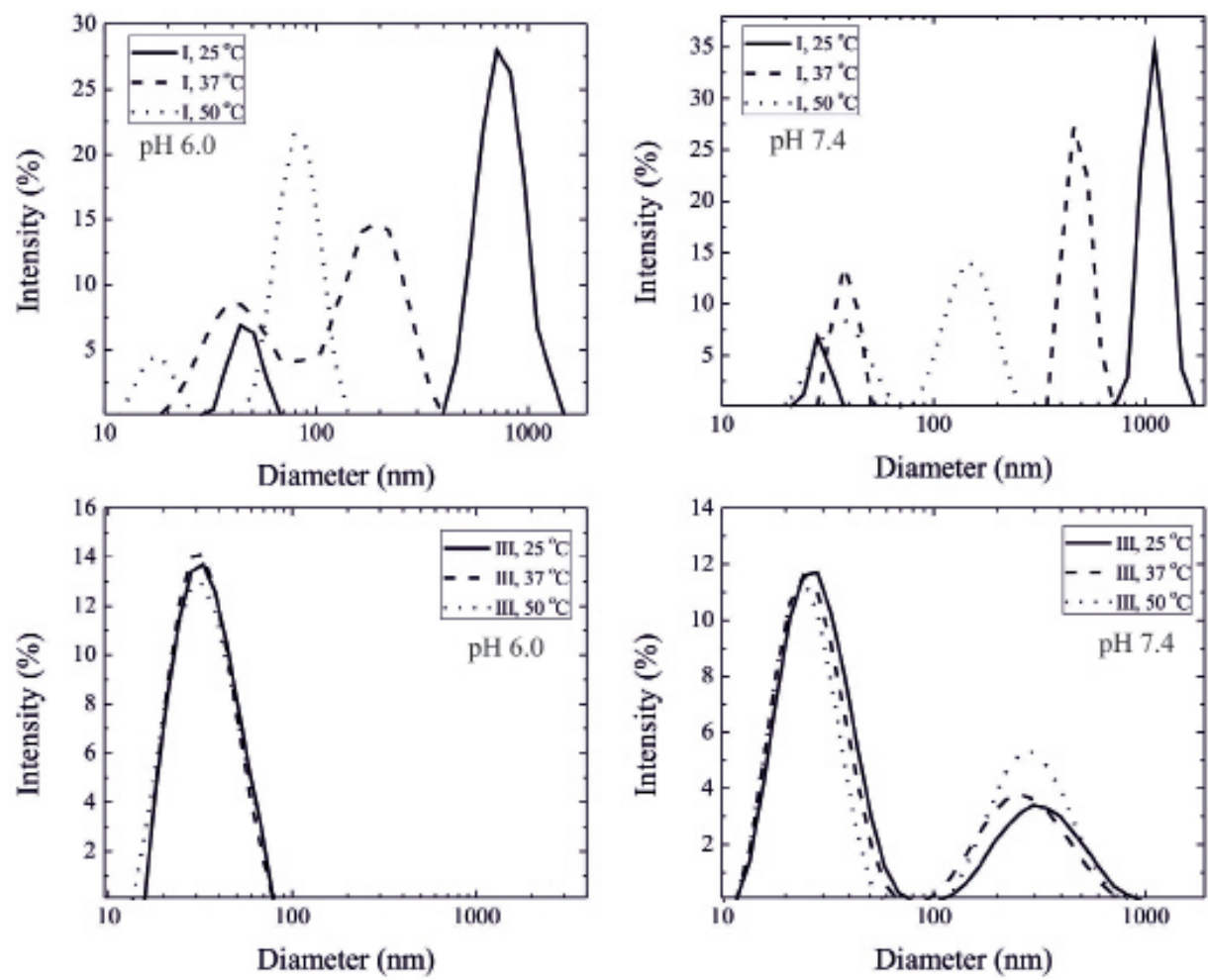

Figure 8. DLS intensity plots of copolymers I and III at pH 6.0 and pH 7.4 (PBS, 0.3 wt \%) at various temperatures.

The effect of the charge on the size of the aggregates of the four armed PLLA-PEG copolymers becomes clearer when copolymer III was dissolved in PBS solutions with different $\mathrm{pH}$ values (Figure 9). At pH 5.0, 6.0 and 7.0 single distributions were found. Upon a further increase in $\mathrm{pH}$ two distributions were observed, one with a size between 10-100 $\mathrm{nm}$ and one with a distribution between 100 and $1000 \mathrm{~nm}$. The latter distribution arises because charge repulsion is effectively reduced. 


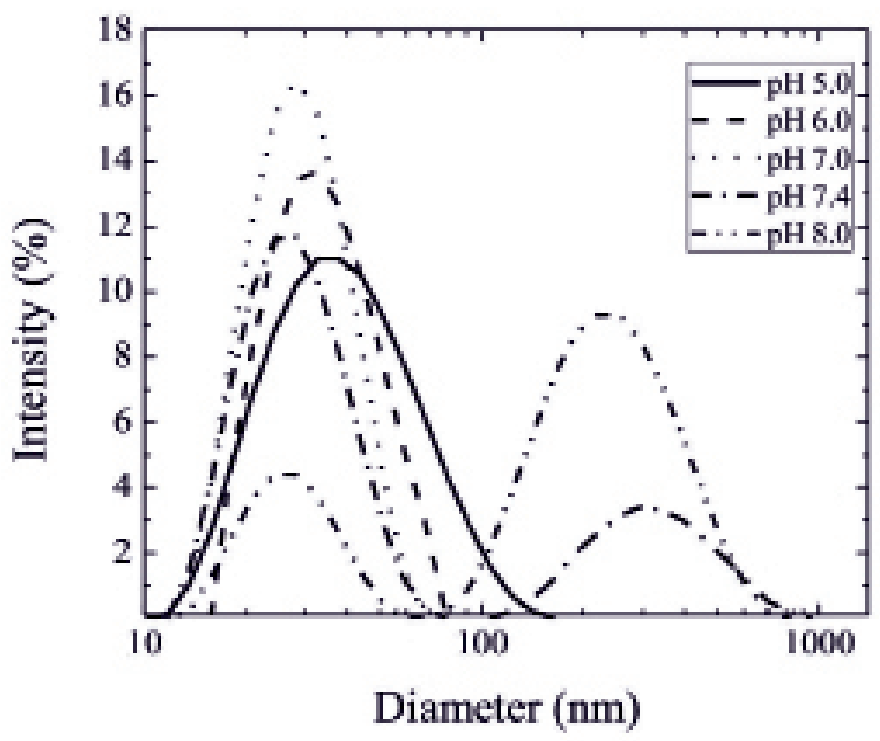

Figure 9. Intensity plot of PBS solutions of copolymer III $(0.3 \mathrm{wt} \%)$ at varying $\mathrm{pH}$ values $\left(25^{\circ} \mathrm{C}\right)$.

Based on the results, the following model for the aggregation and gelation behavior of the copolymers is proposed (Figure 10). Reversible gelation at relatively high copolymer concentrations is only observed for copolymer I. The gel-sol transition upon raising the temperature can be related to dehydration and shrinking of the PEG chains, leading to a decrease in PEG entanglements and subsequent segregation of building elements (micelles and small aggregates) of the gel. This is also confirmed by DLS of dilute suspensions of $\mathbf{I}$ (Fig. 7). Upon temperature decrease, PEG becomes more hydrophilic and at relatively high concentrations, entanglements will lead to gel formation. 


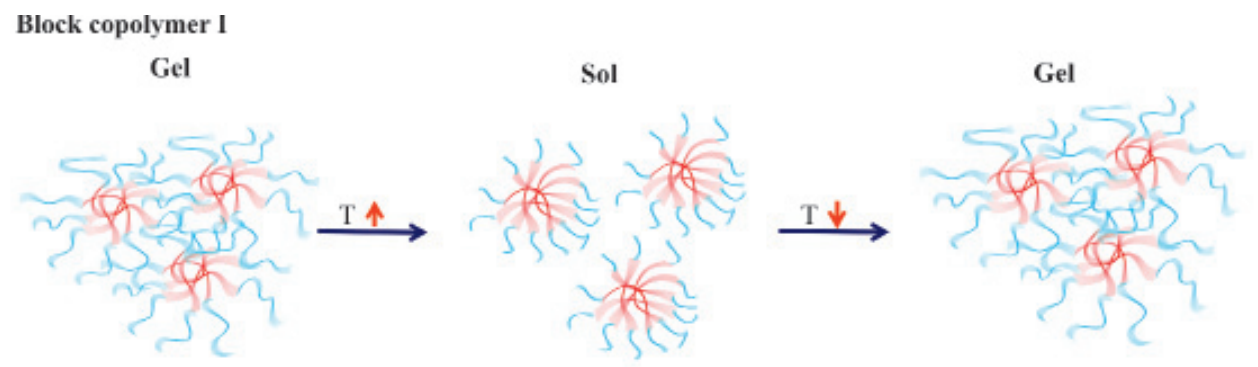

Block copolymers II-VI
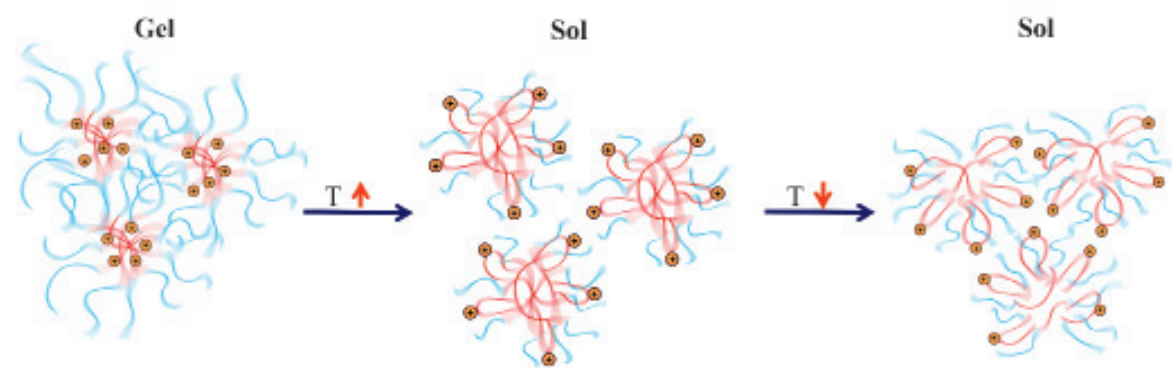

Figure 10. Top: Self-assembly of copolymer I. The gel-sol transition upon a temperature increase can be related to dehydration and shrinking of the PEG chains, leading to a decrease in PEG entanglements and subsequent dissociation of the micelles. Upon a temperature decrease the reverse process occurs. Bottom: Copolymer gels of II-VI are initially formed after mixing the copolymer with PBS. Upon a temperature increase a gel to sol transition occurs. The cationic moieties move in the PEG corona of the micelles and charge repulsion prohibits interaction between micelles. upon seubsequent decreasing the temperature PEG chains become more hydrophilic but the cationic charges prohibit re-entanglement of the PEG chains resulting in a system that remains in the sol state.

For the systems containing a cationic moiety (II-VI), the response to temperature becomes more intricate. As described above at high concentrations gels are initially formed when the solid polymer was mixed with PBS. Upon temperature increase the gel to sol transition occurs. It can be speculated that the cationic moieties move towards the corona of the micelles/small aggregates prohibiting interactions between these entities. Upon a subsequent decrease in temperature, the PEG chains become more hydrophilic but the presence of cationic charges results in a repulsive force that hampers re-entanglement of the PEG chains, resulting in a system that remains in the 'sol' state at low temperatures. A second possibility is that the PEG blocks form non-covalent inclusion complexes with the protonated secondary amines to stabilize the micelles, preventing reestablishment of PEG entanglements ${ }^{20,21}$. 


\section{Conclusions}

Using bis-MPA as an initiator PEG-PLLA block copolymers were synthesized with a central activated ester group. Coupling with different $\alpha, \omega$-diamines afforded a variety of four-armed PEG-PLLA copolymers with ethyleneamine or propyleneamine functionalities.

Rheology measurements revealed that copolymers containing no formal charged groups provided thermo-reversible hydrogels ( $\geq 5 \mathrm{wt} \%$, PBS). Temperature dependent DLS measurements showed that aggregation of micelles occurs at lower temperatures and likely leads to gelation at high concentrations by growth of micelles and aggregates and PEG entanglements.

On the other hand copolymers containing cationic secondary amine groups do not show temperature dependent sol-gel transitions. DLS measurements revealed that at equilibrium copolymer solutions contain predominantly micelles with a particle size independent of temperature.

It is hypothesized that the protonated amine groups are randomly distributed in the micelles preferably at the PEG corona resulting in charge repulsion. Moreover, the shielding of the positive charges by the PEG chains, which as a consequence stabilize the micellar type aggregates, prevents increased micellar interactions at lower temperatures and also prohibits the formation of PEG entanglements and consequent gelation.

\section{References}

1. Mano, J. F., Stimuli-Responsive Polymeric Systems for Biomedical Applications. Advanced Engineering Materials 2008, 10, (6), 515-527.

2. Ruel-Gariepy, E.; Leroux, J. C., In situ-forming hydrogels - review of temperaturesensitive systems. European Journal of Pharmaceutics and Biopharmaceutics 2004, 58, (2), 409-426.

3. Lau, B. K.; Wang, Q. Q.; Sun, W.; Li, L., Micellization to gelation of a triblock copolymer in water: Thermoreversibility and scaling. Journal of Polymer Science Part BPolymer Physics 2004, 42, (10), 2014-2025.

4. Signori, F.; Chiellini, F.; Solaro, R., New self-assembling biocompatible-biodegradable amphiphilic block copolymers. Polymer 2005, 46, (23), 9642-9652.

5. Velthoen, I. W.; Tijsma, E. J.; Dijkstra, P. J.; Feijen, J., Thermo-Responsive Hydrogels Based on Branched Poly(L-lactide)-poly(ethylene glycol) Copolymers. Macromolecular Symposia 2008, 272, (1), 13-27.

6. Nguyen, M. K.; Lee, D. S., Injectable Biodegradable Hydrogels. Macromolecular Bioscience 2010, 10, (6), 563-579.

7. Jeong, B.; Bae, Y. H.; Lee, D. S.; Kim, S. W., Biodegradable block copolymers as injectable drug-delivery systems. Nature 1997, 388, (6645), 860-862.

8. Choi, S. W.; Choi, S. Y.; Jeong, B.; Kim, S. W.; Lee, D. S., Thermoreversible gelation of poly(ethylene oxide) biodegradable polyester block copolymers. II. Journal of Polymer Science Part a-Polymer Chemistry 1999, 37, (13), 2207-2218. 
9. Huynh, C. T.; Nguyen, M. K.; Lee, D. S., Injectable Block Copolymer Hydrogels: Achievements and Future Challenges for Biomedical Applications. Macromolecules 2011, 44, (17), 6629-6636.

10. Jeong, B.; Bae, Y. H.; Kim, S. W., Thermoreversible Gelation of PEG-PLGAPEG Triblock Copolymer Aqueous Solutions. Macromolecules 1999, 32, (21), 7064-7069.

11. Ottenbrite, R. M.; Park, K.; Okano, T., Biomedical applications of hydrogels handbook. 1 ed.; Springer: NY, 2011; p 123-146.

12. Jeong, B.; Han Bae, Y.; Wan Kim, S., Biodegradable thermosensitive micelles of PEG-PLGA-PEG triblock copolymers. Colloids and Surfaces B: Biointerfaces 1999, 16, (1-4), 185-193.

13. Fee, C. J.; Van Alstine, J. A., PEG-proteins: Reaction engineering and separation issues. Chemical Engineering Science 2006, 61, (3), 924-939.

14. Dayananda, K.; He, C.; Park, D. K.; Park, T. G.; Lee, D. S., pH- and temperature-sensitive multiblock copolymer hydrogels composed of poly(ethylene glycol) and poly(amino urethane). Polymer 2008, 49, (23), 4968-4973.

15. Nguyen, M. K.; Park, D. K.; Lee, D. S., Injectable Poly(amidoamine)poly(ethylene glycol)-poly(amidoamine) Triblock Copolymer Hydrogel with Dual Sensitivities: pH and Temperature. Biomacromolecules 2009, 10, (4), 728-731.

16. Nguyen, M. K.; Huynh, C. T.; Lee, D. S., pH-sensitive and bioadhesive poly(betaamino ester)-poly(ethylene glycol)-poly(beta-amino ester) triblock copolymer hydrogels with potential for drug delivery in oral mucosal surfaces. Polymer 2009, 50, (22), 5205 5210 .

17. Elbert, D. L.; Hubbell, J. A., Conjugate addition reactions combined with freeradical cross-linking for the design of materials for tissue engineering. Biomacromolecules 2001, 2, (2), 430-441.

18. Kanayama, N.; Fukushima, S.; Nishiyama, N.; Itaka, K.; Jang, W. D.; Miyata, K.; Yamasaki, Y.; Chung, U. I.; Kataoka, K., A PEG-based biocompatible block catiomer with high buffering capacity for the construction of polyplex micelles showing efficient gene transfer toward primary cells. Chemmedchem 2006, 1, (4), 439-444.

19. Kim, K.-Y.; Chang, H.-C.; Lee, Y. T.; Cho, U.-I.; Boo, D. W., Vibrational Predissociation Spectroscopic and Ab Initio Theoretical Studies on Protonated Ethylenediamineâ^'(Water)3 Complex. The Journal of Physical Chemistry A 2003, 107, (25), 5007-5013.

20. Williamson, B. L.; Creaser, C. S., Noncovalent inclusion complexes of protonated amines with crown ethers. International Journal of Mass Spectrometry 1999, 188, (1-2), 53-61.

21. Krupers, M. J.; Van der Gaag, F. J.; Feijen, J., Complexation of poly(ethylene oxide) with poly(acrylic acid-co-hydroxyethyl methacrylate)s. European Polymer Journal 1996, 32, (6), 785-790. 



\section{Chapter 4 Aggregation and gelation behavior of stereocomplexed four-arm PLA-PEG copolymers}

Jos W.H. Wennink, Francesca Signori, Marcel Karperien, Jan Feijen and Pieter J. Dijkstra 


\begin{abstract}
Four-arm stereocomplexed (PEG-PLA) $)_{2} \mathrm{C}(\mathrm{O})-\mathrm{NH}-\mathrm{R}-\mathrm{NH}-\mathrm{C}(\mathrm{O})-(\mathrm{PLA}-\mathrm{PEG})_{2}$ hydrogels were prepared by mixing PBS solutions of polymers with opposite chirality. Gel formation is driven by stereocomplexation of PLLA and PDLA blocks, since single enantiomer solutions did not form gels at similar concentrations. When $\mathrm{R}$ is a heptamethylene unit, stereocomplexation induced gelation of $5 \mathrm{wt} \%$ solutions at $25^{\circ} \mathrm{C}$ took place after $35 \mathrm{~min}$. At polymer concentrations higher than $10 \mathrm{wt} \%$ no suspensions of the single enantiomers could be prepared and gels were obtained. Enantiomeric copolymers containing cationic moieties ( $\mathrm{R}$ is norspermidine or spermine) were highly soluble in PBS. Upon stereocomplexation of $30 \mathrm{wt} \%$ solutions of these polymers at $25{ }^{\circ} \mathrm{C}$, gelation occurred in less than $2 \mathrm{~min}$. Temperature dependent rheology experiments showed that the gel-sol phase transitions of the stereocomplexed hydrogels with $\mathrm{R}$ as a heptamethylene linker are thermo-reversible but for stereocomplexed hydrogels with $\mathrm{R}$ containing one or two secondary amine groups no gel-sol transition was observed after repeated heating and cooling cycles between $25-75{ }^{\circ} \mathrm{C}$. After mixing solutions of enantiomeric block copolymers at low concentrations all block copolymers initially showed a bimodal size distribution of micelles/aggregates which shifted in time to a mono-modal distribution. Differences observed in the aggregation behavior of these polymers were related to the type of micelles formed. Whereas the polymer with a neutral R-group most likely forms core shell type micelles, incorporation of a cationic moiety (R) in the 4-arm copolymers affords micelles with a more random distribution of block copolymer molecules due to the repulsion between the positive charges. In the latter case gelation upon stereocomplexation at high concentrations leads to small stereocomplexed domains, which act as crosslinks.
\end{abstract}




\section{Introduction}

It is well known that di-block copolymers can spontaneously self-assemble in solvents that are selective for one of the blocks to form a wide range of nanostructures, such as micelles, wormlike micelles or vesicles ${ }^{1-5}$. In recent years, particular interest has been given to the self-assembly of block copolymers in aqueous systems, since this may afford new applications in the controlled delivery of drugs 6, 7 . To this end amphiphilic block copolymers have been widely studied as building blocks to generate highly ordered self-assembled structures ${ }^{8-10}$. Generally, self-organization of amphiphilic copolymers is driven by hydrophobic interactions whereby the selective solvation of the hydrophilic block in aqueous solutions arranges polymer molecules in a manner that most effectively reduces their free energy ${ }^{11,12}$. The dimensions of the resultant assemblies are largely controlled by the molecular weight of the polymer blocks whereas the molar ratio of the blocks has a significant effect on the morphology of the resultant particles ${ }^{13}$. Notably, access to non-spherical particle morphologies is also possible by harnessing assembly conditions ${ }^{14}$, mid-block interactions ${ }^{15}$, electrostatic interactions and crystallization ${ }^{14,16,17}$. While polymeric micelles are relatively stable in an aqueous environment, they remain equilibrium systems held together by hydrophobic interactions and hence are readily disrupted via changes in conditions such as dilution, ultrasound, heat or $\mathrm{pH}{ }^{18-20}$. Strategies to increase the stability of polymeric micelles generally rely on chemical crosslinking of either the core or shell to produce robust nanoparticles ${ }^{21}$. While this technique successfully facilitates the preparation of stable particles it can also lead to a reduced hydrophilicity and/ or biodegradability. As an alternative, enhanced stability can also be achieved by dynamic polymer-polymer interactions such as polyelectrolyte interactions ${ }^{22}$, stereocomplexation ${ }^{23}$ and hydrogen bonding ${ }^{24}$ in either the core or the shell of polymeric micelles. It is well known that a 1:1 mixture of PLLA and PDLA forms a stable crystalline stereocomplex which has a higher melting point than either homopolymer ${ }^{25}$. Stereocomplexation has been applied by several groups to form hydrogels in situ using mixtures of water soluble amphiphilic copolymers containing PLLA and PDLA blocks ${ }^{26-29}$. Hennink et al. ${ }^{26}$ reported stereocomplex induced gelation of PLLA- and PDLA- grafted dextrans. Hydrogel formation by stereocomplexation has also been shown for PLA-PEG-PLA tri-block copolymers. Hiemstra et al. ${ }^{27}$ reported thata 1:1 mixture ofeightarmPEG-PLLAandPEG-PDLA, formedstereocomplexed hydrogels with improved mechanical properties compared to linear tri-block copolymers. The systems described above are examples of BAB systems with PEG (A block) in the center and PLA (B block) outer blocks. Gelation at moderate polymer concentrations results from polymer molecules that act as bridges between flowerlike micelles resulting in hydrogels that are thermo-reversible. When polymer bridging 
molecules are involved in stereocomplexation, increasing the temperature does not lead to the removal of bridging molecules and thermo-irreversible gels are obtained. To our knowledge up to now only one paper has been published concerning stereocomplexed ABA systems ${ }^{30}$. A PEG-PLA-PEG tri-block copolymer with molecular weights of the blocks of 2000-2000-2000 was used to investigate the gel properties. While copolymer solutions of the single-enantiomer didn't form gels, copolymer solutions containing both enantiomers formed a stereocomplexed gel that was thermo-reversible. An interesting approach to develop in-situ forming hydrogels is based on hydrogel formation by stereocomplexation of enantiomeric PLA blocks. These gels can be simply prepared by mixing aqueous enantiomeric polymer solutions. For the $\mathrm{BAB}$ type copolymers in some cases short gelation times are obtained. However, gelation times of the known ABA type copolymers are in the order of several hours, which renders them unsuitable for application as in situ forming hydrogels ${ }^{29}$. In previous research we showed that 4-arm (PEG-PLA) $)_{2} \mathrm{C}(\mathrm{O})-\mathrm{NH}-\mathrm{R}-\mathrm{NH}-\mathrm{C}(\mathrm{O})-(\mathrm{PLA}-$ $\mathrm{PEG})_{2}$ block copolymers with a central R-group containing secondary amine groups do not form hydrogels. In contrast when block copolymers with a corresponding neutral linker were used fully thermo-reversible gels were obtained ${ }^{31}$. Dynamic light scattering revealed that dilute solutions of copolymers with a cationically charged central moiety show a temperature independent distribution of micelles and micellar aggregates. These results indicate that the protonated amine groups are located at the corona of the micelles and micellar aggregates and are shielded by the PEG blocks. It can be envisaged that this will also hinder the formation of hydrogels when the temperature of concentrated solutions of charged polymers is lowered. In this paper the effect of stereocomplexation on the aggregation behavior and gel formation of 4-arm block copolymers containing a linker with or without cationic charge will be described. The mechanical properties of the hydrogels were studied by rheology. These results, combined with the time dependent aggregation behavior of micelles as measured by DLS, were used to model the self-assembly of micellar structures of the 4-arm block-copolymers.

\section{Materials and methods}

\section{Materials}

L-lactide (L-LA) was purchased from Purac (Gorinchem, the Netherlands). 2,2-Bis(hydroxymethyl)propionic acid (bis-MPA) was obtained from Acros (Geel, Belgium). Tin (II) 2-ethylhexanoate $\left(\mathrm{Sn}(\mathrm{Oct})_{2}\right)$, succinic anhydride, N-hydroxysuccinimide (NHS), N,N'-dicyclohexylcarbodiimide (DCC), mesyl chloride, deuterated chloroform $\left(\mathrm{CDCl}_{3}\right)$, aqueous ammonia (25\%), glacial acetic acid, 1,7-diaminoheptane, norspermidine and spermine were obtained from Sigma-Aldrich (Zwijndrecht, the Netherlands). Methoxy- 
hydroxy poly(ethylene glycol) with a molecular weight of $5000 \mathrm{~g} / \mathrm{mol}(\mathrm{mPEG} 5000-\mathrm{OH})$ was purchased from Fluka (Buchs, Switzerland). Triethylamine and 4-dimethylaminopyridine (DMAP) were acquired from Merck (Darmstadt, Germany). All other solvents were from Biosolve (Valkenswaard, the Netherlands). Dichloromethane and toluene were dried over calcium hydride (Aldrich) and sodium wire, respectively, and distilled prior to use. All other chemicals were used as received. The 4-arm PLLA-PEG block copolymers and 4-arm PDLAPEG block copolymers were synthesized as described previously ${ }^{31}$ (Figure 1) where polymer I contains a heptamethylene linker, II a norspermidine and III a spermine linker.

\section{Characterization}

Vial tilting method: Block copolymers were dissolved in PBS. Solutions ( $250 \mu \mathrm{l})$ containing equimolar amounts of the single enantiomers were mixed and gently shaken until a gel was formed. The time to form a gel (denoted as gelation time) was determined using the vial tilting method. No flow within 1 min upon inverting the vial was regarded as the gel state. For each sample the experiments were performed in triplicate.

Rheology: Rheology experiments were performed with an Anton Paar Physica MCR 301 rheometer with flat plate geometry $(20 \mathrm{~mm}$ diameter, $0.3 \mathrm{~mm}$ gap) in oscillating mode. Solutions of the polymers in PBS were prepared as described above, mixed and the gels were kept at $4{ }^{\circ} \mathrm{C}$ overnight prior to measurement. The gels were applied to the rheometer. To prevent evaporation of water a solvent trap was placed over the geometry. A pre-shear was applied for $10 \mathrm{~s}$, after which the gel was allowed to equilibrate for $10 \mathrm{~min}$. Subsequently, the hydrogel was heated to $75^{\circ} \mathrm{C}$ at $1{ }^{\circ} \mathrm{C} / \mathrm{min}$, and then cooled to $20^{\circ} \mathrm{C}$ at $1{ }^{\circ} \mathrm{C} / \mathrm{min}$. The storage modulus G' and the loss modulus G" were monitored applying a frequency $\omega$ of $1 \mathrm{~Hz}$ and a strain $\gamma$ of $1 \%$ to ensure that measurements were performed in the linear viscoelastic range of the hydrogels. After a number of heating and cooling cycles, a frequency and amplitude sweep were performed at $\omega 0.01-10 \mathrm{~Hz}(\gamma=1 \%)$ and $\gamma 0.01-10 \%(\omega=1 \mathrm{~Hz})$ at $20^{\circ} \mathrm{C}$, to confirm that the applied frequency of $1 \mathrm{~Hz}$ and a strain of $1 \%$ were within the linear viscoelastic range.

DLS: Dynamic light scattering experiments were performed on 0.3 wt \% solutions using a Malvern zetasizer 4000 (Malvern Corp., Malvern, UK), and a laser wavelength of 633 nm. The CONTIN method was applied for data processing. The diameter of micelles and/ or aggregates of copolymers in PBS were determined as a function of temperature between 25 and $50{ }^{\circ} \mathrm{C}$. All solutions were allowed to equilibrate at each measuring temperature for $15 \mathrm{~min}$. In the DLS experiments described above the size of the peak maximum shifted over time to $50 \mathrm{~nm}$ for copolymer I and to $32 \mathrm{~nm}$ for copolymers II and III. Therefore, kinetic experiments were performed with systems obtained after mixing of 0.3 wt \% solutions 
of enantiomeric copolymers (equimolar amounts) in PBS. The changes in the scattering intensities of micelles at $32 \mathrm{~nm}$ (II, III; D + L) and small aggregates at $50 \mathrm{~nm}(\mathbf{I}$; D + L) were determined every 15 min for 15 hours at 25,37 and $50{ }^{\circ} \mathrm{C}$.

\section{Results and discussion}

Enantiomeric 4-arm (PEG-PLA) $)_{2}-\mathrm{C}(\mathrm{O})-\mathrm{NH}-\mathrm{R}-\mathrm{NH}-\mathrm{C}(\mathrm{O})-(\mathrm{PLA}-\mathrm{PEG})_{2}$ block copolymers with similar PLA and PEG block lengths and central moieties were prepared as described previously (Figure 1). Whereas copolymer I, with a central heptamethylene moiety shows a thermo-reversible gel-sol transition at concentrations above $10 \mathrm{wt} \%$, copolymers II and III, containing a linking unit comprising one or two secondary amine groups, respectively, are viscous solutions up to high concentrations of at least $40 \mathrm{wt} \%$. Aqueous solutions (PBS, $\mathrm{pH}$ 7.4) of these materials show large differences in their aggregation behavior upon changes in temperature. Whereas copolymer I shows a temperature dependent aggregation behavior with a shift to micelles and smaller aggregates at higher temperatures, aqueous suspensions of copolymers II and III consist of micellar aggregates with an average diameter of $\sim 30$ $\mathrm{nm}$, independent of temperature. The gelation mechanism as observed for $\mathbf{I}$ is related to the formation of PEG entanglements, characteristic for PEG-PLA-PEG (ABA type) block copolymers. The absence of a reversible sol-gel behavior of II and III is likely caused by the location of the positively charged amine groups (pKa 8-9) in the outer sphere of the micelles preventing micellar interactions through charge repulsion. Moreover, the shielding of positive charges by the PEG chains may hamper the formation of PEG entanglements necessary for gelation.

It is well known that sol-gel transitions in $\mathrm{BAB}$ type $(\mathrm{A}=\mathrm{PEG}$ and $\mathrm{B}=\mathrm{PLA})$ linear or multiarm amphiphilic PEG-PLA block copolymers can be induced by stereocomplex formation at low concentrations ${ }^{32}$. Upon mixing enantiomeric BAB systems, crosslinks are formed by bridging copolymer molecules between micelles. The outer PLA blocks are part of stereocomplexed domains, and because such domains are much more thermally stable than domains composed of single enantiomer PLA blocks, the formed hydrogel becomes thermoirreversible ${ }^{33}$. Contrary, stereocomplexed ABA type PEG-PLA-PEG (2000-2000-2000) triblock copolymers, afford thermo-reversible gels ${ }^{30}$. In such a block copolymer temperature induced reversible gel to sol transitions are not related to stereocomplex formation present in the core of the micelles, but only to the formation of PEG entanglements at lower temperatures.

Gelation upon mixing enantiomeric block copolymer solutions (I-III in PBS) with comparable PLA block lengths was tested by the vial tilting method. All 4-arm copolymers showed gelation upon mixing, while the single enantiomer solutions did not form a gel at 
similar concentrations. In all cases transparent stereocomplexed hydrogels were obtained from transparent precursor solutions and a typical example is presented in Figure 1.
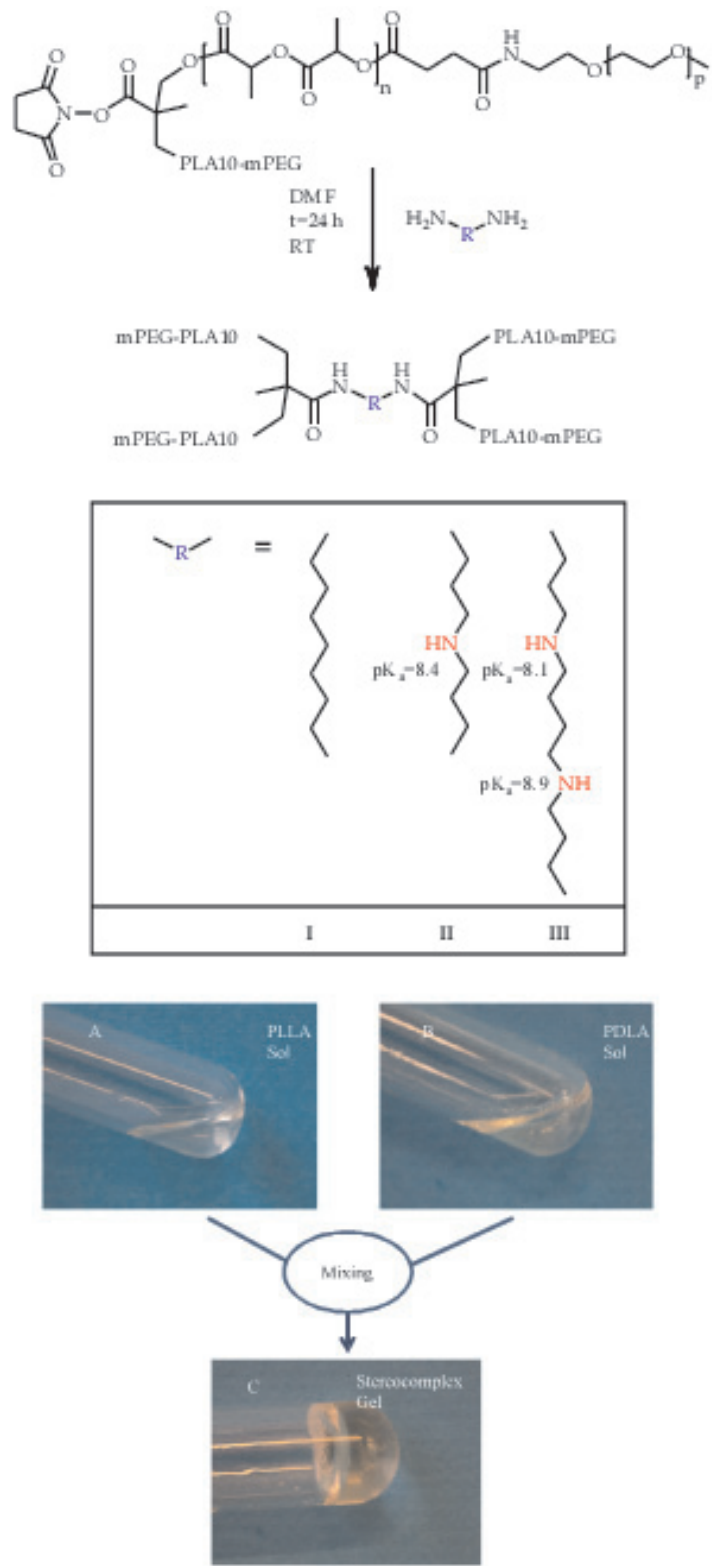

Figure 1. Synthesis route for the preparation of 4-arm copolymers I-III with different central moieties. Example of gelation upon mixing $30 \mathrm{wt} \%$ solutions of copolymer II with opposite chirality. 
For copolymer I, it was observed that at concentrations lower than $5 \mathrm{wt} \%$ no stereocomplexed hydrogels could be formed. At concentrations between 5 and $10 \mathrm{wt} \%$ mixing of solutions containing enantiomeric block copolymers afforded hydrogels. The gelation time at a concentration of $5 \mathrm{wt} \%$ was $36 \mathrm{~min}$ and decreased to $20 \mathrm{~min}$ at a concentration of 10 wt $\%$. At concentrations higher than $10 \mathrm{wt} \%$ no single enantiomeric copolymer solutions could be prepared since such samples are already hydrogels. Copolymers II and III can be dissolved in PBS up to high concentrations. Upon mixing $20 \mathrm{wt} \%$ enantiomeric copolymer II solutions, hydrogels were obtained. This concentration appeared the lower limit for gel formation through stereocomplexation, and noticeably this occurred within $2 \mathrm{~min}$. The lower concentration limit for gelation of copolymer III was $25 \mathrm{wt} \%$ and at this concentration the gelation time was also $2 \mathrm{~min}$ at ambient temperatures. It has to be noted that the faster gelation of II and III as compared to I partly results from the differences in copolymer concentrations used which are at least two times higher for copolymers II and III compared to I. Because the hydrophobic PLA domains in II and III are more exposed to the hydrophilic phase due to the positively charged secondary amine groups the rate of formation of stereocomplexed PLA domains is much faster than for $\mathbf{I}$.

The storage and loss moduli of the hydrogels prepared from copolymer I were subsequently determined by oscillatory rheology experiments (Figure 2). Gels were subjected to temperature cycles in between 25 and $75^{\circ} \mathrm{C}$. Importantly, similar as with the single enantiomer solutions of copolymer $\mathbf{I}^{31}$, the stereocomplexed hydrogels (10 wt \%) revealed a thermo-reversible gel-sol transition on heating and a sol-gel transition upon cooling both at approximately 65 ${ }^{\circ} \mathrm{C}$. Furthermore, the stereocomplexed hydrogel displayed a similar loss modulus but a much higher storage modulus of $123 \mathrm{~Pa}$ compared to the storage modulus of the single enantiomer gel $(32 \mathrm{~Pa})$ at a concentration of $10 \mathrm{wt} \%{ }^{31}$. 


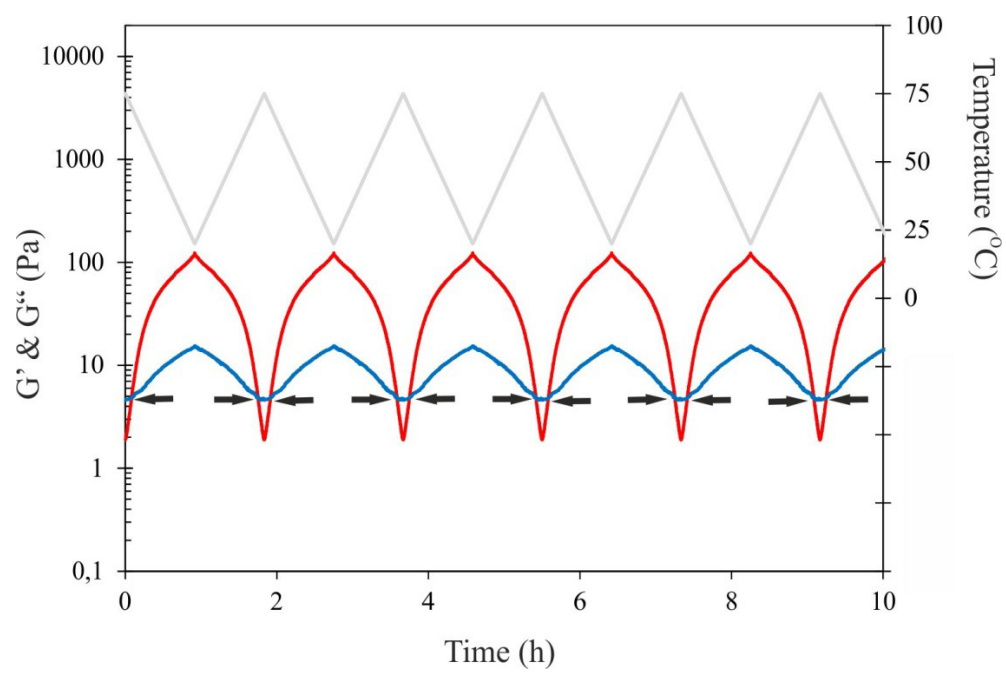

Figure 2. Temperature dependent storage (G', - - ) and loss (G", - - moduli of stereocomplexed copolymer I hydrogels (10 wt \%, PBS pH 7.4) upon heating to $75^{\circ} \mathrm{C}$ and subsequent cooling to $25^{\circ} \mathrm{C}$ ( $\longrightarrow$ ).

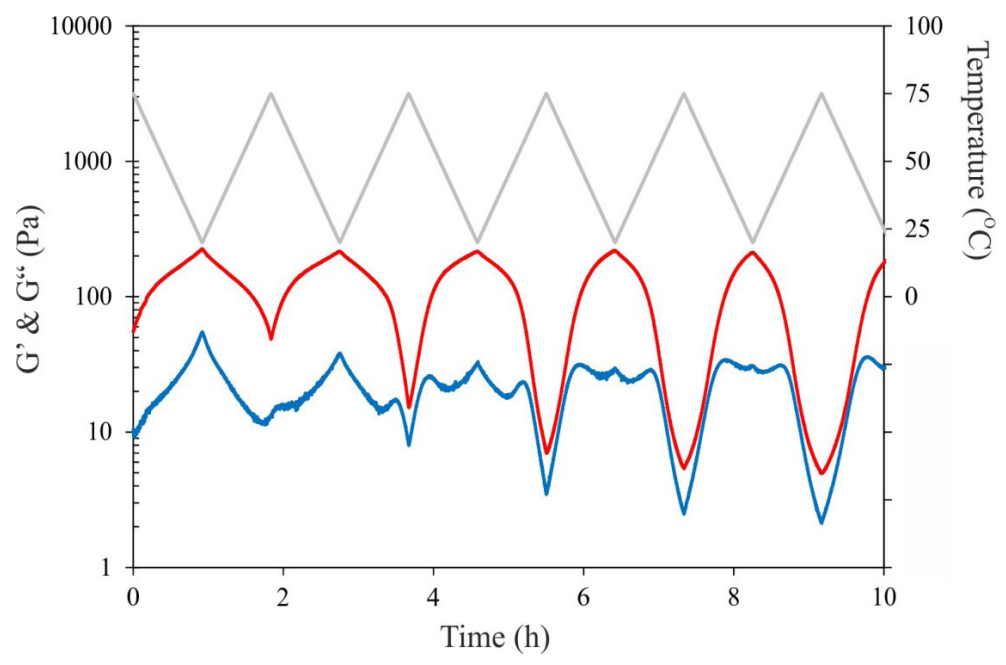

Figure 3. Temperature dependent storage (G', - - ) and loss (G", - - moduli of stereocomplexed copolymer II hydrogels ( $30 \mathrm{wt} \%$, PBS pH 7.4) upon heating to $75^{\circ} \mathrm{C}$ and subsequent cooling to $25^{\circ} \mathrm{C}$ ( $\longrightarrow$ ). 
As previously shown, enantiomeric block copolymers containing a central cationic moiety (II, III) may initially form gels after mixing the polymer with PBS but after several heating and cooling cycles convert into viscous solutions and remain in the sol state ${ }^{31}$. As shown above by the vial tilting method, gels are rapidly formed within 2 min upon mixing enantiomeric copolymer solutions. Rheology experiments revealed that these gels are thermo-irreversible as illustrated in Figure 3. Upon mixing enantiomeric polymer solutions (II(L) + II(D)) the stereocomplexed hydrogel obtained showed major changes in the storage modulus $\left(\mathrm{G}^{\prime}\right)$ and loss modulus (G') during the first and second heating and cooling cycles but $G$ ' remains higher then G'. After approximately 4 cycles the changes in G' and G" as a function of temperature follow a similar pattern. Upon heating $G^{\prime}$ decreases rapidly but a sudden decrease in $G$ " is only observed at $50{ }^{\circ} \mathrm{C}$. At this temperature stereocomplexed domains may melt assuming the domains are small.

The results described above reveal a profound impact of the presence of highly hydrated positively charged moieties in the four-arm copolymers on the properties of the stereocomplexed hydrogel. The differences observed in the kinetics of formation and temperature dependent rheological behavior of stereocomplexed gels of copolymers I and II-III reveal that the poly(lactide) blocks in II-III are more readily available for stereocomplexation and likely not only present in the central core of the micelles and micellar aggregates.

To get a better insight in the observed differences in the kinetics of stereocomplex formation from enantiomeric polymer solutions, the aqueous aggregation behavior was studied at dilute conditions using Dynamic Light Scattering (DLS). The aggregate size and aggregate size distribution of stereocomplexed copolymers I, II and III, at a concentration of $0.3 \mathrm{wt} \%$ in PBS are presented in Figure 4. It is observed that directly after mixing all copolymer solutions show a bimodal distribution and after equilibration for 48 hours at $25{ }^{\circ} \mathrm{C}$ this bimodal distribution has shifted to a broad unimodal distribution with maximum intensities for copolymer I at $50 \mathrm{~nm}$ and much more narrow unimodal distributions for II and III at 32 $\mathrm{nm}$. These results suggest that the polymeric micelles are equilibrium systems held together by hydrophobic interactions and are readily reorganized by formation of stereocomplexes. Stereocomplexation forces the initially formed micelles and micellar aggregates to rearrange in micelles or micellar type aggregates containing the compact crystalline structures of stereocomplexed poly(lactide) blocks. 

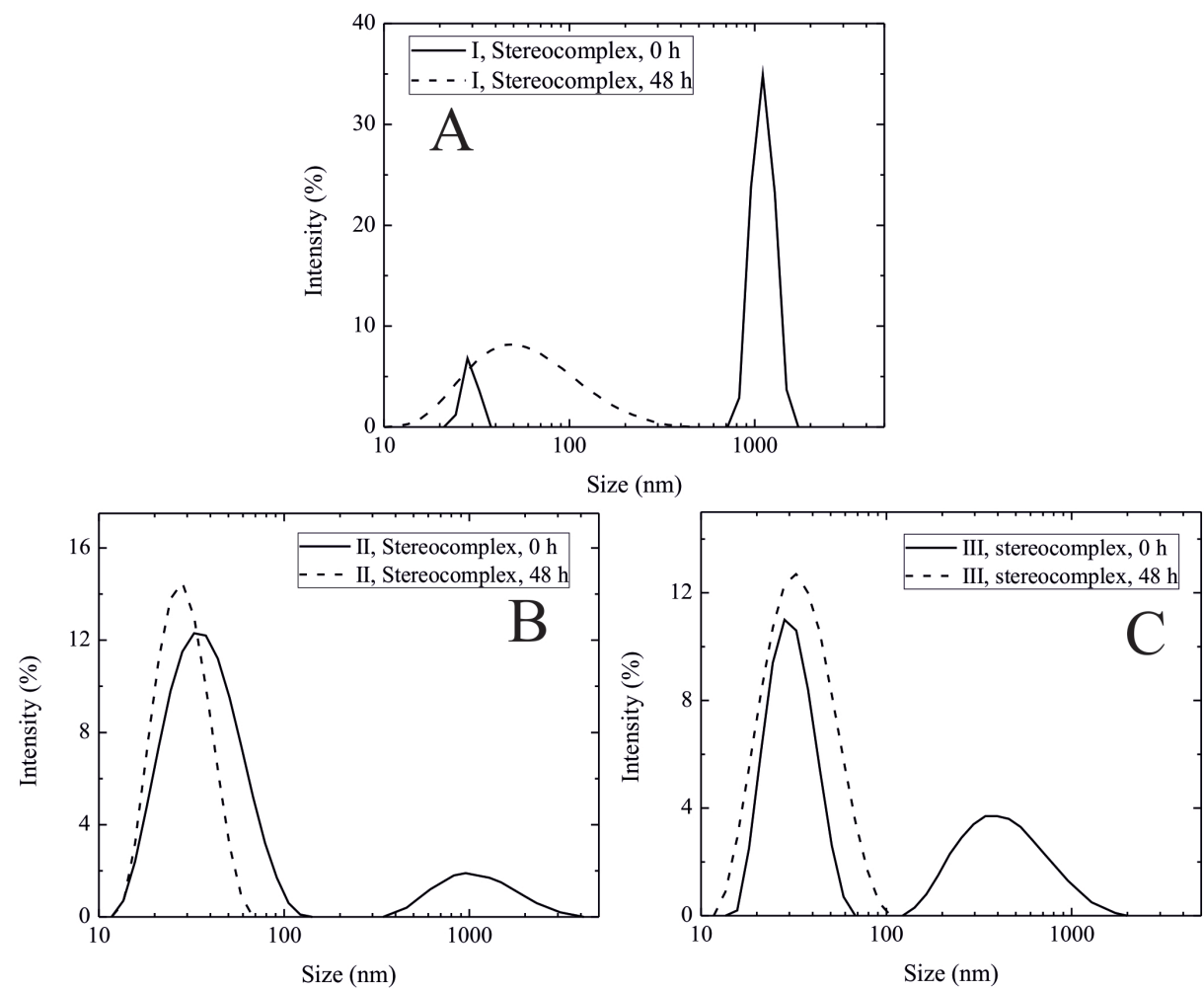

Figure 4. DLS intensity plots of stereocomplexed I (A), II (B) and III (C) directly after mixing (0 h) and after 48 h (PBS, $\left.0.3 \mathrm{wt} \%, 25^{\circ} \mathrm{C}\right)$.

This prompted us to study the kinetics of the observed aggregation phenomena. Enantiomeric copolymer solutions $(0.3 \mathrm{wt} \%)$ were mixed and the aggregate sizes were monitored over time for $15 \mathrm{~h}$ at 25,37 and $50{ }^{\circ} \mathrm{C}$ by DLS measurements. Every $15 \mathrm{~min}$ an aggregate size distribution was taken and the intensities at $50 \mathrm{~nm}$ and $32 \mathrm{~nm}$ for copolymers I and II, III, respectively, were plotted over time (Figure 5). In figure 5A it is shown for copolymer I that within the first minutes after mixing stereocomplexed domains are formed. The slow linear increase in the intensity plot indicates that the exchange of polymer molecules between micelles is very slow and does not lead to a substantial increase in the amount of stereocomplexed domains. This is reflected in the temperature dependent rheology experiments of these thermo-reversible gels, which showed similar storage and loss moduli values after several heating and cooling cycles. 
For copolymer II, as depicted in Figures $5 \mathrm{~B}$ and 6 , equilibrium at $25^{\circ} \mathrm{C}$ is slowly reached after approximately 14 hours. The size distribution of the micelles and micellar type aggregates shifts to smaller sizes and the distribution becomes narrower. Upon increasing the temperature to 37 or $50{ }^{\circ} \mathrm{C}$ an almost instantaneous reorganization to stereocomplexed micelles was observed and the equilibrium did not change anymore in time. The formation of stereocomplexed micelles in case of copolymer III, plotted in Figure 5C, shows a similar pattern but reorganization to an equilibrium appears slower at the measured temperatures.
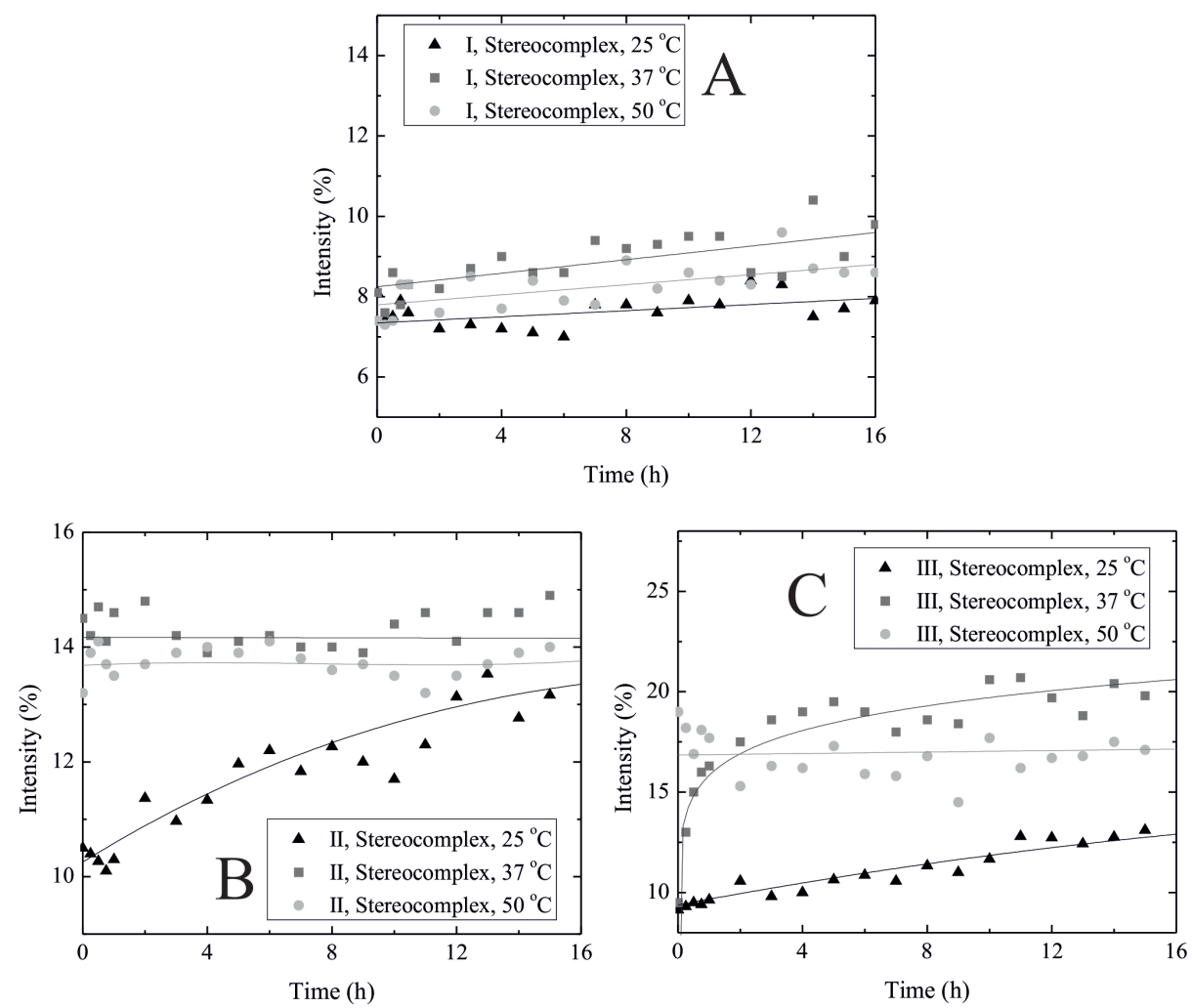

Figure 5. Relative DLS intensity plots after mixing enantiomeric equimolar solutions of copolymers I, at $50 \mathrm{~nm}$ (A), II, at $32 \mathrm{~nm}$ (B) and III, at $32 \mathrm{~nm}$ (C) during 15 hours at various temperatures, PBS, $0.3 \mathrm{w} / \mathrm{v} \%$. 


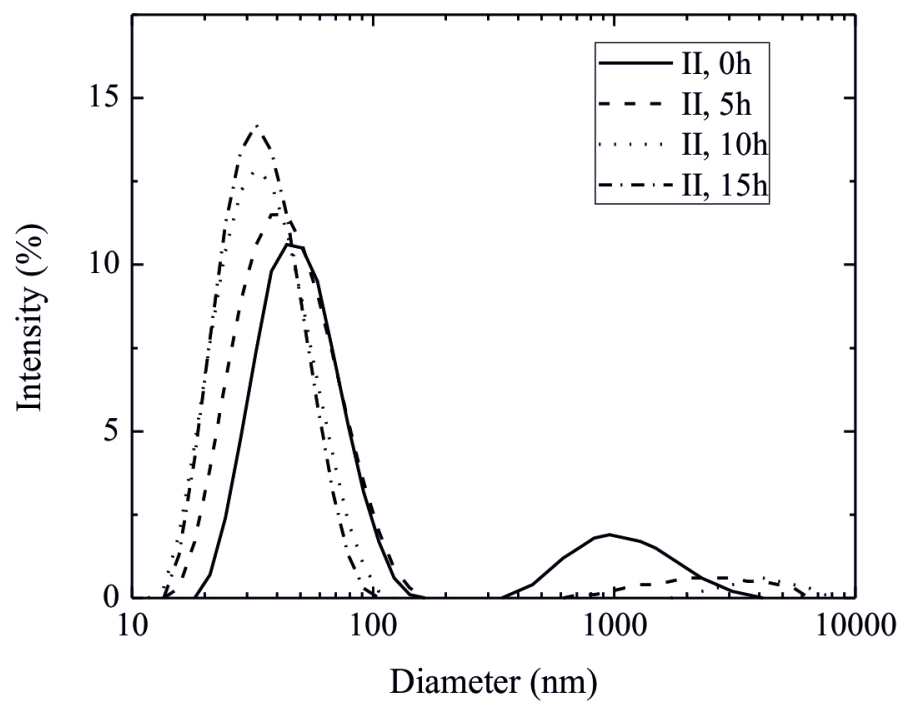

Figure 6. DLS intensity plots of stereocomplexed copolymer II directly after mixing $(0 \mathrm{~h}), 5 \mathrm{~h}, 10 \mathrm{~h}$ and $15 \mathrm{~h}$ (PBS, 0.3 wt $\left.\%, 25{ }^{\circ} \mathrm{C}\right)$.

From these kinetic studies using dilute systems the following conclusions can be drawn. First, the rate of formation of stereocomplexed micelles and micellar aggregates is very high. Secondly, it is shown that the size distribution of stereocomplexed micelles is narrower when a positively charged central unit is present. Because the hydrophobic domains are expected to be relatively small and more randomly dispersed in the micelles and micellar aggregates optimal packing of stereocomplexed domains in time takes a longer period. The higher the charge density, as in copolymer III, the more time is needed to reach a thermodynamic equilibrium.

Based on these studies a schematic model of the gelation mechanism of the stereocomplexed block copolymers is depicted in Figure 7. Upon mixing I(L) and I(D) stereocomplexed hydrophobic domains are formed very fast at room temperature. Repeated heating and cooling cycles revealed that thermo-reversible gelation occurred likely due to the formation and breaking of entangled PEG chains.

Hydrogel formation in case of copolymers II and III occurs through a different mechanism (Figure 7). At room temperature aqueous solutions of the single-enantiomer of copolymer II and III are in a sol state up to high concentrations. The introduction of the positively charged central moiety results in temperature insensitive micellar systems and prevents entanglements 
of the PEG chains ${ }^{31}$. Upon mixing e.g. II(L) and II(D) at a concentration of at least $20 \mathrm{wt}$ $\%$ a stereocomplexed hydrogel was formed within $2 \mathrm{~min}$. In this case hydrogel formation is caused by small stereocomplexed domains that act as crosslinks and might afford micelles. It can be argued that PEG entanglements contribute to the gel stability. Fujiwara et al. ${ }^{28}$ have shown by WAXS measurements on stereocomplexed hydrogels that stereocomplexes are present up to at least $75{ }^{\circ} \mathrm{C}$. Although the amount of stereocomplexed domains reduces at a temperature of $75^{\circ} \mathrm{C}$ still stereocomplex bridges appear to be present to retain a gel state ${ }^{29}$. The change in mechanical properties also suggests that the stereocomplexation of PLA chains is the driving force in the gelation and not the PEG chain interdigitation mechanism, since the PEG chains lose their entanglements at elevated temperatures. 


\section{Block copolymer I}

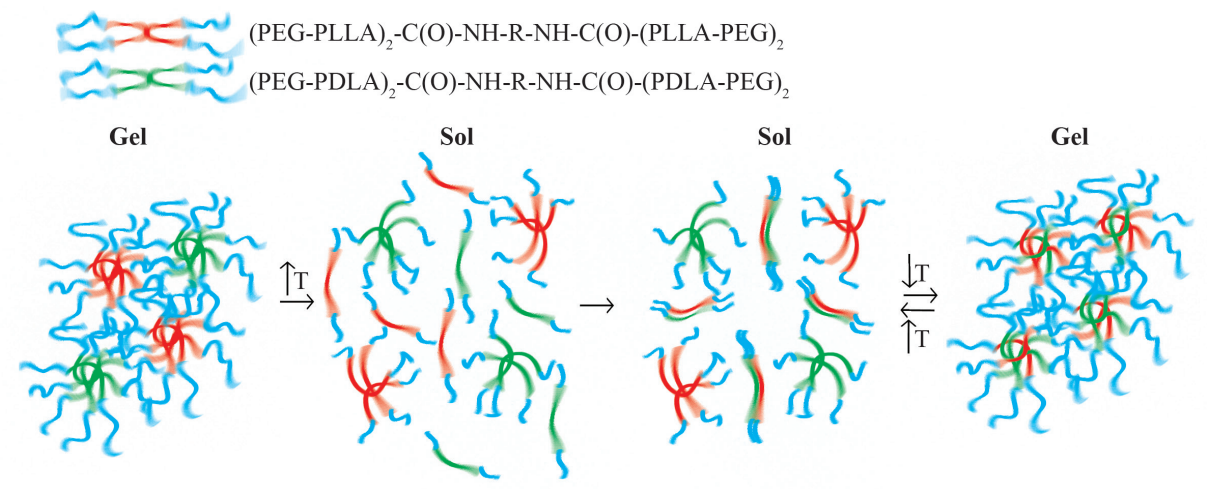

\section{Block copolymers II and III}

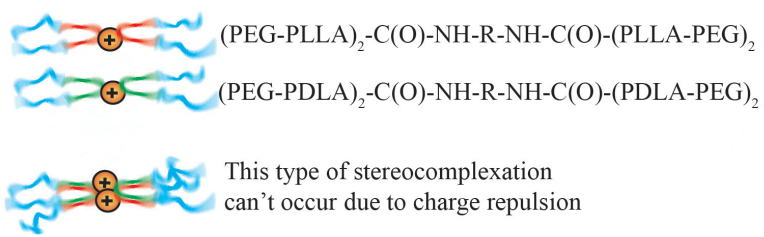

Sol
Gel

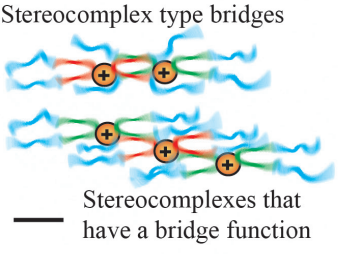

Gel

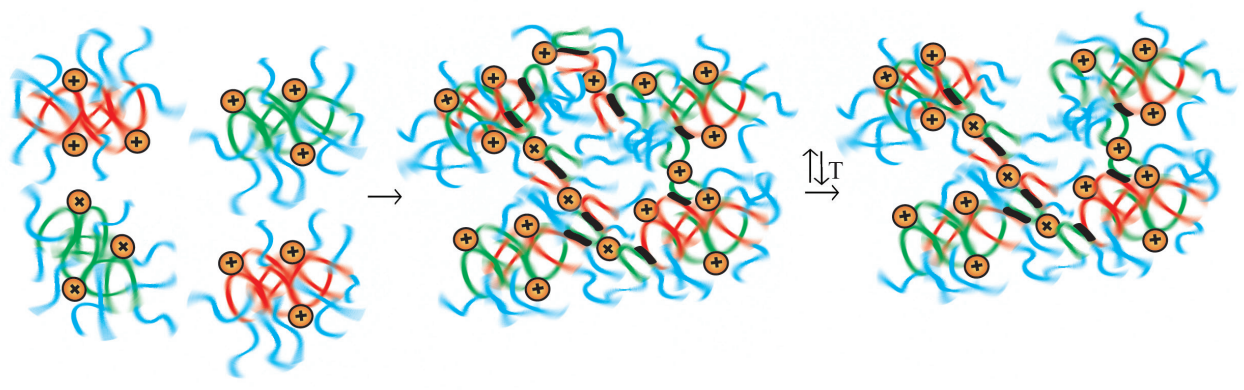

Figure 7. Model of aggregation and hydrogel formation for block copolymer I and block copolymers II and III. 


\section{Conclusions}

Four-arm (PEG-PLA) $)_{2}-\mathrm{C}(\mathrm{O})-\mathrm{NH}-\mathrm{R}-\mathrm{NH}-\mathrm{C}(\mathrm{O})-(\mathrm{PLA}-\mathrm{PEG})_{2}$ hydrogels were prepared by mixing PBS solutions of copolymers with opposite chirality. Gel formation is driven by stereocomplexation of PLA blocks, since single enantiomer solutions did not form a gel at similar concentrations. When $\mathrm{R}$ is a heptane linker a thermo-reversible gel is obtained. Gelation is driven by the formation of PEG entanglements at lower temperatures. Incorporating central cationic moieties in the copolymers revealed a pronounced effect on the gelation behavior. The enantiomeric copolymers have high aqueous solubility, but mixtures of enantiomeric copolymers at relatively high concentrations afforded stereocomplexed gels which are thermo-irreversible. The gelation mechanism of these copolymers is related to the formation of stereocomplexed domains randomly dispersed in the gel, which act as crosslinks.

\section{References}

1. Antonietti, M.; Förster, S., Vesicles and Liposomes: A Self-Assembly Principle Beyond Lipids. Advanced Materials 2003, 15, (16), 1323-1333.

2. Förster, S.; Plantenberg, T., From Self-Organizing Polymers to Nanohybrid and Biomaterials. Angewandte Chemie International Edition 2002, 41, (5), 688-714.

3. Pochan, D. J.; Chen, Z.; Cui, H.; Hales, K.; Qi, K.; Wooley, K. L., Toroidal Triblock Copolymer Assemblies. Science 2004, 306, (5693), 94-97.

4. Wang, X.; Guerin, G.; Wang, H.; Wang, Y.; Manners, I.; Winnik, M. A., Cylindrical Block Copolymer Micelles and Co-Micelles of Controlled Length and Architecture. Science 2007, 317, (5838), 644-647.

5. Zhang, L.; Eisenberg, A., Multiple Morphologies of "Crew-Cut" Aggregates of Polystyrene-b-poly(acrylic acid) Block Copolymers. Science 1995, 268, (5218), 1728-1731. 6. Ju, B.; Yan, D.; Zhang, S., Micelles self-assembled from thermoresponsive 2-hydroxy-3-butoxypropyl starches for drug delivery. Carbohydrate Polymers 2012, 87, (2), 1404-1409.

7. Qiu, X. Y.; Jiang, M. W.; Guo, C. G.; He, Y. J.; Wang, C. Q., Self-assembled nanowire of an amphiphilic biodegradable oligosaccharide-based graft copolymer in water. Carbohydrate Polymers 2012, 87, (3), 2306-2312.

8. Rösler, A.; Vandermeulen, G. W. M.; Klok, H. A., Advanced drug delivery devices via self-assembly of amphiphilic block copolymers. Advanced Drug Delivery Reviews 2001, 53, (1), 95-108.

9. $\quad$ Schenning, A. P. H. J.; Elissen-Román, C.; Weener, J. W.; Baars, M. W. P. L.; Van Der Gaast, S. J.; Meijer, E. W., Amphiphilic dendrimers as building blocks in supramolecular assemblies. Journal of the American Chemical Society 1998, 120, (32), 8199-8208.

10. Urbani, C. N.; Bell, C. A.; Lonsdale, D.; Whittaker, M. R.; Monteiro, M. J., Selfassembly of amphiphilic polymeric dendrimers synthesized with selective degradable linkages. Macromolecules 2008, 41, (1), 76-86. 
11. Zhang, S., Fabrication of novel biomaterials through molecular self-assembly. Nat Biotech 2003, 21, (10), 1171-1178.

12. Blanazs, A.; Armes, S. P.; Ryan, A. J., Self-Assembled Block Copolymer Aggregates: From Micelles to Vesicles and their Biological Applications. Macromolecular Rapid Communications 2009, 30, (4-5), 267-277.

13. Stubenrauch, K.; Moitzi, C.; Fritz, G.; Glatter, O.; Trimmel, G.; Stelzer, F., Precise Tuning of Micelle, Core, and Shell Size by the Composition of Amphiphilic Block Copolymers Derived from ROMP Investigated by DLS and SAXS. Macromolecules 2006, 39, (17), 5865-5874.

14. Hayward, R. C.; Pochan, D. J., Tailored Assemblies of Block Copolymers in Solution: It Is All about the Process. Macromolecules 2010, 43, (8), 3577-3584.

15. Kim, S. H.; Nederberg, F.; Jakobs, R.; Tan, J. P. K.; Fukushima, K.; Nelson, A.; Meijer, E. W.; Yang, Y. Y.; Hedrick, J. L., A Supramolecularly Assisted Transformation of Block-Copolymer Micelles into Nanotubes. Angewandte Chemie International Edition 2009, 48, (25), 4508-4512.

16. Gröhn, F., Electrostatic Self-Assembly as Route to Supramolecular Structures. Macromolecular Chemistry and Physics 2008, 209, (22), 2295-2301.

17. Lazzari, M.; López-Quintela, M. A., Micellization Phenomena in Semicrystalline Block Copolymers: Reflexive and Critical Views on the Formation of Cylindrical Micelles. Macromolecular Rapid Communications 2009, 30, (21), 1785-1791.

18. Huang, X.; Du, F.; Cheng, J.; Dong, Y.; Liang, D.; Ji, S.; Lin, S.-S.; Li, Z., AcidSensitive Polymeric Micelles Based on Thermoresponsive Block Copolymers with Pendent Cyclic Orthoester Groups. Macromolecules 2009, 42, (3), 783-790.

19. Magnusson, J. P.; Khan, A.; Pasparakis, G.; Saeed, A. O.; Wang, W.; Alexander, C., Ion-Sensitive "Isothermal" Responsive Polymers Prepared in Water. Journal of the American Chemical Society 2008, 130, (33), 10852-10853.

20. Zhao, Y.; Bertrand, J.; Tong, X.; Zhao, Y., Photo-Cross-Linkable Polymer Micelles in Hydrogen-Bonding-Built Layer-by-Layer Films. Langmuir 2009, 25, (22), 13151-13157.

21. Read, E. S.; Armes, S. P., Recent advances in shell cross-linked micelles. Chemical Communications 2007, (29), 3021-3035.

22. Harada, A.; Kataoka, K., Formation of Polyion Complex Micelles in an Aqueous Milieu from a Pair of Oppositely-Charged Block Copolymers with Poly(ethylene glycol) Segments. Macromolecules 1995, 28, (15), 5294-5299.

23. Chen, L.; Xie, Z.; Hu, J.; Chen, X.; Jing, X., Enantiomeric PLA-PEG block copolymers and their stereocomplex micelles used as rifampin delivery. Journal of Nanoparticle Research 2007, 9, (5), 777-785.

24. Lee, S. C.; Lee, H. J., pH-Controlled, Polymer-Mediated Assembly of Polymer Micelle Nanoparticles. Langmuir 2006, 23, (2), 488-495.

25. Tsuji, H.; Ikada, Y., Stereocomplex formation between enantiomeric poly(lactic acid)s. XI. Mechanical properties and morphology of solution-cast films. Polymer 1999, 40, (24), 6699-6708.

26. de Jong, S. J.; De Smedt, S. C.; Wahls, M. W. C.; Demeester, J.; Kettenes-van den Bosch, J. J.; Hennink, W. E., Novel self-assembled hydrogels by stereocomplex formation in aqueous solution of enantiomeric lactic acid oligomers grafted to dextran. Macromolecules 2000, 33, (10), 3680-3686.

27. Hiemstra, C.; Zhong, Z. Y.; Li, L. B.; Dijkstra, P. J.; Feijen, J., In-situ formation of 
biodegradable hydrogels by stereocomplexation of PEG-(PLLA)(8) and PEG-(PDLA)(8) star block copolymers. Biomacromolecules 2006, 7, (10), 2790-2795.

28. Fujiwara, T.; Mukose, T.; Yamaoka, T.; Yamane, H.; Sakurai, S.; Kimura, Y., Novel thermo-responsive formation of a hydrogel by stereo-complexation between PLLA-PEGPLLA and PDLA-PEG-PDLA block copolymers. Macromolecular Bioscience 2001, 1, (5), 204-208.

29. Li, S. M.; Vert, M., Synthesis, characterization, and stereocomplex-induced gelation of block copolymers prepared by ring-opening polymerization of L(D)-lactide in the presence of poly(ethylene glycol). Macromolecules 2003, 36, (21), 8008-8014.

30. Mukose, T.; Fujiwara, T.; Nakano, J.; Taniguchi, I.; Miyamoto, M.; Kimura, Y.; Teraoka, I.; Woo Lee, C., Hydrogel Formation between Enantiomeric B-A-B-Type Block Copolymers of Polylactides (PLLA or PDLA: A) and Polyoxyethylene (PEG: B); PEGPLLA-PEG and PEG-PDLA-PEG. Macromolecular Bioscience 2004, 4, (3), 361-367.

31. J.W.H.Wennink; Signori, F.; Grote, A.S.; Karperien, M.; Feijen, J.; Dijkstra, P. J., Aggregation behavior of thermoresponsive and $\mathrm{pH}$-sensitive star-shaped PLLA-PEG hydrogels. 2012, (Chapter 3 of this thesis).

32. Hiemstra, C.; Zhong, Z. Y.; Dijkstra, P.; Feijen, J., Stereocomplex mediated gelation of PEG-(PLA)(2) and PEG-(PLA)(8) block copolymers. Macromolecular Symposia 2005, 224, 119-131.

33. Ottenbrite, R. M.; Park, K.; Okano, T., Biomedical applications of hydrogels handbook. 1 ed.; Springer: NY, 2011; p 157-177. 



\section{Chapter 5 Aggregation and gelation behavior of hyperbranched PEI-PLLA-PEG copolymers}

Jos W.H. Wennink, Francesca Signori, Freek Jansen, Marcel Karperien, Jan Feijen and Pieter J. Dijkstra

"Before you criticize someone, you should walk a mile in their shoes. That way when you criticize them, you are a mile away from them and you have their shoes." 


\begin{abstract}
Hyperbranched poly(ethyleneimine)-poly(L-lactide)-poly(ethylene glycol) ( $\alpha$-HPEI- $\gamma$ $(\text { PLLA-mPEG })_{2}$ ) copolymers were synthesized by coupling of NHS-(PLLA-mPEG) $)_{2}$ to the primary amine groups of HPEI with molecular weights $(\alpha)$ of $600,1200,1800,5000$ or $10000 \mathrm{~g} / \mathrm{mol}$. The maximum conversion of primary amine groups in all cases was 70 $\%$ yielding hyperbranched copolymers with $\gamma$ (average number of groups per molecule of HPEI) varying from 3 to 40 with increasing HPEI molecular weight and a PEG content of 75.5 wt \%. Dynamic light scattering (DLS) measurements showed that aqueous solutions of 1200-HPEI-5.5-(PLLA-mPEG) ${ }_{2}$ and 1800-HPEI-8.2-(PLLA-mPEG) $)_{2}$ had a distinct bimodal distribution of small aggregates with an average diameter of $35 \mathrm{~nm}$ and larger aggregates of $1000 \mathrm{~nm}$. Both the low molecular weight 600-HPEI-2.8-(PLLA-mPEG), and high molecular weight 5000-HPEI-19.5-(PLLA-mPEG) ${ }_{2}$ and 10000-HPEI-40.3-(PLLA-mPEG) hyperbranched copolymers showed an almost unimodal distribution of small aggregates of $35 \mathrm{~nm}$ at low concentrations. All $\alpha$-HPEI- $\gamma$-(PLLA-mPEG), copolymers had a $\xi$-potential of $0 \mathrm{mV}$ suggesting that the HPEI moiety was shielded by the PLLA-mPEG arms. At high concentrations ( $\geq 25 \mathrm{wt} \%$ ) vial tilting and oscillatory rheology measurements showed that 1200-HPEI-5.5-(PLLA-mPEG) ${ }_{2}$ and 1800-HPEI-8.2-(PLLA-mPEG) $)_{2}$ formed hydrogels while all other hyperbranched copolymers afforded solutions. HR-MAS ${ }^{1} \mathrm{H}-\mathrm{NMR}$ showed that at $25{ }^{\circ} \mathrm{C}$ the PLLA moieties of 1800-HPEI-8.2-(PLLA-mPEG) $)_{2}$ were predominantly immobile revealing the formation of hydrophobic domains. At higher temperatures these hydrophobic domains as well as HPEI became more mobile consistent with a gel to sol phase transition. HR-MAS ${ }^{1}$ H-NMR spectra of 10000-HPEI-40.3-(PLLA-mPEG) $)_{2}$ showed that the PLLA groups were relatively mobile at room temperature suggesting a low efficiency in the packing of the PLLA blocks into hydrophobic domains. Most probably stabilization of the aggregates by the PEG blocks prohibited the formation of a hydrogel by PEG entanglements.
\end{abstract}




\section{Introduction}

Hydrogels have received much interest for use in biomedical applications such as tissue engineering and the controlled delivery of biologically active agents, because they generally exhibit excellent biocompatibility due to their high water content ${ }^{1,2}$. Hydrogels are highly water swollen polymer networks comprising either chemical crosslinks or physical crosslinks, by e.g. hydrophobic or ionic interactions. Amphiphilic biodegradable copolymers composed of poly(ethylene glycol) (PEG) as the hydrophilic component and aliphatic polyesters such as poly(L-lactide) (PLLA) or poly( $\varepsilon$-caprolactone) (PCL) as the hydrophobic component have been extensively investigated for their thermo-responsive behavior ${ }^{3-5}$. Recent advances in polymer synthesis have led to more complex architectures such as graft copolymers ${ }^{6}$, dendrimers ${ }^{7}$, hyperbranched and star shaped copolymers ${ }^{8,9}$. Each of these various architectures imparts a whole new set of intriguing properties to amphiphilic copolymers such as a low critical gel concentration and control over the degradation rate and gel to sol transition temperature.

The widespread research and potential applications of linear block copolymer based hydrogels have increased the desire to understand how gel properties can change when amphiphilic block copolymers are used in a star shaped construct. Moreover, the combination of virtually any type and number of polymer arms into a single unique architecture receives increasing interest ${ }^{10-12}$. Within the class of star-shaped polymers several subgroups can be distinguished such as mikto-arm copolymers ${ }^{13}$ and $(\mathrm{A}-\mathrm{b}-\mathrm{B})_{\mathrm{n}}, \mathrm{A}(\mathrm{B}-\mathrm{b}-\mathrm{C})_{2}, \mathrm{~A}_{\mathrm{n}}(\mathrm{B}-\mathrm{b}-\mathrm{C})_{\mathrm{n}}$ hetero-arm star block copolymers ${ }^{14}$ in which $\mathrm{A}, \mathrm{B}$ and $\mathrm{C}$ represent different polymers. Two different synthetic strategies are generally used to prepare star-shaped (co)polymers. Either their synthesis is started from a multifunctional core by using different polymerization techniques (divergent approach) or by a convergent synthetic approach in which precursor polymers are prepared and coupled to a core molecule ${ }^{13}$.

Star-shaped block copolymers comprising an aliphatic polyester core and PEG outer arms may show a thermo-responsive gelation behavior depending on the hydrophilic to hydrophobic weight ratio. Lee et al. prepared low molecular weight 3- and 4-armed star block copolymers with a PLGA core and PEG outer arms ${ }^{15}$. These star shaped block copolymers with a low PEG content of $\sim 30 \mathrm{wt} \%$ form a gel at higher concentrations in contrast to PEG-PLGA-PEG triblock copolymers having the same PEG block length and a similar PLGA content. The 3- and 4-armed star block copolymers form a gel at higher concentrations due to hampered hydrophobic interactions between nano-sized particles. Studies on linear and star shaped copolymers with high molecular weights and a central PLLA moiety and outer PEG blocks (PEG content of $77 \mathrm{wt} \%$ ) show an opposite behavior ${ }^{4,5,9}$. A three-arm star shaped copolymer 
with a PLLA core and PEG outer blocks formed hydrogels at somewhat lower concentrations than the linear triblock PEG-PLLA-PEG copolymer with the same PEG content.

Hyperbranched (co)polymers have proven excellent precursors in supramolecular selfassembly, and many delicate supramolecular structures and hybrids at all scales and dimensions have been generated. Most importantly, these materials show several unique properties compared to their linear analogues, including lower viscosities, lower crystallinities and the presence of high numbers of functional end-groups that offer the possibility for further modification ${ }^{16,17,18}$. Especially poly(ethylene imine)s have received considerable attention due to their ability to complex negatively charged (macro)molecules like e.g. DNA. Only in a few cases the use of hyperbranched poly(ethylene imine)s as an architectural unit in combination with amphiphilic block copolymers has been reported.

Coupling of one to four amphiphilic PCL-mPEG arms on hyperbranched poly(ethylene imine) (HPEI) with a molecular weight of $25000 \mathrm{~g} / \mathrm{mol}$ yields efficient nonviral gene delivery vectors ${ }^{19,20}$. In water the copolymer self assembles in core-shell micellar structures with a hydrophobic PCL core and a corona composed of HPEI and PEG moieties. Degradation studies have revealed the detachment of HPEI and mPEG from the micelles by cleavage of ester bonds ${ }^{21}$. Biological studies show that the inherent cytotoxicity of HPEI decreases by increasing the number of PCL-mPEG arms ${ }^{22}$.

After reacting the amine groups of HPEI with short amphiphilic moieties composed of aliphatic and mPEG unit's multi-shell nanoparticles with a HPEI core could be obtained. In these structures, the polar HPEI core is surrounded by a double layered shell consisting of a nonpolar inner shell and a hydrophilic mPEG outer shell ${ }^{23,24}$. These multi-shell nanoparticles of 30-50 nm can be used as transporters of polar guest molecules or water insoluble compounds.

In previous research it has been shown that 4-arm star PLLA-PEG in which the arms are coupled to a central small unit containing secondary amine groups (cationic moiety) has a large influence on the aggregation and gelation behavior compared to a non-charged analogue. A 4-arm star PLLA-mPEG with a neutral central moiety shows the typical gel to sol phase transition of an ABA type amphiphilic copolymer at higher temperatures. Corresponding 4-arm star PLLA-mPEG in which the arms are coupled to a central small unit containing secondary amine groups (cationic moiety) retain a sol state at higher temperatures ${ }^{25}$. It is proposed that the observed changes in aggregation behavior can be explained by the presence of protonated amine groups in the micelles, which are also present in the PEG corona resulting in charge repulsion. Moreover, the shielding of the positive charges by the PEG chains, which 
as a consequence stabilize the micellar type aggregates prevents micellar growth at lower temperatures and prohibits the formation of PEG entanglements and consequent gelation.

In this study we have used the primary amine groups of HPEI to couple NHS-(PLLA10mPEG5000), an ABA type amphiphilic block copolymer comprising a central activated ester group. A range of $\alpha$-HPEI- $\gamma$-(PLLA-mPEG) ${ }_{2}$ star block copolymers in which $\alpha$ is the molecular weight of the HPEI and $\gamma$ the number of (PLLA-mPEG) arms coupled to the HPEI core have been prepared. The temperature dependent aggregation behavior of these low to high molecular weight hyperbranched polymers has been studied and related to the formation of stable nanoparticles.

\section{Materials and methods}

\section{Materials}

L-lactide (L-LA) was purchased from Purac (Gorinchem, the Netherlands). 2,2-Bis(hydroxymethyl)propionic acid (bis-MPA) was obtained from Acros (Geel, Belgium). Tin(II) 2-ethylhexanoate ( $\mathrm{Sn}(\mathrm{Oct})_{2}$ ), succinic anhydride, N-hydroxysuccinimide(NHS), N,N'dicyclohexylcarbodiimide (DCC), mesyl chloride, deuterated chloroform $\left(\mathrm{CDCl}_{3}\right)$, aqueous ammonia (25\%), glacial acetic acid, 1,6-diphenyl-1,3,5-hexatriene (DPH) and $\mathrm{NaHCO}_{3}$ were obtained from Sigma-Aldrich (Zwijndrecht, the Netherlands). 2,4,6-Trinitro benzenesulfonic acid (TNBS) and methoxy-hydroxy poly(ethylene glycol) with a molecular weight of 5000 g/mol (mPEG5000-OH) were purchased from Fluka (Buchs, Switzerland). Triethylamine and 4-dimethylaminopyridine (DMAP) were acquired from Merck (Darmstadt, Germany). Hyperbranched poly(ethylene imine) (HPEI) with molecular weights of 600, 1200, 1800 and 10000 were purchased from Polysciences (Warrington, USA). HPEI with a molecular weight of 5000 was obtained from Nanopartica (Berlin, Germany). All other solvents were from Biosolve (Valkenswaard, the Netherlands). Dichloromethane and toluene were dried over calcium hydride (Sigma-Aldrich) and sodium wire, respectively, and distilled prior to use. All other chemicals were used as received. NHS-(PLLA10-mPEG5000) $)_{2}$ was prepared as previously described ${ }^{25}$.

\section{Synthesis}

General procedure for the synthesis of $\alpha$-HPEI- $\gamma$-(PLLA-mPEG): In a typical procedure, NHS-(PLLA10-mPEG5000) $2(3.17 \mathrm{~g}, 0.23 \mathrm{mmol})$ was dissolved in $15 \mathrm{~mL}$ of dichloromethane under an $\mathrm{N}_{2}$ atmosphere and 1800-HPEI (54 mg, $0.03 \mathrm{mmol}$ ) dissolved in $5 \mathrm{~mL}$ of dichloromethane was added. The resulting reaction mixture was stirred for $24 \mathrm{~h}$ at room temperature under an $\mathrm{N}_{2}$ atmosphere. The polymer was precipitated in an excess of cold 
diethyl ether. The product (1800-HPEI-8-(PLLA-mPEG) $)_{2}$ ) was dried in vacuo overnight to give a white powder (yield: $96 \%$ ).

${ }^{1} \mathrm{H} \mathrm{NMR}\left(\mathrm{CDCl}_{3}\right): \delta=6.50\left(\mathrm{~s}, \mathrm{CH}_{2} \mathrm{NHCO}\right), 5.15\left(\mathrm{~m}, \mathrm{CHCH}_{3}\right), 4.10-4.40\left(\mathrm{~m}, \mathrm{CCH}_{2}\right), 3.65$ (m, PEG protons), $3.55\left(\mathrm{~m}, \mathrm{NHCH}_{2}\right), 3.37\left(\mathrm{~s}, \mathrm{CH}_{2} \mathrm{OCH}_{3}\right), 2.50-2.75\left(\mathrm{~m}, \mathrm{OCOCH}_{2}\right), 1.57$ (d, $\left.\mathrm{CHCH}_{3}\right), 1.22\left(\mathrm{~s}, \mathrm{CCH}_{3}\right)$.

\section{Characterization}

${ }^{1}$ H-NMR: ${ }^{1} \mathrm{H}(300 \mathrm{MHz}) \mathrm{NMR}$ spectra were recorded using a Varian Inova NMR spectrometer. Polymers were dissolved in $\mathrm{CDCl}_{3}$ at a concentration of $0.015 \mathrm{~g} / \mathrm{mL}$.

Primary amine group content: The primary amine group content of HPEI and $\alpha$-HPEI$\gamma$-(PLLA-mPEG) ${ }_{2}$ copolymers was determined by a TNBS assay ${ }^{26}$. To $1 \mathrm{~mL}$ of a polymer solution $(1.5 \mathrm{mg} / \mathrm{mL}), 1 \mathrm{~mL}$ of a $4 \mathrm{wt} \% \mathrm{NaHCO}_{3}$ solution and $1 \mathrm{~mL}$ of a freshly prepared $0.5 \mathrm{wt} \%$ TNBS solution in water were added. After a reaction time of $2 \mathrm{~h}$ at $37^{\circ} \mathrm{C}, 3 \mathrm{~mL}$ of a $6 \mathrm{M} \mathrm{HCl}$ solution was added and the resulting solution was stirred for another $1.5 \mathrm{~h}$ at 37 ${ }^{\circ} \mathrm{C}$. Finally, each sample was diluted with $2 \mathrm{~mL}$ of water, and the absorption was measured at $420 \mathrm{~nm}$ using a Cary 300 Bio UV-Vis spectrophotometer (Varian). A calibration curve was derived from the absorption of $\mathrm{mPEG}$-amine $\left(\mathrm{M}_{\mathrm{w}}=5000 \mathrm{~g} / \mathrm{mol}\right)$ measured at different concentrations.

Vial tilting method: The phase behavior of aqueous polymer solutions was investigated by the vial tilting method. Block copolymers were dissolved in PBS (10-40 wt \%) in tightly capped $5 \mathrm{~mL}$ vials by repeatedly heating to $80{ }^{\circ} \mathrm{C}$ for $2 \mathrm{~min}$ and shaking while cooling. The copolymer solutions were kept at $4{ }^{\circ} \mathrm{C}$ overnight prior to measurement. The temperature was increased step-wise with 2 or $4{ }^{\circ} \mathrm{C}$ and the samples were left at the measuring temperature for $10 \mathrm{~min}$ to equilibrate. The gel-sol transition temperature was determined by tilting the vials $90 \square$ for $1 \mathrm{~min}$. If there was no flow, the sample was regarded as a gel. In other cases it was regarded as a sol.

Rheology: Rheology experiments were performed on an Anton Paar Physica MCR 301 rheometer with flat plate geometry (20 mm diameter, $0.3 \mathrm{~mm}$ gap) in oscillating mode. PBS polymer solutions or gels were prepared at $27.5 \mathrm{wt} \%$ as described above. The copolymer solutions were kept at $25{ }^{\circ} \mathrm{C}$ overnight prior to measurement. The copolymer solutions or gels were then applied to the rheometer. To prevent evaporation of water a solvent trap was placed over the geometry. A pre-shear was applied for $10 \mathrm{~s}$, after which the copolymer solution or gel was allowed to equilibrate for $10 \mathrm{~min}$ at $25{ }^{\circ} \mathrm{C}$. Subsequently, the copolymer solution or gel was heated to $75{ }^{\circ} \mathrm{C}$ at $1{ }^{\circ} \mathrm{C} / \mathrm{min}$, and then cooled to $25{ }^{\circ} \mathrm{C}$ at $1{ }^{\circ} \mathrm{C} / \mathrm{min}$. Sol to gel 
transitions were monitored by measuring the storage modulus $\left(\mathrm{G}^{\prime}\right)$ and the loss modulus (G'). A frequency $\omega$ of $1 \mathrm{~Hz}$ and a strain $\gamma$ of $1 \%$ were applied to minimize the influence of deformation on the formation of the hydrogels. After heating and cooling cycles, a frequency and amplitude sweep were performed at $\omega 0.01-10 \mathrm{~Hz}(\gamma=1 \%)$ and $\gamma 0.01-10 \%(\omega=1 \mathrm{~Hz})$ at $20{ }^{\circ} \mathrm{C}$, to confirm that the measurements were performed within the linear viscoelastic range.

Critical Association Concentration: The critical association concentration of the $\alpha$-HPEI$\gamma$-(PLLA-mPEG) ${ }_{2}$ copolymers in PBS at $20 \square \mathrm{C}$ was determined by the dye solubilization method. To $1.0 \mathrm{~mL}$ of copolymer solutions with concentrations ranging from 0.0018 to 0.3 wt $\%, 10 \mu \mathrm{L}$ of a $0.5 \mathrm{mM}$ DPH solution in methanol was added. The resulting mixture was stored in the dark and equilibrated overnight. UV-Vis absorption spectra of the solutions were recorded in the 300 to $500 \mathrm{~nm}$ range. The difference in the absorption at $375 \mathrm{~nm}$ relative to $397 \mathrm{~nm}$ was plotted against the polymer concentration and the intercept of the extrapolated straight lines was taken as the critical association concentration of the copolymer.

DLS: Dynamic light scattering experiments were performed with a Malvern zetasizer 4000 (Malvern Corp., Malvern, UK), using a laser wavelength of $633 \mathrm{~nm}$ and a scattering angle of $90^{\circ}$. The CONTIN method was applied for data processing. The diameter of micelles or aggregates of copolymers in PBS was determined as a function of temperature in between 20 and $50{ }^{\circ} \mathrm{C}$. The copolymer solution was allowed to equilibrate at each measuring temperature for $15 \mathrm{~min}$.

HR-MAS ${ }^{1}$ H-NMR: HR-MAS NMR spectra were recorded using a Bruker Avance II 600 spectrometer operating at $600 \mathrm{MHz}$. Samples of $\alpha$-HPEI- $\gamma$-(PLLA-mPEG) $)_{2}$ were prepared (27.5 wt \%) and analyzed using a high resolution magic angle spinning (HR-MAS) probe equipped with a gradient coil along the rotor axis. The samples were placed in $50 \mu \mathrm{L} \mathrm{KelF}$ rotors and allowed to spin at a frequency of $6 \mathrm{kHz}$. Spectra were recorded from 25 to $53{ }^{\circ} \mathrm{C}$, with a step-wise increase of $4{ }^{\circ} \mathrm{C}$. At each temperature measurements were performed after 10 min equilibration. 


\section{Results and discussion}

The amphiphilic copolymer NHS-(PLLA-mPEG) ${ }_{2}$ (Scheme 1) with outer PEG blocks and a centrally located active NHS ester group is a versatile precursor block copolymer for the synthesis of mikto-arm and star block copolymers ${ }^{9,25}$. As an example the centrally located NHS active ester was used in the coupling reaction with primary and secondary amine group containing small molecules to provide 4-arm star shaped copolymers with centrally located secondary amine groups which are protonated at physiological $\mathrm{pH}^{25}$. The incorporation of such cationic moieties had a dramatic effect on the association behavior in water compared to analogous non-charged star copolymers. Thermo-responsive sol-gel phase transitions as commonly observed for many PEG-PLLA type copolymers is absent when positively charged blocks are incorporated and these branched copolymers preferably aggregate into nano-sized particles. Such nanoparticles may be useful as carriers of negatively charged biologically active compounds. This potential application may become even more prominent by the incorporation of hyperbranched poly(ethyleneimine)s (HPEIs). Therefore, HPEIs with different molecular weights ranging from 600 to $10000 \mathrm{~g} / \mathrm{mol}$ were used to generate $\alpha$-HPEI$\gamma$-(PLLA-PEG) $)_{2}$ type copolymers with $\alpha$ representing the molecular weight of HPEI and $\gamma$ the average number of macromonomers attached (Scheme 1).

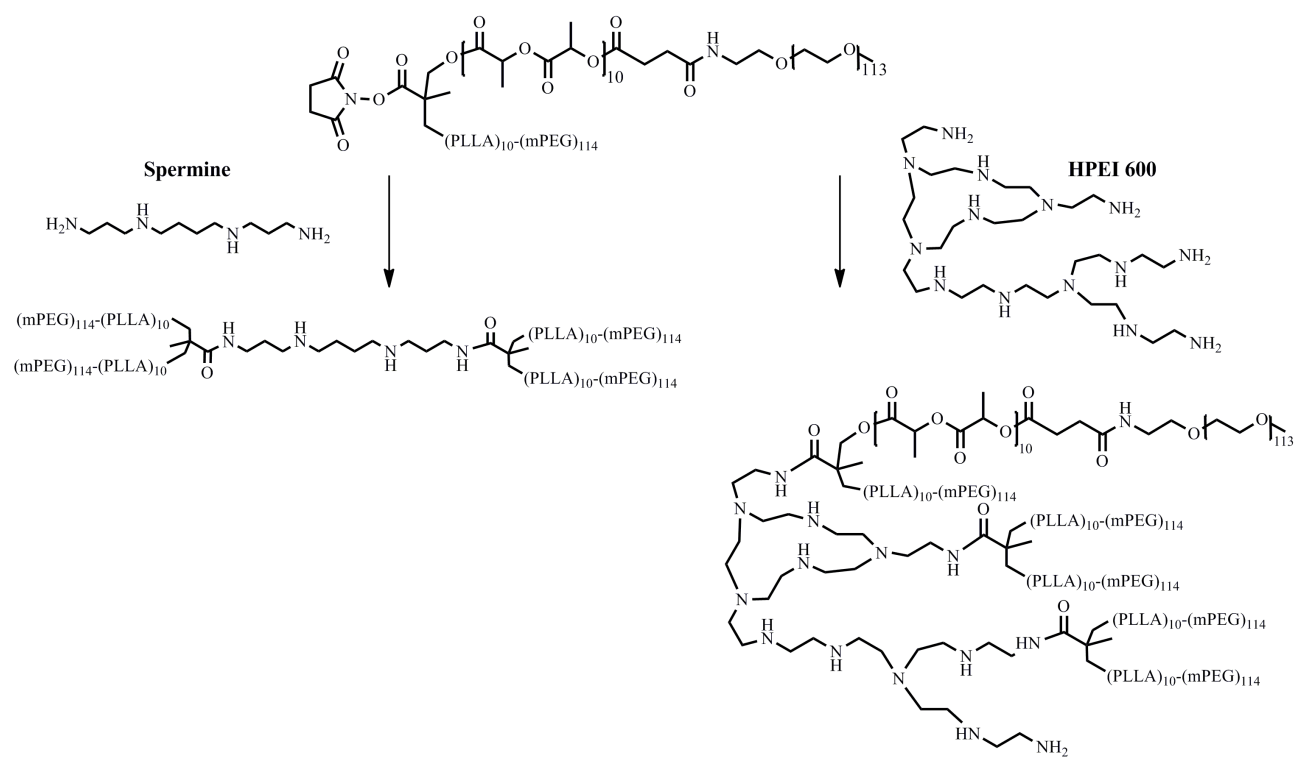

600-HPEI-3-(PLLA-mPEG)

Scheme 1. Schematic synthesis route for the preparation of 600-HPEI-3-(PLLA-mPEG) $)_{2}$ and a 4 armed star shaped copolymer ${ }^{25}$. 
Quantitative conversion of the primary amine groups of HPEI with NHS-C(O)-(PLLA$\mathrm{mPEG})_{2}$ could not be established, even when applying an excess of the macromonomer, possibly due to steric hindrance upon increasing conversion or unavailability of primary amines located at the centre of the HPEI structure. As an example the maximal conversion of primary amine groups of 1800-HPEI was determined from a series of reactions at different NHS-C(O)- (PLLA-mPEG) $)_{2}$ to HPEI ratios. The ${ }^{1} \mathrm{H}-\mathrm{NMR}$ spectra of the products obtained showed the disappearance of the NHS methylene protons at molar ratios up to 0.7:1 (NHS$\mathrm{C}(\mathrm{O})$-(PLLA-mPEG) $)_{2}: \mathrm{NH}_{2}$ of HPEI) (Figure 1). At higher molar ratios a peak originating from NHS methylene protons appears at $2.82 \mathrm{ppm}$, indicating the presence of unreacted NHS-(PLLA-mPEG) ${ }_{2}$. This result appeared representative for all coupling reactions applying HPEIs of different molecular weight. Therefore all $\alpha$-HPEI- $\gamma$-(PLLA-mPEG) $)_{2}$ copolymers described were prepared at the same molar ratio 0.7:1 (NHS-(PLLA-mPEG) ${ }_{2}: \mathrm{NH}_{2}$ of HPEI). All copolymers have a hydrophobic to hydrophilic weight ratio of 77:23.

Table 1. Primary amine group content of HPEIs, molecular weights $\left(M_{n}\right)$ of $c$ The most exciting phrase to hear in science, the one that heralds new discoveries, is not Eureka! (I found it!) but rather, 'hmm... that's funny... The most exciting phrase to hear in science, the one that heralds new discoveries, is not Eureka! (I found it!) but rather, 'hmm... that's funny... opolymers, number of (PLLA-mPEG) $)_{2}$ arms and HPEI and PEG content of $\boldsymbol{\alpha}$-HPEI$\boldsymbol{\gamma}$-(PLLA-mPEG) $)_{2}$

\begin{tabular}{|c|c|c|c|c|c|c|}
\hline \multicolumn{3}{|c|}{ HPEI } & \multicolumn{4}{|c|}{$\alpha$-HPEI- $\gamma-(\text { PLLA-mPEG })_{2}$} \\
\hline $\begin{array}{c}\alpha \\
M_{n} \\
(g / m o l)\end{array}$ & $\begin{array}{l}\text { number of } \\
\mathrm{NH}_{2} \text { groups }^{\mathrm{a}}\end{array}$ & $\begin{array}{c}\text { Determined } \\
\text { number of } \\
\mathrm{NH}_{2} \text { groups }^{\mathrm{b}}\end{array}$ & $\underset{(\mathrm{kg} / \mathrm{mol})}{M_{\mathrm{n}}}$ & $\gamma^{\mathfrak{c}}$ & $\begin{array}{c}\text { HPEI } \\
(\text { wt \%) }\end{array}$ & $\begin{array}{c}\text { PEG } \\
(w t \%)\end{array}$ \\
\hline 600 & 4 & $4.0 \pm 0.1$ & 39.6 & $2.8 \pm 0.1$ & 1.6 & 75.6 \\
\hline 1200 & 7 & $7.7 \pm 0.1$ & 66.2 & $5.5 \pm 0.1$ & 1.6 & 75.6 \\
\hline 1800 & 11 & $11.5 \pm 0.1$ & 106 & $8.2 \pm 0.3$ & 1.7 & 75.6 \\
\hline 5000 & 29 & $28.9 \pm 0.1$ & 265 & $19.5 \pm 0.3$ & 1.9 & 75.4 \\
\hline 10000 & 58 & $59.1 \pm 0.1$ & 543 & $40.3 \pm 0.3$ & 1.9 & 75.5 \\
\hline
\end{tabular}

${ }^{a}$ According to the manufacturer all HPEI polymers contain primary, secondary, and tertiary amine groups in a $25 / 50 / 25$ ratio ${ }^{27,28}$.

${ }^{\mathrm{b}}$ Determined by the TNBS assay.

cNumber of $-\mathrm{C}(\mathrm{O})$-(PLLA-mPEG) ${ }_{2}$ moieties coupled to $\alpha$-HPEI determined from the free amine group content of the hyperbranched copolymers with a TNBS assay. 


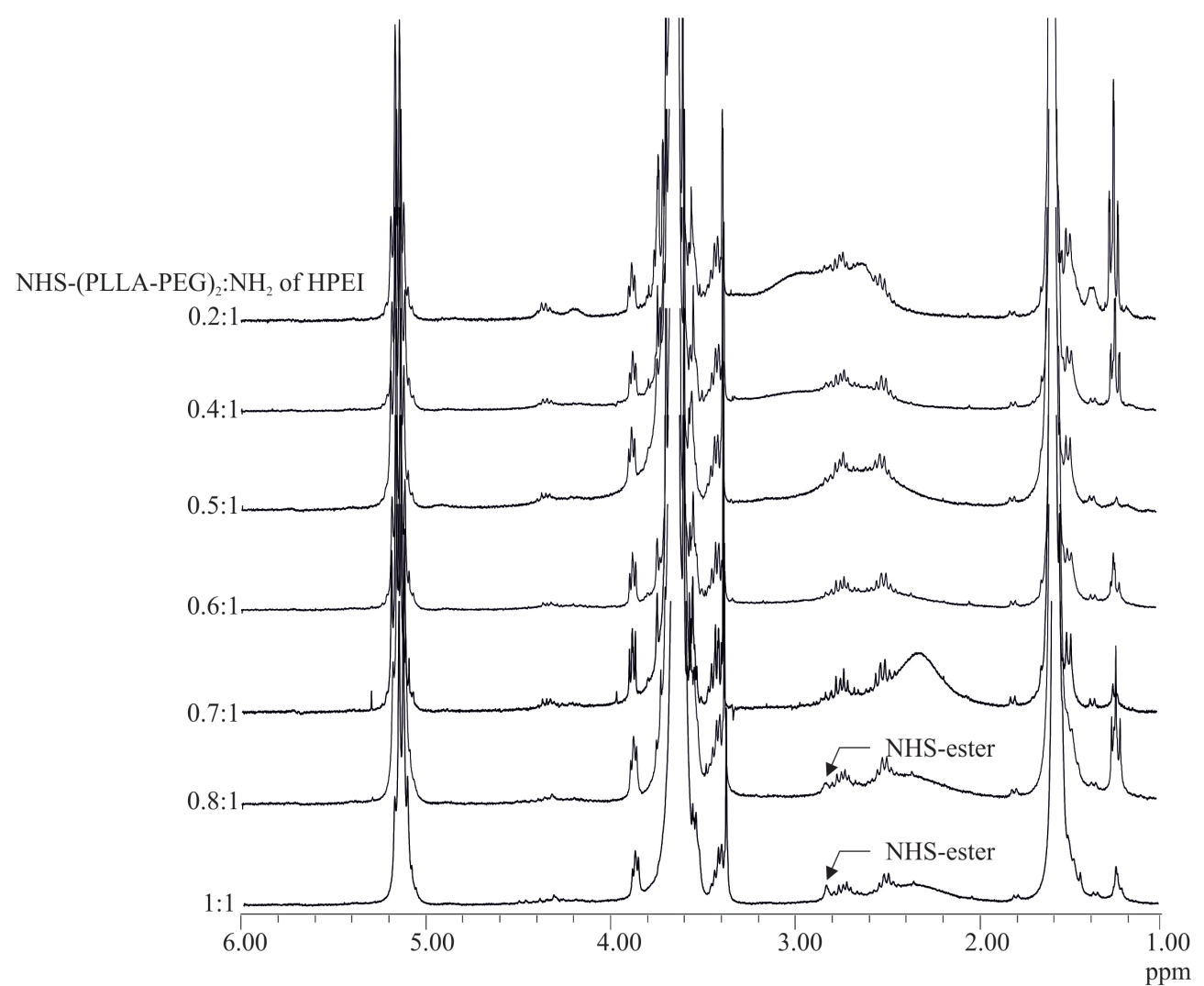

Figure 1. ${ }^{1} \mathrm{H}-\mathrm{NMR}$ spectra of $1800-\mathrm{HPEI}-\gamma-(\mathrm{PLLA}-\mathrm{mPEG})_{2}$ at different molar ratios of NHS-(PLLA-mPEG) ${ }_{2}$ to HPEI. Arrows indicate NHS methylene protons from unreacted NHS-C(O)-(PLLA-mPEG), Solvent $\mathrm{CDCl}_{3}$.

At low concentrations the hyperbranched copolymers are well soluble in water but large differences were observed for their aggregation behavior. First, the critical association concentration (CAC) values of aqueous solutions of the $\alpha$-HPEI- $\gamma$-(PLLA-mPEG) $)_{2}$ copolymers were determined by UV/Vis using DPH as a probe. The CAC values decrease from 0.095 wt $\%$ for 600-HPEI-2.8-(PLLA-mPEG) 2 to $0.064 \mathrm{wt} \%$ for 1200-HPEI-5.5-(PLLA-mPEG) and $0.057 \mathrm{wt} \%$ for 1800 -HPEI-8.2-(PLLA-mPEG) 2 but increase again to $0.063 \mathrm{wt} \%$ for 5000-HPEI-19.5-(PLLA-mPEG) ${ }_{2}$ and 0.079 wt \% for 10000-HPEI-40.3-(PLLA-mPEG) (Figure 2). At a concentration of $0.3 \mathrm{wt} \%$, well above the CAC, dynamic light scattering measurements revealed that the 600-HPEI-2.8-(PLLA-mPEG) ${ }_{2}$ copolymer had an almost monomodal distribution of aggregates with an average size of $28 \mathrm{~nm}$. Decreasing the copolymer concentration to $0.018 \mathrm{wt} \%$, well below the CAC, showed an average distribution at $10 \mathrm{~nm}$ indicative of fully dissolved polymer molecules. A similar to 600-HPEI-2.8-(PLLA-mPEG) association behavior was observed for 1200-HPEI-5.5-(PLLA-mPEG) ${ }_{2}$ and 1800-HPEI8.2-(PLLA-mPEG) $)_{2}$, although the average aggregate size was approximately $42 \mathrm{~nm}$ and the 
fraction of larger particles of $\sim 700-1000 \mathrm{~nm}$ was somewhat larger. At concentrations above the CAC the high molecular weight hyperbranched copolymers 5000-HPEI-19.5-(PLLA$\mathrm{mPEG})_{2}$ and 10000-HPEI-40.3-(PLLA-mPEG) $)_{2}$ showed a major distribution of aggregates at $30 \mathrm{~nm}$ and only a very small fraction present at $650 \mathrm{~nm}$. At a concentration of $0.018 \mathrm{wt}$ $\%$, below the CAC, no changes in the aggregate size distribution were observed but the larger aggregates disappeared. This indicated that in solutions of 5000-HPEI-19.5-(PLLA$\mathrm{mPEG})_{2}$ and 10000-HPEI-40.3-(PLLA-mPEG) $)_{2}$ aggregates are formed below the measured $\mathrm{CAC}$ value. The differences in the concentration dependent aggregation behavior may be due to reorganization of the hydrophilic and hydrophobic domains. For the high molecular weight materials, 5000-HPEI-19.5-(PLLA-mPEG) 2 and 10000-HPEI-40.3-(PLLA-mPEG), it is assumed that PLLA and HPEI are in the center of the assemblies and surrounded by a PEG shell. For aggregation into larger particles not only PEG entanglements are needed but also hydrophobic PLLA chains can influence hydrophilic PEG chains and might promote the packing towards larger aggregates. 

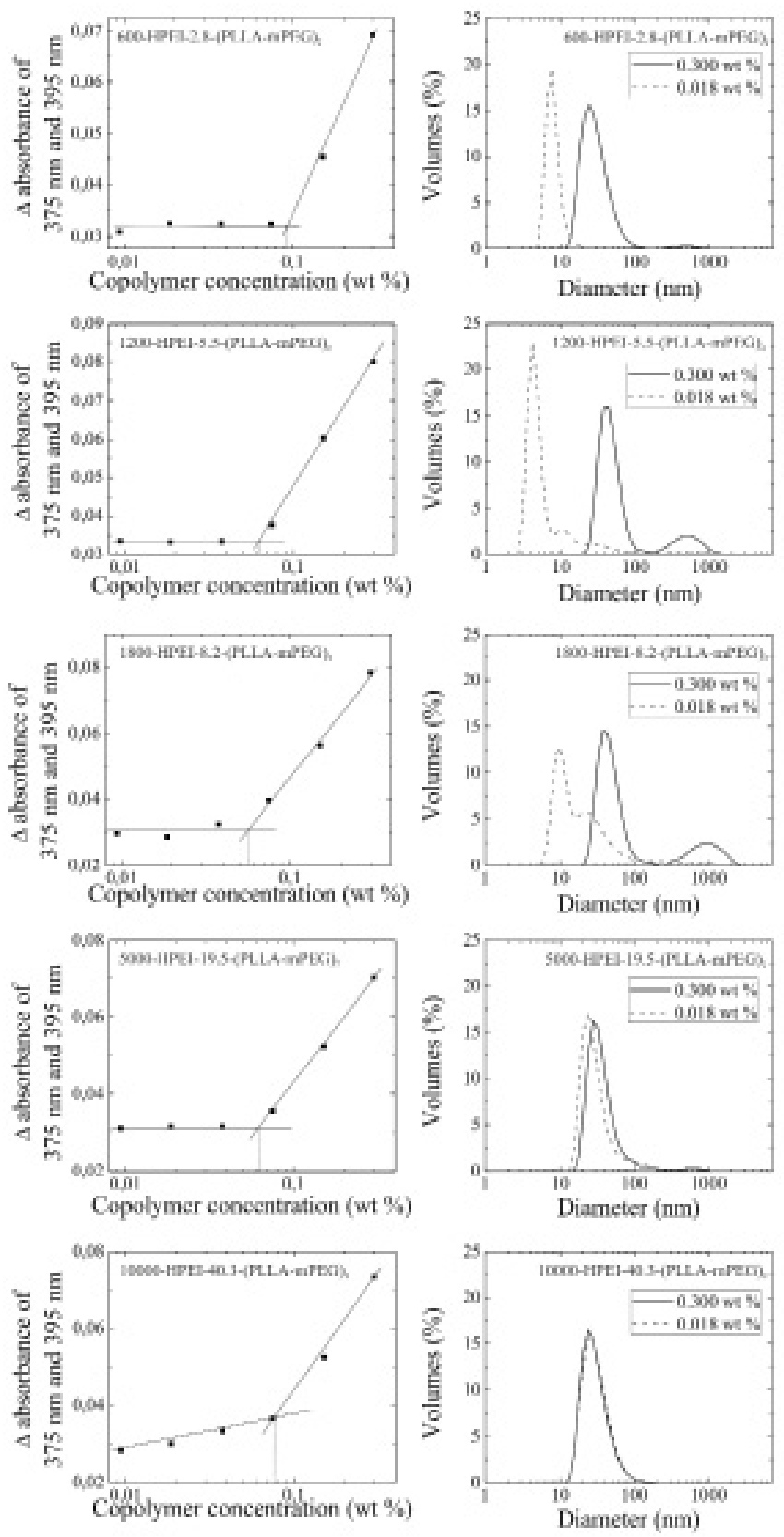

Figure 2. Critical association concentration (wt \%) and size distribution (volume) plots of 0.3 and $0.018 \mathrm{wt} \%$ copolymer aqueous solutions as determined by DLS of 600-HPEI-2.8-(PLLA-mPEG), 1200-HPEI-5.5-(PLLA$\mathrm{mPEG})_{2}, \quad$ 1800-HPEI-8.2-(PLLA-mPEG), 5000-HPEI-19.5-(PLLA-mPEG) ${ }_{2}$ and 10000-HPEI-40.3-(PLLA$\mathrm{mPEG})_{2}(\mathrm{PBS}, \mathrm{pH}$ 7.4). 
The thermo-responsive character of the copolymers $\left(17\right.$ to $\left.47{ }^{\circ} \mathrm{C}\right)$ was determined using dynamic light scattering (DLS) (Figure 3). It has to be noted that in this case intensity plots are presented contrary to the volume plots as presented in Figure 2. In the intensity plots the intensity of the scattered light cannot directly be related to the number of particles, since the intensity of light scattered by larger particles is much higher than that of smaller particles. In general it is seen that the size of the small and larger aggregates becomes smaller with increasing temperatures. The distribution remains the same and the decrease in aggregate sizes can be ascribed to the increasing hydrophobicity of the PEG chains at higher temperatures.

In order to investigate whether the HPEI moiety is located in the core or corona of the micelles/aggregates, $\xi$-potential measurements were performed using 0.3 wt $\%$ solutions. For all $\alpha$-HPEI- $\gamma$-(PLLA-mPEG) ${ }_{2}$ copolymers the $\xi$-potential is close to $0 \mathrm{mV}$, indicating that HPEI is not located at the surface of the aggregates. A similar result has been found for HPEI$\gamma$-(PCL-mPEG) copolymers which also afforded $\xi$-potentials close to 0 , most probably due to shielding of HPEI by the PEG blocks ${ }^{22}$. Since the hyperbranched copolymers described here have a maximum graft density this also suggests that the HPEI moiety in $\alpha$-HPEI- $\gamma$-(PLLA$\mathrm{mPEG})_{2}$ copolymers is not located at the surface and that the charge is most likely shielded by the PEG blocks. 

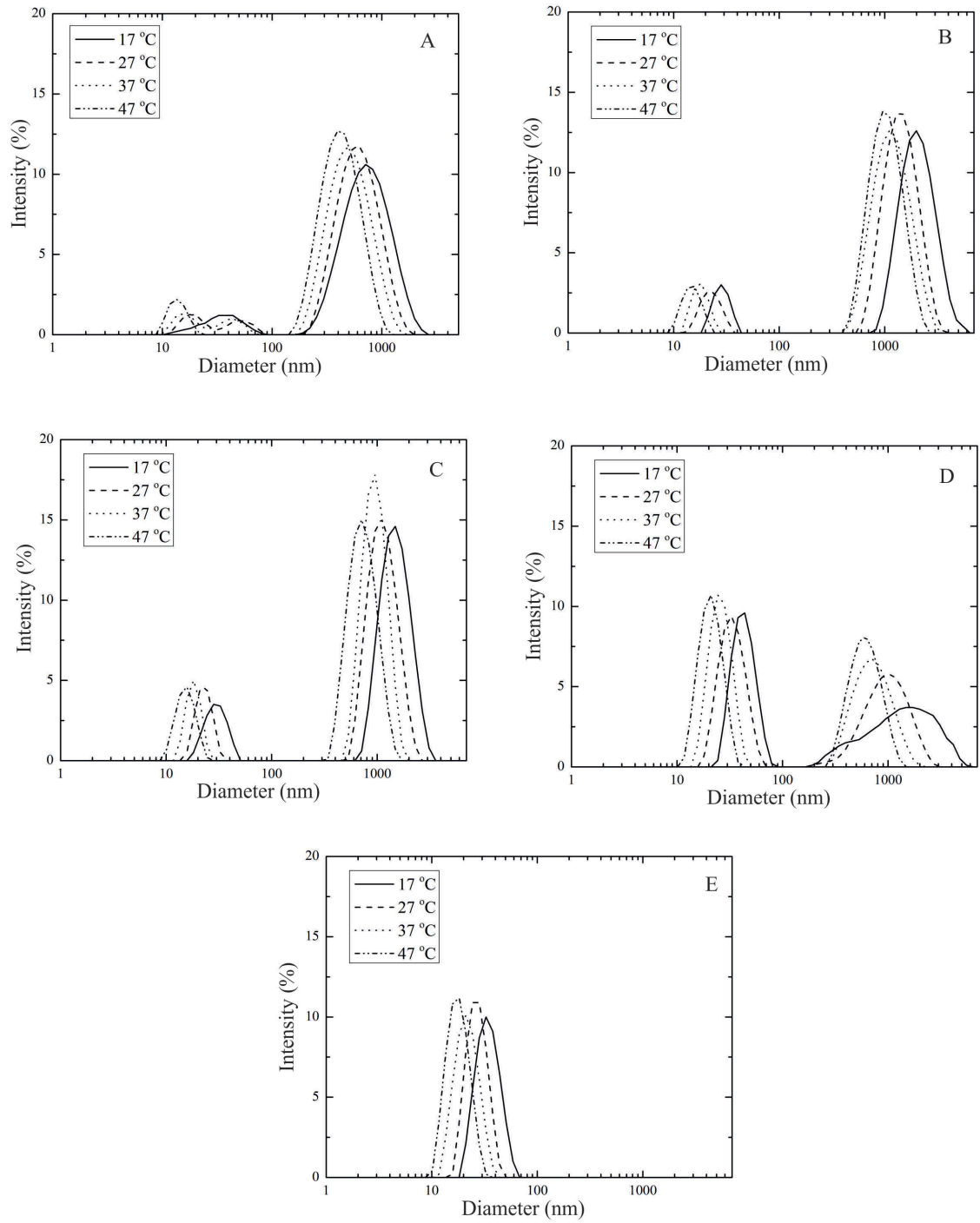

Figure 3. Temperature dependent DLS intensity plots of $0.3 \mathrm{wt} \%$ aqueous solutions of 600-HPEI-2.8-(PLLA$\mathrm{mPEG}_{2}(\mathrm{~A}), 1200$-HPEI-5.5-(PLLA-mPEG) ${ }_{2}$ (B), 1800-HPEI-8.2-(PLLA-mPEG) ${ }_{2}$ (C), 5000-HPEI-19.5-(PLLA$\mathrm{mPEG})_{2}(\mathrm{D})$ and 10000-HPEI-40.3-(PLLAmPEG) $)_{2}$ (E) copolymers (PBS, pH 7.4). 
It was observed that at relatively high concentrations ( $>25$ wt \%, PBS, pH 7.4) at room temperature the 1200-HPEI-5.5-(PLLA-mPEG) $)_{2}$ and 1800-HPEI-8.2-(PLLA-mPEG) hyperbranched copolymers formed hydrogels at low temperatures, whereas all other copolymers were soluble and did form viscous solutions. The thermo-reversible gel to sol behavior of $27.5 \mathrm{wt} \%$ hydrogels of 1200-HPEI-5.5-(PLLA-mPEG) and 1800-HPEI-8.2(PLLA-mPEG) ${ }_{2}$ were studied by the vial tilting method. Samples were heated stepwise from 4 to $76{ }^{\circ} \mathrm{C}$ and subsequent cooling to $4{ }^{\circ} \mathrm{C}$ (Figure 4). It was seen that the 1800-HPEI-8.2(PLLA-mPEG) $)_{2}$ copolymer gel upon heating turned into a sol at $68{ }^{\circ} \mathrm{C}$ and upon cooling returned to a gel at $64{ }^{\circ} \mathrm{C}$. For the 1200-HPEI-5.5-(PLLA-mPEG) $2(27.5 \mathrm{wt} \%)$ the gel-sol transition was found at $62{ }^{\circ} \mathrm{C}$, and the sol-gel transition at $60{ }^{\circ} \mathrm{C}$.
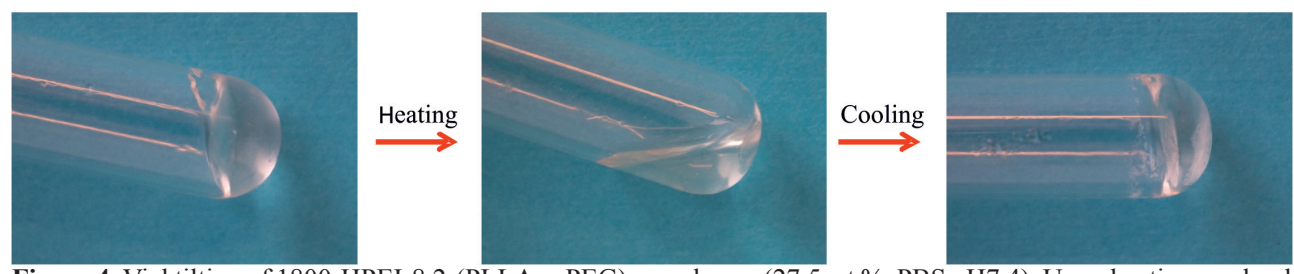

Figure 4. Vial tilting of 1800-HPEI-8.2-(PLLA-mPEG) ${ }_{2}$ copolymer (27.5 wt \%, PBS pH7.4). Upon heating a gel-sol transition takes place at $68{ }^{\circ} \mathrm{C}$ and upon cooling a sol-gel transition takes place at $64{ }^{\circ} \mathrm{C}$.

The temperature dependent changes in storage and loss moduli of the copolymers were determined by oscillatory rheology measurements. The storage ( $\left.G^{\prime}\right)$ and loss $\left(G^{\prime \prime}\right)$ moduli of copolymer solutions with concentrations of $27.5 \mathrm{wt} \%$ were monitored upon heating the system from 25 to $75{ }^{\circ} \mathrm{C}$ and subsequent cooling to $25{ }^{\circ} \mathrm{C}$ (Figure 5). Applying multiple temperature cycles allowed to determine if the systems were in equilibrium. Upon preparing a $27.5 \mathrm{wt} \%$ copolymer solution and cooling to $4{ }^{\circ} \mathrm{C}$ the 600 -HPEI-2.8-(PLLA-mPEG) ${ }_{2}$ formed a viscous hydrogel. During several heating and cooling cycles a gradually decreasing sol to gel transition temperature was observed and eventually no sol to gel transition took place anymore. This behavior is similar to that of four armed copolymers composed of PLLAmPEG arms and a centrally located spermine goup, thus containing two secondary amine groups ${ }^{25}$. 

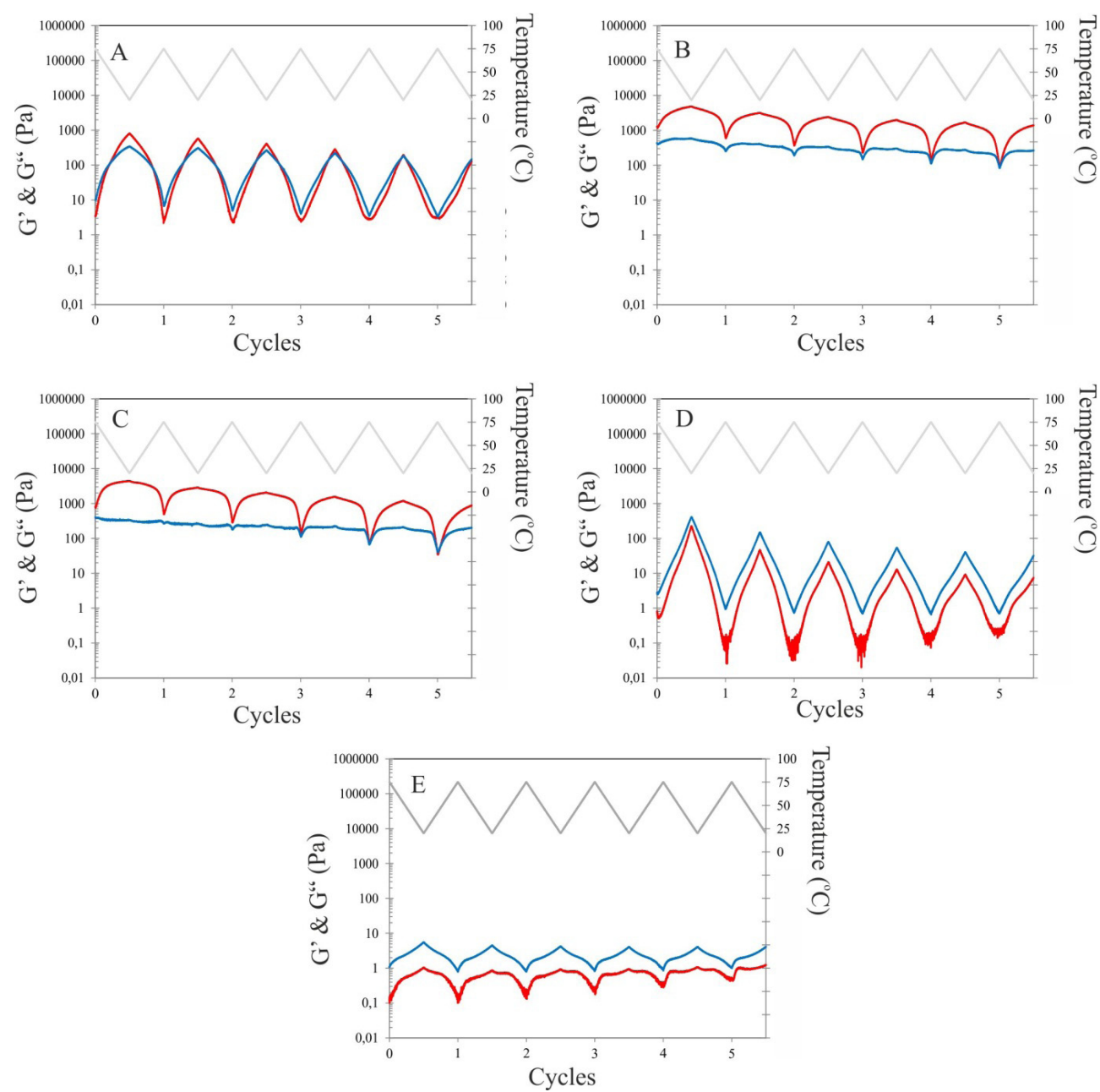

Figure 5. Temperature dependent storage (G', - $)$ and loss (G", - $)$ moduli and profile of 600-HPEI-2.8(PLLA-mPEG) $_{2}$ (A), 1200-HPEI-5.5-(PLLA-mPEG) $)_{2}$ (B), 1800-HPEI-8.2-(PLLA-mPEG) ${ }_{2}$ (C), 5000-HPEI-19.5(PLLA-mPEG) $_{2}$ (D) and 10000-HPEI-40.3-(PLLA-mPEG) $)_{2}$ (E) copolymers (27.5 wt \%), upon repeated heating from 25 to $75{ }^{\circ} \mathrm{C}$ and cooling from 75 to $25^{\circ} \mathrm{C}\left(\longrightarrow\right.$ ) with $1{ }^{\circ} \mathrm{C} / \mathrm{min}$ (PBS, pH7.4).

Hyperbranched copolymers prepared from HPEI with molecular weights of 1200 and 1800 (1200-HPEI-5.5-(PLLA-mPEG) $_{2}$ and 1800-HPEI-8.2-(PLLA-mPEG) $)_{2}$ afford thermoreversible hydrogels. As indicated by the relatively low CAC values and the results of the DLS experiments (Figure 2) formation of larger aggregates can take place, most probably affording physically crosslinked gels by PEG entanglements like commonly seen for ABA type PEG-PLLA-PEG block copolymers.

In contrast, the high molecular weight copolymers 5000-HPEI-19.5-(PLLA-mPEG) ${ }_{2}$ and 
10000-HPEI-40.3-(PLLA-mPEG) ${ }_{2}$ form solutions even at high concentrations up to $40 \mathrm{wt}$ $\%$. This indicates that the PEG chains in 5000-HPEI-19.5-(PLLA-mPEG) ${ }_{2}$ and 10000-HPEI40.3-(PLLA-mPEG) ${ }_{2}$ copolymers do not form entanglements. To gain a better insight in the differences in aggregation behavior between gel forming and non-gel forming copolymers high resolution ${ }^{1} \mathrm{H}-\mathrm{NMR}$ data of $27.5 \mathrm{wt} \%$ samples of 1800-HPEI-8.2-(PLLA-mPEG) and 10000-HPEI-40.3-(PLLA-mPEG) ${ }_{2}$ at different temperatures were obtained by HR-MAS (Figure 6). At room temperature 1800-HPEI-8.2-(PLLA-mPEG) $)_{2}$ is in the gel state while 10000-HPEI-40.3-(PLLA-mPEG) $)_{2}$ is in the sol state. By heating the copolymers from $25^{\circ} \mathrm{C}$ to $53{ }^{\circ} \mathrm{C}$ and recording spectra with intervals of $4{ }^{\circ} \mathrm{C}$, changes in the mobility of the PLLA, PEG and HPEI protons can be determined (Figure 6). At $25^{\circ} \mathrm{C}$ in both spectra the $\mathrm{CH}$ protons of the PLLA blocks are observed at 5.00-5.30 ppm and the $\mathrm{CH}_{3}$ protons at 1.44- $1.60 \mathrm{ppm}$. The HPEI and mPEG signals are found at 2.60-2.80 ppm and 3.50-3.90 ppm, respectively. Previously it was shown that the chemical shift of the methyl protons in star shaped $\mathrm{PEG}_{65}{ }^{-}$ $\left(\mathrm{PLA}_{13}\right)_{8}$ block copolymers can be ascribed to PLA chains dangling in water $\left(\delta \mathrm{CH}_{3}=1.58\right.$; $1.48)$ and mobile PLA chains in hydrophobic aggregates $\left(\delta \mathrm{CH}_{3}=1.54\right) .{ }^{29}$ Comparing the 1800-HPEI-8.2-(PLLA-mPEG) ${ }_{2}$ and 10000-HPEI-40.3-(PLLA-mPEG) ${ }_{2}$ HR-MAS ${ }^{1} \mathrm{H}-\mathrm{NMR}$ spectra shows a much higher mobility of the PLLA domains in the latter case. By increasing the temperature from 25 to $53{ }^{\circ} \mathrm{C}$ a progressive growth of the methyl signal at $1.54 \mathrm{ppm}$ and the methine peak at $5.20 \mathrm{ppm}$ is observed for 1800-HPEI-8.2-(PLLA-mPEG), although the signals remain broad. Furthermore, the signals of the methylene protons of the HPEI at $2.70 \mathrm{ppm}$ showed an increase in intensity and became narrower. By HR-MAS it is thus shown that the 1800-HPEI-8.2-(PLLA-mPEG) forms immobile hydrophobic domains at 25 ${ }^{\circ} \mathrm{C}$ and these immobile regions result in a relatively immobile HPEI. Upon a temperature increase the hydrophobic domains become more mobile and this also results in an increased mobility of HPEI. The HR-MAS spectra of 10000-HPEI-40.3-(PLLA-mPEG) 2 show a much higher mobility of the HPEI and PLLA blocks compared to 1800-HPEI-8.2-(PLLA-mPEG). Extrapolation of the results from DLS measurements, which revealed that the aggregate size did not depend on the concentration in the range measured, to the much higher concentrations as used in these measurements are only indicative. However the much higher mobility of the PLLA and PEI blocks indicates that the formation of hydrophobic domains is hindered. This also may prohibit the formation of PEG entanglements by formation of larger aggregates necessary for gelation. 

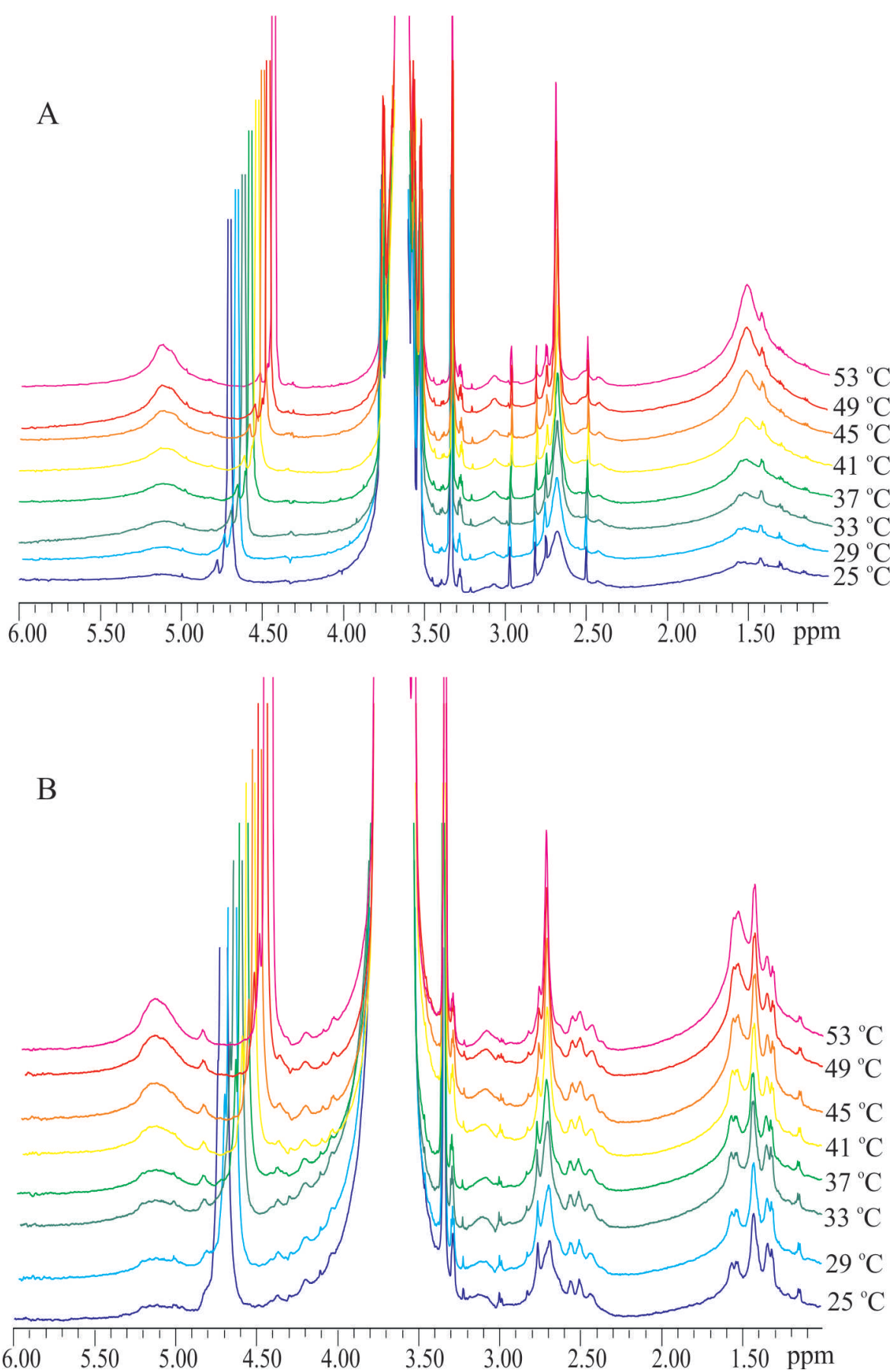

Figure 6. HR-MAS ${ }^{1} \mathrm{H}$-NMR spectrum of 1800-HPEI-8.2-(PLLA-mPEG) ${ }_{2}$ (A) and 10000-HPEI-40.3-(PLLA$\mathrm{mPEG})_{2}(\mathrm{~B})$ at various temperatures $(27.5 \mathrm{wt} \%)$. Solvent $\mathrm{D}_{2} \mathrm{O}$. 
Based on these studies a schematic model of the aggregation and thermo-reversible gelation behavior of the $\alpha$-HPEI- $\gamma$-(PLLA-mPEG) $)_{2}$ copolymers was made. At equilibrium the copolymer 600-HPEI-3-(PLLA-mPEG) forms aggregates in PBS at $\mathrm{pH}$ of 7.4 possibly also at high concentrations. Upon a decrease in temperature, the PEG chains become more hydrophilic but the presence of the charged amine groups induce a repulsive force that hampers entanglement of the PEG chains, resulting in a system that remains in the 'sol' state even at low temperatures. It cannot be excluded that the PEG blocks do form inclusion complexes with the protonated secondary amines and thereby stabilize the aggregates, preventing PEG entanglements to be formed ${ }^{30,31}$. In this respect this hyperbranched copolymer behaves similar as the 4 armed block copolymer with a central spermine group ${ }^{25}$.

The 1200-HPEI-5.5-(PLLA-mPEG) ${ }_{2}$ and 1800-HPEI-8.2-(PLLA-mPEG) $)_{2}$ copolymers form stable hydrogels. These hydrogels are formed due to the formation of well phase separated immobile PLLA domains. At room temperature the micelles form large aggregates due to PEG entanglements and upon a temperature increase the PEG becomes more hydrophobic resulting in collapse of the particles and disruption of entanglements causing a gel to sol transition.

5000-HPEI-19.5-(PLLA-mPEG) ${ }_{2}$ and 10000-HPEI-40.3-(PLLA-mPEG) 2 copolymers form stable particles of approximately $30 \mathrm{~nm}$ and do not aggregate into larger particles. Likely the HPEI core is too hydrophilic and does not allow the formation of immobile phase separated PLLA domains. Although a thermo-responsive behavior of the PEG chains is observed these chains do not entangle and no gelation takes place. This result also illustrates that the formation of immobile PLLA domains provides a basis for placing the PEG chains to the outer shell and thereby influencing the formation of larger aggregates and gelation.

\section{Conclusions}

$\alpha$-HPEI- $\gamma$-(PLLA-mPEG) ${ }_{2}$ copolymers were synthesized by coupling of NHS-(PLLA$\mathrm{mPEG})_{2}$ to primary amine groups of HPEI of $600,1200,1800,5000$ or $10000 \mathrm{~g} / \mathrm{mol}$. The maximum conversion of primary amine groups was $70 \%$ as determined by ${ }^{1} \mathrm{H}-\mathrm{NMR}$ analysis. Vial tilting and oscillatory rheology measurements for 1200-HPEI-5.5-(PLLA-mPEG) 2 and 1800-HPEI-8.2-(PLLA-mPEG) ${ }_{2}$ gave stable hydrogels while 600-HPEI-2.8-(PLLA-mPEG), 5000-HPEI-19.5-(PLLA-mPEG) ${ }_{2}$ and 10000-HPEI-40.3-(PLLA-mPEG) $)_{2}$ form solutions. Dynamic light scattering (DLS), $\xi$-potential and high resolution magic angle spinning (HRMAS) ${ }^{1} \mathrm{H}-\mathrm{NMR}$ measurements were used to study the aggregation mechanism. All $\alpha$-HPEI$\gamma$-(PLLA-mPEG) ${ }_{2}$ copolymers have a $\xi$-potential of $0 \mathrm{mV}$ suggesting that the HPEI moiety in $\alpha$-HPEI- $\gamma$-(PLLA-mPEG) $)_{2}$ copolymers is shielded by PLLA and/or PEG blocks. DLS 
volume plots showed that only 1200-HPEI-5.5-(PLLA-mPEG) ${ }_{2}$ and 1800-HPEI-8.2-(PLLA$\mathrm{mPEG})_{2}$ copolymers show a bimodal distribution with large aggregates present. HR-MAS ${ }^{1} \mathrm{H}-\mathrm{NMR}$ showed that at $25^{\circ} \mathrm{C}$ PLLA groups of 1800-HPEI-8.2-(PLLA-mPEG) 2 are largely immobile revealing the formation of hydrophobic domains. Contrary, for the 10000-HPEI40.3-(PLLA-mPEG) $)_{2}$ it is observed that much less hydrophobic domains are present. In the whole temperature range measured this copolymer remains in solution. Based on these results it can be concluded that depending on the molecular weight of the central HPEI moiety the formation of distinct hydrophobic domains will largely determine the formation of larger aggregates and thereby also entangling of PEG chains necessary for the formation of a physically crosslinked gel.

\section{References}

1. Drury, J. L.; Mooney, D. J., Hydrogels for tissue engineering: scaffold design variables and applications. Biomaterials 2003, 24, (24), 4337-4351.

2. Hennink, W. E.; van Nostrum, C. F., Novel crosslinking methods to design hydrogels. Advanced Drug Delivery Reviews 2002, 54, (1), 13-36.

3. Gong, C. Y.; Shi, S. A.; Dong, P. W.; Kan, B.; Gou, M. L.; Wang, X. H.; Li, X. Y.; Luo, F.; Zhao, X.; Wei, Y. Q.; Qian, Z. Y., Synthesis and characterization of PEG-PCL-PEG thermosensitive hydrogel. International Journal of Pharmaceutics 2009, 365, (1-2), 89-99.

4. Park, S. Y.; Han, B. R.; Na, K. M.; Han, D. K.; Kim, S. C., Micellization and gelation of aqueous solutions of star-shaped PLLA-PEO block copolymers. Macromolecules 2003, 36, (11), 4115-4124.

5. Jeong, B.; Bae, Y. H.; Lee, D. S.; Kim, S. W., Biodegradable block copolymers as injectable drug-delivery systems. Nature 1997, 388, (6645), 860-862.

6. Jeong, B.; Kibbey, M. R.; Birnbaum, J. C.; Won, Y. Y.; Gutowska, A., Thermogelling biodegradable polymers with hydrophilic backbones: PEG-g-PLGA. Macromolecules 2000, 33, (22), 8317-8322.

7. Gitsov, I.; Zhu, C., Amphiphilic hydrogels constructed by poly(ethylene glycol) and shape-persistent dendritic fragments. Macromolecules 2002, 35, (22), 8418-8427.

8. Hiemstra, C.; Zhong, Z. Y.; Li, L. B.; Dijkstra, P. J.; Feijen, J., In-situ formation of biodegradable hydrogels by stereocomplexation of PEG-(PLLA)(8) and PEG-(PDLA)(8) star block copolymers. Biomacromolecules 2006, 7, (10), 2790-2795.

9. Velthoen, I. W.; Tijsma, E. J.; Dijkstra, P. J.; Feijen, J., Thermo-Responsive Hydrogels Based on Branched Poly(L-lactide)-poly(ethylene glycol) Copolymers. Macromolecular Symposia 2008, 272, 13-27.

10. Paleos, C. M.; Tsiourvas, D.; Sideratou, Z.; Tziveleka, L. A., Drug delivery using multifunctional dendrimers and hyperbranched polymers. Expert Opinion on Drug Delivery 7, (12), 1387-1398.

11. Zhou, Y.; Huang, W.; Liu, J.; Zhu, X.; Yan, D., Self-assembly of hyperbranched polymers and its biomedical applications. Advanced Materials 22, (41), 4567-4590.

12. Lapienis, G., Star-shaped polymers having PEO arms. Progress in Polymer Science 2009, 34, (9), 852-892.

13. Khanna, K.; Varshney, S.; Kakkar, A., Miktoarm star polymers: advances in 
synthesis, self-assembly, and applications. Polymer Chemistry 2010, 1, (8), 1171-1185. 14. Iatridi, Z.; Tsitsilianis, C., Water-Soluble Stimuli Responsive Star-Shaped Segmented Macromolecules. Polymers 2011, 3, (4), 1911-1933.

15. Lee, S. J.; Han, B. R.; Park, S. Y.; Han, D. K.; Kim, S. C., Sol-gel transition behavior of biodegradable three-arm and four-arm star-shaped PLGA-PEG block copolymer aqueous solution. Journal of Polymer Science Part a-Polymer Chemistry 2006, 44, (2), 888-899.

16. MalmstrÃ $\llbracket m$, E.; Johansson, M.; Hult, A., A review of hyperbranched polyesters. Polymer News 1997, 22, (4), 128-133.

17. Jansen, J.; Debrabandervandenberg, E. M. M.; Meijer, E. W., Encapsulation of guest molecules into a dendritic box. Science 1994, 266, (5188), 1226-1229.

18. Vanhest, J. C. M.; Delnoye, D. A. P.; Baars, M.; Vangenderen, M. H. P.; Meijer, E. W., Polystyrene-dendrimer amphiphilic block-copolymers with a generation-dependent aggregation. Science 1995, 268, (5217), 1592-1595.

19. Liu, Y. X.; Chan-Park, M. B., Hydrogel based on interpenetrating polymer networks of dextran and gelatin for vascular tissue engineering. Biomaterials 2009, 30, (2), 196-207.

20. Shuai, X. T.; Merdan, T.; Unger, F.; Wittmar, M.; Kissel, T., Novel biodegradable ternary copolymers hy-PEI-g-PCL-b-PEG: Synthesis, characterization, and potential as efficient nonviral gene delivery vectors. Macromolecules 2003, 36, (15), 5751-5759.

21. Liu, Y.; Steele, T.; Kissel, T., Degradation of Hyper-Branched Poly(ethylenimine)graft-poly(caprolactone)-block-monomethoxyl-poly(ethy lene glycol) as a Potential Gene Delivery Vector. Macromolecular Rapid Communications 2010, 31, (17), 1509-1515.

22. Liu, Y.; Samsonova, O.; Sproat, B.; Merkel, O.; Kissel, T., Biophysical characterization of hyper-branched polyethylenimine-graft-polycaprolactone-block-monomethoxyl-poly(ethylen e glycol) copolymers (hy-PEI-PCL-mPEG) for siRNA delivery. Journal of Controlled Release 2011, 153, (3), 262-268.

23. Radowski, M. R.; Shukla, A.; von Berlepsch, H.; Bottcher, C.; Pickaert, G.; Rehage, H.; Haag, R., Supramolecular aggregates of dendritic multishell architectures as universal nanocarriers. Angewandte Chemie-International Edition 2007, 46, (8), 1265 1269.

24. Kuchler, S.; Abdel-Mottaleb, M.; Lamprecht, A.; Radowski, M. R.; Haag, R.; Schafer-Korting, M., Influence of nanocarrier type and size on skin delivery of hydrophilic agents. International Journal of Pharmaceutics 2009, 377, (1-2), 169-172.

25. Wennink, J.W.H.; Signori, F.; Grote, A.S.; Karperien, M.; Feijen, J.; Dijkstra, P. J., Aggregation behavior of thermoresponsive and $\mathrm{pH}$-sensitive star-shaped PLLA-PEG hydrogels. 2012, (Chapter 3 of this thesis).

26. Damink, L.; Dijkstra, P. J.; Vanluyn, M. J. A.; Vanwachem, P. B.; Nieuwenhuis, P.; Feijen, J., Glutaraldehyde as a cross-linking agent for collagen-based biomaterials. Journal of Materials Science-Materials in Medicine 1995, 6, (8), 460-472.

27. Halter, D.; Burgath, A.; Frey, H., Degree of branching in hyperbranched polymers. Acta Polymerica 1997, 48, (1-2), 30-35.

28. Dick, C. R.; Ham, G. E., Characterization of polyethylenimine. 1970, 29, (2), 190201.

29. Calucci, L.; Forte, C.; Buwalda, S. J.; Dijkstra, P. J.; Feijen, J., Self-Aggregation of Gel Forming PEG-PLA Star Block Copolymers in Water. Langmuir 2010, 26, (15), 12890 - 
12896.

30. Williamson, B. L.; Creaser, C. S., Noncovalent inclusion complexes of protonated amines with crown ethers. International Journal of Mass Spectrometry 1999, 188, (1-2), 53-61.

31. Krupers, M. J.; VanderGaag, F. J.; Feijen, J., Complexation of poly(ethylene oxide) with poly(acrylic acid-co-hydroxyethyl methacrylate)s. European Polymer Journal 1996, 32, (6), 785-790. 


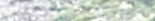

the

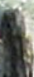

(19)

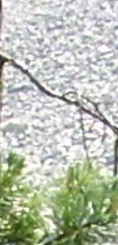

10.
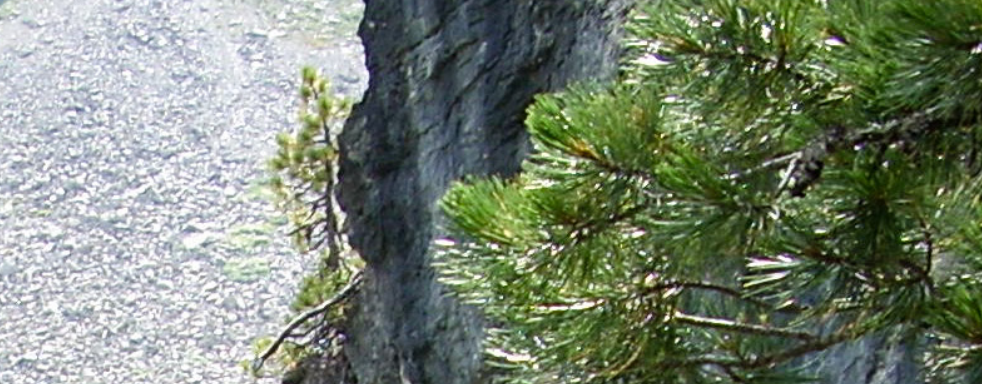

\section{.} C.8.

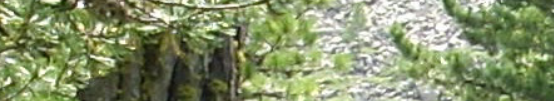
,

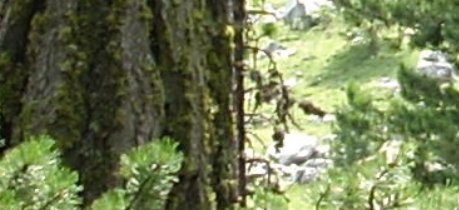

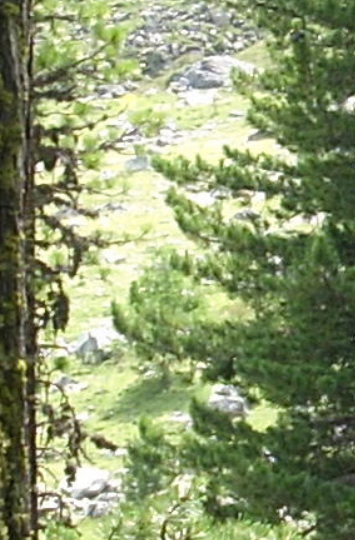

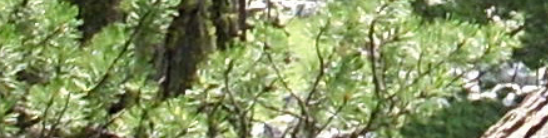

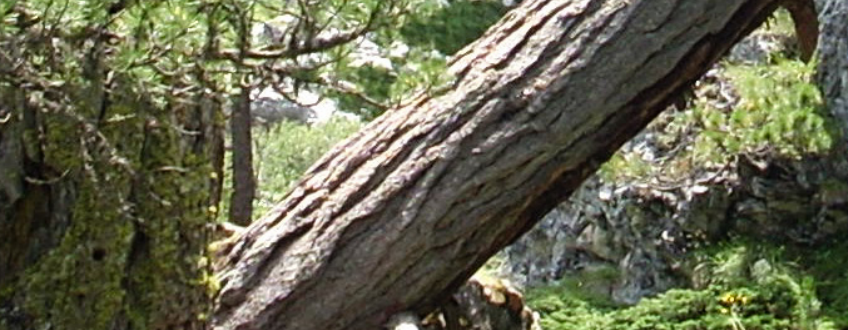

ran $2=2$

3x:

(t) 12

11.

1)

$1)^{3}$

(1)

4

4. 1,1

exts

$x^{2}=$

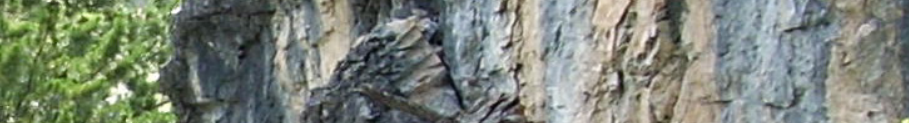

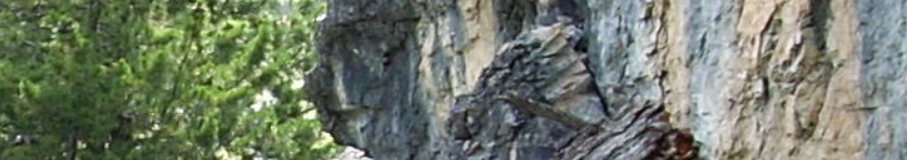

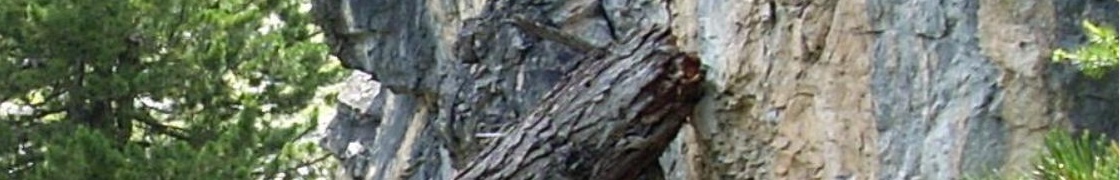

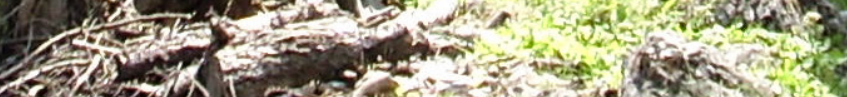

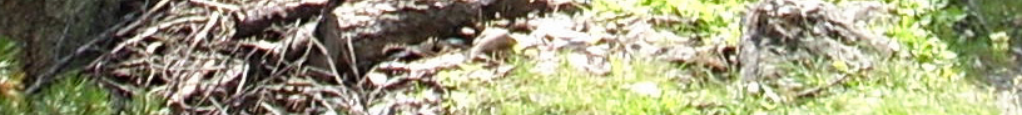

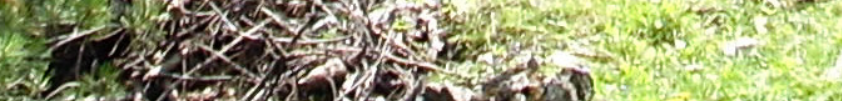

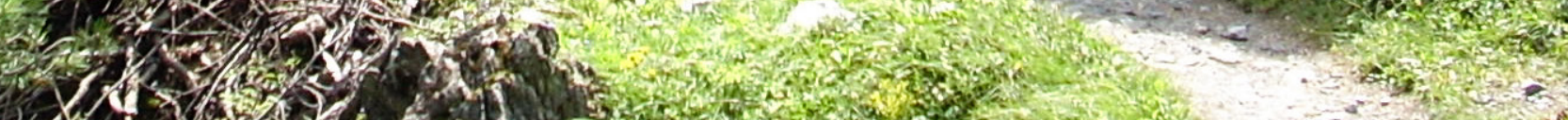

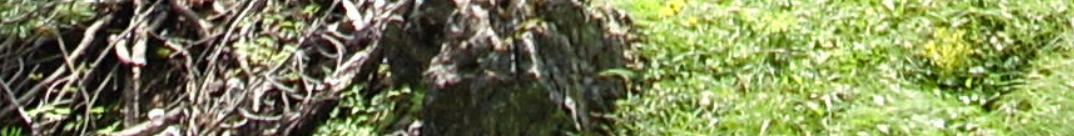

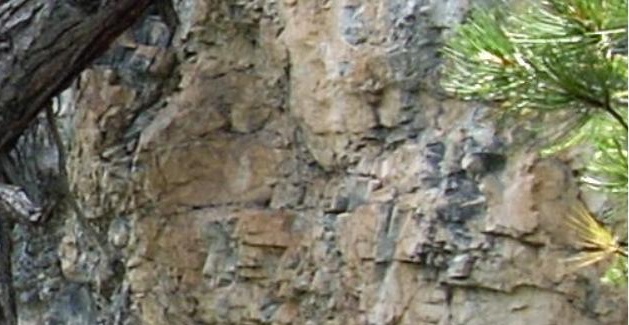




\section{Chapter 6 PLLA block length dependent aggregation behavior and enzymatic crosslinking of star-shaped PEG-(PLLA-Tyramine $)_{8}$ copolymers}

Jos W.H. Wennink, Agnieszka I. Bochyńska, Marcel Karperien, ${ }^{\dagger}$ Jan Feijen and Pieter J. Dijkstra 


\begin{abstract}
Eight-armed poly(ethylene glycol)-poly(L-lactide)-tyramine (PEG-(PLLA-TA) $)_{8}$ ) star block copolymers with different PLLA block length were synthesized. It was found that the introduction of tyramine end functional groups influenced the aggregation behavior of the PEG-PLLA star block copolymers in an aqueous environment. Compared to PEG-(PLLA) 8 copolymers PEG-(PLLA-TA) 8 copolymers with a similar PLLA block length had a lower critical association concentration value and formed physically crosslinked hydrogels with a thermo-reversible gel to sol phase transition at lower concentrations.

Enzymatic crosslinking of the PEG-(PLLA-TA) ${ }_{8}$ star block copolymers with HRP and $\mathrm{H}_{2} \mathrm{O}_{2}$ was only possible when the tyramine units were exposed to the aqueous phase. Due to this prerequisite the upper limit of the DP of the PLLA blocks for efficient crosslinking was 4 . At higher DP values the tyramine groups are embedded in the hydrophobic core of aggregates and show no reaction in the presence of the enzyme. At a DP of 4 of the PLLA blocks both 5 and $10 \mathrm{wt} \%$ solutions of the copolymers could be crosslinked with the formation of viscous hydrogels. Lowering the DP of the PLLA blocks to 3, only afforded hydrogels upon reaction with $\mathrm{HRP}$ and $\mathrm{H}_{2} \mathrm{O}_{2}$ at relatively high polymer concentrations of 15 and $20 \mathrm{wt} \%$. These elastic hydrogels had storage moduli of 3-4 $\mathrm{kPa}$. At lower concentrations no gels were formed but crosslinking within nanoparticles took place. The chemically crosslinked hydrogels were hydrolytically degraded at pH 7.4 in 1-2 weeks depending on the concentration of the precursor polymer solution and PLLA block length. The possibility to prepare either nanoparticles or hydrogels from PEG-(PLLA-TA) ${ }_{8}$ star block copolymers by tuning their composition and concentration before crosslinking makes them interesting for biomedical applications such as matrices for tissue engineering and controlled drug delivery systems.
\end{abstract}




\section{Introduction}

Various types of hydrogels have been investigated in the past decade as injectable scaffolds for a variety of biomedical applications ${ }^{1-3}$. Injectable, biodegradable hydrogels can be used as delivery systems ${ }^{4}$, cell carriers and scaffolds for tissue engineering ${ }^{5,6}$. Major advantages of injectable hydrogels are that they can be administered by a minimally invasive procedure, that they can fill any defect size or shape and that therapeutic agents like drugs, genes, peptides, proteins and cells can be easily encapsulated in the precursor solutions ${ }^{2,7,8}$. In the past decades, many methods have been employed for the preparation of in situ forming hydrogels. These hydrogel systems can be divided into physically crosslinked systems, such as those based on charge attractions ${ }^{9}$, hydrophobic interactions ${ }^{10,11}$ and stereo-complexation ${ }^{12,13}$, and chemically crosslinked systems using e.g. Michael-type addition reactions ${ }^{14}$ and photopolymerization ${ }^{15,16}$. Although, physically crosslinked hydrogels have several distinct advantages, such as hydrogel formation under mild conditions, they have limitations such as low stability towards degradation or dissolution and low mechanical stability. Chemically crosslinked hydrogels have several advantages including good mechanical properties and hydrogel stability towards degradation. However, toxic reagents, such as photoinitiators, are often required for hydrogel formation.

Recently, an enzyme-mediated crosslinking reaction of tyramine conjugates using horseradish peroxidase (HRP) and hydrogen peroxide $\left(\mathrm{H}_{2} \mathrm{O}_{2}\right)$ has been shown to provide an alternative method for the in situ formation of the hydrogels ${ }^{17,18}$. The HRP mediated crosslinking reaction has several advantages including tunable reaction rates, mild crosslinking conditions and good cytocompatibility. Several studies have been directed to the use of this enzymatic crosslinking reaction in the preparation of in situ forming hydrogels composed of dextran ${ }^{17}$, hyaluronic acid ${ }^{6,18}$, alginate ${ }^{19}$, cellulose ${ }^{20}$, gelatin ${ }^{21}$ and heparin ${ }^{22,23}$. The precursor solutions are easy to handle and homogenous loading with cells or bioactive molecules appears well possible because of the low viscosity of the precursor solutions. Many of these materials showed to be adequate biomaterials for use in tissue engineering because of their tissue like properties, biocompatibility, high water content and excellent permeability for nutrients and metabolites.

In recent years the group of Park published several papers on ABA type copolymers endfunctionalized with tyramine groups, where A is a hydrophilic PEG block and B a hydrophobic PPO block 24-27. These synthetic copolymers showed good mechanical properties and cytocompatibility but the degradation of the hydrogel was relatively fast.

In this study we report on the aggregation and gelation behavior of BAB type 8 arm star shaped 
PEG-PLLA copolymers end-functionalized with tyramine groups. It was demonstrated that upon varying the lactide block length the differences in availability of the tyramine end group's result in either formation of hydrogels or absence of crosslinking with HRP and $\mathrm{H}_{2} \mathrm{O}_{2}$. Depending on the concentration of the polymer solution and the lactide block length of the star polymer, crosslinking can also lead to the formation of well-defined nanoparticles, which makes these systems very versatile for biomedical applications.

\section{Materials and methods}

\section{Materials}

L-lactide (L-LA) was purchased from Purac (Gorinchem, the Netherlands). Tin (II) 2-ethylhexanoate $\left(\mathrm{Sn}(\mathrm{Oct})_{2}\right)$, deuterated chloroform $\left(\mathrm{CDCl}_{3}\right)$, 1,6-diphenyl-1,3,5-hexatriene (DPH), tyramine and p-nitrophenyl chloroformate (PNC), anhydrous dimethylformamide (DMF), pyridine (anhydrous), hydrogen peroxide $\left(\mathrm{H}_{2} \mathrm{O}_{2}\right)$ and horseradish peroxidase (HRP, 311 purpurogallin unit/mg solid) were obtained from Sigma-Aldrich (Zwijndrecht, the Netherlands). 8-Armed poly(ethylene glycol) with a $\mathrm{M}_{\mathrm{w}}$ of $20000 \mathrm{~g} / \mathrm{mol}$ was purchased from Jenkem (Allen, TX, USA). Dimethyl sulfoxide- $\mathrm{d}_{6}\left(\mathrm{DMSO}_{6} \mathrm{~d}_{6}\right)$ was obtained from Merck (Darmstadt, Germany). All other solvents were from Biosolve (Valkenswaard, the Netherlands).

\section{Synthesis}

PEG-(PLLA $\left.)_{n}\right)_{8}$ : A typical procedure for the synthesis of a PEG-(PLLA) $)_{8}$ star block copolymer with a degree of polymerization of the PLLA arms of 5.0 was as follows. To a solution of $(\mathrm{PEG}-\mathrm{OH})_{8}(5.00 \mathrm{~g}, 0.2 \mathrm{mmol})$ in $22 \mathrm{~mL}$ of dry toluene, L-lactide $(1.15 \mathrm{~g}, 8.0 \mathrm{mmol})$ and stannous octoate ( 1 drop) were added. The reaction was allowed to proceed overnight at 110 ${ }^{\circ} \mathrm{C}$ in a nitrogen atmosphere. The product was purified by precipitation in a 20 -fold excess of a mixture of cold diethyl ether and methanol $(20 / 1 \mathrm{v} / \mathrm{v})$. The PEG-(PLLA $\left.{ }_{5.0}\right)_{8}$ was filtered and dried overnight in vacuo at room temperature to give a white powder (yield: $96 \%$ ). ${ }^{1} \mathrm{H}$ $\operatorname{NMR}\left(\mathrm{CDCl}_{3}\right): \delta=5.15\left(\mathrm{~m}, \mathrm{CHCH}_{3}\right), 4.35\left(\mathrm{~m}, \mathrm{CH}_{3} \mathrm{CHOH}, \mathrm{CH}_{2} \mathrm{CH}_{2} \mathrm{OCOCH}\right), 3.64$ (m, PEG protons), 2.68 (s, $\left.\mathrm{CH}_{3} \mathrm{CHOH}\right) 1.57$ (d, $\left.\mathrm{CHCH}_{3}\right), 1.48$ (d, $\left.\mathrm{CH}_{3} \mathrm{CHOH}\right)$.

PEG-(PLLA -PNC): In a typical procedure PEG-(PLLA $\left.{ }_{5.0}\right)_{8}(5.0 \mathrm{~g}, 0.17 \mathrm{mmol})$ was dissolved in DMF in a nitrogen atmosphere. The solution was cooled to $0 \square \mathrm{C}$ and pyridine $(0.12 \mathrm{~g}, 1.5 \mathrm{mmol})$ and subsequently PNC $(0.3 \mathrm{~g}, 1.5 \mathrm{mmol})$ were added to the solution while stirring. After $1 \mathrm{~h}$ the mixture was poured into cold diethyl ether and the product was filtered and carefully washed with a small amount of ethanol and diethyl ether. The resulting product was dried in a vacuum oven and was obtained as a white powder (yield: 95\%). ${ }^{1} \mathrm{H}$ NMR 
$\left(\mathrm{CDCl}_{3}\right): \delta=8.43\left(\mathrm{~d}\right.$, aromatic protons), 7.95 (d, aromatic protons), $5.15\left(\mathrm{~m}, \mathrm{CHCH}_{3}\right), 4.35$ (m, $\mathrm{OCH}_{2} \mathrm{CH}_{2} \mathrm{OC}(\mathrm{O}) \mathrm{CH}$ ), 3.64 (m, PEG protons), 1.57 (d, $\mathrm{CHCH}_{3}$ ).

PEG-(PLLA -TA) : $_{\mathbf{n}}$ PEG-(PLLA ${ }_{5.0}$-PNC) $_{8}(5 \mathrm{~g}, 0.17 \mathrm{mmol})$ was dissolved in $40 \mathrm{~mL}$ of anhydrous DMF. To the resulting solution tyramine $(0.20 \mathrm{~g}, 1.5 \mathrm{mmol})$ was added and the reaction mixture was stirred for $1 \mathrm{~h}$ at room temperature under a nitrogen atmosphere. The mixture was poured into a mixture of cold diethyl ether and methanol $(10 / 1 \mathrm{v} / \mathrm{v})$, filtered and carefully washed with ethanol and diethyl ether. The product was dried in a vacuum oven and obtained as an off white powder (yield: 97\%). ${ }^{1} \mathrm{H}$ NMR $\left(\mathrm{CDCl}_{3}\right): \delta=7.15(\mathrm{~d}$, aromatic protons), $6.80\left(\mathrm{~d}\right.$, aromatic protons), $5.60(\mathrm{~d}, \mathrm{NH}), 5.15\left(\mathrm{~m}, \mathrm{CHCH}_{3}\right), 4.35(\mathrm{~m}$, $\mathrm{CH}_{2} \mathrm{CH}_{2} \mathrm{OCOCH}$ ), 3.64 (m, PEG protons), 3.00 (m, $\mathrm{CH}_{2} \mathrm{CH}_{2}$ ), 2.77 (m, $\mathrm{CH}_{2} \mathrm{CH}_{2}$ ), 1.57 (d, $\left.\mathrm{CHCH}_{3}\right)$.

\section{Characterization}

${ }^{1}$ H-NMR: ${ }^{1} \mathrm{H}(300 \mathrm{MHz})$ NMR spectra were recorded using a Varian Inova NMR spectrometer. Polymers were dissolved in $\mathrm{CDCl}_{3}$ at a concentration of $0.015 \mathrm{~g} / \mathrm{mL}$ or $\mathrm{D}_{2} \mathrm{O}$ at a concentration of $0.25 \mathrm{wt} \%$.

UV-VIS: The critical association concentrations of the copolymers in PBS at $20^{\circ} \mathrm{C}$ were determined by the dye solubilization method. To $1.0 \mathrm{~mL}$ of copolymer solutions with concentrations ranging from 0.0001 to $1 \mathrm{wt} \%, 10 \mu \mathrm{L}$ of a $0.5 \mathrm{mM} \mathrm{DPH}$ solution in methanol was added. The resulting mixture was stored in the dark and equilibrated overnight. UV-Vis absorption spectra of the solutions were recorded in the 300 to $500 \mathrm{~nm}$ range. The difference in the absorption at $377 \mathrm{~nm}$ relative to $400 \mathrm{~nm}$ was plotted against the polymer concentration and the intercept of the extrapolated straight lines was defined as the critical association concentration of the copolymer.

DLS: Dynamic light scattering experiments were performed to measure the diameter of micelles or aggregates on solutions (concentration between 0.015 and $5 \mathrm{wt} \%$, at room temperature) using a Malvern zetasizer 4000 (Malvern Corp., Malvern, UK), using a laser wavelength of $633 \mathrm{~nm}$. The CONTIN method was applied for data processing.

Vial tilting method: The phase behavior of aqueous polymer solutions was investigated by the vial tilting method. Block copolymers were dissolved in PBS (5-30 wt \%) in tightly capped $5 \mathrm{~mL}$ vials by repeatedly heating to $\sim 60{ }^{\circ} \mathrm{C}$ for $2 \mathrm{~min}$ and stirring while cooling. The blockcopolymer solutions were kept at $4{ }^{\circ} \mathrm{C}$ overnight prior to measurement. The temperature was increased step-wise with 2 or $4{ }^{\circ} \mathrm{C}$ and the samples were kept at the measuring temperature for $10 \mathrm{~min}$ to equilibrate. The gel-sol transition temperature was determined by tilting the 
vials $90^{\circ}$ for $1 \mathrm{~min}$. If there was no flow, the sample was regarded as a gel. In other cases it was regarded as a sol.

Enzymatic crosslinking and gelation time: Hydrogel samples of PEG-(PLLA - TA $)_{8}$ at different polymer concentrations (5-20 wt \%) were prepared in vials at room temperature. In a typical procedure, to a polymer solution in PBS $(200 \mu \mathrm{L})$, a freshly prepared solution of $\mathrm{H}_{2} \mathrm{O}_{2}$ in PBS ( $25 \mu \mathrm{L}$ of a $0.3 \mathrm{wt} \%$ stock solution) and HRP in PBS ( $25 \mu \mathrm{L}$ of a $150 \mathrm{units} / \mathrm{mL}$ stock solution) were added and the mixture was gently shaken until gel formation occurred. The time to form a gel was determined using the vial tilting method. No flow within $1 \mathrm{~min}$ upon inverting the vial was regarded as the gel state. The experiment was performed in triplicate.

Gel content and water uptake: To determine the gel content, copolymer samples were weighed $\left(\mathrm{W}_{\mathrm{d}}\right)$. The polymers were dissolved in PBS and crosslinked as described in the previous section to form hydrogels. The samples were incubated in $3 \mathrm{~mL}$ of demi water and the solution was refreshed every day for 3 days to remove salts and uncrosslinked polymer. The samples were dried by lyophilization to a constant weight $\left(\mathrm{W}_{\mathrm{g}}\right)$. The gel content was expressed as $\mathrm{W}_{\mathrm{g}} / \mathrm{W}_{\mathrm{d}} \mathrm{x} 100 \%$.

The water uptake of the hydrogels was determined by first preparing $250 \mu \mathrm{L}$ of hydrogels in PBS as described in the previous section. The dry polymer weight in hydrogels was calculated according to their concentration $\left(\mathrm{W}_{\mathrm{d}}\right)$. The initial weight $\mathrm{W}_{\mathrm{d}}$ was corrected for the gel content and expressed as $\mathrm{W}_{\mathrm{d}}{ }^{*}$. The hydrogels were immersed in $3 \mathrm{~mL}$ of demi water for 3 days to reach swelling equilibrium. The swollen samples were then removed from the water and after removal of surface water, the samples were weighed $\left(\mathrm{W}_{\mathrm{s}}\right)$. The water uptake was calculated from: $\left(\mathrm{W}_{\mathrm{s}}-\mathrm{W}_{\mathrm{d}}^{*}\right) /\left(\mathrm{W}_{\mathrm{d}}^{*}\right) \times 100 \%$. The experiments were performed in triplicate.

Rheology: Rheology experiments were performed with an Anton Paar Physica MCR 301 rheometer with flat plate geometry (20 $\mathrm{mm}$ diameter, $0.3 \mathrm{~mm}$ gap) in oscillating mode. Solutions of the polymers in PBS were prepared by dissolving the appropriate amount of polymer as described above. The solutions were then applied to the rheometer and freshly prepared solutions of $\mathrm{H}_{2} \mathrm{O}_{2}$ in PBS ( $25 \mu \mathrm{L}$ of a $0.3 \mathrm{wt} \%$ stock solution) and HRP in PBS ( $25 \mu \mathrm{L}$ of a 150 units/mL stock solution) were added, the measuring head was lowered to a $0.3 \mathrm{~mm}$ gap size and recording of the G' and G' was started. Water evaporation was prevented by placing a solvent trap over the geometry. The storage modulus G' and the loss modulus G" were monitored for $25 \mathrm{~min}$ to investigate hydrogel formation. The system was considered a gel if the value of G' became larger than G'. A frequency $\omega$ of $1 \mathrm{~Hz}$ and a strain $\gamma$ of $1 \%$ were applied to minimize the influence of deformation on the hydrogels. 
After the measurement, a frequency and amplitude sweep were performed at $\omega$ 0.01-10 $\mathrm{Hz}(\gamma=1 \%)$ and $\gamma 0.01-10 \%(\omega=1 \mathrm{~Hz})$ at $20{ }^{\circ} \mathrm{C}$, respectively to confirm that the applied frequency of $1 \mathrm{~Hz}$ and a strain of $1 \%$ was within the linear viscoelastic range.

Scanning electron microscopy (SEM): The morphology of lyophilized hydrogels was studied using a Zeiss-Merlin scanning electron microscope operating at a voltage of $5 \mathrm{kV}$. The samples were gold sputtered (Carringdon) and analyzed with SEM. The size of enzymatically crosslinked nanoparticles was evaluated by SEM. One drop of nanoparticle dispersion in water was applied to a carbon-coated grid and the water was allowed to evaporate. Images were obtained with a Zeiss-Merlin scanning electron microscope operating at a voltage of $0.5 \mathrm{kV}$.

Degradation: Hydrogel samples $(250 \mu \mathrm{L})$ were prepared in vials according to the procedure described above. The samples were taken out of the vials and weighed $\left(\mathrm{W}_{\mathrm{i}}\right)$. The samples were placed in $3 \mathrm{~mL}$ of PBS at $37^{\circ} \mathrm{C}$. The PBS solution was replaced every day during the first 3 days and then twice a week. At predetermined time intervals samples were taken out and weighed $\left(\mathrm{W}_{\mathrm{s}}\right)$. The remaining gel $(\%)$ was calculated from the original weight after preparation $\left(\mathrm{W}_{\mathrm{i}}\right)$ and remaining gel weight after exposure to the PBS buffer $\left(\mathrm{W}_{\mathrm{s}}\right)$, expressed as $\left(\mathrm{W}_{\mathrm{s}}-\mathrm{W}_{\mathrm{i}}\right) / \mathrm{W}_{\mathrm{i}} \mathrm{x} 100 \%$. The experiments were performed in triplicate.

\section{Results and discussion}

PEG-(PLLA $)_{8}$ star block copolymers were prepared by the stannous octoate catalyzed ring opening polymerization of L-lactide using PEG- $(\mathrm{OH})_{8}$ as an initiator. Polymerizations were carried out in toluene at $110^{\circ} \mathrm{C}$ (Scheme 1). By varying the monomer to initiator ratio the DP of the PLLA blocks was varied from $~ 3-5$. The average PLLA block length was calculated from the ${ }^{1} \mathrm{H}-\mathrm{NMR}$ spectrum using the integrals of peaks corresponding to the methyl protons of the lactyl units and the main chain protons of PEG (Figure 1). The end-hydroxyl groups of the PEG-(PLLA) ${ }_{8}$ copolymers were reacted with p-nitrophenyl chloroformate (PNC) to afford p-nitrophenyl carbonate end-groups. The structure of the PEG-(PLLA-PNC) ${ }_{8}$ copolymers was confirmed by ${ }^{1} \mathrm{H}-\mathrm{NMR}$ by the appearance of signals at $\delta 7.90$ and 8.45 of the aromatic protons and the disappearance of methyl and methine signals of the end-lactyl unit. The conversion of hydroxyl groups was determined from the integral ratio of aromatic protons to the main chain protons of PEG and was almost quantitative. Subsequently, PEG-(PLLAPNC) ${ }_{8}$ was reacted with an excess of tyramine affording the PEG-(PLLA-TA) ${ }_{8}$ star block copolymers. The ${ }^{1} \mathrm{H}-\mathrm{NMR}$ of the product showed the appearance of the tyramine methylene protons at $\delta=2.78$ and 3.00 and the aromatic protons at $\delta=6.80$ and 7.15 (Figure 1). In all cases quantitative conversion was found (Table 1). 
Table 1. Composition and molecular weights of PEG-(PLLA-TA) ${ }_{8}$ block copolymers.

\begin{tabular}{|c|c|c|c|c|c|}
\hline \multirow[b]{2}{*}{ Name } & \multicolumn{2}{|c|}{ DP PLLA } & \multirow{2}{*}{$\begin{array}{r}\mathbf{D S}^{\mathbf{c}} \\
\mathbf{T A}\end{array}$} & \multirow{2}{*}{$\begin{array}{c}M_{n} \\
(\mathrm{~g} / \mathrm{mol})\end{array}$} & \multirow{2}{*}{$\begin{array}{c}\text { PEG } \\
(\text { wt \%) }\end{array}$} \\
\hline & Theory $^{\mathrm{a}}$ & Found $^{\text {b }}$ & & & \\
\hline PEG-(PLLA $\left.{ }_{2.9}-\mathrm{TA}\right)_{8}$ & 3.0 & 2.9 & 99 & 27300 & 83.8 \\
\hline PEG-(PLLA $\left.40_{0}-\mathrm{TA}\right)_{8}$ & 4.0 & 4.0 & 98 & 28560 & 80.1 \\
\hline PEG-(PLLA $\left.{ }_{5.0}-\mathrm{TA}\right)_{8}$ & 5.0 & 5.0 & 99 & 29720 & 77.0 \\
\hline
\end{tabular}

${ }^{a}$ based on the feed composition.

${ }^{\mathrm{b}}$ calculated from ${ }^{1} \mathrm{H}-\mathrm{NMR}$ integral ratios.

${ }^{\mathrm{c}}$ Degree of substitution corresponding to TA groups in percentage per PEG-(PLLA-TA) ${ }_{8}$ as determined with ${ }^{1} \mathrm{H}-\mathrm{NMR}$.<smiles>CCOCC(COCC(COCC(COCCOCCO)OCC)OCC)OCC</smiles>

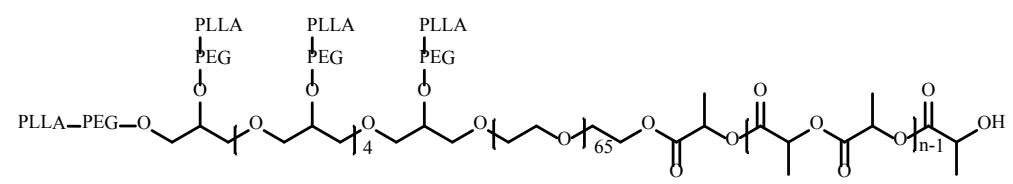<smiles>O=C(Cl)Oc1ccc([N+](=O)[O-])cc1</smiles>

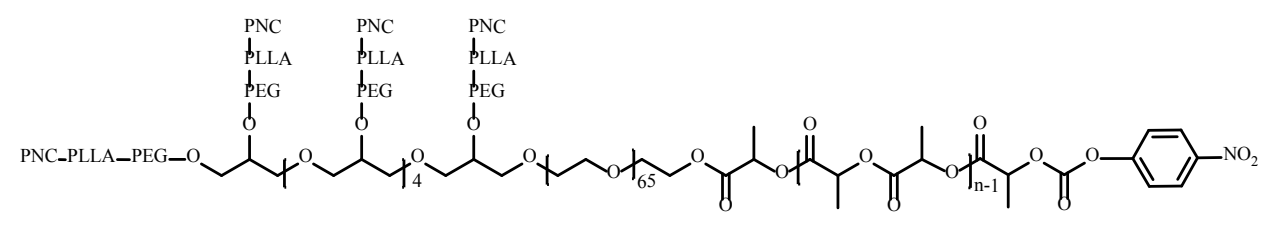

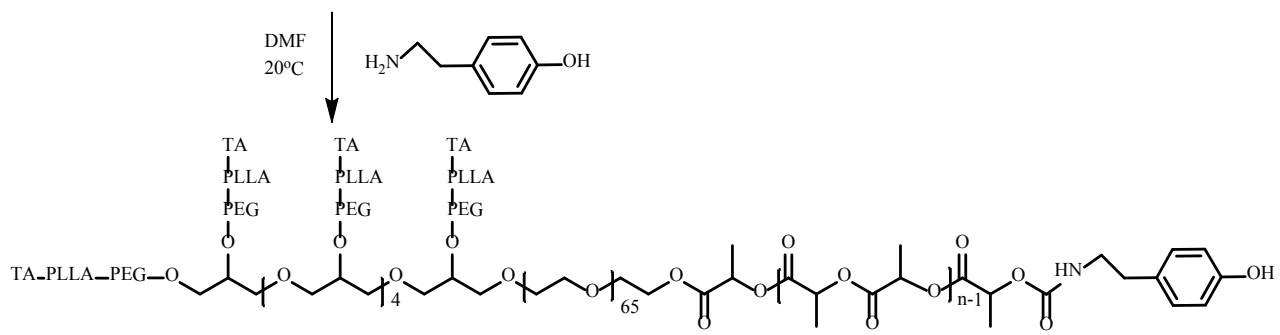

Scheme 1. Schematic synthesis route for the preparation of PEG-(PLLA-TA) 8 star block copolymers. 

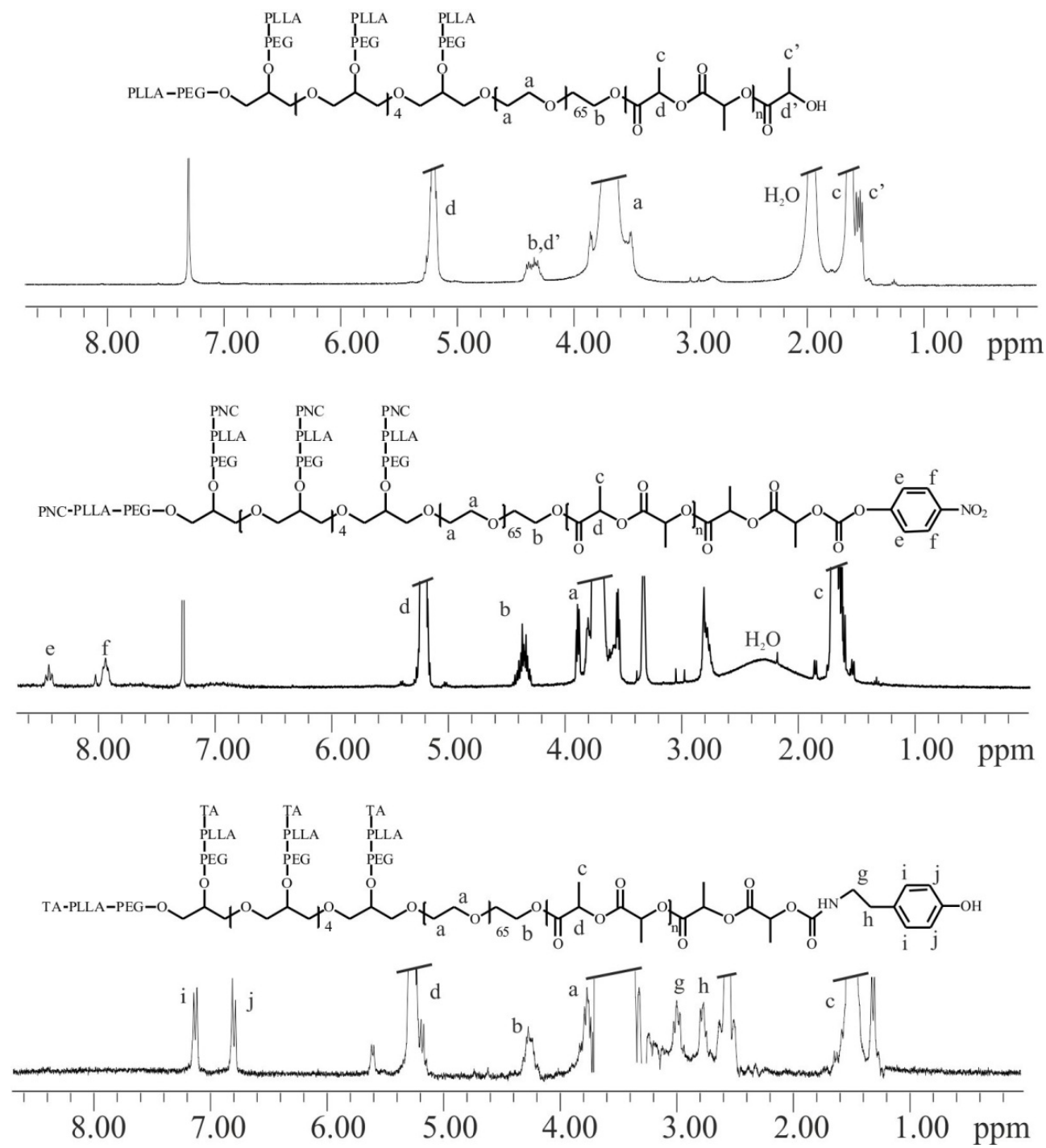

Figure 1. ${ }^{1} \mathrm{H}-\mathrm{NMR}$ spectra of PEG-(PLLA) $)_{8}$, PEG-(PLLA-PNC) ${ }_{8}\left(\mathrm{CDCl}_{3}\right)$ and PEG-(PLLA-TA $)_{8}\left(\right.$ DMSO-d $\left._{6}\right)$.

\section{Self-assembly of PEG-(PLLA-TA $)_{8}$ in PBS}

PEG-PLLA type tri- and star block copolymers are amphiphilic materials which at low concentrations in water assemble into micelles and/or small aggregates depending on the hydrophilic to hydrophobic weight ratio. The critical association concentration (CAC) of these copolymers can be determined with the solubilisation method using a hydrophobic dye like DTH ${ }^{28}$. As expected, the CAC values of the PEG-(PLLA - TA $)_{8}$ copolymers decrease with increasing PLLA block length and are $0.110 \mathrm{wt} \%$ for PEG-(PLLA 2.9 -TA), $0.090 \mathrm{wt}$ 
$\%$ for PEG-(PLLA $\left.{ }_{4.0}-\mathrm{TA}\right)_{8}$ and 0.045 wt \% for PEG-(PLLA $\left.{ }_{5.0}-\mathrm{TA}\right)_{8}$. Furthermore, it was observed that end-group functionalization with hydrophobic tyramine moieties decreases the CAC compared to the hydroxyl end functionalized copolymers. As an example the PEG$\left(\mathrm{PLLA}_{7.0}\right)_{8}$ star block copolymer has a CAC value of $0.21 \mathrm{wt} \%$, substantially higher than the CAC values of PEG-(PLLA - TA $)_{8}$ star block copolymers with shorter PLLA block lengths ${ }^{29}$. At a copolymer concentration of $0.015 \mathrm{wt} \%$, well below the CAC, DLS measurements only show the presence of single polymer molecules (diameter $\leq 10 \mathrm{~nm}$ ). For aqueous eight arm star block copolymer solutions with a concentration of $0.25 \mathrm{wt} \%$, well above the CAC, DLS showed large differences in the aggregation behaviour. The PEG-(PLLA 2.9 -TA) ${ }_{8}$ copolymer shows a unimodal distribution at $45 \mathrm{~nm}$ resembling micellar type aggregates. The PEG(PLLA $\left._{4.0}-\mathrm{TA}\right)_{8}$ copolymer predominately aggregates into particles with an average diameter of $\sim 100 \mathrm{~nm}$ and a minor fraction of larger aggregates. An increase in the PLLA block length to a degree of polymerization of 5.0 revealed a further shift to increasing particle sizes, which also becomes visible by eye as a white hue.

In previous research it was shown that aggregation of star shaped PEG-(PLLA) 8 copolymers above the CAC leads to the formation of hydrophobic domains in which the PLLA segments have a diminished mobility ${ }^{30}$. Importantly, not all PLLA segments are in hydrophobic domains but also partially present in the PEG phase and are much more mobile. This has been illustrated by ${ }^{1} \mathrm{H}-\mathrm{NMR}$ analysis of the copolymer solutions in $\mathrm{D}_{2} \mathrm{O}$. Similarly, ${ }^{1} \mathrm{H}-\mathrm{NMR}$ spectra of the copolymers dissolved in $\mathrm{D}_{2} \mathrm{O}$ as presented in Figure 3 revealed that for PEG(PLLA $\left._{2.9}-\mathrm{TA}\right)_{8}$ about $75 \%$ of the PLLA methyl protons can be detected relative to the PEG protons which are always highly mobile. This value decreased to $31 \%$ and $5 \%$ for PEG$\left(\text { PLLA }_{4.0}-\mathrm{TA}\right)_{8}$ and PEG-(PLLA $\left.{ }_{5.0}-\mathrm{TA}\right)_{8}$, respectively. The tyramine end groups followed a similar trend, in PEG-(PLLA $2.9-\mathrm{TA})_{8} 80 \%$ of the aromatic tyramine protons could be detected. This decreased to $27 \%$ and $1 \%$ for PEG-(PLLA $4.0-T A)_{8}$ and PEG-(PLLA 5.0 -TA $)_{8}$, respectively. 

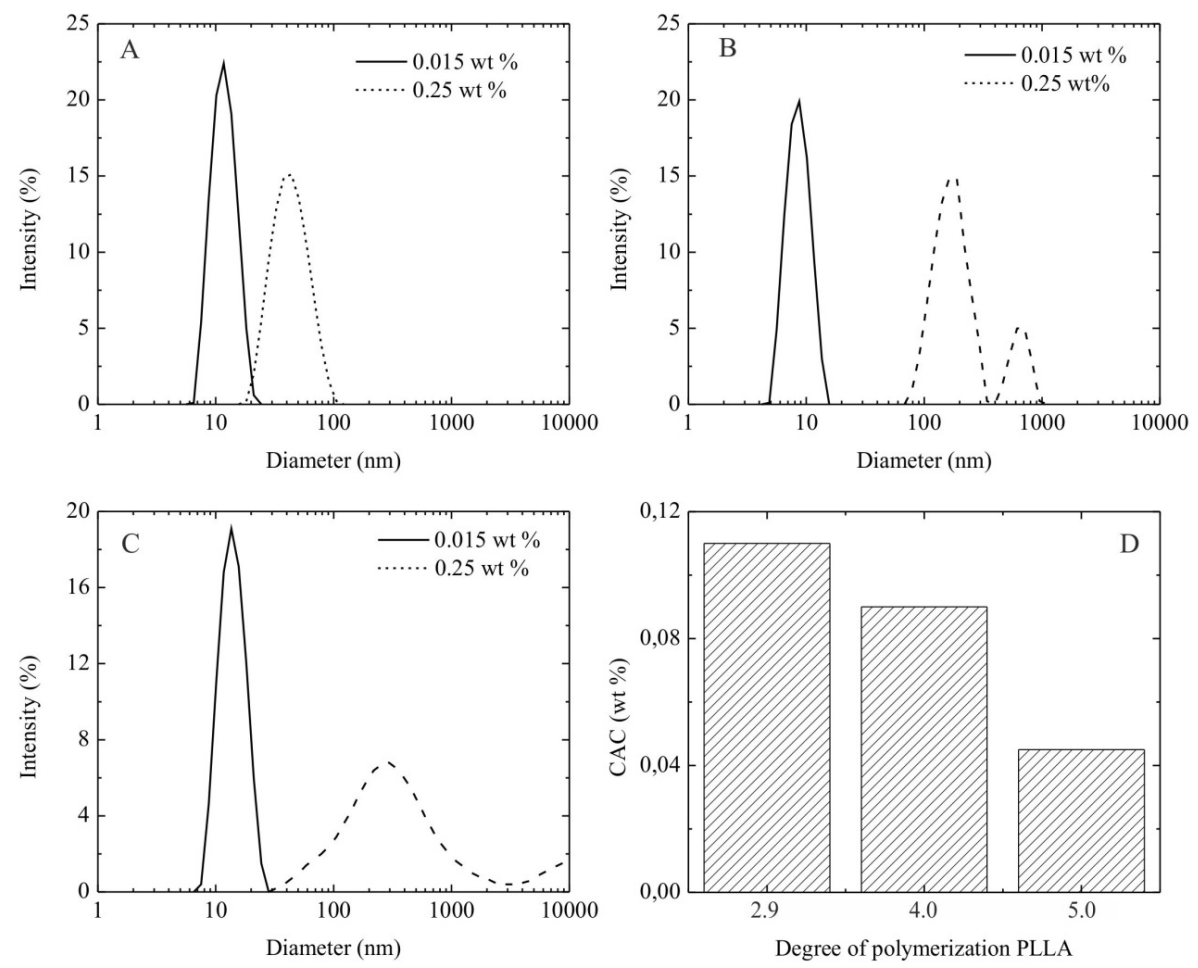

Figure 2. DLS intensity plots of 0.015 and $0.25 \mathrm{wt} \%$ solutions of A) PEG-(PLLA 2.9 -TA $\left.)_{8}, \mathrm{~B}\right)$ PEG-(PLLA 4.0 -TA $)_{8}$, C) PEG-(PLLA $\left.{ }_{5.0}-T_{A}\right)_{8}$ star block copolymers (PBS, pH 7.4) and D) CAC values (wt \%) of PEG-(PLLA -TA $_{8}$ star block copolymers.

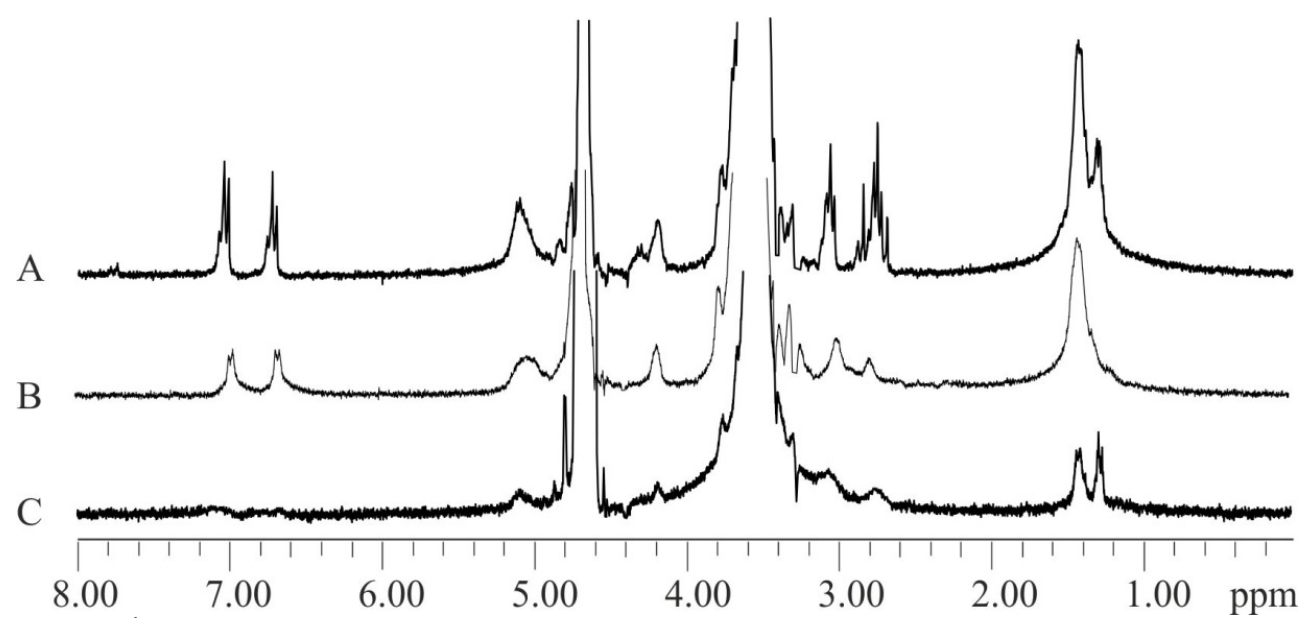

Figure 3. ${ }^{1} \mathrm{H}-\mathrm{NMR}$ spectra of PEG-(PLLA $\left.2.9-\mathrm{TA}\right)_{8}(\mathrm{~A})$, PEG-(PLLA $\left.4.0-\mathrm{TA}\right)_{8}(\mathrm{~B})$ and PEG-(PLLA 5.0 -TA $)_{8}(\mathrm{C})(0.25$ wt \%). Solvent $\mathrm{D}_{2} \mathrm{O}$. 


\section{Gelation of PEG-(PLLA-TA) $)_{8}$ in PBS}

The PEG-(PLLA-TA) 8 star block copolymers resemble BAB type amphiphilic copolymers which generally form thermo-reversible physically crosslinked hydrogels at high concentrations. The PEG-(PLLA $2.9-\mathrm{TA})_{8}$ and PEG-(PLLA $\left.4.0-\mathrm{TA}\right)_{8}$ star block copolymers afford transparent hydrogels at concentrations above 20 and $10 \mathrm{wt} \%$, respectively (Figure 4). The PEG-(PLLA 5.0 -TA $)_{8}$ star block copolymers form translucent gels at concentrations above 5 wt $\%$. The translucency of the PEG-(PLLA 5.0 -TA $)_{8}$ hydrogels may be the result of phase separation between the PEG and PLLA phases into small domains. All copolymers showed a fully thermo-reversible gelation behaviour and sol-gel-sol phase transition temperatures were determined by stepwise cooling copolymer solutions from $70{ }^{\circ} \mathrm{C}$ to $4{ }^{\circ} \mathrm{C}$ and subsequent heating to $70^{\circ} \mathrm{C}$ (Figure 4). Upon increasing the hydrophobic block length of PEG-(PLLATA) 8 star block copolymers, the gel to sol transitions shifted to higher temperatures due to an increased number of physical crosslinks present. Furthermore, incorporation of hydrophobic tyramine moieties shifted the gel to sol window to lower concentrations compared to for example a PEG-(PLLA $\left.{ }_{7.0}\right)_{8}$ star block copolymer which at room temperature shows a reversible transition at $20 \mathrm{wt} \%{ }^{29}$. This effect may be ascribed to better packing of the PLLA segments but also $\pi-\pi$ interactions between tyramine groups may play a role ${ }^{31}$.

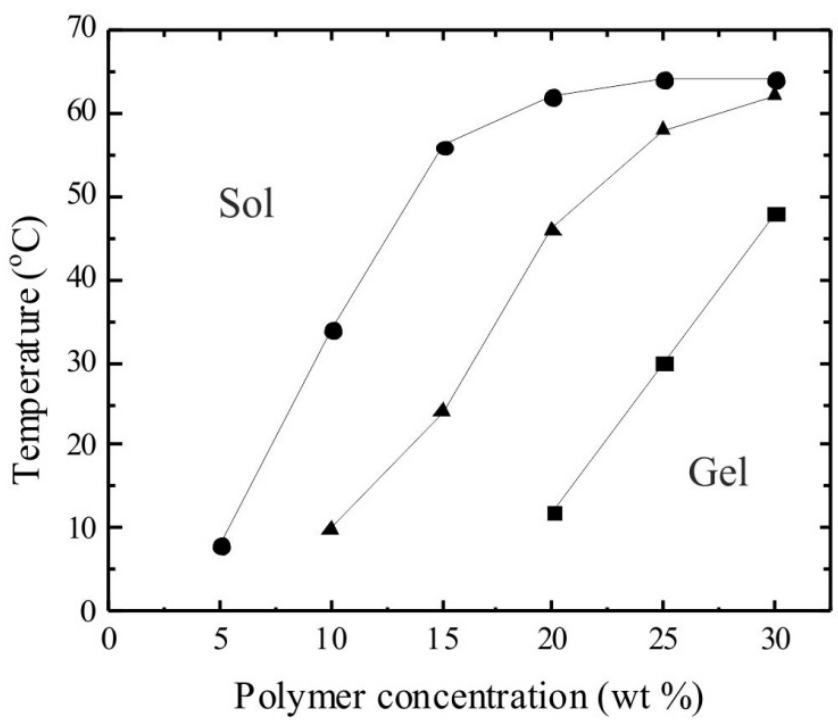

Figure 4 Gel-sol transition temperatures of PEG-(PLLA-TA) ${ }_{8}$ copolymers as determined with the vial tilting method upon heating (PBS, pH 7.4). $\longrightarrow$ PEG-(PLLA $2.9^{-}$TA $)_{8} ; \longrightarrow$ PEG-(PLLA $_{4.0^{-}}$TA $)_{8}$ and $\longrightarrow$ PEG-(PLLA $\left.{ }_{5.0}-\mathrm{TA}\right)_{8}$. 


\section{Enzymatic crosslinking with $\mathrm{HRP}$ and $\mathrm{H}_{2} \mathrm{O}_{2}$}

The horse radish peroxidase (HRP) mediated crosslinking of polysaccharide-tyramine conjugates in the presence of $\mathrm{H}_{2} \mathrm{O}_{2}$ is a highly effective method to prepare chemically crosslinked hydrogels ${ }^{6,17-23}$. The high aqueous solubility of such conjugates and high reaction rates generally lead to short gelation times, high gel content and hydrogels having a high storage modulus $\left(\mathrm{G}^{\prime}\right)$. $\mathrm{HRP} / \mathrm{H}_{2} \mathrm{O}_{2}$ crosslinking takes place via the formation of either carboncarbon bonds at the ortho positions of phenol groups or via carbon-oxygen bond formation between the carbon atom at the ortho position of the phenol and the phenoxy oxygen. In PEG(PLLA $-\mathrm{TA})_{8}$ the phenolic groups are partly present in hydrophobic domains and hydrophilic domains and the ratio is mainly dependent on the PLLA block length. Because these materials do show a thermo-reversible gelation behavior the availability of phenolic groups for crosslinking is likely dependent on temperature. To investigate the possible enzymatic crosslinking of the copolymers into hydrogels, precursor solutions of PEG-(PLLA - TA $)_{8}$ star block copolymers were prepared that were in a sol state at $37{ }^{\circ} \mathrm{C}$. Copolymer solutions of 5, 10, 15 and 20 wt \% of PEG-(PLLA $2.9-\mathrm{TA})_{8}$ were prepared, whereas for PEG-(PLLA $4.0^{-}$ TA $)_{8}$ only 5 and $10 \mathrm{wt} \%$ solutions and for PEG-(PLLA 5.0 TA $)_{8}$ only a $5 \mathrm{wt} \%$ solution were prepared. Upon addition of $\mathrm{HRP}$ and $\mathrm{H}_{2} \mathrm{O}_{2}$ a color change to yellowish brown was seen for all solutions of PEG-(PLLA $2.9-\mathrm{TA})_{8}$ and PEG-(PLLA $\left.4.0-\mathrm{TA}\right)_{8}$ indicative of the coupling of phenol moieties except for the PEG-(PLLA $5.0-\mathrm{TA})_{8}$ (Figure 5). In the latter case ${ }^{1} \mathrm{H}-\mathrm{NMR}$ analysis showed that no reaction had taken place. Apparently, the phenolic groups located in the phase separated hydrophobic domains of the aggregates are not available for crosslinking. From this it can be concluded that HRP in the presence of $\mathrm{H}_{2} \mathrm{O}_{2}$ only reacts with mobile phenolic groups in a hydrophilic region. The results of the $\mathrm{HRP} / \mathrm{H}_{2} \mathrm{O}_{2}$ addition to the PEG-(PLLA ${ }_{\mathrm{n}}$ TA) ${ }_{8}$ copolymers at different concentrations are summarized in Table 2. 

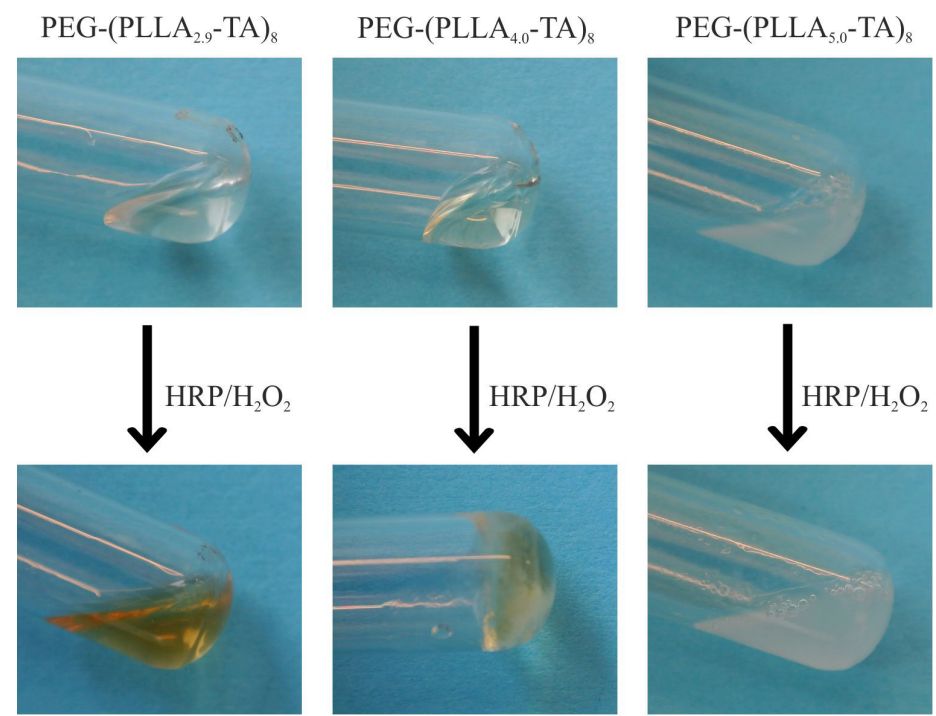

Figure 5. Photographic examples of 5 wt \% PEG-(PLLA - TA $)_{8}$ solutions before and after addition of $\mathrm{HRP}_{2} / \mathrm{H}_{2} \mathrm{O}_{2}$.

Table 2. HRP/ $\mathrm{H}_{2} \mathrm{O}_{2}$ mediated reactions of PEG-(PLLA $\left.-\mathrm{TA}\right)_{8}$ block copolymers.

\begin{tabular}{|c|c|c|c|c|c|}
\hline Name & $\begin{array}{c}\text { Concentration } \\
\text { (wt \%) }\end{array}$ & Gelation & $\begin{array}{c}\text { Gelation } \\
\text { time (s) }\end{array}$ & $\begin{array}{c}\text { Gel } \\
\text { content }^{\mathbf{a}} \\
\mathbf{( \% )}\end{array}$ & $\begin{array}{c}\text { Water }_{\text {uptake }^{\mathbf{a}}} \\
\mathbf{( \% )}\end{array}$ \\
\hline PEG-(PLLA $\left._{2.9}-\mathrm{TA}\right)_{8}$ & 5 & No & - & - & - \\
& 10 & No & - & - & - \\
& 15 & Yes & $7 \pm 1$ & $96 \pm 1$ & $640 \pm 40$ \\
& 20 & Yes & $40 \pm 3$ & $72 \pm 2$ & $540 \pm 30$ \\
\hline PEG-(PLLA $\left._{4.0}-\mathrm{TA}\right)_{8}$ & 5 & Yes & $29 \pm 2$ & $94 \pm 1$ & $2200 \pm 100$ \\
& 10 & Yes & $45 \pm 4$ & $77 \pm 4$ & $1140 \pm 60$ \\
\hline PEG-(PLLA & 5 & No & - & - & - \\
\hline
\end{tabular}

${ }^{\mathrm{a}}$ Measured in demi water of $\mathrm{pH} 6.0$ 
At concentrations of 5 and $10 \mathrm{wt} \%$, solutions of PEG-(PLLA $4.0-\mathrm{TA})_{8}$ formed hydrogels within $1 \mathrm{~min}$. The gel content of $5 \mathrm{wt} \%$ gels was $94 \%$ and decreased to $77 \%$ for the $10 \mathrm{wt} \%$ hydrogel. This decrease may be attributed to the increase in viscosity at a higher concentration resulting in a lower reaction rate. A similar trend is seen for the 15 and 20 wt \% PEG-(PLLA 2.9 -TA) $)_{8}$ hydrogels. Subsequently, the rheological properties of $15 \mathrm{wt} \%$ PEG-(PLLA 2.9 -TA $)_{8}$ and 5 wt \% PEG-(PLLA $\left.{ }_{4.0}-\mathrm{TA}\right)_{8}$ hydrogels were determined at $37{ }^{\circ} \mathrm{C}$ by injecting a copolymer and enzyme precursor solution between the gap of the base and measuring plate of the rheometer and monitoring the storage ( $\left.G^{\prime}\right)$ and loss (G') moduli during gel formation. The storage modulus reaches a plateau value after $5 \mathrm{~min}$ for the 15 wt \% PEG-(PLLA ${ }_{2.9}$-TA) $)_{8}$ copolymer. An elastic hydrogel with a storage modulus of 3600 $\mathrm{Pa}$ is formed (Figure 6). In a similar experiment applying a $5 \mathrm{wt} \%$ PEG-(PLLA 4.0 -TA $)_{8}$ precursor solution, gelation is also fast (crossing of $\mathrm{G}^{\prime}$ and $\mathrm{G}$ ” in $\sim 1 \mathrm{~min}$ ) but a plateau value is found after $22 \mathrm{~min}$. A viscous gel is formed having a storage modulus of only $16 \mathrm{~Pa}$. The low mechanical stiffness of this hydrogel likely results from the low amount of available TA groups and thus a low crosslink density. These results are reflected in the water uptake of the hydrogels. A higher amount of available TA groups for crosslinking as in PEG-(PLLA $2.9-\mathrm{TA})_{8}$ compared to PEG-(PLLA 4.0 -TA) ${ }_{8}$ provides hydrogels which are more densely crosslinked and thus show a lower water uptake. SEM images of these freeze dried hydrogels show a regular structure with thin pore walls in case of $5 \mathrm{wt} \%$ PEG-(PLLA $4.0-\mathrm{TA})_{8}$ hydrogels but a less regular structure and thick pore walls in case of the $15 \mathrm{wt} \%$ PEG-(PLLA $2.9-\mathrm{TA})_{8}$ hydrogel.

The degradation rate of the PEG-(PLLA $-\mathrm{TA})_{8}$ block copolymers in $\mathrm{PBS}$ at $\mathrm{pH} 7.4$ is primarily dependent on the hydrolysis of the ester linkage between PEG and PLLA blocks and on the crosslinking density ${ }^{29}$. The $15 \mathrm{wt} \%$ PEG-(PLLA 2.9 -TA) ${ }_{8}$ hydrogels degrade in approximately $12 \mathrm{~d}$ and the $5 \mathrm{wt} \%$ PEG-(PLLA $\left._{4.0}-\mathrm{TA}_{8}\right)_{8}$ hydrogels in $5 \mathrm{~d}$. This is expected since the crosslink density in the $15 \mathrm{wt} \%$ PEG-(PLLA 2.9 -TA $)_{8}$ is much higher (Figure 7). 

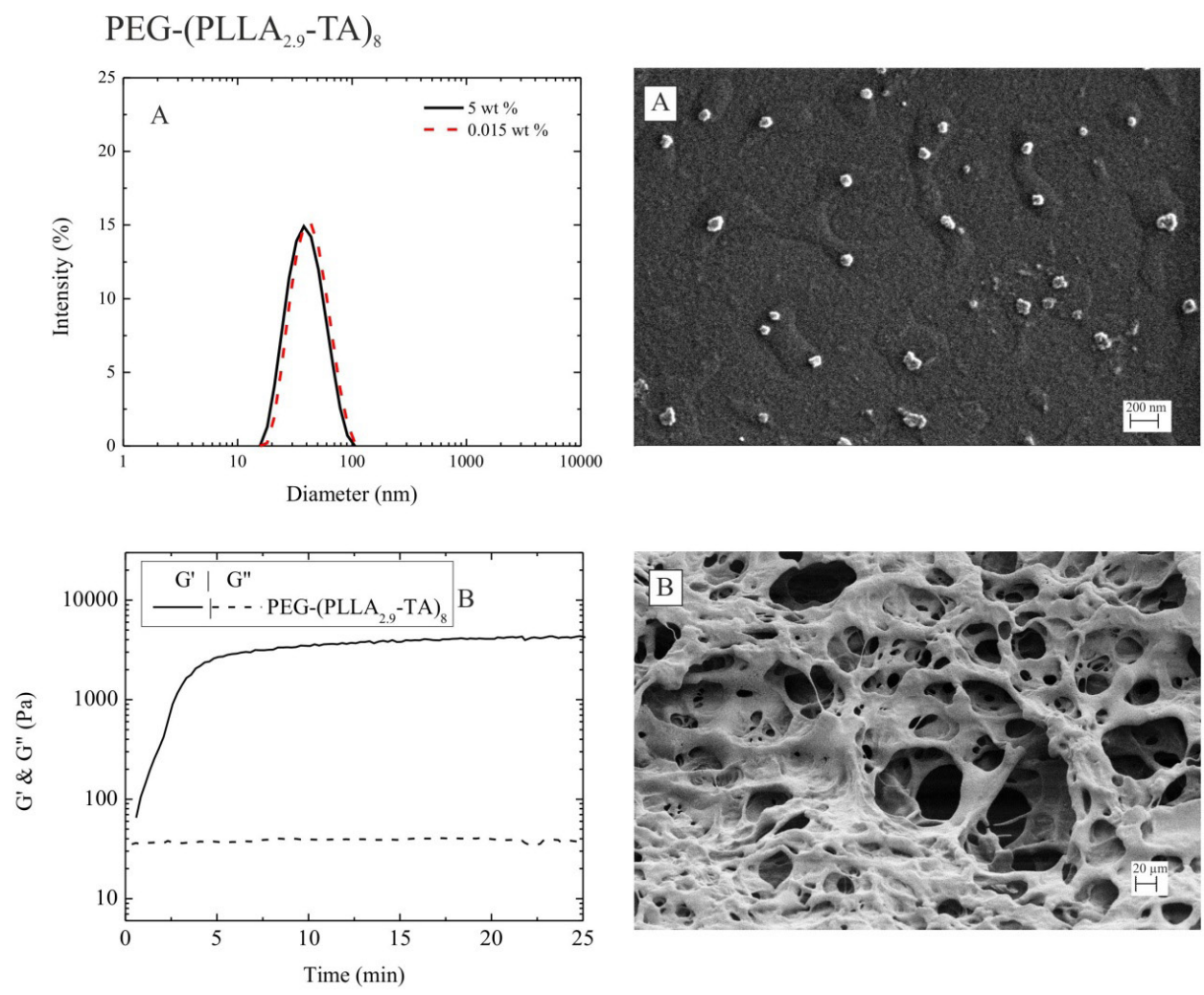

$$
\text { PEG-(PLLA } 4.0 \text {-TA) }
$$
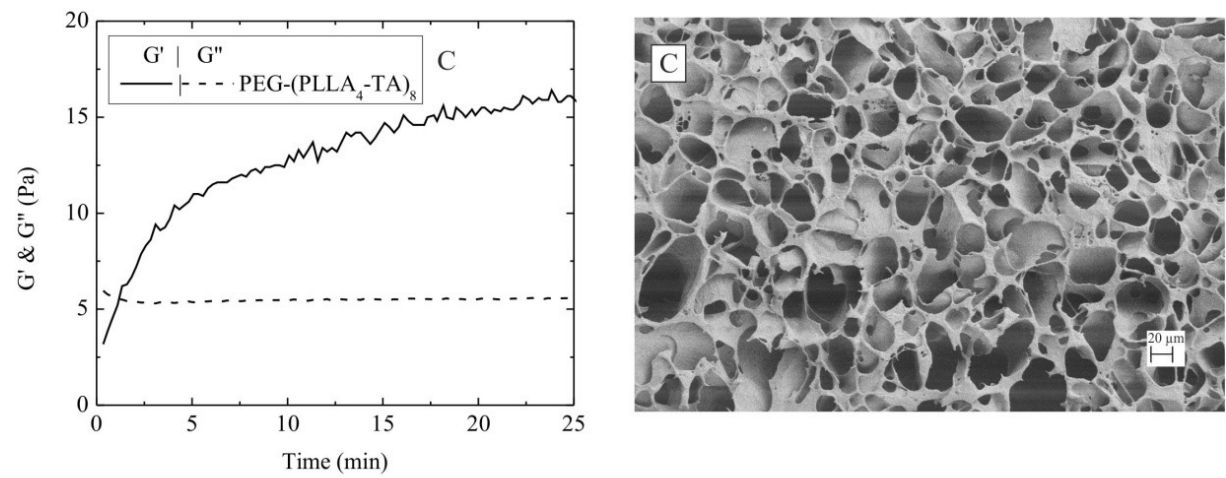

Figure 6. A) DLS intensity plots of a $0.015 \mathrm{wt} \%$ and $5 \mathrm{wt} \%$ PEG-(PLLA 2.9 -TA) ${ }_{8}$ solution and SEM image of nanoparticles; B) The evolution of the storage $\left(\mathrm{G}^{`}\right)$ and loss $\left(\mathrm{G}^{\prime \prime}\right)$ modulus in time of $15 \mathrm{wt} \%$ PEG-(PLLA 2. PA $_{8}$ after addition of $\mathrm{HRP} / \mathrm{H}_{2} \mathrm{O}_{2}(\mathrm{PBS}, \mathrm{pH} 7.4)$ and SEM image of the resulting freeze dried hydrogel; C) The evolution of the storage $\left(\mathrm{G}^{\prime}\right)$ and loss $\left(\mathrm{G}^{\prime \prime}\right)$ moduli of $5 \mathrm{wt} \%$ PEG-(PLLA 4.0 -TA) $)_{8}$ after addition of $\mathrm{HRP}_{2} \mathrm{H}_{2} \mathrm{O}_{2}(\mathrm{PBS}, \mathrm{pH} 7.4)$ and SEM image of the resulting freeze dried hydrogel. 
Interesting results were obtained upon addition of $\mathrm{HRP} / \mathrm{H}_{2} \mathrm{O}_{2}$ to 5 or $10 \mathrm{wt} \%$ PEG-(PLLA ${ }_{2.9^{-}}$ TA) $)_{8}$ solutions. The visible color change reveals that coupling reactions do occur but that no gelation takes place. DLS measurements on PEG-(PLLA $2.9-\mathrm{TA})_{8}$ solutions up to $5 \mathrm{wt} \%$ revealed the absence of large aggregates. After the addition of a $\mathrm{HRP} / \mathrm{H}_{2} \mathrm{O}_{2}$ mixture to such solutions and subsequent dilution to a concentration below the CAC it was found that still nanosized particles of 50 to $60 \mathrm{~nm}$ were present. The size and stability of these particles were confirmed by SEM images (Figure 6). This might be ascribed to the fact that in 5 and $10 \mathrm{wt} \%$ PEG-(PLLA 2.9 -TA $)_{8}$ solutions, the block copolymers do not form inter-micellar bridges. In 15 and $20 \mathrm{wt} \%$ PEG-(PLLA 2.9 -TA $)_{8}$ solutions it is likely that inter-micellar and inter-aggregate bridges are present, which after addition of $\mathrm{HRP} / \mathrm{H}_{2} \mathrm{O}_{2}$ result in the formation of crosslinked hydrogels.

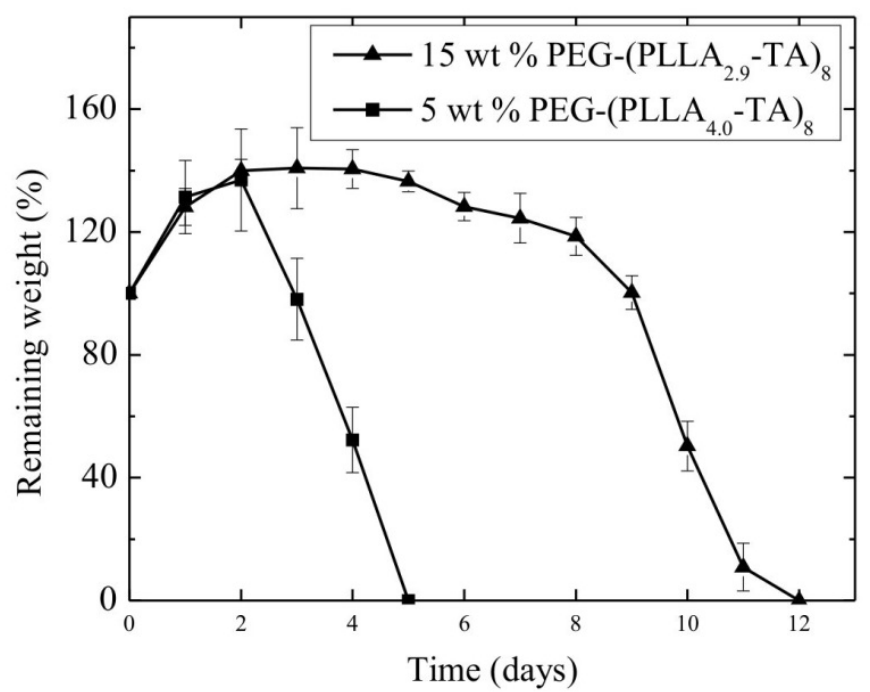

Figure 7. Degradation profiles of $15 \mathrm{wt} \%$ PEG-(PLLA $2.9-\mathrm{TA})_{8}$ and $5 \mathrm{wt} \%$ PEG-(PLLA 4.0 -TA $)_{8}$ hydrogels in PBS $(\mathrm{pH}, 7.4)$ at $37^{\circ} \mathrm{C}$.

\section{Conclusions}

PEG-(PLLA $-\mathrm{nA})_{8}$ star block copolymers with different PLLA block lengths were prepared by ring opening polymerization initiated by (PEG-OH), activation of the hydroxyl groups and subsequent reaction with tyramine. Due to the incorporation of the TA units, gelation occurred at lower concentrations than for the corresponding PEG-(PLLA $)_{8}$ star block copolymers with a similar PLLA block length. Enzymatic crosslinking with HRP and $\mathrm{H}_{2} \mathrm{O}_{2}$ of PEG-(PLLA $\left.-\mathrm{TA}\right)_{8}$ star block copolymers was dependent on the availability of TA 
groups in the hydrophilic phase. Copolymers with short PLLA blocks can form crosslinked nanoparticles and at higher concentrations afford hydrogels possibly to the presence of intermicellar bridges. At higher PLLA block lengths viscous hydrogels are formed and when the PLLA block length is further increased no reaction is taken place. PEG-(PLLA-TA) ${ }_{8}$ star block copolymers either assembled into nanoparticles or into larger aggregates (hydrogels) are interesting materials for biomedical applications such as matrices for tissue engineering in case of hydrogels and controlled drug delivery systems in case of nanoparticles.

\section{References}

1. Kashyap, N.; Kumar, N.; Kumar, M., Hydrogels for pharmaceutical and biomedical applications. Critical Reviews in Therapeutic Drug Carrier Systems 2005, 22, (2), 107-149.

2. Van Tomme, S. R.; Storm, G.; Hennink, W. E., In situ gelling hydrogels for pharmaceutical and biomedical applications. International Journal of Pharmaceutics 2008, $355,(1-2), 1-18$.

3. Oh, J. K.; Drumright, R.; Siegwart, D. J.; Matyjaszewski, K., The development of microgels/nanogels for drug delivery applications. Progress in Polymer Science 2008, 33, (4), 448-477.

4. Jeong, B.; Bae, Y. H.; Lee, D. S.; Kim, S. W., Biodegradable block copolymers as injectable drug-delivery systems. Nature 1997, 388, (6645), 860-862.

5. Jin, R.; Hiemstra, C.; Zhong, Z.; Feijen, J., Enzyme-mediated fast in situ formation of hydrogels from dextran-tyramine conjugates. Biomaterials 2007, 28, (18), 2791-2800.

6. Wennink, J. W. H.; Niederer, K.; Bochyńska, A. I.; Moreira Teixeira, L. S.;

Karperien, M.; Feijen, J.; Dijkstra, P. J., Injectable hydrogels by enzymatic co-crosslinking of dextran and hyaluronic acid tyramine conjugates. Macromolecular Symposia 2011, 309310, (1), 213-221.

7. Burdick, J. A.; Anseth, K. S., Photoencapsulation of osteoblasts in injectable RGD-modified PEG hydrogels for bone tissue engineering. Biomaterials 2002, 23, (22), 4315-4323.

8. $\quad$ Elisseeff, J.; Anseth, K.; Sims, D.; McIntosh, W.; Randolph, M.; Langer, R., Transdermal photopolymerization for minimally invasive implantation. Proceedings of the National Academy of Sciences of the United States of America 1999, 96, (6), 3104-3107.

9. Van Tomme, S. R.; van Steenbergen, M. J.; De Smedt, S. C.; van Nostrum, C. F.; Hennink, W. E., Self-gelling hydrogels based on oppositely charged dextran microspheres. Biomaterials 2005, 26, (14), 2129-2135.

10. Li, J.; Li, X.; Ni, X. P.; Wang, X.; Li, H. Z.; Leong, K. W., Self-assembled supramolecular hydrogels formed by biodegradable PEO-PHB-PEO triblock copolymers and alpha-cyclodextrin for controlled drug delivery. Biomaterials 2006, 27, (22), 4132 4140 .

11. van de Manakker, F.; Vermonden, T.; van Nostrum, C. F.; Hennink, W. E., Cyclodextrin-Based Polymeric Materials: Synthesis, Properties, and Pharmaceutical/ Biomedical Applications. Biomacromolecules 2009, 10, (12), 3157-3175.

12. Hiemstra, C.; Zhong, Z. Y.; Dijkstra, P.; Feijen, J., Stereocomplex mediated gelation of PEG-(PLA)(2) and PEG-(PLA)(8) block copolymers. Macromolecular 
Symposia 2005, 224, 119-131.

13. Hiemstra, C.; Zhong, Z. Y.; Li, L. B.; Dijkstra, P. J.; Feijen, J., In-situ formation of biodegradable hydrogels by stereocomplexation of PEG-(PLLA)(8) and PEG-(PDLA)(8) star block copolymers. Biomacromolecules 2006, 7, (10), 2790-2795.

14. Hiemstra, C.; van der Aa, L. J.; Zhong, Z. Y.; Dijkstra, P. J.; Feijen, J., Rapidly in situ-forming degradable hydrogels from dextran thiols through michael addition. Biomacromolecules 2007, 8, (5), 1548-1556.

15. Elisseeff, J.; Anseth, K.; Sims, D.; McIntosh, W.; Randolph, M.; Yaremchuk, M.; Langer, R., Transdermal photopolymerization of poly(ethylene oxide)-based injectable hydrogels for tissue-engineered cartilage. Plastic and Reconstructive Surgery 1999, 104, (4), 1014-1022.

16. Li, Q.; Wang, J.; Shahani, S.; Sun, D. D. N.; Sharma, B.; Elisseeff, J. H.; Leong, K. W., Biodegradable and photocrosslinkable polyphosphoester hydrogel. Biomaterials 2006, 27, (7), 1027-1034.

17. Jin, R.; Hiemstra, C.; Zhong, Z. Y.; Feijen, J., Enzyme-mediated fast in situ formation of hydrogels from dextran-tyramine conjugates. Biomaterials 2007, 28, (18), 2791-2800.

18. Kurisawa, M.; Chung, J. E.; Yang, Y. Y.; Gao, S. J.; Uyama, H., Injectable biodegradable hydrogels composed of hyaluronic acid-tyramine conjugates for drug delivery and tissue engineering. Chemical Communications 2005, (34), 4312-4314.

19. Sakai, S.; Kawakami, K., Synthesis and characterization of both ionically and enzymatically cross-linkable alginate. Acta Biomaterialia 2007, 3, (4), 495-501.

20. Ogushi, Y.; Sakai, S.; Kawakami, K., Synthesis of enzymatically-gellable carboxymethylcellulose for biomedical applications. Journal of Bioscience and Bioengineering 2007, 104, (1), 30-33.

21. Amini, A. A.; Nair, L. S., Enzymatically cross-linked injectable gelatin gel as osteoblast delivery vehicle. Journal of Bioactive and Compatible Polymers 2012, 27, (4), $342-355$.

22. Jin, R.; Teixeira, L. S. M.; Dijkstra, P. J.; van Blitterswijk, C. A.; Karperien, M.; Feijen, J., Chondrogenesis in injectable enzymatically crosslinked heparin/dextran hydrogels. Journal of Controlled Release 2011, 152, (1), 186-195.

23. Teixeira, L. S. M.; Bijl, S.; Pully, V. V.; Otto, C.; Rong, J.; Feijen, J.; van Blitterswijk, C. A.; Dijkstra, P. J.; Karperien, M., Self-attaching and cell-attracting insitu forming dextran-tyramine conjugates hydrogels for arthroscopic cartilage repair. Biomaterials 2012, 33, (11), 3164-3174.

24. Lee, S. H.; Lee, Y.; Lee, S. W.; Ji, H. Y.; Lee, J. H.; Lee, D. S.; Park, T. G., Enzyme-mediated cross-linking of Pluronic copolymer micelles for injectable and in situ forming hydrogels. Acta Biomaterialia 2011, 7, (4), 1468-1476.

25. Park, K. M.; Jun, I.; Joung, Y. K.; Shin, H.; Park, K. D., In situ hydrogelation and RGD conjugation of tyramine-conjugated 4-arm PPO-PEO block copolymer for injectable bio-mimetic scaffolds. Soft Matter 2011, 7, (3), 986-992.

26. Park, K. M.; Lee, Y.; Son, J. Y.; Oh, D. H.; Lee, J. S.; Park, K. D., Synthesis and Characterizations of In Situ Cross-Linkable Gelatin and 4-Arm-PPO-PEO Hybrid Hydrogels via Enzymatic Reaction for Tissue Regenerative Medicine. Biomacromolecules 2012, 13, (3), 604-611.

27. Park, K. M.; Shin, Y. M.; Joung, Y. K.; Shin, H.; Park, K. D., In Situ Forming 
Hydrogels Based on Tyramine Conjugated 4-Arm-PPO-PEO via Enzymatic Oxidative Reaction. Biomacromolecules 2010, 11, (3), 706-712.

28. Ottenbrite, R. M.; Park, K.; Okano, T., Biomedical applications of hydrogels handbook. 1 ed.; Springer: NY, 2011; p 157-177.

29. Buwalda, S. J.; Dijkstra, P. J.; Calucci, L.; Forte, C.; Feijen, J., Influence of Amide versus Ester Linkages on the Properties of Eight-Armed PEG-PLA Star Block Copolymer Hydrogels. Biomacromolecules 2010, 11, (1), 224-232.

30. Calucci, L.; Forte, C.; Buwalda, S. J.; Dijkstra, P. J.; Feijen, J., Self-Aggregation of Gel Forming PEG-PLA Star Block Copolymers in Water. Langmuir 2010, 26, (15), 12890 12896.

31. Yokoyama, M.; Opanasopit, P.; Okano, T.; Kawano, K.; Maitani, Y., Polymer design and incorporation methods for polymeric micelle carrier system containing waterinsoluble anti-cancer agent camptothecin. Journal of Drug Targeting 2004, 12, (6), 373384. 


\section{Chapter 7 Injectable Hydrogels by Enzymatic Co-Crosslinking of Dextran and Hyaluronic Acid Tyramine Conjugates}

Jos W.H.Wennink, Kerstin Niederer, Agnieszka I. Bochyńska, Liliana S. Moreira Teixeira, Marcel Karperien, Jan Feijen and Pieter J. Dijkstra

My momma always said, "Life was like a box of chocolates. You never know what you're gonna get." 


\begin{abstract}
In this study, injectable hydrogels were prepared by the horseradish peroxidase mediated co-crosslinking of dextran-tyramine (Dex-TA) and hyaluronic acid-tyramine (HA-TA) conjugates intended for cartilage tissue engineering. In general the gelation times of $10 \mathrm{wt}$ $\%$ polysaccharide solutions are $<20$ seconds and their storage moduli can be adjusted by varying the composition between Dex-TA and HA-TA. Dex-TA/HA-TA (50/50) hydrogels were fully degradable in the presence of hyaluronidase. Chondrocytes incorporated in 10 wt \% Dex-TA and Dex-TA/HA-TA (50/50) gels showed good viability after 28 days. These results indicate that Dex-TA/HA-TA (50/50) hydrogels are promising injectable and biodegradable hydrogels for cartilage repair.
\end{abstract}




\section{Introduction}

Tissue engineering represents a promising method to regenerate damaged cartilage ${ }^{1}$. This method involves the incorporation of cells (chondrocytes) into a scaffold, which serves as a temporary extracellular matrix (ECM) and promotes cartilage regeneration. In situ forming hydrogels are attractive scaffold candidates because they allow minimally invasive techniques, are able to fill irregularly shaped defects, and easy encapsulation of chondrocytes in a polymer solution is possible prior to gelation ${ }^{2-5}$. Additionally, such hydrogels provide a 3D environment, which facilitates cells proliferation and differentiation and meanwhile allows transport of nutrients and waste products. Because hydrogels are 3D elastic networks having high water content, they mimic hydrated native cartilage tissue and are considered suitable scaffolds for cartilage tissue engineering.

Injectable hydrogels can be obtained via chemical crosslinking, for example photopolymerization. In this approach, a solution of a polymer containing vinylic groups converts into a gel by exposure to visible or ultraviolet light in the presence of photo-initiators ${ }^{6-9}$. The preparation of hydrogels by photo-initiation has the advantage of fast crosslinking rates upon exposure to UV irradiation. However, the disadvantage of this method is the exposure of cells to UV at high intensities or long exposure times which may have an adverse effect on cellular metabolic activity ${ }^{10}$. Moreover, local heat release during the crosslinking process may give rise to cellular necrosis ${ }^{11}$. Alternatively injectable hydrogels can be generated via Michael type addition reactions of thiol groups to (meth)acrylate, (meth)acrylamide, or vinyl sulfone groups ${ }^{12-17}$. In this approach, it was also shown that thiol-bearing bioactive molecules such as adhesion peptides and matrix metalloproteinase substrate peptides can be relatively easily incorporated to create biomimetic hydrogels ${ }^{14}$. Generally, hydrogels that are prepared via Michael type addition reactions have gelation times less than $0.5 \mathrm{~min}$ to about 1 hour, and have moderate storage moduli and their properties can be adjusted by tuning the reactivity of functional groups and crosslinking density ${ }^{12,13,17,18}$. Since Michael additions reactions generally take place at mild conditions, the reaction does not seriously influence cell viability during the hydrogel formation process. It was reported that incorporated cells in these type of hydrogels remained viable and survived from days to months, depending on the applied materials ${ }^{19,20}$. However, some caution has to be taken in the use of thiol functional groups for unreacted thiols may cause cell death ${ }^{21}$.

Recently, we showed that injectable hydrogels can be prepared by the enzymatic crosslinking of polysaccharide tyramine conjugates ${ }^{22-25}$. Crosslinking takes place via an oxidative coupling reaction of phenol moieties in the presence of horseradish peroxidase (HRP) and $\mathrm{H}_{2} \mathrm{O}_{2}{ }^{26}$. This method afforded fast gelation and showed good cytocompatibility of incorporated 
chondrocytes.

Hyaluronic acid has abundant carboxylic acid groups, amendable to various types of chemical modifications. This offers the opportunity to conjugate hyaluronic acid with tyramine groups by activation of the carboxylic acid groups and subsequent reaction with the tyramine amine groups. In this way, biofunctional scaffolds may be created to modulate cell adhesion, migration, proliferation and differentiation as well as new tissue formation.

We here describe biofunctional injectable hydrogels based on dextran and hyaluronic acid applicable as injectable hydrogels for cartilage tissue engineering. The properties of the hydrogels such as gelation times, gel content, water uptake and mechanical properties were investigated. Moreover, bovine chondrocytes were incorporated in these hydrogels to evaluate their cytocompatibility.

\section{Materials and Methods}

\section{Materials}

Dextran $\left(\mathrm{M}_{\mathrm{w}}=15\right.$ to $\left.25 \mathrm{~kg} / \mathrm{mol}\right)$ was obtained from Sigma-Aldrich and dried by lyophilization. Hyaluronic acid sodium salt $\left(\mathrm{M}_{\mathrm{w}}=15\right.$ to $\left.25 \mathrm{~kg} / \mathrm{mol}\right)$ was purchased from CPN-shop. N-hydroxysuccinimide (NHS), tyramine and p-nitrophenyl chloroformate (PNC), Anhydrous Dimethylformamide (DMF), Pyridine (anhydrous), hydrogen peroxide $\left(\mathrm{H}_{2} \mathrm{O}_{2}\right)$ and lithiumchloride, Horseradish peroxidase (HRP, 311 purpurogallin unit/mg solid) were obtained from Sigma-Aldrich and were used without further purification. N-Ethyl$\mathrm{N}^{\prime}$-(3-dimethylaminopropyl) carbodiimide hydroxide (EDAC) was obtained from Fluka. Phospate buffered saline (PBS, pH 7,4) was purchased from B. Braun Co. Dextran-tyramine conjugates (Dex-TA) was synthesized as described previously ${ }^{25}$.

\section{Synthesis}

Hyaluronic acid-tyramine conjugate (HA-TA): A HA-TA conjugate was synthesized by the coupling reaction of primary amine groups from tyramine to hyaluronic acid carboxylic groups using EDAC/NHS activation. Sodium hyaluronate $(2 \mathrm{~g})$ was dissolved in $30 \mathrm{~mL}$ of MES buffer (0.1 M, pH 6.0), to which EDAC (288 mg, $1.5 \mathrm{mmol})$ and NHS (227 mg, 1.5 mmol) were added. After $30 \mathrm{~min}$ of stirring $6 \mathrm{~mL}$ of a DMF solution containing tyramine (69 $\mathrm{mg}, 0.5 \mathrm{mmol}$ ) was added and the mixture was stirred under nitrogen for 3 days. The mixture was neutralized with $1 \mathrm{M} \mathrm{NaOH}$ and ultrafiltrated (MWCO 1000), first with PBS and then MilliQ-water. The resultant HA-Tyr conjugate was obtained after lyophilization as a white foam. Yield: $1.89 \mathrm{~g}(95 \%)$. DS (UV/Vis): 17. 


\section{Characterization}

${ }^{1}$ H-NMR: ${ }^{1} \mathrm{H}(300 \mathrm{MHz})$ NMR spectra were recorded using a Varian Inova NMR spectrometer. Polymers were dissolved in $\mathrm{D}_{2} \mathrm{O}$ or DMSO at a concentration of $0.020 \mathrm{~g} / \mathrm{ml}$.

UV/Vis: The degree of substitution of tyramine residues in the HA-TA conjugate was 17 as determined by an UV measurement. The HA-TA conjugate was dissolved in PBS at a concentration of $5 \mu \mathrm{g} / \mathrm{mL}$ and the absorbance was measured at $275 \mathrm{~nm}$ using a Cary 300 Bio spectrometer (Varian). The absorbance was correlated to the DS of tyramine groups in the HA-TA using a calibration curve from tyramine in PBS.

Hydrogel formation and gelation time: Hydrogel samples of Dex-TA and Dex-TA/HATA $(50 / 50)$ at a polymer concentration of 10 or $20 \mathrm{wt} \%$ were prepared in vials at room temperature. In a typical procedure, to a polymer solution $(200 \mu \mathrm{L}, 12.5 \mathrm{wt} \%$ and $25 \mathrm{wt} \%$ respectively in PBS), a freshly prepared solution of $\mathrm{H}_{2} \mathrm{O}_{2}(25 \mu \mathrm{L}$ of $0.3 \%$ stock solution in PBS) and HRP ( $25 \mu \mathrm{L}$ of 150 unit/mL stock solution in PBS) were added and the mixture was gently shaken until gel formation occurred. The time to form a gel (denoted as gelation time) was determined using the vial tilting method. No flow within 1 minute upon inverting the vial was regarded as the gel state. The experiment was performed in triplicate.

Gel content and degree of swelling: To determine the gel content, samples of $25 \mathrm{mg}$ or $50 \mathrm{mg}\left(\mathrm{W}_{\mathrm{d}}\right)$ of Dex-TA or Dex-TA/HA-TA (50/50) were converted into hydrogels (10 and 20 wt \%) as described above. The samples were subsequently incubated in $3 \mathrm{~mL}$ of MilliQ water and the solution was refreshed every day for 3 days to remove salts and uncrosslinked polymer. The samples were dried in a vacuum oven to a constant weight $\left(\mathrm{W}_{\mathrm{g}}\right)$. The gel content was expressed as $\mathrm{W}_{\mathrm{g}} / \mathrm{W}_{\mathrm{d}} \mathrm{x} 100 \%$.

The degree of swelling of the hydrogels was determined as follows. $250 \mu \mathrm{L}$ hydrogels were weighted $\left(\mathrm{W}_{\mathrm{i}}\right)$ and then immersed in $3 \mathrm{~mL}$ of MilliQ water for 3 days to reach swelling equilibrium. The swollen samples were removed from the water and after removal of surface water, the samples were weighted $\left(\mathrm{W}_{\mathrm{s}}\right)$. the degree of swelling was calculated from: $\left(\mathrm{W}_{\mathrm{s}}-\mathrm{W}_{\mathrm{i}}\right) /$ $\mathrm{W}_{\mathrm{i}}$. The experiments were performed in triplicate.

Rheological analysis: Rheological experiments were carried out with a MCR 301 rheometer (Anton Paar) using parallel plates $\left(25 \mathrm{~mm}\right.$ diameter) configuration at $37^{\circ} \mathrm{C}$ in the oscillatory mode. In a typical experiment the polymer dissolved in PBS $(200 \mu \mathrm{L}, 12.5$ and $25 \mathrm{wt} \%$ polymer) was placed at the ground plate and a freshly mixed solution of $\mathrm{HRP}(25 \mu \mathrm{L}, 150$ units/mL stock solution) and $\mathrm{H}_{2} \mathrm{O}_{2}(25 \mu \mathrm{L}, 0.3 \%$ stock solution $)$ was pipetted into the polymer solution. After the samples were mixed, the upper plate was immediately lowered 
to a measuring gap size of $0.3 \mathrm{~mm}$, and the measurement was started. To prevent water evaporation, a layer of oil was introduced around the polymer sample. The evolution of the storage $\left(\mathrm{G}^{\prime}\right)$ and loss $\left(\mathrm{G}^{\prime \prime}\right)$ modulus was recorded for 6 hours, using a strain of $0.1 \%$ and a frequency of $0.5 \mathrm{~Hz}$.

Swelling and enzymatic degradation assays of hydrogels: Hydrogel samples $(250 \mu \mathrm{L})$ were prepared in vials according to the procedure described above. Samples were taken out of the vials, accurately weighed $\left(\mathrm{W}_{\mathrm{i}}\right)$, and incubated in $3 \mathrm{~mL}$ of PBS containing $20 \mathrm{U} /$ $\mathrm{mL}$ hyaluronidase at $37{ }^{\circ} \mathrm{C}$. The enzyme-solution was replaced every day during the first 3 days, then twice a week. The hydrogels were weighted $\left(\mathrm{W}_{\mathrm{t}}\right)$ and the remaining gel $(\%)$ was calculated from the initial weight $\left(\mathrm{W}_{\mathrm{i}}\right)$ and remaining gel weight after exposure to the enzyme containing buffer $\left(\mathrm{W}_{\mathrm{t}}\right)$, expressed as $\mathrm{W}_{\mathrm{t}} / \mathrm{W}_{\mathrm{i}} \mathrm{x} 100 \%$. The experiments were performed in triplicate.

In situ chondrocyte incorporation: Bovine chondrocytes were isolated as previously reported $^{22-24}$. Hydrogels containing chondrocytes were prepared under sterile conditions by mixing a polymer/cell suspension with $\mathrm{HRP} / \mathrm{H}_{2} \mathrm{O}_{2}$. Polymer solutions of Dex-TA and Dex-TA/HA-TA (50/50) were made in Chondrocyte expansion medium (DMEM with 10\% heat inactivated fetal bovine serum, $1 \%$ penincilin/streptomycin (Gibco), 0.01 M MEM nonessential amino acids (Gibco), $10 \mathrm{mM}$ HEPES and $0.04 \mathrm{mM}$ L-proline) and HRP and $\mathrm{H}_{2} \mathrm{O}_{2}$ stock solutions were made in PBS. All components were sterilized by filtration through filters with a pore size of $0.22 \mu \mathrm{m}$. Chondrocytes (P0) were dispersed in the polysaccharide precursor solution. The hydrogels were prepared using the same procedure as in the absence of cells. The final polymer concentration was $10 \mathrm{wt} \%$ and the cell seeding density in the gels was $20 \times 10^{6}$ cells $/ \mathrm{mL}$. After gelation, the hydrogels $(100 \mu \mathrm{L}$ each $)$ were transferred to a culture plate and $2 \mathrm{~mL}$ of chondrocyte differentiation medium (DMEM with $0.1 \mu \mathrm{M}$ dexamethasone (Sigma-Aldrich), $100 \mu \mathrm{g} / \mathrm{mL}$ sodium pyruvate (Sigma-Aldrich) $0.2 \mathrm{mM}$ ascorbic acid, 50 $\mathrm{mg} / \mathrm{mL}$ insulin-transferrin-selenite (ITS +1 , Sigma-Aldrich) $100 \mathrm{U} / \mathrm{ml}$ penicillin, $100 \mu \mathrm{g} / \mathrm{ml}$ streptomycin, $10 \mathrm{ng} / \mathrm{mL}$ transforming growth factor 33 (TGF- $33, \mathrm{R} \& \mathrm{D}$ systems)) was added. The samples were incubated at $37{ }^{\circ} \mathrm{C}$ in a humidified atmosphere containing $5 \% \mathrm{CO}_{2}$. The medium was replaced every 3 or 4 days.

Cell viability: A viability study on the hydrogel-mixtures with incorporated cells was performed with a live-dead assay. For the live-dead assay at day 14 and 28 the hydrogel constructs were rinsed with PBS and stained with calcein AM/ethidium homodimer using the Live/Dead assay Kit (Invitrogen), according to the manufactures instruction. Hydrogel/cell constructs were visualized using fluorescence microscopy (Nikon Eclipse E600), as a result living cells fluorescence green and the nuclei of dead cells red. 
Scanning electron microscopy (SEM): The morphology of the chondrocytes in the hydrogels was studied using a Philips XL 30 ESEM-FEG scanning electron microscope operating at a voltage of 5 or $10 \mathrm{kV}$. After 14 and 28 days in vitro culturing the hydrogel/cell constructs were fixed with formalin by sequential dehydration and critical point drying. These samples were gold sputtered (Carringdon) and analyzed with SEM. 


\section{Results and Discussion}

\section{Synthesis}

In this study, dextran-tyramine (Dex-TA) conjugates were prepared by first activating hydroxyl groups of dextran with p-nitrophenyl chloroformate (PNC) to form p-nitrophenyl carbonate derivitaves (Dex-PNC). Subsequently, the obtained Dex-PNC was treated with an excess of tyramine to give Dex-TA conjugates. The structure of the Dex-TA conjugate was confirmed by ${ }^{1} \mathrm{H}-\mathrm{NMR}$ and the degree of substitution (DS) of TA to the dextran was 15 (Figure 1). The DS is defined as the number of conjugated groups per 100 anhydroglucose units in dextran. The key material of this study, a hyaluronic acid-tyramine (HA-TA) conjugate, with a degree of substitution of tyramine residues of 17 (DS 17), was synthesized by the coupling reaction of the amino group of tyramine to the carboxylic acid groups of hyaluronic acid using EDAC/ NHS activation (Figure 1). 
Chapter 7 Crosslinking of Dextran and Hyaluronic Acid Tyramine Conjugates

143

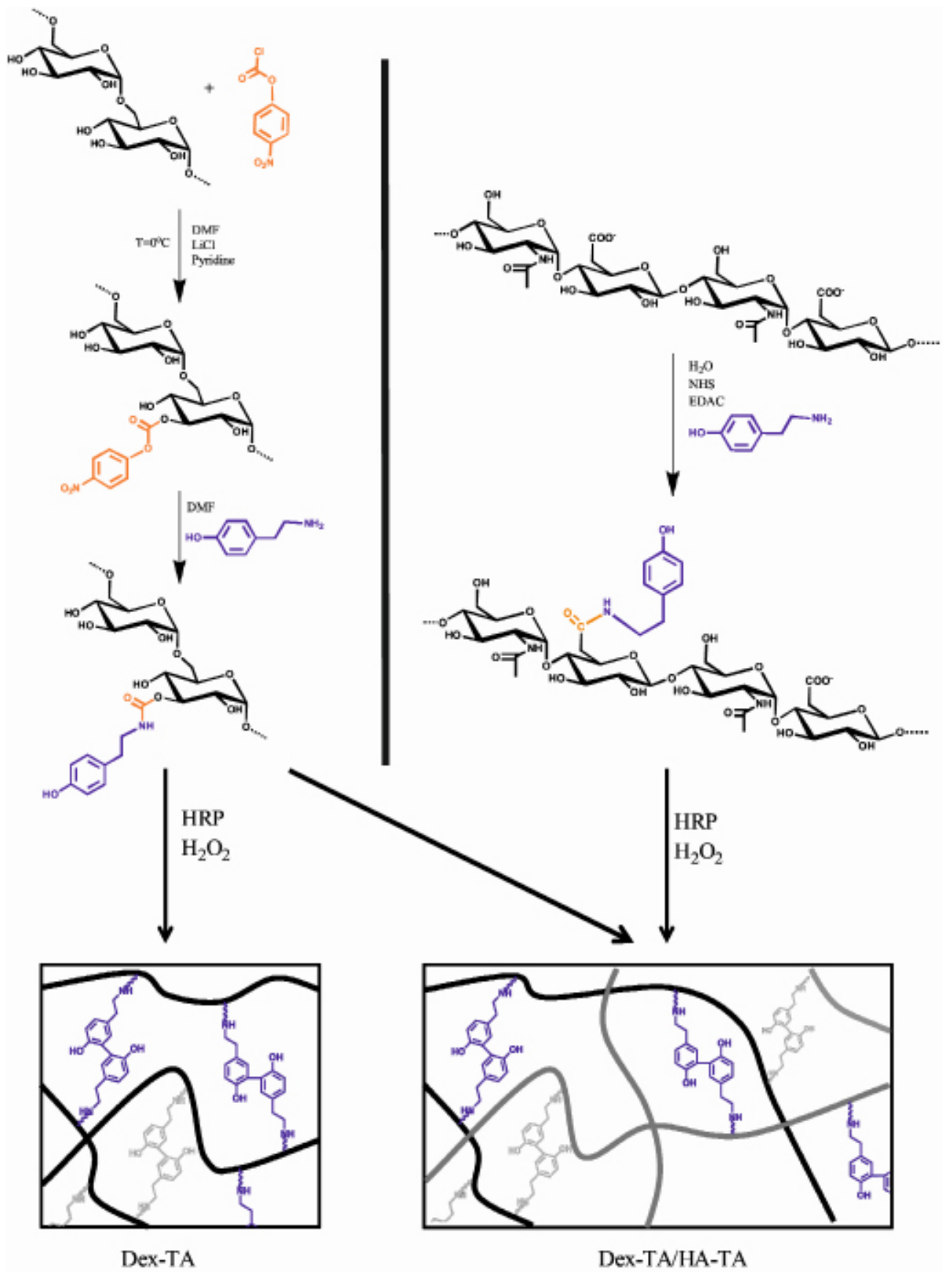

Figure 1. Synthesis of Dex-TA conjugates and HA-TA conjugates and $\mathrm{HRP} / \mathrm{H}_{2} \mathrm{O}_{2}$ mediated crosslinking to Dex-TA or Dex-TA/HA-TA (50/50) hydrogels. 


\section{Hydrogel formation and characterization}

Hydrogels were prepared by the horseradish peroxidase (HRP, 15 units/mL) and $\mathrm{H}_{2} \mathrm{O}_{2}(0.01$ M) mediated coupling reaction of phenolic moieties in Dex-TA (DS 15) and HA-TA (DS 17) conjugates in PBS. Coupling of phenolic rings through the radicals generated at the ortho positions of the phenolic groups can both take place via carbon-carbon bond and carbonoxygen bond formation. In previous research ${ }^{22-25}$, it was shown that at these concentrations of HRP and $\mathrm{H}_{2} \mathrm{O}_{2}$ the resulting hydrogels/cell constructs have good cytocompatibility ${ }^{24}$. DexTA and Dex-TA/HA-TA (50/50) hydrogels were prepared at polymer concentrations of 10 and $20 \mathrm{wt} \%$.

Because a short gelation time is a prerequisite for injectable gel/cell constructs, the gelation times of Dex-TA and Dex-TA/HA-TA (50/50) were investigated by the vial tilting method (Figure 2A). The enzymatic crosslinking of Dex-TA 10 and $20 \mathrm{wt} \%$ hydrogel led to fast gelation of approximately 10 seconds. The gelation time of a Dex-TA/HA-TA (50/50) at 10 wt \% was also ca. 10 seconds but at $20 \mathrm{wt} \%$ the gelation time increased considerably to 60 seconds. At this concentration a pronounced increase in viscosity was observed. This increase in viscosity likely hampers the diffusion of $\mathrm{HRP}$ and $\mathrm{H}_{2} \mathrm{O}_{2}$ and tyramine units resulting in a much slower crosslinking rate.

The gel content of the crosslinked hydrogels was determined gravimetrically by extracting the gels with water for 3 days and was approximately $80 \%$ for all gels prepared (Figure $2 \mathrm{~B}$ ).

The Dex-TA/HA-TA (50/50) hydrogels show a much higher degree of swellling compared to Dex-TA hydrogels (Figure 2C). Especially at $20 \mathrm{wt} \%$ a lower crosslink density due to the high viscosity may hamper efficient crosslinking. 

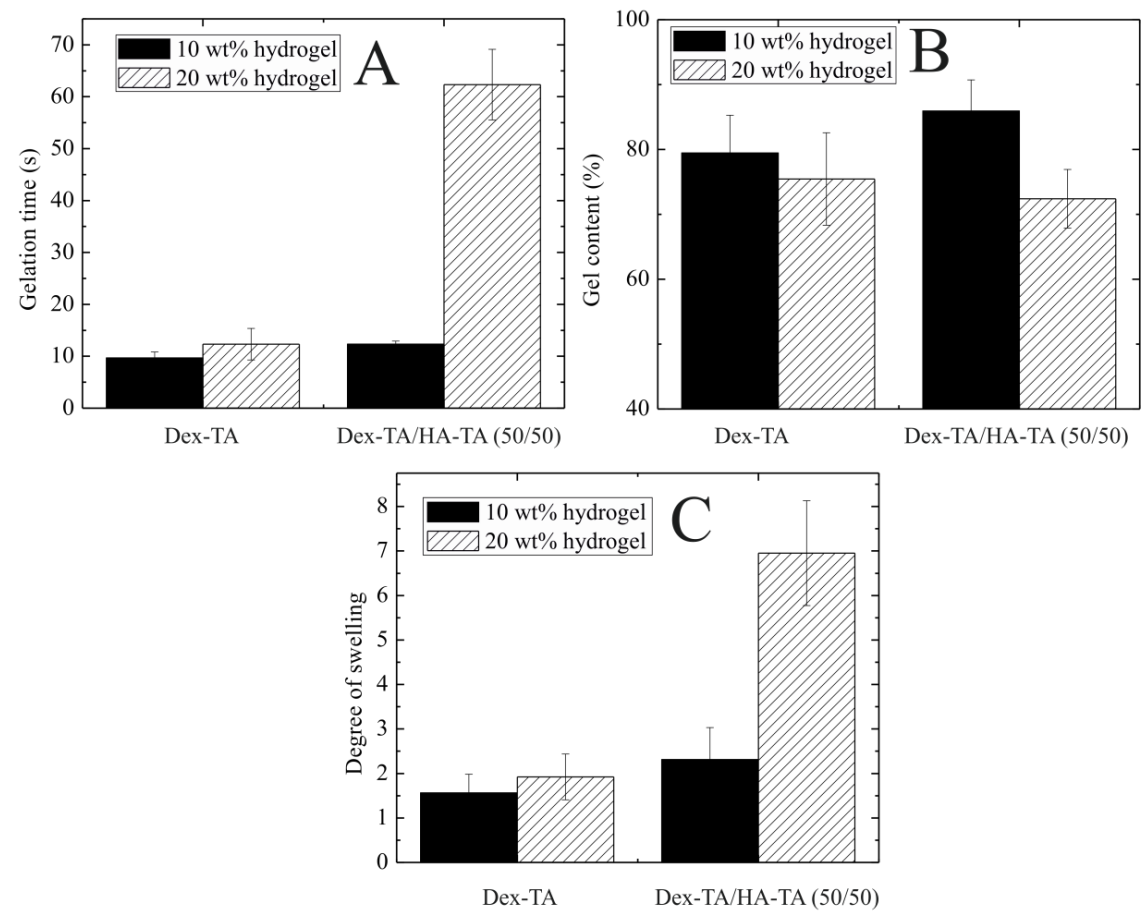

Figure 2. A) Gelation times of 10 and 20 wt $\%$ hydrogels. B) Gel content of 10 wt $\%$ and 20 wt $\%$ hydrogels. C) Degree of swelling of $10 \mathrm{wt} \%$ and $20 \mathrm{wt} \%$ hydrogels.

\section{Rheological analysis}

The mechanical properties of 10 and 20 wt \% Dex-TA and Dex-TA/HA-TA (50/50) hydrogels were studied by oscillatory rheology experiments at $37^{\circ} \mathrm{C}$. Gel formation kinetics was followed by monitoring the storage modulus ( $\left.G^{\prime}\right)$ and loss modulus (G') in time directly after mixing a polymer and a $\mathrm{HRP} / \mathrm{H}_{2} \mathrm{O}_{2}$ solution. It was seen that after 3 minutes all samples reached a plateau value. When the plateau was reached some notable differences could be seen (Figure 3). For Dex-TA 10 and $20 \mathrm{wt} \%$ hydrogels the stiffness is approximately the same. The Dex-TA/HA-TA (50/50) hydrogels showed a decrease in the stiffness upon increasing the polymer concentration from 10 to $20 \mathrm{wt} \%$. This is in line with the results found for the gel content and water uptake. The low crosslink density makes the $20 \mathrm{wt} \%$ Dex-TA/HA-TA (50/50) difficult to handle and only the $10 \mathrm{wt} \%$ Dex-TA and Dex-TA/HATA $(50 / 50)$ hydrogels were used to test the degradation and cytocompatibility.

Comparing the $10 \mathrm{wt} \%$ Dex-TA and Dex-TA/HA-TA (50/50) hydrogels it is seen that 
addition of HA-TA increases the stiffness of the hydrogel. Whereas 10 wt \% Dex-TA hydrogels have $\tan \delta$ values of 0.18 incorporation of HA-TA lower this to 0.13 in Dex-TA/ HA-TA (50/50) hydrogels.
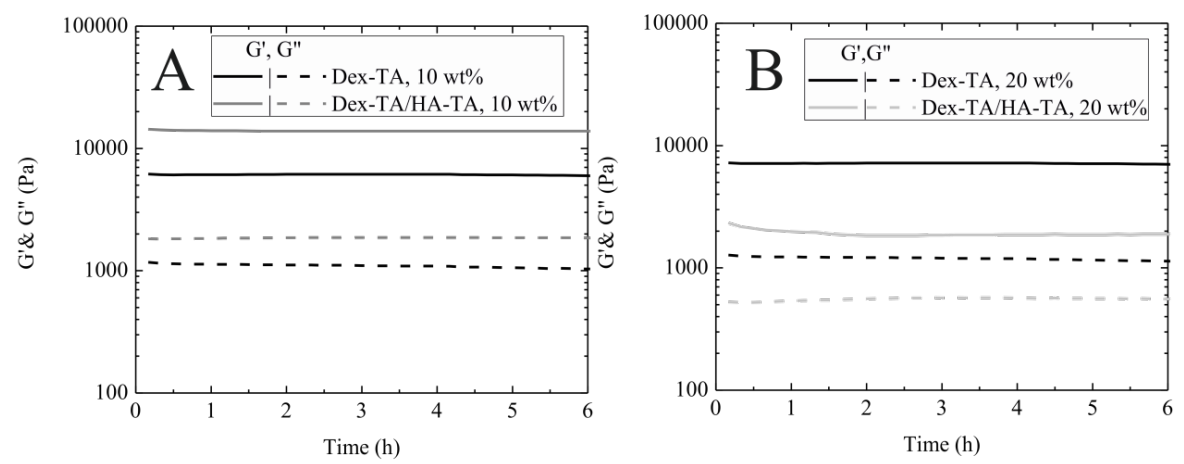

Figure 3. Storage and loss modulus of $10 \mathrm{wt} \%$ Dex-TA and Dex-TA/HA-TA (50/50) hydrogels.

\section{Degradation}

The enzymatic degradation profiles of the $10 \mathrm{wt} \%$ Dex-TA and Dex-TA/HA-TA(50/50) were determined by placing $3 \mathrm{~mL}$ of PBS containing $20 \mathrm{U} / \mathrm{mL}$ hyaluronidase $(6$ times as much as present in human articular cartilage ${ }^{27}$ ) on top of $250 \mu \mathrm{L}$ of hydrogels. The hydrogels were kept at $37^{\circ} \mathrm{C}$ and their wet weights were monitored at regular time intervals. The remaining gel $(\%)$ was expressed as the gel weight after exposure to enzyme buffer $\left(\mathrm{W}_{\mathrm{t}}\right)$ divided by the original gel weight after preparation $\left(\mathrm{W}_{\mathrm{i}}\right)$. In buffer without enzymes present, the Dex-TA and Dex-TA/HA-TA (50/50) hydrogels swelled and the weight increased during the first 3 days, and remained stable up to 50 days (data not shown). In the presence of hyaluronidase, the Dex-TA showed no degradation for 60 days. In the first days the weight of the Dex-TA/HATA (50/50) increased because of chain scission of HA causing increased water uptake, and followed by weight loss due to the dissolution and release of small fragments. It was found that the Dex-TA/HA-TA (50/50) was fully degradable within 55 days (Figure 4). Compared to previously reported HA-TA hydrogels ${ }^{28}$ which were completely degraded within 1 day in the presence of $25 \mathrm{U} / \mathrm{mL}$ of hyaluronidase in PBS, these gels were much more stable most likely due to co-crosslinking with Dex-TA. Compared to results of HA grafted with Dex-TA obtained by Jin et al. it is seen that combining Dex-TA and HA-TA gives similar stabilization of the hydrogels, but avoids the relative complex synthesis of the HA grafted with Dex-TA ${ }^{23}$. 


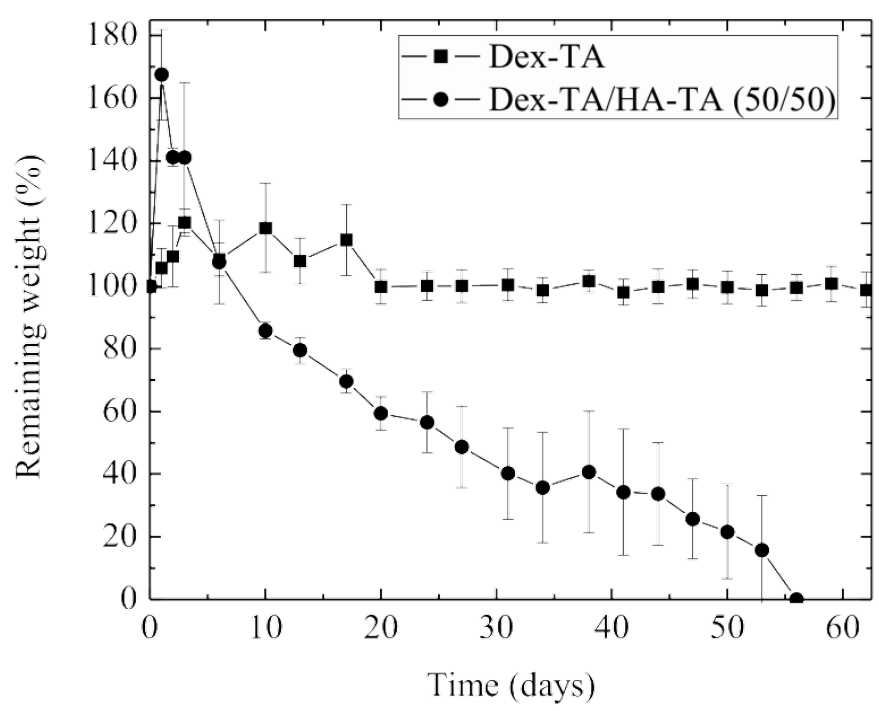

Figure 4. Enzymatic degradation of Dex-TA and Dex-TA/HA-TA (50/50) hydrogels in PBS containing 20 U/mL hyaluronidase at $37^{\circ} \mathrm{C}$.

\section{Cell viability and proliferation}

The cytocompatibility of $10 \mathrm{wt} \%$ Dex-TA and Dex-TA/HA-TA (50/50) was analyzed by a live/dead assay after culturing for 14 and 28 days, in which the live cells fluorescence green, and dead cells fluorescence red. For both the Dex-TA and Dex-TA/HA-TA (50/50) it was shown that $95 \%$ of the cells fluorescence green after both 14 (data not shown) and 28 days (Figure 5).

It is known that chondrocytes in culture may rapidly dedifferentiate and obtain a fibroblastlike phenotype ${ }^{29}$. Whereas these dedifferentiated show a flattened morphology a round cell shape is correlated with the maintenance of the chondrocyte phenotype. To assess if the chondrocytes maintained a round shape SEM images were taken of Dex-TA and DexTA/HA-TA (50/50) hydrogels cultured for 28 days. The morphology of the chondrocytes incorporated in the Dex-TA hydrogel showed a flattened morphology. Contrary, the Dex-TA/ HA-TA (50/50) hydrogels exhibited a distinctly round cell shape showing that hyaluronic acid may stimulate the regeneration of cartilage in these constructs (Figure 5). 


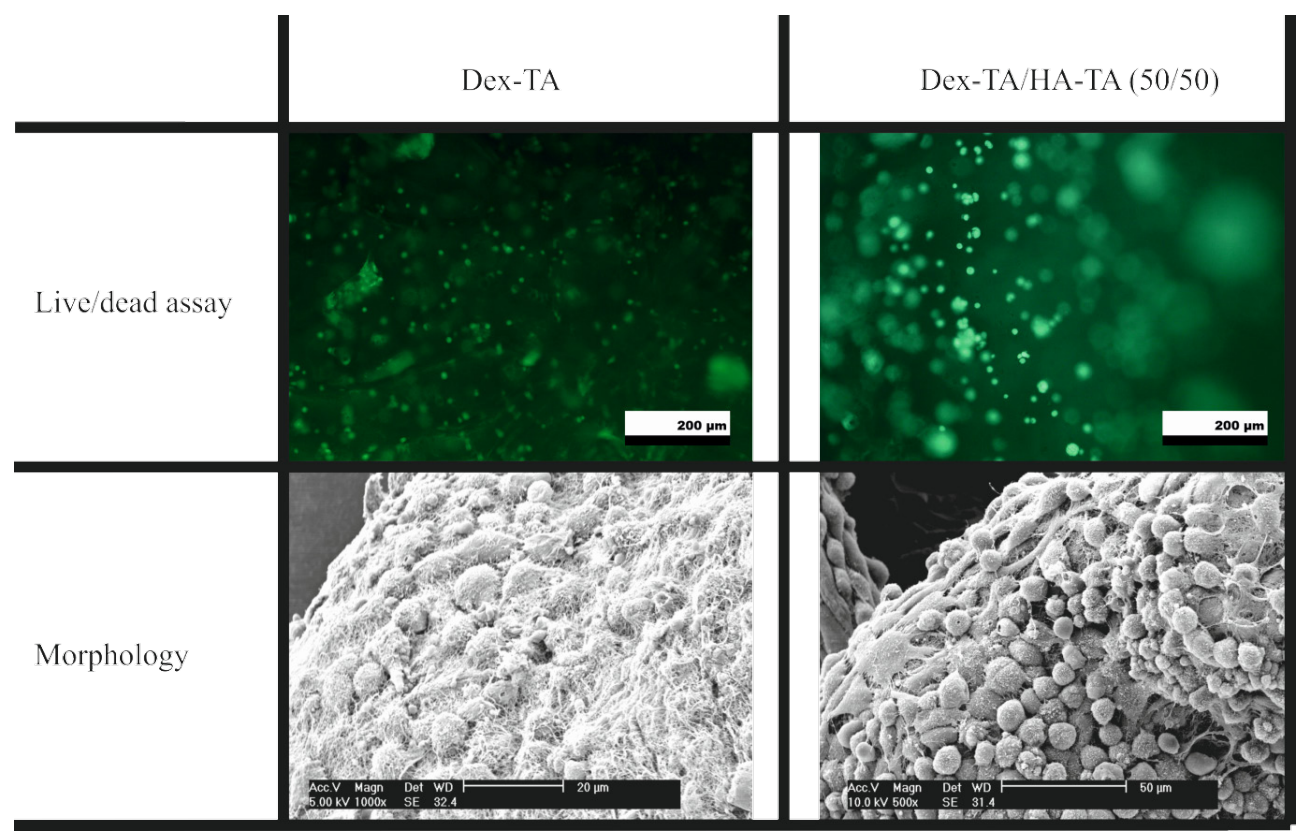

Figure 5. Live-dead assay showing the chondrocytes incorporated in Dex-TA or Dex-TA/HA-TA (50/50) after 28 days. SEM images showing the morphology of chondrocytes incorporated in Dex-TA or Dex-TA/HA-TA (50/50) hydrogels at 28 days.

\section{Conclusions}

We have shown that injectable hydrogels containing naturally occurring hyaluronic acid, can be prepared via enzymatic crosslinking of Dex-TA and HA-TA conjugates. The gelation is fast with gelation times lower than $1 \mathrm{~min}$, which can be regulated by varying the polymer concentration. Hydrogels containing HA-TA are readily degraded in the presence of hyaluronidase. $10 \mathrm{wt} \%$ Dex-TA/HA-TA (50/50) hydrogels had a higher storage modulus compared to Dex-TA, while $20 \mathrm{wt} \%$ Dex-TA/HA-TA (50/50) showed an increase in viscosity hampering the crosslinking reaction. The behavior of chondrocytes incorporated in Dex-TA/ HA-TA (50/50) hydrogels demonstrated that the gel systems had good cytocompatibility. These results indicate that Dex-TA/HA-TA (50/50) hydrogels have a high potential as matrices for cartilage tissue engineering.

\section{References}

1. Jin, R.; Dijkstra, P. J., Hydrogels for tissue engineering applications. In Biomedical applications of hydrogels, Ottenbrite, R. M., Ed. Springer: NY, 2010.

2. Kretlow, J. D.; Klouda, L.; Mikos, A. G., Injectable matrices and scaffolds for drug delivery in tissue engineering. Advanced Drug Delivery Reviews 2007, 59, (4-5), 263-273. 
3. Kretlow, J. D.; Young, S.; Klouda, L.; Wong, M.; Mikos, A. G., Injectable biomaterials for regenerating complex craniofacial tissues. Advanced Materials 2009, 21 , (32-33), 3368-3393.

4. Van Tomme, S. R.; Storm, G.; Hennink, W. E., In situ gelling hydrogels for pharmaceutical and biomedical applications. International Journal of Pharmaceutics 2008, 355, (1-2), 1-18.

5. Yu, L.; Ding, J., Injectable hydrogels as unique biomedical materials. Chemical Society Reviews 2008, 37, (8), 1473-1481.

6. Bryant, S. J.; Anseth, K. S., Controlling the spatial distribution of ECM components in degradable PEG hydrogels for tissue engineering cartilage. Journal of Biomedical Materials Research - Part A 2003, 64, (1), 70-79.

7. Bryant, S. J.; Bender, R. J.; Durand, K. L.; Anseth, K. S., Encapsulating chondrocytes in degrading PEG hydrogels with high modulus: Engineering gel structural changes to facilitate cartilaginous tissue production. Biotechnology and Bioengineering 2004, 86, (7), 747-755.

8. $\quad$ Bryant, S. J.; Chowdhury, T. T.; Lee, D. A.; Bader, D. L.; Anseth, K. S., Crosslinking density influences chondrocyte metabolism in dynamically loaded photocrosslinked poly(ethylene glycol) hydrogels. Annals of Biomedical Engineering 2004, 32, (3), 407-417.

9. Bryant, S. J.; Durand, K. L.; Anseth, K. S., Manipulations in hydrogel chemistry control photoencapsulated chondrocyte behavior and their extracellular matrix production. Journal of Biomedical Materials Research - Part A 2003, 67, (4), 1430-1436.

10. Bryant, S. J.; Nuttelman, C. R.; Anseth, K. S., Cytocompatibility of UV and visible light photoinitiating systems on cultured NIH/3T3 fibroblasts in vitro. Journal of Biomaterials Science, Polymer Edition 2000, 11, (5), 439-457.

11. Łukaszczyk, J.; Śmiga, M.; Jaszcz, K.; Adler, H. J. P.; Jähne, E.; Kaczmarek, M., Evaluation of oligo(ethylene glycol) dimethacrylates effects on the properties of new biodegradable bone cement compositions. Macromolecular Bioscience 2005, 5, (1), 64-69. 12. Hiemstra, C.; van der Aa, L. J.; Zhong, Z.; Dijkstra, P. J.; Feijen, J., Rapidly in situ-forming degradable hydrogels from dextram triols through Michael addition. Biomacromolecules 2007, 8, (5), 1548-1556.

13. Hiemstra, C.; Van Der Aa, L. J.; Zhong, Z.; Dijkstra, P. J.; Feijen, J., Novel in situ forming, degradable dextran hydrogels by michael addition chemistry: Synthesis, rheology, and degradation. Macromolecules 2007, 40, (4), 1165-1173.

14. Lutolf, M. P.; Lauer-Fields, J. L.; Schmoekel, H. G.; Metters, A. T.; Weber, F. E.; Fields, G. B.; Hubbell, J. A., Synthetic matrix metalloproteinase-sensitive hydrogels for the conduction of tissue regeneration: Engineering cell-invasion characteristics. Proceedings of the National Academy of Sciences of the United States of America 2003, 100, (9), 54135418.

15. Lutolf, M. P.; Raeber, G. P.; Zisch, A. H.; Tirelli, N.; Hubbell, J. A., Cellresponsive synthetic hydrogels. Advanced Materials 2003, 15, (11), 888-892.

16. Shu, X. Z.; Liu, Y.; Palumbo, F. S.; Luo, Y.; Prestwich, G. D., In situ crosslinkable hyaluronan hydrogels for tissue engineering. Biomaterials 2004, 25, (7-8), 1339-1348.

17. Tortora, M.; Cavalieri, F.; Chiessi, E.; Paradossi, G., Michael-type addition reactions for the in situ formation of poly(vinyl alcohol)-based hydrogels.

Biomacromolecules 2007, 8, (1), 209-214. 
18. Vanderhooft, J. L.; Mann, B. K.; Prestwich, G. D., Synthesis and characterization of novel thiol-reactive poly(ethylene glycol) cross-linkers for extracellular-matrix-mimetic biomaterials. Biomacromolecules 2007, 8, (9), 2883-2889.

19. Kim, J.; Kim, I. S.; Cho, T. H.; Lee, K. B.; Hwang, S. J.; Tae, G.; Noh, I.; Lee, S. H.; Park, Y.; Sun, K., Bone regeneration using hyaluronic acid-based hydrogel with bone morphogenic protein-2 and human mesenchymal stem cells. Biomaterials 2007, 28, (10), 1830-1837.

20. Park, Y.; Lutolf, M. P.; Hubbell, J. A.; Hunziker, E. B.; Wong, M., Bovine Primary Chondrocyte Culture in Synthetic Matrix Metalloproteinase-Sensitive Poly(ethylene glycol)-Based Hydrogels as a Scaffold for Cartilage Repair. Tissue Engineering 2004, 10, (3-4), 515-522.

21. Salinas, C. N.; Cole, B. B.; Kasko, A. M.; Anseth, K. S., Chondrogenic differentiation potential of human mesenchymal stem cells photoencapsulated within poly(ethylene glycol)-arginine-glycine-aspartic acid-serine thiol-methacrylate mixed-mode networks. Tissue Engineering 2007, 13, (5), 1025-1034.

22. Jin, R.; Moreira Teixeira, L. S.; Dijkstra, P. J.; Karperien, M.; van Blitterswijk, C. A.; Zhong, Z. Y.; Feijen, J., Injectable chitosan-based hydrogels for cartilage tissue engineering. Biomaterials 2009, 30, (13), 2544-2551.

23. Jin, R.; Moreira Teixeira, L. S.; Dijkstra, P. J.; van Blitterswijk, C. A.; Karperien, M.; Feijen, J., Enzymatically-crosslinked injectable hydrogels based on biomimetic dextran-hyaluronic acid conjugates for cartilage tissue engineering. Biomaterials 2010, 31 , (11), 3103-3113.

24. Jin, R.; Moreira Teixeira, L. S.; Dijkstra, P. J.; Van Blitterswijk, C. A.; Karperien, M.; Feijen, J., Chondrogenesis in injectable enzymatically crosslinked heparin/dextran hydrogels. Journal of Controlled Release 2011, 152, (1), 186-195.

25. Jin, R.; Moreira Teixeira, L. S.; Dijkstra, P. J.; Zhong, Z.; Van Blitterswijk, C. A.; Karperien, M.; Feijen, J., Enzymatically crosslinked dextran-tyramine hydrogels as injectable scaffolds for cartilage tissue engineering. Tissue Engineering - Part A 2010, 16, (8), 2429-2440.

26. Mita, N.; Tawaki, S. I.; Uyama, H.; Kobayashi, S., Precise structure control of enzymatically synthesized polyphenols. Bulletin of the Chemical Society of Japan 2004, 77, (8), 1523-1527.

27. Delpech, B.; Bertrand, P.; Chauzy, C., An indirect enzymoimmunological assay for hyaluronidase. Journal of Immunological Methods 1987, 104, (1-2), 223-229.

28. Lee, F.; Chung, J. E.; Kurisawa, M., An injectable enzymatically crosslinked hyaluronic acid-tyramine hydrogel system with independent tuning of mechanical strength and gelation rate. Soft Matter 2008, 4, (4), 880-887.

29. Yoon, Y.M.; Kim, S.J.; Oh, C.D.; Ju J.W.; Song, W.K.; Yoo Y.J.; Huh, T.L.; Chun J.S.; Maintenance of differentiated phenotype of articular chondrocytes by protein kinase $\mathrm{C}$ and extracellular signal regulated protein kinase. Journal of Biological Chemistry 2002, $277,10,8412-8420$ 


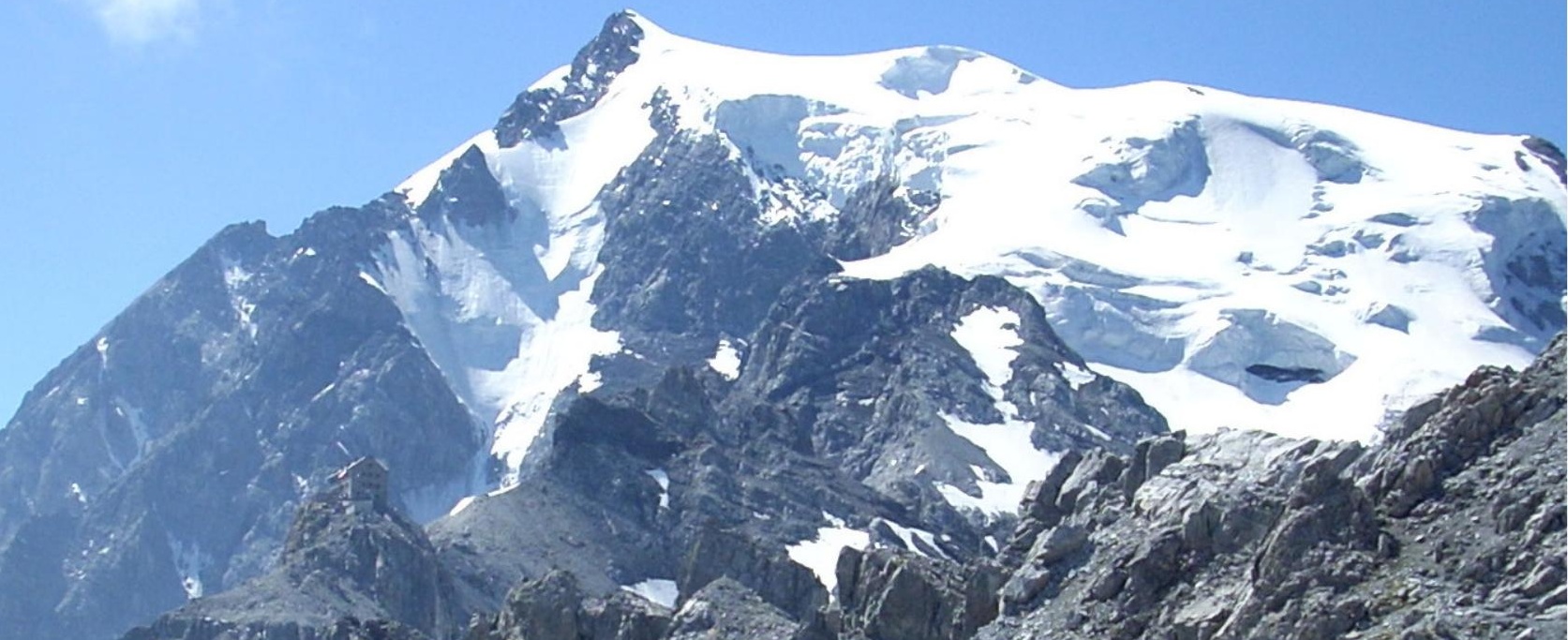

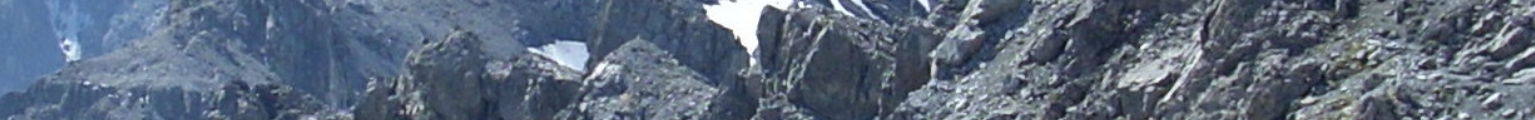
a S. 1.2.

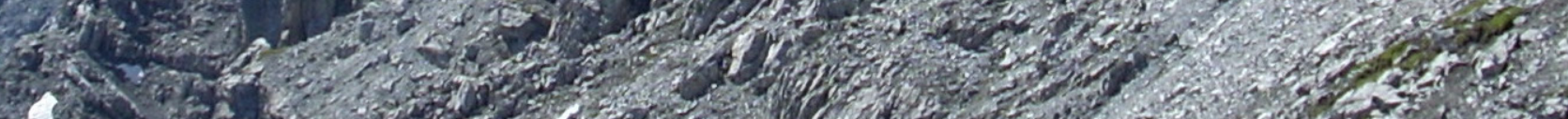

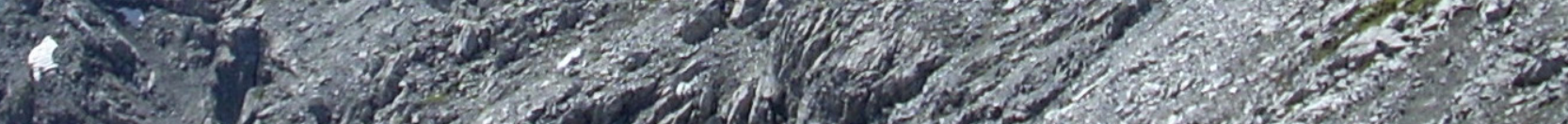
(5) 10. 2.

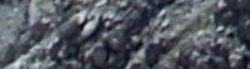
(3)

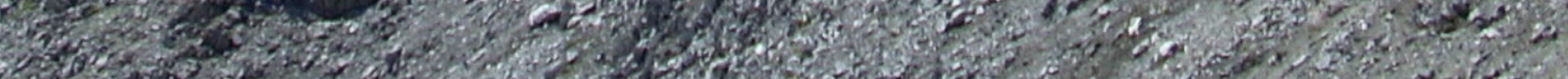

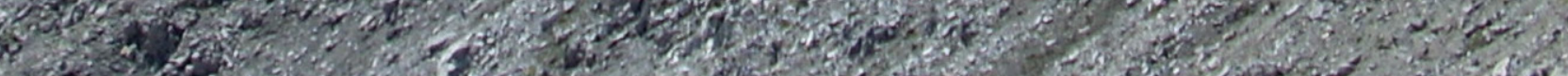

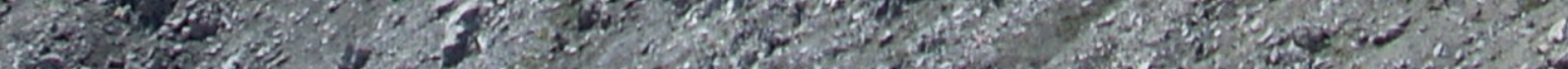




\section{Chapter 8 Injectable In-Situ Forming Hydrogels by Enzymatic Co-Crosslinking of Dextran, Heparin and Hyaluronic Acid Tyramine Conjugates for Cartilage Tissue Engineering}

Jos W.H.Wennink, Kerstin Niederer, Poyan Rashidi, Liliana S. Moreira Teixeira, Marcel Karperien, Jan Feijen and Pieter J. Dijkstra

"Basic research is like shooting an arrow into the air and, where it lands, painting a target." 


\begin{abstract}
In this study, in-situ forming hydrogels were prepared by horseradish peroxidase-mediated co-crosslinking of dextran-tyramine (Dex-TA), heparin-tyramine (Hep-TA) and/or hyaluronic acid-tyramine (HA-TA) conjugates and used as scaffolds for cartilage tissue engineering. The gelation times of $10 \mathrm{wt} \%$ polysaccharide solutions were $<20$ seconds and the gel contents were approximately $80 \%$. Dex-TA/Hep-TA/HA-TA hydrogels with different weight ratios showed good mechanical properties with storage moduli ranging from 36 to $45 \mathrm{kPA}$. DexTA/Hep-TA/HA-TA hydrogels were fully disintegrated in the presence of hyaluronidase and the degradation times decreased with increasing HA-TA content. Furthermore, increasing the HA-TA content of the gels led to increasing porosity of dried gels, important for nutrient transport and cell mobility. Chondrocytes incorporated in $10 \mathrm{wt} \%$ Dex-TA/Hep-TA/HA-TA gels with different weight ratios of the conjugates showed good viability after incubation in chondrocyte differentiation medium for 28 days. Moreover, Dex-TA/Hep-TA/HA-TA (25/50/25 weight ratio) gels containing chondrocytes showed improved production and expression of Collagen type II, compared to e.g. Dex-TA and Dex-TA/Hep-TA chondrocyte containing control hydrogels. These results indicate that these in-situ forming hydrogels are promising injectable and biodegradable materials for cartilage repair.
\end{abstract}




\section{Introduction}

Hyaline cartilage is the most prevalent form of cartilage throughout the body, serving as a low-friction articulating surface in load-bearing, diarthrodial joints ${ }^{1,2}$. Trauma and a variety of diseases can lead to damaged hyaline cartilage, and the avascular and alymphatic nature of cartilage significantly impedes the body's natural ability to repair and regenerate this tissue ${ }^{3}$. Current clinical methods to repair defective cartilage include autologous chondrocyte implantation ${ }^{4,5}$, mosaicplasty and microfracture ${ }^{5}$ all of which are limited in their ability to regenerate functional cartilage both in terms of composition and mechanics. Due to these shortcomings, research in recent years has focused on tissue engineering solutions. In this approach mature or progenitor cells are incorporated in a scaffold that can be placed in the cartilage defect site ${ }^{3}$. An ideal scaffold for cartilage regeneration is expected to have a controlled degradability, provides adequate mechanical strength, promotes cell survival and differentiation and allows nutrient diffusion, adhesion and integration with the surrounding native cartilage tissue.

Hydrogels, 3D elastic networks, mimic hydrated native cartilage tissue and are considered suitable scaffolds for cartilage tissue engineering ${ }^{6}$. Whereas preformed hydrogels may be applied, in-situ forming hydrogels have attracted most attention in recent years since they offer various advantages. They can be applied in a minimally invasive surgical procedure, can fill irregular-shaped defects and allow easy incorporation of cells and bioactive molecules in the precursor solution ${ }^{3}$.

In-situ forming hydrogels may be either physically or chemically crosslinked, but also combinations thereof may be applied. Chemical crosslinking methods may involve photopolymerization ${ }^{7-10}$, Schiff-base formation and Michael-type addition reactions ${ }^{11-18}$. Recently, horseradish peroxidase (HRP) mediated chemical crosslinking has been developed to produce in-situ forming hydrogels ${ }^{19-25}$. Lee et al. ${ }^{20}$ reported on hyaluronic acid-based insitu forming hydrogels for protein release and Sakai et al. ${ }^{24}$ prepared gelatin-based in-situ forming hydrogels in vitro and indicated their potential application in tissue engineering in vivo. In our labs we showed that fast in-situ forming hydrogels can be obtained via enzymatic crosslinking of dextran-tyramine conjugates (Dex-TA) or chitosan-phloretic acid conjugates in the presence of HRP and hydrogen peroxide ${ }^{19,25}$.

In subsequent studies we reported that the glycosaminoglycan heparin can be incorporated in gels via enzymatic co-crosslinking of Dex-TA and heparin tyramine (Hep-TA) conjugates ${ }^{26}$. The results showed that the incorporation of heparin into the hydrogels greatly improved the hydrogel swelling properties, which is favorable for nutrient transport when chondrocytes are 
incorporated in the hydrogels. Such gels show improved chondrocyte viability, proliferation and an enhanced matrix production as compared to the hydrogels prepared from Dex-TA conjugates. It has to be realized that dextran cannot be degraded in the human joint and there is no information that heparin can degrade in the joint. In circulation heparin is only degraded by internalization and depolymerization by endothelial cells and macrophages ${ }^{27,28}$.

In the ECM of articular cartilage hyaluronic acid serves as a core filament of the proteoglycan aggregate. These macromolecular aggregates establish essential biomechanical properties of cartilage ${ }^{29,30}$. Furthermore, hyaluronic acid influences cell behavior which is in part due to its role in the organization of the ECM and its capacity to interact with cells ${ }^{31}$. The protein CD44, present in the cell membrane, serves as a primary trans-membrane receptor for hyaluronic acid, providing cells with a mechanism for matrix attachment and for sensing changes in the $\mathrm{ECM}^{32}$.

Remodeling of cartilage in articular joints is primarily accomplished by the synthesis and degradation of collagen type II and proteoglycan aggregates ${ }^{33,34}$. In the ECM hyaluronidase degrades hyaluronic acid. The effective degradation by this enzyme is also shown by the fast degradation of hyaluronic acid-tyramine (HA-TA) conjugate hydrogels. Such hydrogels were completely degraded within 1 day in the presence of 25 units $/ \mathrm{mL}$ of hyaluronidase in PBS 35. Co-crosslinking of Dex-TA and HA-TA conjugates using $\mathrm{HRP} / \mathrm{H}_{2} \mathrm{O}_{2}$ could be applied to decrease the degradation rate. In the presence of hyaluronidase (20 units/mL) Dex-TA/HATA (50/50 weight ratio) hydrogels were fully degraded in 55 days ${ }^{23}$.

In the current paper we present the preparation and properties of a 3 component system comprising Dex-TA, Hep-TA and HA-TA, thus combining the beneficial effects of each component in hydrogels for cartilage regeneration. In this respect Dex-TA is used to control the degradation rate whereas Hep-TA is important in the binding of growth factors. HATAmay also improve the interaction with cells and introduce cleavable sites to control the degradation rate in hydrogels in which chondrocytes are incorporated. Hydrogels comprising Dex-TA, Hep-TA and HA-TA in different weight ratios were prepared and their physical, mechanical and degradation properties were analyzed. Hydrogel-chondrocyte constructs were analyzed with respect to cell survival and matrix production. 


\section{Materials and Methods}

\section{Materials}

Dextran (Dex, $\mathrm{M}_{\mathrm{w}}=15$ to $25 \mathrm{~kg} / \mathrm{mol}$ ) was obtained from Sigma and dried by lyophilization. Heparin sodium (Hep, from porcine intestinal mucosa, $M_{w}=3-30 \mathrm{~kg} / \mathrm{mol}$ ) was purchased from Celsus, Inc. Hyaluronic acid sodium salt (HA, $M_{w}=15-25 \mathrm{~kg} / \mathrm{mol}$ ) was purchased from CPN-shop. N-hydroxysuccinimide (NHS), tyramine, anhydrous dimethylformamide (DMF), pyridine (anhydrous), hydrogen peroxide $\left(\mathrm{H}_{2} \mathrm{O}_{2}\right)$, lithium chloride and horseradish peroxidase (HRP, 311 purpurogallin units/mg solid) were obtained from Sigma-Aldrich. N-Ethyl-N'-(3-dimethylaminopropyl) carbodiimide hydroxide (EDAC) was obtained from Fluka. Phosphate buffered saline (PBS, pH 7.4) was purchased from B. Braun Co. Dex-TA, Hep-TA and HA-TA were synthesized as described previously ${ }^{19,23,26 .}$

\section{Characterization}

${ }^{1}$ H-NMR: ${ }^{1} \mathrm{H}(300 \mathrm{MHz})$ NMR spectra were recorded using a Varian Inova NMR spectrometer. Polymers were dissolved in $\mathrm{D}_{2} \mathrm{O}$ or DMSO-d6 at a concentration of $0.020 \mathrm{~g} / \mathrm{mL}$.

UV/Vis: The degree of substitution of tyramine residues per 100 saccharide rings in the HepTA and HA-TA conjugates was 31 and 17, respectively, as determined by UV measurements. The Hep-TA or HA-TA conjugate was dissolved in PBS at a concentration of $5 \mathrm{mg} / \mathrm{mL}$ and the absorbance was measured at $275 \mathrm{~nm}$ using a Cary 300 Bio spectrometer (Varian). The number of tyramine groups in the Hep-TA or HA-TA conjugates was derived from a calibration curve relating the concentration of tyramine in PBS to the UV absorbance at 275 nm.

Hydrogel formation and gelation time: Hydrogel samples of Dex-TA, Dex-TA/Hep-TA (50/50 weight ratio) and Dex-TA/Hep-TA/HA-TA (different weight ratios) at a total polymer concentration of 10 or $20 \mathrm{wt} \%$ were prepared in vials at room temperature. In a typical procedure, to a polymer solution in PBS (200 $\mu \mathrm{L}, 12.5 \mathrm{wt} \%$ or $25 \mathrm{wt} \%$, respectively), a freshly prepared PBS solution of $\mathrm{H}_{2} \mathrm{O}_{2}(25 \mu \mathrm{L}$ of a $0.3 \mathrm{wt} \%$ stock solution) and HRP $(25 \mu \mathrm{L}$ of a 150 units $/ \mathrm{mL}$ stock solution) were added and the mixture was gently shaken until gel formation occurred. The time to form a gel was determined using the vial tilting method. No flow within 1 min upon inverting the vial was regarded as the gel state. The experiment was performed in triplicate.

Gel content and water uptake: To determine the gel content, samples of polymer mixtures were weighed $\left(\mathrm{W}_{\mathrm{d}}\right)$. The polymers were dissolved in PBS and crosslinked as described in 
the previous section to form 10 or $20 \mathrm{wt} \%$ hydrogels. The samples were incubated in 3 $\mathrm{mL}$ of demi water and the solution was refreshed every day for 3 days to remove salts and uncrosslinked polymer. The samples were dried by lyophilization to a constant weight $\left(\mathrm{W}_{\mathrm{g}}\right)$. The gel content was expressed as $\mathrm{W}_{\mathrm{g}} / \mathrm{W}_{\mathrm{d}} \mathrm{x} 100 \%$.

The water uptake of the hydrogels was determined by first preparing $250 \mu \mathrm{L}$ of hydrogels in PBS as described in the previous section. The dry polymer weight in the $10 \mathrm{wt} \%$ and 20 wt \% hydrogels is $25 \mathrm{mg}$ and $50 \mathrm{mg}$, respectively $\left(\mathrm{W}_{\mathrm{d}}\right)$. These hydrogels were immersed in $3 \mathrm{~mL}$ of demi water for 3 days to reach swelling equilibrium. The swollen samples were then removed from the water and after removal of surface water, the samples were weighed $\left(\mathrm{W}_{\mathrm{s}}\right)$. The initial weight $\mathrm{W}_{\mathrm{d}}$ was corrected for the gel content and expressed as $\mathrm{W}_{\mathrm{d}}$. The water uptake was calculated from: $\left(\mathrm{W}_{\mathrm{s}}-\mathrm{W}_{\mathrm{d}}{ }^{*}\right) /\left(\mathrm{W}_{\mathrm{d}}{ }^{*}\right) \times 100 \%$. The experiments were performed in triplicate.

Rheological analysis: Rheological experiments were carried out with a MCR 301 rheometer (Anton Paar) using parallel plates $\left(25 \mathrm{~mm}\right.$ diameter, $\left.0^{\circ}\right)$ configuration at $37{ }^{\circ} \mathrm{C}$ in the oscillatory mode. In a typical experiment the polymer dissolved in PBS (200 $\mu \mathrm{L}, 12.5$ and 25 wt \% polymer) was placed at the ground plate and a freshly mixed solution of HRP (25 $\mu \mathrm{L}, 150$ units/mL stock solution) and $\mathrm{H}_{2} \mathrm{O}_{2}(25 \mu \mathrm{L}, 0.3 \mathrm{wt} \%$ stock solution $)$ was pipetted while mixing. After the samples were mixed, the upper plate was immediately lowered to a measuring gap size of $0.3 \mathrm{~mm}$, and the measurement was started. To prevent water evaporation, a layer of oil was introduced around the polymer sample. The evolution of the storage $\left(\mathrm{G}^{\prime}\right)$ and loss $\left(\mathrm{G}^{\prime \prime}\right)$ modulus was recorded as a function of time for $6 \mathrm{~h}$, applying $0.1 \%$ strain and a frequency of $0.5 \mathrm{~Hz}$.

Enzymatic degradation: Hydrogel samples $(250 \mu \mathrm{L})$ were prepared in vials according to the procedure described above. The samples were taken out of the vials and weighed $\left(\mathrm{W}_{\mathrm{i}}\right)$. The samples were placed in $3 \mathrm{~mL}$ of PBS containing 20 units $/ \mathrm{mL}$ hyaluronidase at $37^{\circ} \mathrm{C}$. The enzyme-solution was replaced every day during the first 3 days and then twice a week. At predetermined time intervals samples were taken out and weighed $\left(\mathrm{W}_{\mathrm{s}}\right)$. The remaining gel $(\%)$ was calculated from the original weight after preparation $\left(\mathrm{W}_{\mathrm{i}}\right)$ and remaining gel weight after exposure to the enzyme containing buffer $\left(\mathrm{W}_{\mathrm{s}}\right)$, expressed as $\left(\mathrm{W}_{\mathrm{s}}-\mathrm{W}_{\mathrm{i}}\right) / \mathrm{W}_{\mathrm{i}} \mathrm{x} 100 \%$. The experiments were performed in triplicate.

In situ chondrocyte incorporation: Bovine chondrocytes $(\mathrm{P} 0)$ were isolated as previously reported ${ }^{25}$. Polymer solutions in PBS of Dex-TA and Dex-TA/Hep-TA (50/50 weight ratio) and Dex-TA/Hep-TA/HA-TA (different weight ratios) were sterilized by filtration through filters with a pore size of $0.22 \mu \mathrm{m}$. Hydrogels containing chondrocytes were prepared by 
mixing a polymer/cell suspension in PBS with HRP (150 units/mL stock solution in PBS) and $\mathrm{H}_{2} \mathrm{O}_{2}(0.3 \%$ stock solution in PBS $)$. The final polymer concentration was $10 \mathrm{wt} \%$ and the cell seeding density in the gels was $20 \times 10^{6}$ cells $/ \mathrm{mL}$. After gelation, the hydrogels (100 $\mu \mathrm{L}$ each) were transferred to a culture plate and $2 \mathrm{~mL}$ of chondrocyte differentiation medium (DMEM with $0.1 \mu \mathrm{M}$ dexamethasone (Sigma), $100 \mu \mathrm{g} / \mathrm{mL}$ sodium pyruvate (Sigma), $0.2 \mathrm{mM}$ ascorbic acid, $50 \mathrm{mg} / \mathrm{mL}$ insulin-transferrin-selenite (ITS +1 , Sigma), 100 units $/ \mathrm{mL}$ penicillin, $100 \mu \mathrm{g} /$ $\mathrm{mL}$ streptomycin, $10 \mathrm{ng} / \mathrm{mL}$ transforming growth factor 33 (TGF- $33, \mathrm{R} \& \mathrm{D}$ systems)) was added. The samples were incubated at $37^{\circ} \mathrm{C}$ in a humidified atmosphere containing $5 \% \mathrm{CO}_{2}$. The medium was replaced every 3 or 4 days.

Cell viability and proliferation: A viability study on the cells incorporated in the hydrogels was performed using a live-dead assay. For the live-dead assay at day 14 and 28 the hydrogel constructs were rinsed with PBS and stained with calcein AM/ethidium homodimer using the Live/Dead assay Kit (Invitrogen), according to the manufactures instruction. Hydrogel/ cell constructs were visualized using fluorescence microscopy (Nikon Eclipse E600), as a result living cells fluoresce green and the nuclei of dead cells red. Quantification of total DNA of the constructs cultured for 14 and 28 days was done using the CyQuant dye kit and a fluorescence plate reader (Perkin-Elmer) as previously reported ${ }^{36}$.

Scanning electron microscopy (SEM): The morphology of the chondrocytes in the hydrogels was studied using a Philips XL 30 ESEM-FEG scanning electron microscope operating at a voltage of 5 or $10 \mathrm{kV}$. After 14 and 28 days in vitro culturing the hydrogel/cell constructs were fixed with formalin. Samples were sequentially dehydrated using a series of water ethanol mixtures and subsequent critical point drying. The samples were gold sputtered (Carringdon) and analyzed with SEM.

RNA extraction and reverse transcriptase-polymerase chain reaction (RT-PCR): After culturing the hydrogel/cell constructs in differentiation medium for 14 or 28 days, the samples were collected and washed with PBS. After converting the gels into pieces, trizol reagent (Invitrogen, Carlsbad, CA) was added to lyse the cells. Total RNA was isolated using the nucleospin RNA II kit (Bioke) according to manufacturer's instructions. The RNA yields were determined by UV/Vis based on the absorbance band at $260 \mathrm{~nm}$. Subsequently, the RNA (250 ng) was transcribed into single strand cDNA using the iScript Kit (Biorad) according to manufacturer's recommendations. One microliter of each normalized cDNA sample was analyzed using the "SYBR Green PCR Core Kit" (Applied Biosystems) and a real-time PCR Cycler (BioRad). The expression of Collagen Type I, II and aggrecan (Table 1) was analyzed and normalized to the expression of the housekeeping gene glyceraldehyde-3-phosphate dehydrogenase (GAPDH). The efficiency of the single PCR reactions was determined and 
used in the calculation.

Table 1. Polymerase chain reaction primers

\begin{tabular}{|c|c|c|c|}
\hline Primer & Direction & Sequence & $\begin{array}{l}\text { Annealing } \\
\text { Temp }\left({ }^{\circ} \mathrm{C}\right)\end{array}$ \\
\hline \multirow{2}{*}{$\begin{array}{c}\text { Bovine } \\
\text { aggrecan }\end{array}$} & Forward & 5'GACCAGAAGCTGTGCGAGGA 3' & \multirow{2}{*}{60} \\
\hline & Reverse & 5'GCCAGATCATCACCACACAG 3' & \\
\hline \multirow{2}{*}{$\begin{array}{c}\text { Bovine } \\
\text { collagen, type IIa1 }\end{array}$} & Forward & 5'ATCAACGGTGGCTTCCACT 3' & \multirow{2}{*}{60} \\
\hline & Reverse & 5' TTCGTGCAGCCATCCTTCAG 3' & \\
\hline \multirow{2}{*}{$\begin{array}{c}\text { Bovine } \\
\text { collagen, type Ia1 }\end{array}$} & Forward & 5' GCGGCTACGACTTGAGCTTC 3' & \multirow{2}{*}{60} \\
\hline & Reverse & 5' CACGGTCACGGACCACATTG 3' & \\
\hline \multirow{2}{*}{$\begin{array}{l}\text { Bovine } \\
\text { GAPDH }\end{array}$} & Forward & 5' GCCATCACTGCCACCCAGAA 3' & \multirow{2}{*}{60} \\
\hline & Reverse & 5' GCGGCAGGTCAGATCCACAA 3, & \\
\hline
\end{tabular}

Histological staining: After 14 days of incubation the hydrogel/cell constructs were washed with PBS and fixed in a $10 \%$ buffered formalin solution overnight. The samples were stored in PBS at $4{ }^{\circ} \mathrm{C}$. To section the samples they were embedded in Cryomatrix (Thermo Scientific) and sectioned using a microtome to yield sections of $10 \mu \mathrm{m}$ in thickness.

For immunofluorescence analysis of collagen type II, sections were put into a warm solution of $10 \mathrm{mM}$ citric acid buffer ( $\mathrm{pH}$ 6.0) for $10 \mathrm{~min}$ and then washed with PBS/BSA $1 \%$. Col2A1 monoclonal antibody (purified mouse immunoglobulin IgG1, clone 3HH1-F9, Abnova) was diluted at 1:100 in PBS/BSA 1\% and let to react overnight with the sections at room temperature. After washing twice with PBS/BSA 1\%, the sections were incubated with Alexa Fluor 488-Goat anti-Mouse IgG1 ( $\gamma 1$ ) (Invitrogen, Molecular Probes, 1:1000 diluted in PBS/ BSA 1\%) for $1 \mathrm{~h}$ protected from light. The sections were rinsed twice with PBS and then counterstained with DAPI (4',6'-diamidino-2-phenylindole dihydrochloride) for $10 \mathrm{~min}$ to stain the nuclei. The slides were assembled with VECTASHIELD Mounting Medium (Vector Laboratories, Burlingame, CA) for visualization under the fluorescence microscope. Hydrogels without cells were used as negative controls. 


\section{Results and discussion}

\section{Hydrogel formation, gelation time, gel content and water uptake}

The enzymatic crosslinking of dextran-tyramine (Dex-TA) conjugates using horseradish peroxidase (HRP) and hydrogen peroxide $\left(\mathrm{H}_{2} \mathrm{O}_{2}\right)$ is a highly efficient method to prepare insitu forming hydrogels ${ }^{19}$. Previously we reported that co-crosslinking of Dex-TA and heparintyramine (Hep-TA) conjugates afforded materials that induced better chondrocyte viability and proliferation and an enhanced matrix production compared to Dex-TA hydrogels ${ }^{26}$. Dex-TA conjugates were prepared as described previously by first activating hydroxyl groups of dextran with p-nitrophenyl chloroformate and subsequent reaction with tyramine to give the Dex-TA conjugate. The degree of substitution (DS) of tyramine units to the dextran was 15. Hep-TA and HA-TA conjugates, with a degree of substitution of tyramine residues of 31 (DS 31) and 17 (DS 17), respectively, were synthesized by EDAC/NHS activation of the carboxylic acid groups of heparin or hyaluronic acid and subsequent reaction with tyramine (Figure 1). Hydrogels were conveniently prepared by the horseradish peroxidase (HRP, 150 units/ $\mathrm{mL}$ stock solution) and $\mathrm{H}_{2} \mathrm{O}_{2}(0.3$ wt $\%$ stock solution $)$ mediated coupling reaction of phenolic moieties in Dex-TA, Hep-TA and HA-TA conjugates at concentrations of 10 or $20 \mathrm{wt} \%$ and in different weight ratios in PBS (Figure 1 and Table 2).

Table 2. Conjugate weight ratios and degree of substitution (DS) of tyramine units to dextran (Dex), heparin (Hep) and hyaluronic acid (HA) in hydrogels.

\begin{tabular}{|c|c|c|}
\hline & Weight Ratio & DS $^{\mathbf{a}}$ \\
\hline Dex-TA & 100 & 15 \\
\hline Dex-TA/Hep-TA & $50 / 50$ & $15 / 31$ \\
\hline & $50 / 25 / 25$ & $15 / 31 / 17$ \\
\hline
\end{tabular}

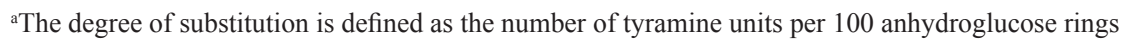




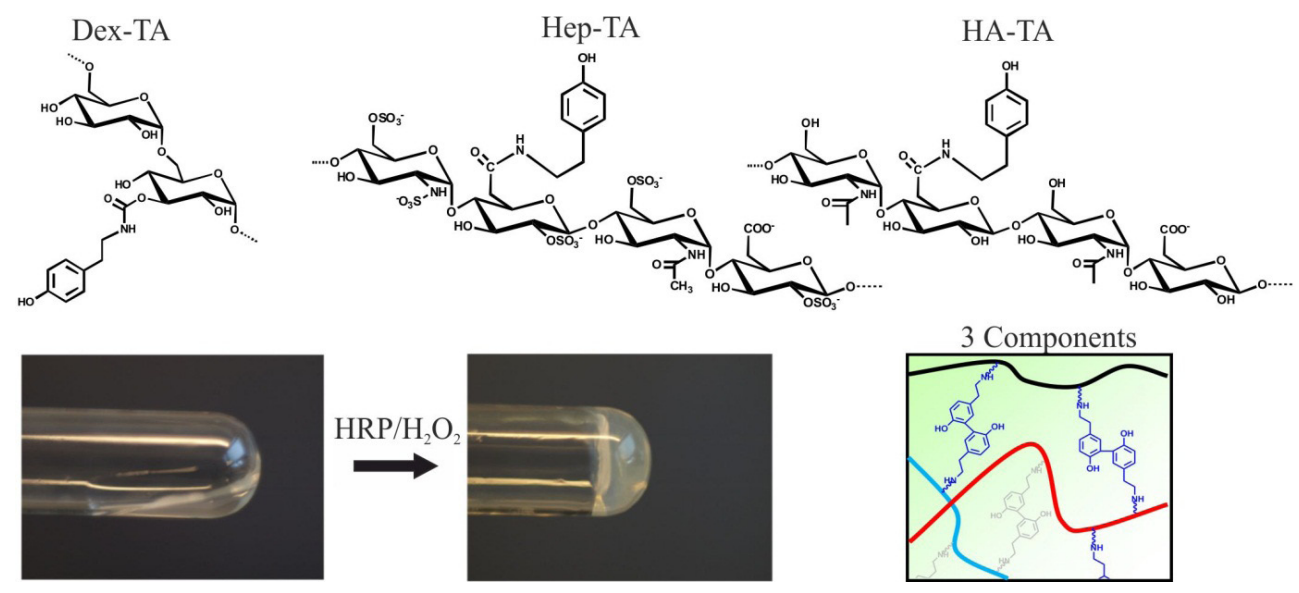

Figure 1. At the top the chemical structures of Dex-TA, Hep-TA and HA-TA. At the bottom photographs of a $10 \mathrm{wt}$ $\%$ solution of Dex-TA/Hep-TA/HA-TA (25/50/25 weight ratio) and a hydrogel obtained via $\mathrm{HRP} / \mathrm{H}_{2} \mathrm{O}_{2}$ mediated crosslinking and a schematic representation of the formed network using the 3 components.

The enzymatic crosslinking of Dex-TA, Hep-TA and HA-TA, as determined by the vial tilting method, led to fast gelation i.e. the gelation times were within $80 \mathrm{~s}$ for all combinations tested. The enzymatic crosslinking of Dex-TA and Dex-TA/Hep-TA (50/50 weight ratio) 10 wt $\%$ and $20 \mathrm{wt} \%$ solutions was approximately $15 \mathrm{~s}$. The gelation times of Dex-TA/Hep-TA/ HA-TA solutions at a total polymer concentration of $10 \mathrm{wt} \%$ also showed a fast gelation of ca. $15 \mathrm{~s}$, but increased to $40-60 \mathrm{~s}$ at a concentration of $20 \mathrm{wt} \%$ (Figure $2 \mathrm{~A}$ ).

The longer crosslinking times and possibly the lower number of crosslinks formed in the latter case are reflected in the gel content and water uptake of the hydrogels (Figure 2B, C and D). The gel content of all $10 \mathrm{wt} \%$ hydrogels was in between 80 and $90 \%$ and similar values were found for the 20 wt \% Dex-TA and Dex-TA/Hep-TA (50/50 weight ratio) hydrogels. The gel content of the $20 \mathrm{wt} \%$ Dex-TA/Hep-TA/HA-TA hydrogels, however, was in between 60 and $70 \%$ indicating that the much higher viscosity of these solutions may have hampered the diffusion of the enzyme and thus the crosslinking reaction. In Figure 2D it is shown that 10 wt \% Dex-TA and Dex-TA/Hep-TA (50/50 weight ratio) hydrogels have a higher water uptake than $20 \mathrm{wt} \%$ hydrogels, suggesting that $20 \mathrm{wt} \%$ hydrogels have a denser network. The Dex-TA/Hep-TA/HA-TA systems both at 10 and $20 \mathrm{wt} \%$ show approximately similar water uptake values of $\sim 1500 \%$. This indicated that the $20 \mathrm{wt} \%$ Dex-TA/Hep-TA/HA-TA hydrogels had a similar crosslink density as the $10 \mathrm{wt} \%$ Dex-TA/Hep-TA/HA-TA hydrogels, confirming that the crosslinking reaction is hampered. 

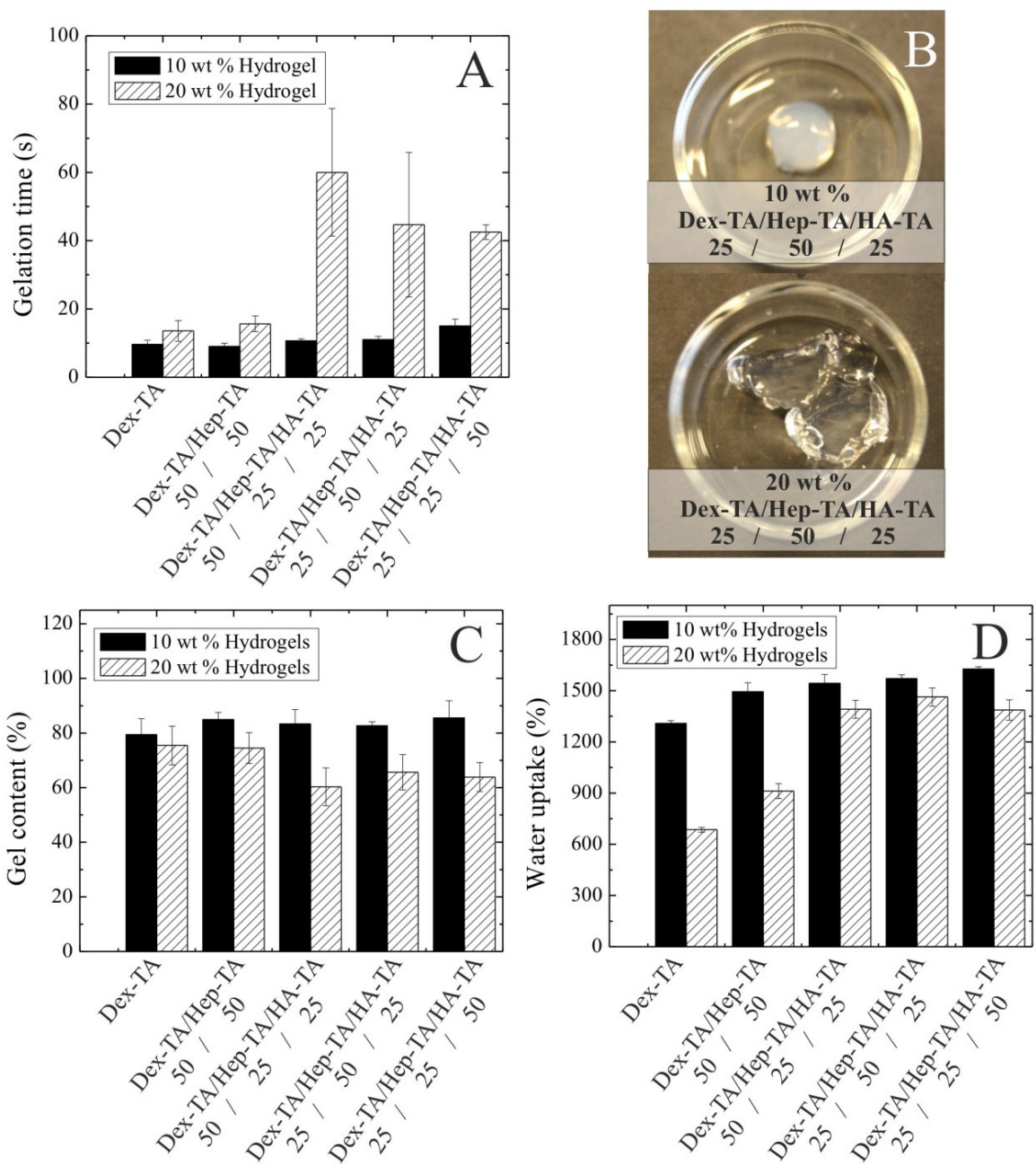

Figure 2. A) Gelation times of 10 and $20 \mathrm{wt} \%$ hydrogels. B) Examples of 10 and $20 \mathrm{wt} \%$ Dex-TA/Hep-TA/HA-TA (25/50/25 weight ratio) hydrogels after swelling. C) Gel content of $10 \mathrm{wt} \%$ and $20 \mathrm{wt} \%$ hydrogels. D) Water uptake of $10 \mathrm{wt} \%$ and $20 \mathrm{wt} \%$ hydrogels.

\section{Rheological analysis and morphology}

Rheological measurements were performed to study the influence of the composition on the mechanical properties of the hydrogels. In Figure 3 the storage modulus ( G') and the loss modulus (G”) of all $10 \mathrm{wt} \%$ hydrogels are presented. The Dex-TA hydrogel had a G' of $44.0 \mathrm{kPa}$ and the Dex-TA/Hep-TA (50/50 weight ratio) had a $\mathrm{G}^{\prime}$ of $18.7 \mathrm{kPa}$, values similar as described previously ${ }^{26}$. The Dex-TA/Hep-TA/HA-TA hydrogels afforded values of $\mathrm{G}^{\prime}$ between 32 and $42 \mathrm{kPa}$, indicating that introducing HA-TA had a beneficial effect on the 
mechanical properties compared to Dex-TA/Hep-TA hydrogels. This can be explained by the presence of stiff sections in HA due to intramolecular hydrogen bonding which is also demonstrated by the resistance to periodate oxidation ${ }^{28}$.

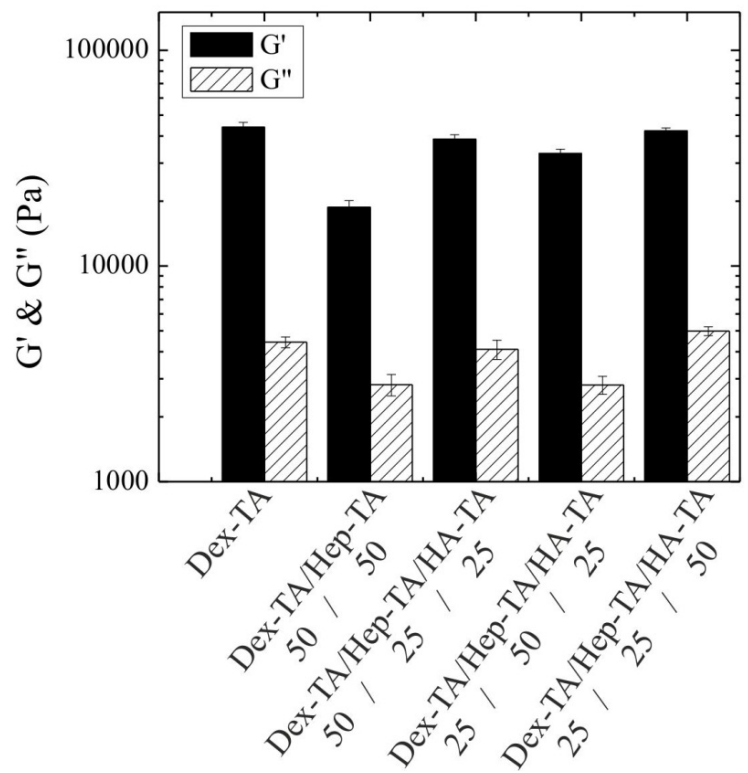

Figure 3. Storage and loss modulus of $10 \mathrm{wt} \%$ hydrogels $\left(25^{\circ} \mathrm{C}\right)$.

To allow cell growth over prolonged periods of time hydrogels need to be highly porous and have a well-interconnected pore structure. The morphologies of freeze dried hydrogels prepared from Dex-TA, Dex-TA/Hep-TA (50/50 weight ratio) and all Dex-TA/Hep-TA/HATA hydrogels were visualized by scanning electron microscopy (SEM) (Figure 4). In all cases the hydrogels appeared to be highly porous and had a well-interconnected pore structure. Compared to the $10 \mathrm{wt} \%$ Dex-TA and Dex-TA/Hep-TA (50/50 weight ratio) hydrogels, which have similar pore sizes of 5-10 $\mu \mathrm{m}$, Dex-TA/Hep-TA/HA-TA hydrogels showed a higher pore size of 10-20 $\mu \mathrm{m}$. Increasing the HA-TA content to 50\% in Dex-TA/Hep-TA/HATA hydrogels resulted in large cavities with an average diameter of $50 \mu \mathrm{m}$. This increase in pore size can enhance the transportation of nutrients and waste products and facilitate better cell mobility, making the Dex-TA/Hep-TA/HA-TA hydrogels more suitable for cell growth over prolonged periods of time. 


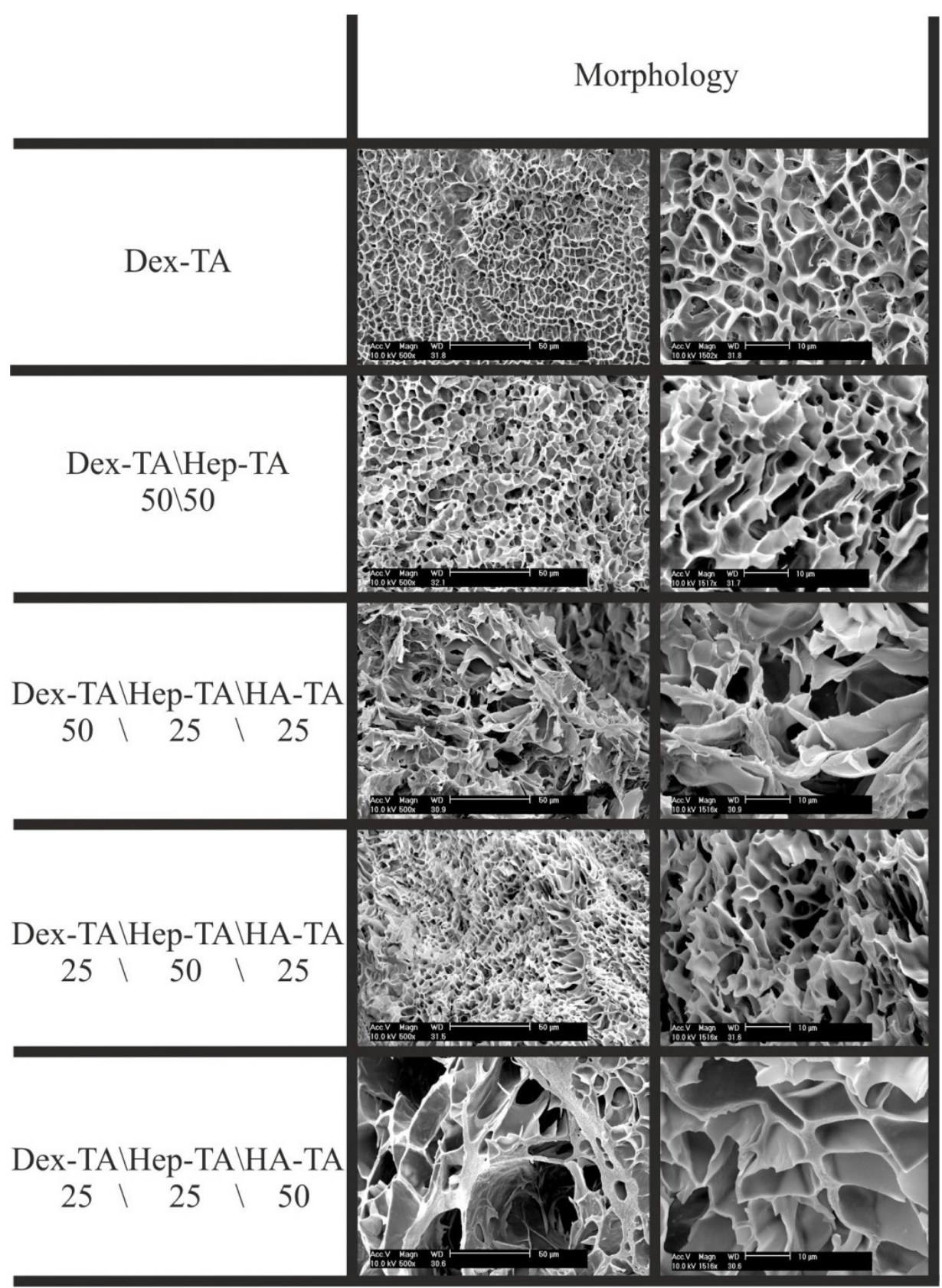

Figure 4. SEM images of $10 \mathrm{wt} \%$ freeze dried hydrogels. Scale bar left: $50 \mu \mathrm{m}$ and right $20 \mu \mathrm{m}$

\section{Enzymatic degradation}

The enzymatic degradation profiles of the $10 \mathrm{wt} \%$ hydrogels were determined by placing 250 
$\mu \mathrm{L}$ of preformed hydrogels in $3 \mathrm{~mL}$ of PBS containing 20 units/mL hyaluronidase $(6$ times as much as present in human articular cartilage ${ }^{37}$ ). It has to be emphasized that equilibrium swelling is not reached yet and the hydrogels will swell further upon placing them in PBS. The hydrogels were placed in $3 \mathrm{~mL}$ of PBS and kept at $37 \square \mathrm{C}$ and their wet weights were monitored at regular time intervals. The remaining gel (\%) was expressed as the gel weight after exposure to enzyme buffer $\left(\mathrm{W}_{\mathrm{t}}\right)$ divided by the original gel weight after preparation $\left(\mathrm{W}_{\mathrm{i}}\right)$. In general, the weight of the hydrogels first increased due to water uptake and then gradually decreased. The Dex-TA showed almost no degradation over a period of 60 days. The Dex-TA/Hep-TA(50/50 weight ratio) showed a slight decrease in weight to around $90 \%$. This shows that hyaluronidase can cleave heparin but at a very slow rate and a better control over the disintegration rate might be necessary for cartilage repair. In the first days the weight of all Dex-TA/Hep-TA/HA-TA hydrogels increased due to water uptake. When the effect of chain scission of HA chains was greater than the water uptake, the hydrogels showed weight loss due to the dissolution and release of small fragments. It was found that the Dex-TA/HepTA/HA-TA hydrogels were fully disintgratable (Figure 5). The rate of disintegration was mainly influenced by the ratio of Dex-TA and HA-TA in the hydrogels. The Dex-TA/HepTA/HA-TA (50/25/25 weight ratio) hydrogel showed complete disintegration in $62 \mathrm{~d}$ while the Dex-TA/Hep-TA/HA-TA (25/25/50 weight ratio) hydrogel was fully disintegrated in 34 d. Compared to previously reported HA-TA hydrogels ${ }^{35}$ which were completely degraded within $1 \mathrm{~d}$ in the presence of 25 units/mL of hyaluronidase in PBS, co-crosslinking with DexTA allowed to regulate the degradation over prolonged periods of time.

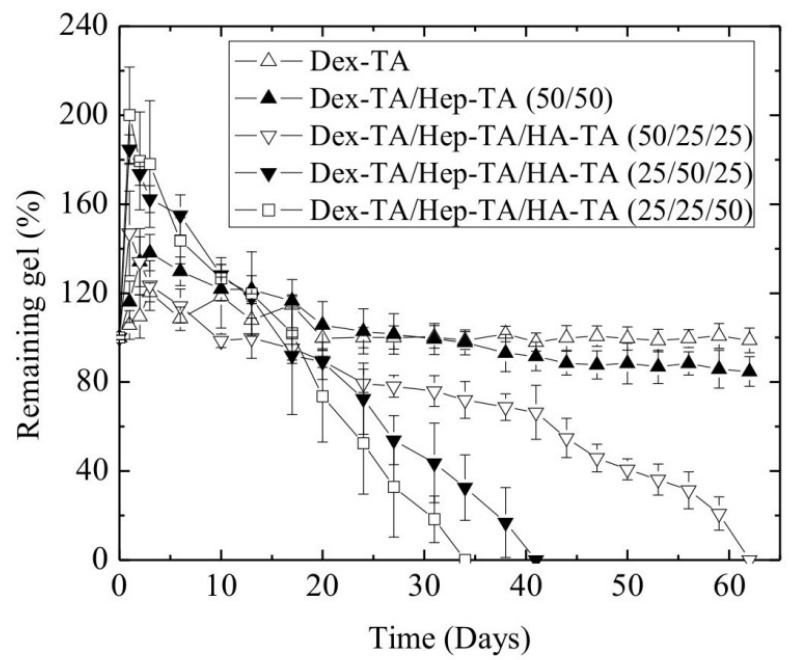

Figure 5. Enzymatic degradation of $10 \mathrm{wt} \%$ hydrogels in PBS containing 20 units $/ \mathrm{mL}$ hyaluronidase at $37^{\circ} \mathrm{C}$. 


\section{Chondrocyte incorporation and cytocompatibility}

In separate syringes a $12.5 \mathrm{wt} \%$ polymer solution in PBS was mixed with chondrocytes resulting in $20 \times 10^{6}$ cells/mL polymer mixture. The other syringe was loaded with HRP (150 units/mL stock solution) and $\mathrm{H}_{2} \mathrm{O}_{2}(0.3 \mathrm{wt} \%$ stock solution $)$. After preparation, the polymercell suspension was pipetted in a 96 well-plate followed by the $\mathrm{HRP} / \mathrm{H}_{2} \mathrm{O}_{2}$ mixture and gently shaken until gelation occurred. The hydrogel was transferred to a culture plate with chondrocyte differentiation medium. The samples were incubated for 14 or 28 days.

The cytocompatibility of all hydrogels was analyzed by a live/dead assay after culturing for 28 days, in which live cells fluoresce green, and dead cells fluoresce red. For all hydrogel combinations it is shown that $95 \%$ of the cells fluoresce green after 28 days of culture (Figure $6)$.

A CyQuant DNA assay was used to determine the viability and proliferation of chondrocytes inside all the hydrogels at day 14 and day 28 (Figure 7A). In general, the DNA content increased in time for all hydrogel-cell constructs, indicative of cell proliferation. The chondrocytes in the Dex-TA/Hep-TA/HA-TA hydrogels proliferated better than in Dex-TA and Dex-TA/Hep$\mathrm{TA}(50 / 50$ weight ratio) at all-time intervals. This can be ascribed to the larger pore size allowing better nutrient exchange and the potential biological role of hyaluronic acid on the chondrocytes. It is known that chondrocytes in culture may rapidly dedifferentiate and obtain a fibroblastlike phenotype [29]. Whereas these dedifferentiated cells show a flattened morphology a round cell shape is correlated with the maintenance of the chondrocyte phenotype. To assess if the chondrocytes maintained a round shape SEM images were taken of all cell/hydrogel constructs cultured for 28 days. The chondrocytes incorporated in all hydrogels after 28 days of culture showed a round morphology, suggesting that independent of composition the chondrocyte phenotype maintained (Figure 6). 


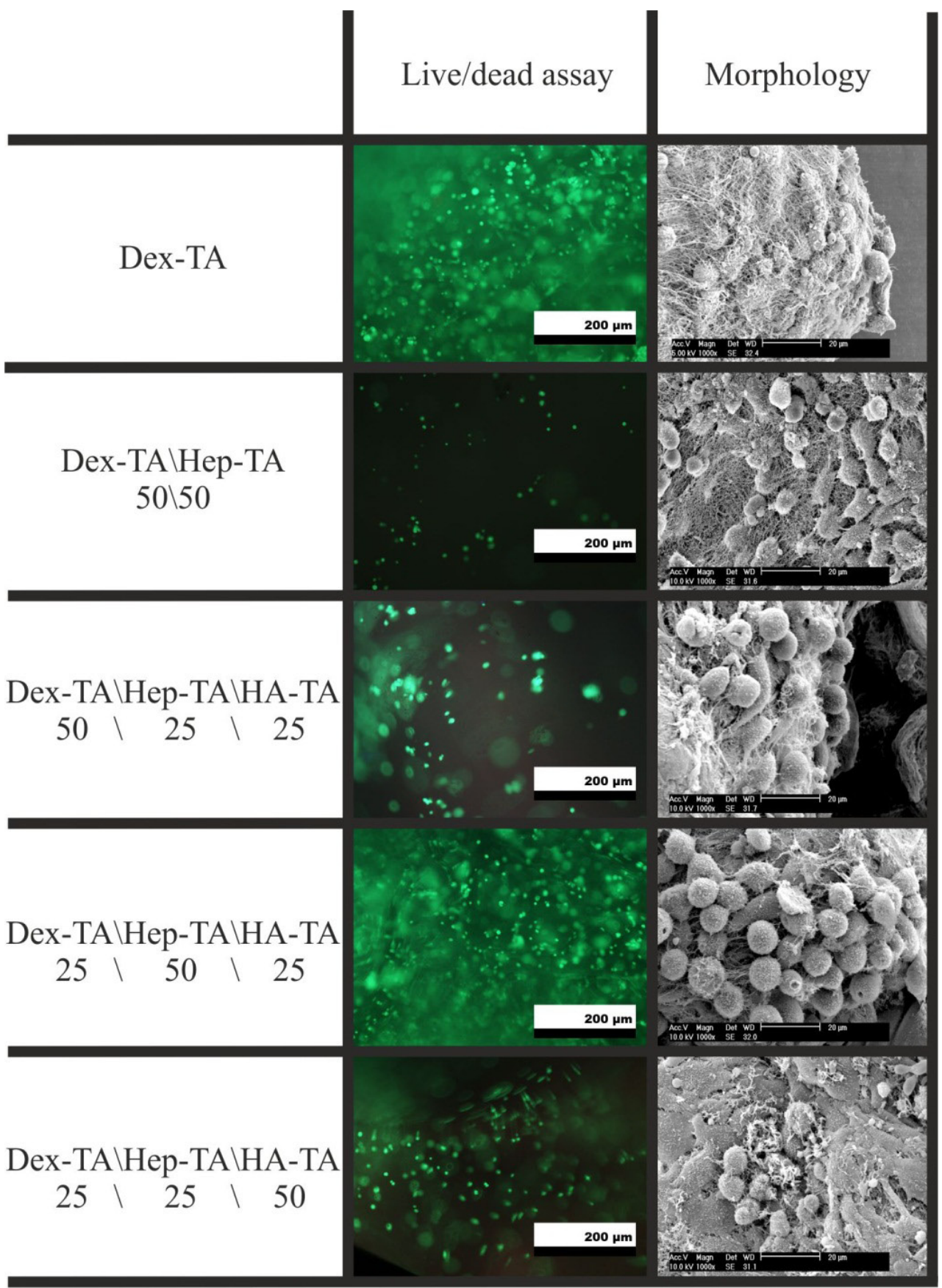

Figure 6. Left: live-dead assay showing the chondrocytes incorporated in $10 \mathrm{wt} \%$ hydrogels after 28 days. Right: SEM images showing the morphology of chondrocytes incorporated in $10 \mathrm{wt} \%$ hydrogels at 28 days. Scale bar: $20 \mu \mathrm{m}$ 


\section{Matrix production}

A hydroxyproline assay at day 14 and 28 was used to evaluate if the chondrocytes deposited collagen, in the hydrogel constructs. The total collagen content was normalized to the dry gel weight. The results showed that the collagen accumulation increased in time and reached the highest value at day 28 for all hydrogel-cell constructs. Furthermore, it was seen that the DexTA/Hep-TA/HA-TA (25/50/25 weight ratio) hydrogels showed significantly higher collagen production compared to Dex-TA and Dex-TA/Hep-TA (50/50 weight ratio) hydrogels (Figure 7B).

When the total collagen content is normalized to the DNA amount it was seen that for DexTA/Hep-TA/HA-TA the collagen content compared to the DNA content increased from day 14 to day 28, while for Dex-TA and Dex-TA/Hep-TA (50/50 weight ratio) hydrogels a decrease in collagen content per DNA content was observed (Figure 7C). Furthermore, it was seen that Dex-TA/Hep-TA/HA-TA (25/50/25 weight ratio) hydrogels performed the best in total collagen production and the collagen amount per DNA was similar compared to DexTA/Hep-TA (50/50 weight ratio) hydrogels after 28 days, making the Dex-TA/Hep-TA/HATA (25/50/25 weight ratio) hydrogels an interesting material as a degradable in-situ forming hydrogel for cartilage repair. 

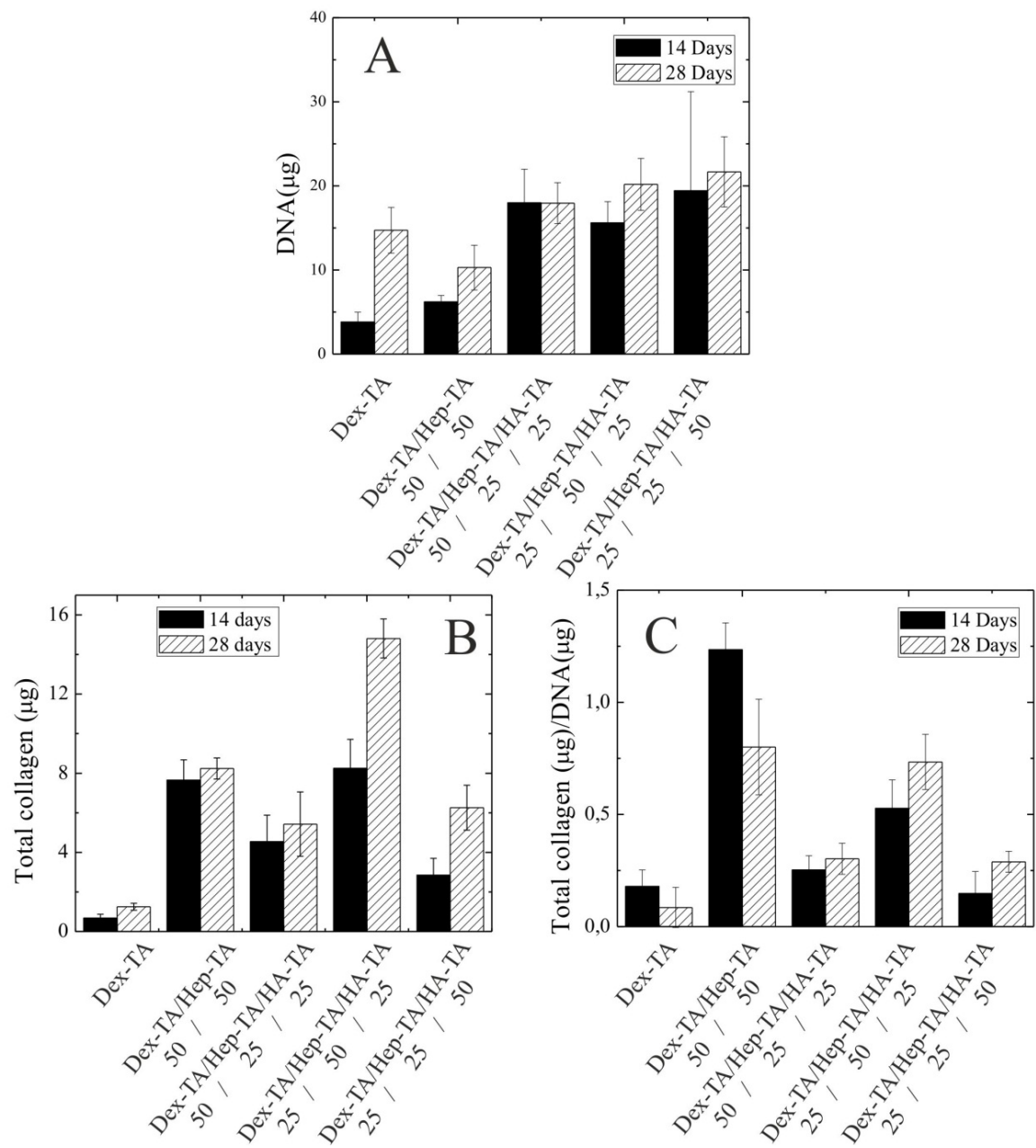

Figure 7. A) DNA content of all $10 \mathrm{wt} \%$ hydrogels and B) total collagen and C) total collagen normalized to the DNA content in all hydrogels containing chondrocytes after in vitro culturing for 14 and 28 days. Cell seeding density: $2 \times 10^{7}$ cells $/ \mathrm{mL}$

Regeneration of cartilage is highly dependent on the production of collagen type II and aggrecan. The production of aggrecan is important since it serves as a component in cartilage that has the ability to resist compressive loads. The major part of the macromolecular protein framework of adult articular cartilage consists of collagen type II. The main functions of collagen e.g. collagen fibrils, are to give structure and compressive and shear strength to the articular cartilage ${ }^{1,2,38}$. Nowadays, popular treatments for articular cartilage repair include: microfacture mosaicplasty, ACT and osteochondral allograft transplantation. Although these techniques have successfully relieved pain and improved joint function, each are plagued 
with their disadvantages that can menace their long-term clinical application. For example, cartilage produced from these techniques is often composed of type I collagen (characteristic of fibrocartilage) which is biochemically and biomechanically inferior to hyaline cartilage 4 . A gene expression analysis of collagen type I \& II and aggrecan were performed by RT-PCR and the results are presented in Figure 8. For all genes it was shown that gene expression was dependent on the composition of the hydrogels. Aggrecan was significantly higher expressed in Dex-TA/Hep-TA (50/50 weight ratio) hydrogels compared to Dex-TA hydrogels which was in agreement with literature ${ }^{26}$ (Figure 8A). For Dex-TA/Hep-TA/HA-TA hydrogels it was seen that aggrecan mRNA expression increased by increasing the Hep-TA or the HATA content in the hydrogel. Similar levels of aggrecan mRNA were found in Dex-TA/HepTA/HA-TA (25/25/50 weight ratio) hydrogels and Dex-TA/Hep-TA (50/50 weight ratio) hydrogels.

Incorporation of HA-TA in the hydrogels resulted in a higher expression of collagen type II (Figure 8C). Collagen type II expression in Dex-TA/Hep-TA/HA-TA (25/50/25 weight ratio) hydrogels was 40 fold higher compared to Dex-TA hydrogels and 2 fold higher compared to Dex-TA/Hep-TA (50/50 weight ratio) hydrogels. Investigating the ratio between collagen type II and collagen type I expression showed that Dex-TA/Hep-TA/HA-TA (25/50/25 weight ratio) hydrogels had the highest ratio and thus best resembled a hyaline type cartilage mRNA profile compared to other hydrogel compositions (Figure 8D). This showed that incorporation of HA-TA into the gels stimulated collagen type II expression in the chondrocytes.

Improved expression of collagen type II does not directly relate to production of collagen type II. Next we examined collagen type II protein production in the hydrogel constructs using immunofluorescence staining to detect the accumulation of newly formed cartilaginous matrix. The results confirmed the production of collagen type II in all hydrogels (Figure 9). Using an exposure time of $275 \mathrm{~ms}$ it was seen that the incorporation of HATA in the gels resulted in a more intense and a more evenly distributed collagen type II expression compared to the Dex-TA and Dex-TA/Hep-TA(50/50 weight ratio) hydrogels. From the total collagen, RT-PCR and immunofluorescence staining it was shown that DexTA/Hep-TA/HA-TA (25/50/25 weight ratio) hydrogels performed the best in producing a cartilaginous extracellular matrix. With a degradation time of 41 days, this hydrogel turns out to be an interesting scaffold for cartilage tissue engineering. 

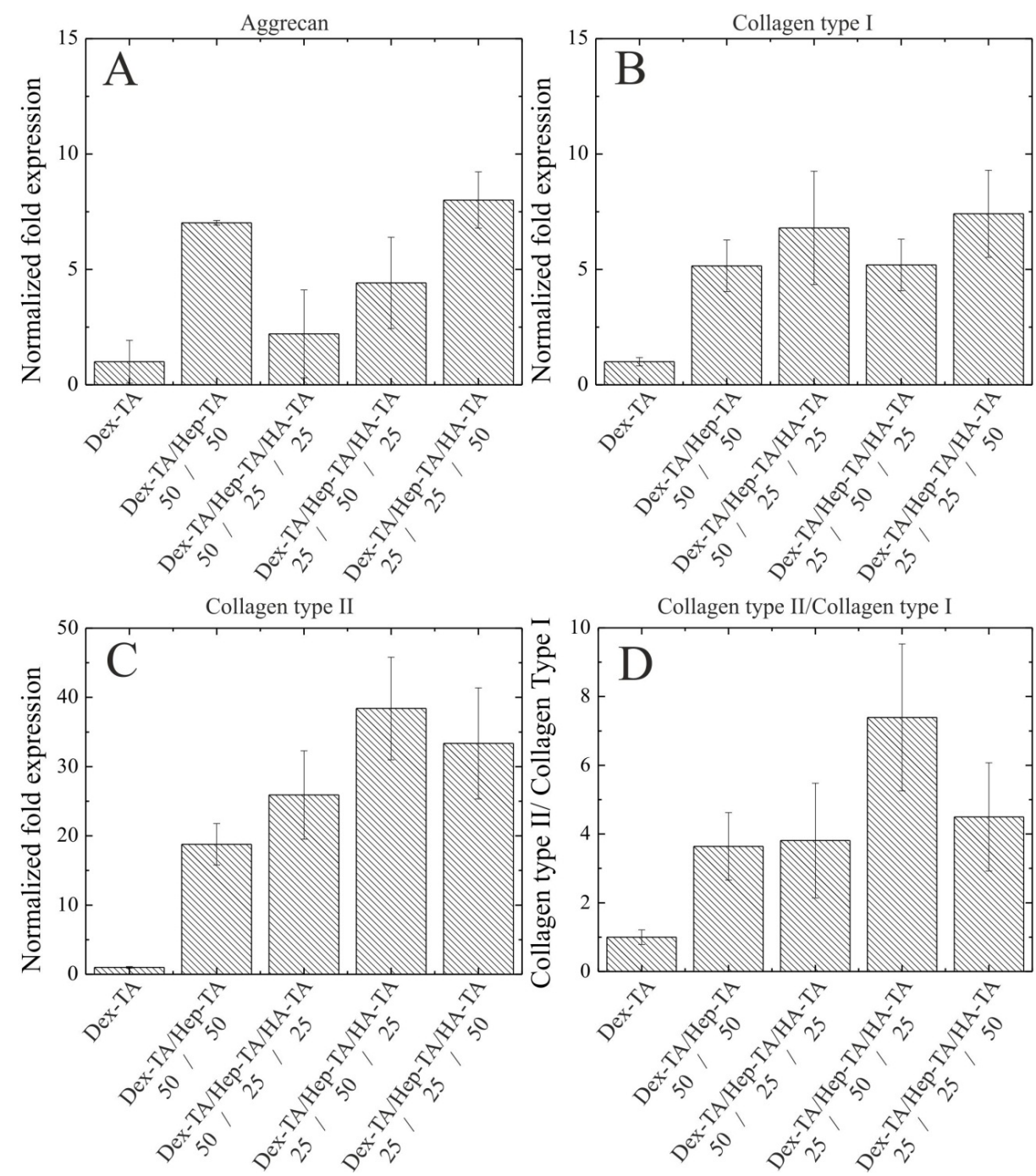

Figure 8. Real-time PCR of cartilage specific markers (Aggrecan (A), Collagen type I (B) and Collagen type II (C)) by incorporated chondrocytes in $10 \mathrm{wt} \%$ hydrogels after 28 days in culture, D) ratio of Collagen type II and Collagen type I mRNA expression. The expressions of collagen type I \& II and aggrecan were normalized to the expression of the housekeeping gene GAPDH. The standard deviation of the presented data is from independent experiments. 


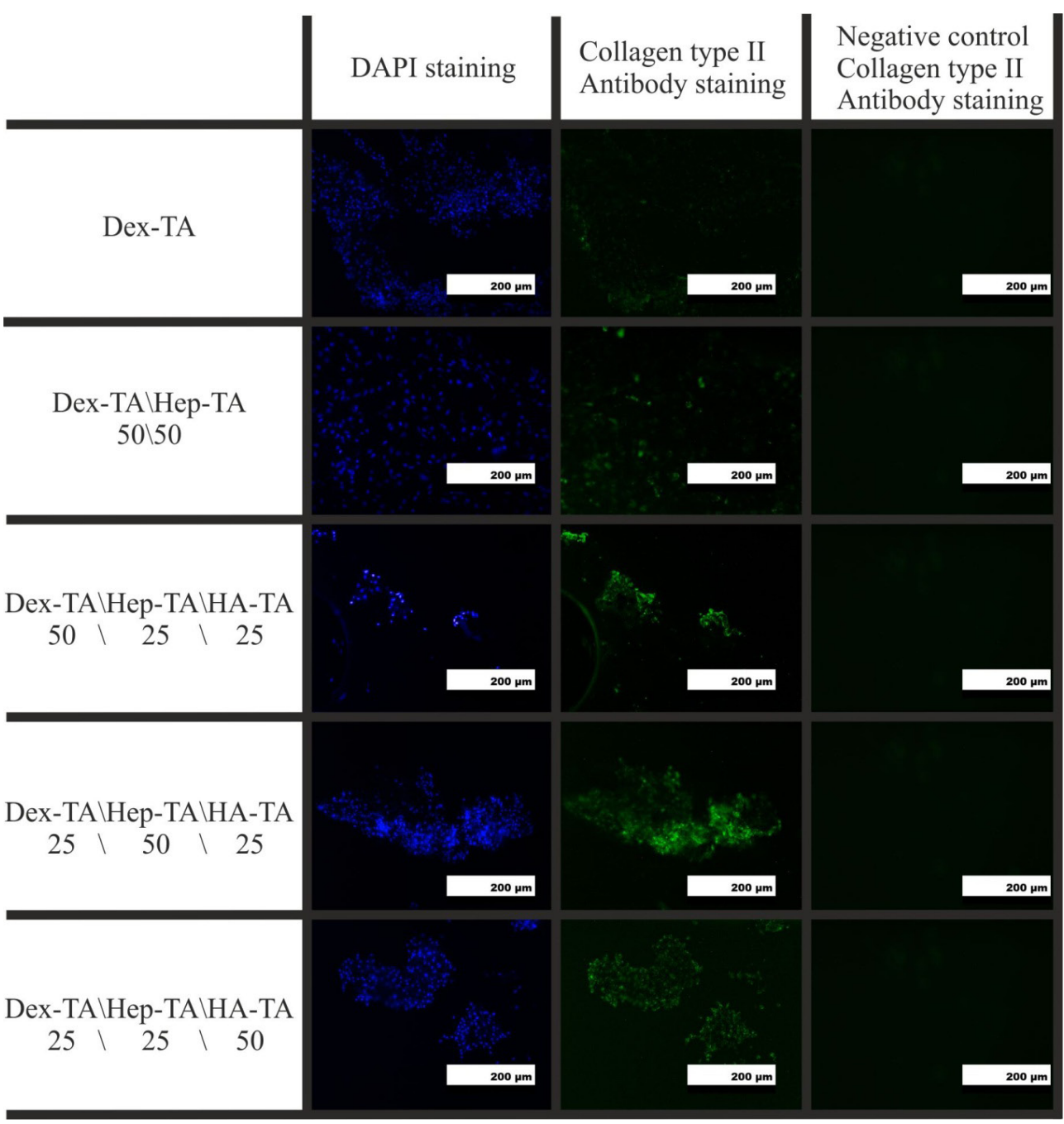

Figure 9. Left: DAPI staining of the cell nuclei; Middle: collagen type II immunofluorescent staining of all hydrogels containing chondrocytes after in vitro culturing for 28 days and right their respective negative controls. 


\section{Conclusions}

In-situ forming hydrogels were prepared by the horseradish peroxidase-mediated cocrosslinking of dextran-tyramine (Dex-TA), heparin-tyramine (Hep-TA) and/or hyaluronic acid-tyramine (HA-TA) conjugates and used as scaffolds for cartilage tissue engineering. We have shown that incorporation of HA-TA resulted in full degradation of the hydrogels in the presence of hyaluronidase. The degradation time can be adjusted by varying the composition of the mixture of Dex-TA and HA-TA. Bovine chondrocytes incorporated in $10 \mathrm{wt} \%$ DexTA and Dex-TA/Hep-TA (50/50 weight ratio) and Dex-TA/Hep-TA/HA-TA (different weight ratios) gels showed good viability after 28 days incubation in chondrocyte differentiation medium. Hydrogels based on Dex-TA/Hep-TA/HA-TA (25/50/25 weight ratio) showed a descend expression of Aggrecan and the highest production and expression of Collagen type II as compared to Dex-TA/Hep-TA (50/50 weight ratio) hydrogels. It is concluded that that Dex-TA/Hep-TA/HA-TA (25/50/25 weight ratio) hydrogels are very promising as in-situ forming and biodegradable materials for cartilage tissue engineering.

\section{References}

1. Buckwalter, J. A.; Mankin, H. J., Instructional Course Lectures, The American Academy of Orthopaedic Surgeons - Articular Cartilage. Part I: Tissue Design and Chondrocyte-Matrix Interactions* $\{\{$ dagger $\}$. J Bone Joint Surg Am 1997, 79, (4), 600-11. 2. Bhosale, A. M.; Richardson, J. B., Articular cartilage: structure, injuries and review of management. British Medical Bulletin 2008, 87, (1), 77-95.

3. Elisseeff, J., Injectable cartilage tissue engineering. Expert Opinion on Biological Therapy 2004, 4, (12), 1849-1859.

4. Marlovits, S.; Zeller, P.; Singer, P.; Resinger, C.; Vecsei, V., Cartilage repair:

Generations of autologous chondrocyte transplantation. Eur. J. Radiol. 2006, 57, (1), 24-31.

5. Minas, T.; Nehrer, S., Current concepts in the treatment of articular cartilage defects. Orthopedics 1997, 20, (6), 525-538.

6. Hennink, W. E.; van Nostrum, C. F., Novel crosslinking methods to design hydrogels. Advanced Drug Delivery Reviews 2002, 54, (1), 13-36.

7. Bryant, S. J.; Anseth, K. S., Controlling the spatial distribution of ECM components in degradable PEG hydrogels for tissue engineering cartilage. Journal of Biomedical Materials Research - Part A 2003, 64, (1), 70-79.

8. Bryant, S. J.; Bender, R. J.; Durand, K. L.; Anseth, K. S., Encapsulating chondrocytes in degrading PEG hydrogels with high modulus: Engineering gel structural changes to facilitate cartilaginous tissue production. Biotechnology and Bioengineering 2004, 86, (7), 747-755.

9. Bryant, S. J.; Chowdhury, T. T.; Lee, D. A.; Bader, D. L.; Anseth, K. S., Crosslinking density influences chondrocyte metabolism in dynamically loaded photocrosslinked poly(ethylene glycol) hydrogels. Annals of Biomedical Engineering 2004, 32, (3), 407-417.

10. Bryant, S. J.; Durand, K. L.; Anseth, K. S., Manipulations in hydrogel chemistry 
control photoencapsulated chondrocyte behavior and their extracellular matrix production. Journal of Biomedical Materials Research - Part A 2003, 67, (4), 1430-1436.

11. Hiemstra, C.; van der Aa, L. J.; Zhong, Z.; Dijkstra, P. J.; Feijen, J., Rapidly in situ-forming degradable hydrogels from dextram triols through Michael addition.

Biomacromolecules 2007, 8, (5), 1548-1556.

12. Hiemstra, C.; Van Der Aa, L. J.; Zhong, Z.; Dijkstra, P. J.; Feijen, J., Novel in situ forming, degradable dextran hydrogels by michael addition chemistry: Synthesis, rheology, and degradation. Macromolecules 2007, 40, (4), 1165-1173.

13. Lutolf, M. P.; Lauer-Fields, J. L.; Schmoekel, H. G.; Metters, A. T.; Weber, F. E.; Fields, G. B.; Hubbell, J. A., Synthetic matrix metalloproteinase-sensitive hydrogels for the conduction of tissue regeneration: Engineering cell-invasion characteristics. Proceedings of the National Academy of Sciences of the United States of America 2003, 100, (9), 54135418.

14. Lutolf, M. P.; Raeber, G. P.; Zisch, A. H.; Tirelli, N.; Hubbell, J. A., Cellresponsive synthetic hydrogels. Advanced Materials 2003, 15, (11), 888-892.

15. Shu, X. Z.; Liu, Y.; Palumbo, F. S.; Luo, Y.; Prestwich, G. D., In situ crosslinkable hyaluronan hydrogels for tissue engineering. Biomaterials 2004, 25, (7-8), 1339-1348.

16. Tortora, M.; Cavalieri, F.; Chiessi, E.; Paradossi, G., Michael-type addition reactions for the in situ formation of poly(vinyl alcohol)-based hydrogels. Biomacromolecules 2007, 8, (1), 209-214.

17. Balakrishnan, B.; Jayakrishnan, A., Self-cross-linking biopolymers as injectable in situ forming biodegradable scaffolds. Biomaterials 2005, 26, (18), 3941-3951.

18. Lee, K. Y.; Alsberg, E.; Mooney, D. J., Degradable and injectable poly(aldehyde guluronate) hydrogels for bone tissue engineering. Journal of Biomedical Materials Research 2001, 56, (2), 228-233.

19. Jin, R.; Hiemstra, C.; Zhong, Z.; Feijen, J., Enzyme-mediated fast in situ formation of hydrogels from dextran-tyramine conjugates. Biomaterials 2007, 28, (18), 2791-2800.

20. Lee, F.; Chung, J. E.; Kurisawa, M., An injectable hyaluronic acid-tyramine hydrogel system for protein delivery. Journal of Controlled Release 2009, 134, (3), 186193.

21. Lee, S. H.; Lee, Y.; Lee, S. W.; Ji, H. Y.; Lee, J. H.; Lee, D. S.; Park, T. G., Enzyme-mediated cross-linking of Pluronic copolymer micelles for injectable and in situ forming hydrogels. Acta Biomaterialia 2011, 7, (4), 1468-1476.

22. Park, K. M.; Jun, I.; Joung, Y. K.; Shin, H.; Park, K. D., In situ hydrogelation and RGD conjugation of tyramine-conjugated 4-arm PPO-PEO block copolymer for injectable bio-mimetic scaffolds. Soft Matter 2011, 7, (3), 986-992.

23. Wennink, J. W. H.; Niederer, K.; Bochyńska, A. I.; Moreira Teixeira, L. S.; Karperien, M.; Feijen, J.; Dijkstra, P. J., Injectable hydrogels by enzymatic co-crosslinking of dextran and hyaluronic acid tyramine conjugates. Macromolecular Symposia 2011, 309310, (1), 213-221.

24. Sakai, S.; Hirose, K.; Taguchi, K.; Ogushi, Y.; Kawakami, K., An injectable, in situ enzymatically gellable, gelatin derivative for drug delivery and tissue engineering. Biomaterials 2009, 30, (20), 3371-3377.

25. Jin, R.; Teixeira, L. S. M.; Dijkstra, P. J.; Karperien, M.; van Blitterswijk, C. A.; Zhong, Z. Y.; Feijen, J., Injectable chitosan-based hydrogels for cartilage tissue engineering. Biomaterials 2009, 30, (13), 2544-2551. 
26. Jin, R.; Teixeira, L. S. M.; Dijkstra, P. J.; van Blitterswijk, C. A.; Karperien, M.; Feijen, J., Chondrogenesis in injectable enzymatically crosslinked heparin/dextran hydrogels. Journal of Controlled Release 2011, 152, (1), 186-195.

27. Weitz, D. S.; Weitz, J. I., Update on heparin: what do we need to know? Journal of Thrombosis and Thrombolysis 2010, 29, (2), 199-207.

28. Ernst, S.; Langer, R.; Cooney, C. L.; Sasisekharan, R., Enzymatic degradation of glycosaminoglycans. Critical Reviews in Biochemistry and Molecular Biology 1995, 30, (5), 387-444.

29. Hardingham, T. E.; Fosang, A. J., Proteoglycans: Many forms and many functions. FASEB Journal 1992, 6, (3), 861-870.

30. Knudson, W.; Knudson, C. B., An update on hyaluronan and CD44 in cartilage. Current Opinion in Orthopaedics 2004, 15, (5), 369-375.

31. Knudson, C. B.; Knudson, W., Hyaluronan-binding proteins in development, tissue homeostasis, and disease. FASEB Journal 1993, 7, (13), 1233-1241.

32. Toole, B. P., Hyaluronan: From extracellular glue to pericellular cue. Nature Reviews Cancer 2004, 4, (7), 528-539.

33. Cole, A. A.; Chubinskaya, S.; Schumacher, B.; Huch, K.; CsSzabo, G.; Yao, J.; Mikecz, K.; Hasty, K. A.; Kuettner, K. E., Chondrocyte matrix metalloproteinase-8 - Human articular chondrocytes express neutrophil collagenase. Journal of Biological Chemistry 1996, 271, (18), 11023-11026.

34. Chow, G.; Knudson, C. B.; Knudson, W., Expression and cellular localization of human hyaluronidase-2 in articular chondrocytes and cultured cell lines. Osteoarthritis and Cartilage 2006, 14, (9), 849-858.

35. Lee, F.; Chung, J. E.; Kurisawa, M., An injectable enzymatically crosslinked hyaluronic acid-tyramine hydrogel system with independent tuning of mechanical strength and gelation rate. Soft Matter 2008, 4, (4), 880-887.

36. Jin, R.; Teixeira, L. S. M.; Krouwels, A.; Dijkstra, P. J.; van Blitterswijk, C. A.; Karperien, M.; Feijen, J., Synthesis and characterization of hyaluronic acid-poly(ethylene glycol) hydrogels via Michael addition: An injectable biomaterial for cartilage repair. Acta Biomaterialia 2010, 6, (6), 1968-1977.

37. Delpech, B.; Bertrand, P.; Chauzy, C., An indirect enzymoimmunological assay for hyaluronidase. Journal of Immunological Methods 1987, 104, (1-2), 223-229.

38. Williams, G. M.; Klisch, S. M.; Sah, R. L., Bioengineering cartilage growth, maturation, and form. Pediatr. Res. 2008, 63, (5), 527-534. 

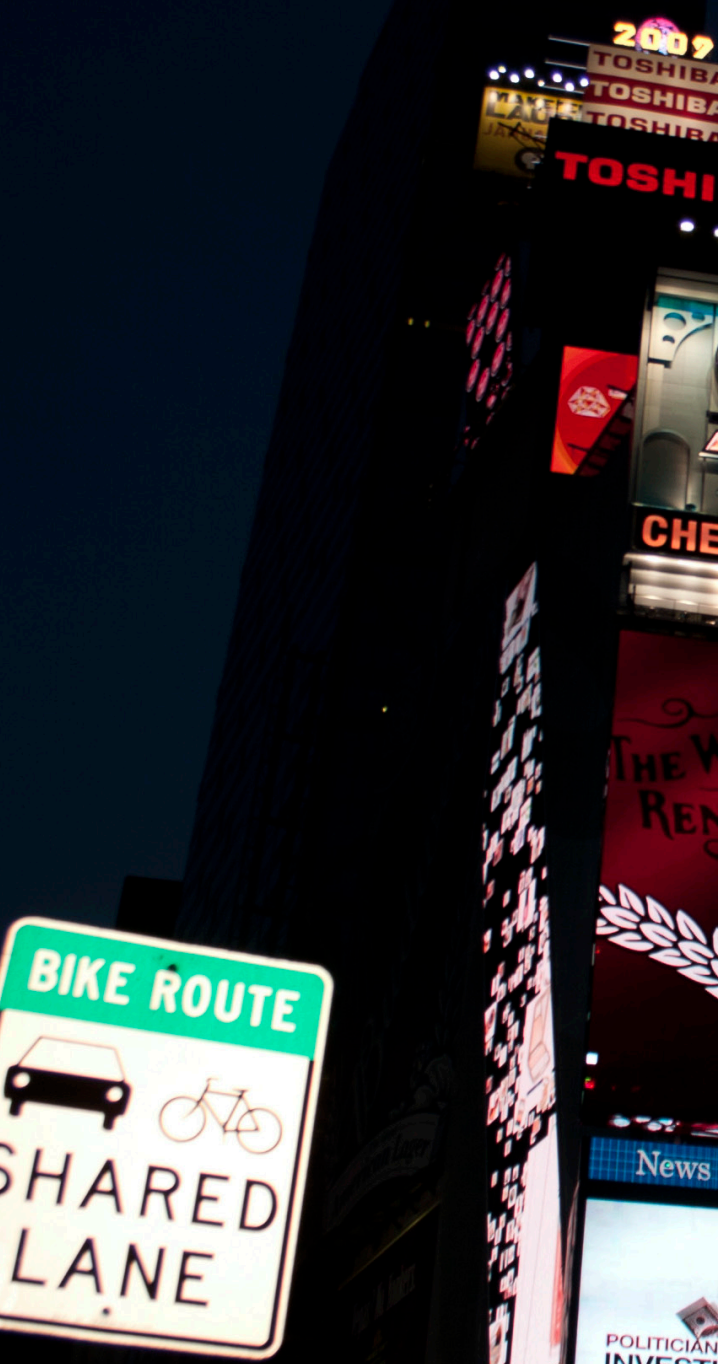

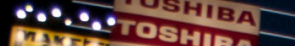

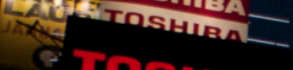

ing
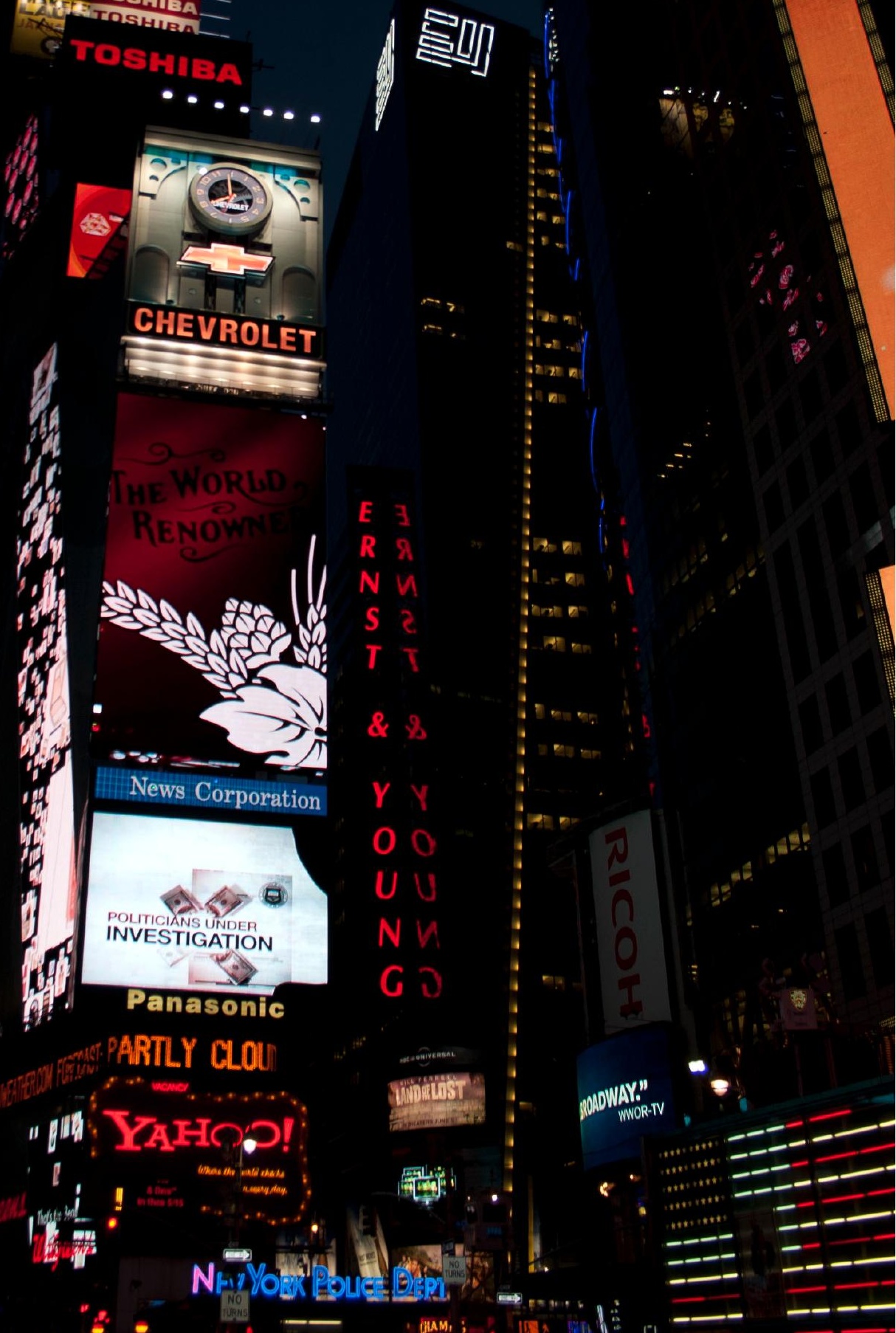

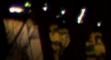

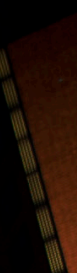

(11)

$N=1+1$ 


\section{Summary}

Cartilage can be damaged due to trauma or diseases like osteoarthritis. These damages cause pain and impair normal articulation of the joint. Current strategies like microfracture, mosaicplasty and autologous chondrocyte implantation for cartilage repair relieve pain and improve joint function but it has been shown that these procedures only lead to a temporary solution. The newly formed tissue often lacks the properties of native cartilage and shows signs of deterioration after 1 year. An alternative approach to cartilage repair is tissue engineering. Tissue engineering is an interdisciplinary field that applies the principles of engineering and life sciences towards the reconstruction or development of biological substitutes that restore, maintain or improve tissue functions ${ }^{1}$. In tissue engineering generally scaffolds are used to provide a stable temporary matrix for cells in order to grow new tissue. Since a hydrogel is a material that closely resembles the natural environment of cells in cartilage, research in tissue engineering of cartilage has mainly focused on these materials to act as a temporary matrix. Although many materials have been designed and prepared to form hydrogels several issues still have to be tackled. One of these issues is the adhesion of hydrogels to the surrounding tissue at the implant site. Hereto we have performed a fundamental study of the effects of incorporating positively charged moieties in amphiphilic block copolymers on their aggregation and (thermo-reversible) gelation behavior and on the formation of physically crosslinked hydrogels. The rationale is to increase the adhesion properties of physically crosslinked hydrogels to soft tissues like cartilage that have an ECM that is negatively charged.

Furthermore, we have studied the influence of the chemical structure and aggregation behavior of tyramine substituted synthetic and natural polymers on their enzymatic crosslinking, an ongoing research subject in our group. Research was aimed at developing injectable and biodegradable scaffolds with controlled degradation times, which support chondrocyte survival and matrix production.

In Chapter 1 a general background of the work described in this thesis is given. Chapter 2 provides a literature overview on cartilage tissue engineering. The review discusses current cartilage repair procedures and associated problems. An overview is given on injectable in situ forming hydrogels currently studied for cartilage tissue engineering. In Chapter $\mathbf{3}$ we describe PEG-PLLA triblock copolymers, comprising a central N-hydroxy succinimide active ester. These copolymers were reacted with $\alpha, \omega$-diamines to afford four-arm (mPEGPLLA) $)_{2}$-R-(PLLA-mPEG) ${ }_{2}$ copolymers with central $\alpha, \omega$-diamide groups (R). When the 
linking unit R contains no secondary amine groups fully thermo-reversible gelation behavior was found. Copolymers comprising an $\mathrm{R}$ group containing secondary amine groups retain a solution state. It is proposed that the protonated amine groups preferably are located at the corona of the micelles and micellar aggregates and/or are shielded by the PEG blocks, hindering the formation of hydrogels by PEG entanglements upon a change in temperature. Chapter 4 describes the gelation behavior of four-arm stereocomplexed (mPEG-PLA) $)_{2}-\mathrm{R}$ (PLA-mPEG) $)_{2}$ copolymers prepared by mixing PBS solutions of polymers with opposite chirality. Gel formation is driven by stereocomplexation of PLLA and PDLA blocks. Temperature dependent rheology experiments showed that the gel-sol phase transitions of the stereocomplexed hydrogels are thermo-reversible when $\mathrm{R}$ is a neutral moiety but become thermo-irreversible when the $\mathrm{R}$ group constitutes one or two secondary amine groups. Differences observed in the gelation behavior of these polymers were related to the type of micelles formed. Whereas the polymer with a neutral R-group most likely forms core shell type micelles, incorporation of a cationic moiety $(\mathrm{R})$ in the 4-arm copolymers affords micelles with a random distribution of block copolymer molecules due to the repulsion between the positive charges. In the latter case gelation upon stereocomplexation at high concentrations leads to small stereocomplexed domains, which act as crosslinks. Chapter 5 reports on hyperbranched poly(ethyleneimine)-poly(L-lactide)-poly(ethylene glycol) ( $\alpha$-HPEI- $\gamma$ (PLLA-mPEG) $)_{2}$ ) copolymers. Hyperbranched copolymers with increasing molecular weight were prepared by coupling NHS-(PLLA-mPEG) ${ }_{2}$ to the primary amine groups of HPEI with molecular weights $(\alpha)$ of $600,1200,1800,5000$ or $10000 \mathrm{~g} / \mathrm{mol}$. At high concentrations $(\geq 25$ wt \%) rheology measurements showed that 1200-HPEI-5.5-(PLLA-mPEG), and 1800-HPEI8.2-(PLLA-mPEG) formed hydrogels while all other hyperbranched copolymers afforded solutions. HR-MAS ${ }^{1} \mathrm{H}-\mathrm{NMR}$ showed that at $25{ }^{\circ} \mathrm{C}$ the PLLA moieties of 1800-HPEI-8.2(PLLA-mPEG) $)_{2}$ were predominantly immobile revealing the formation of hydrophobic domains. HR-MAS ${ }^{1}$ H-NMR spectra of 10000-HPEI-40.3-(PLLA-mPEG), showed that the PLLA groups were relatively mobile at room temperature suggesting a low efficiency in the packing of the PLLA blocks into hydrophobic domains.

The second part of this thesis is directed to enzymatically crosslinked hydrogels for cartilage tissue engineering. It is part of our ongoing research in the field of injectable in-situ forming hydrogels.

In Chapter 6 eight-armed poly(ethylene glycol)-poly(L-lactide)-tyramine (PEG-(PLLATA $)_{8}$ ) star block copolymers with different PLLA block length are described. It was found that the introduction of tyramine end functional groups influenced the aggregation behavior of the PEG-PLLA star block copolymers in an aqueous environment. Compared to PEG$(\text { PLLA })_{8}$ copolymers PEG-(PLLA-TA) ${ }_{8}$ copolymers with a similar PLLA block length had 
a lower critical association concentration and formed physically crosslinked hydrogels with thermo-reversible gel to sol phase transitions at lower concentrations. Enzymatic crosslinking of the PEG-(PLLA-TA) ${ }_{8}$ star block copolymers with horseradish peroxidase (HRP) and $\mathrm{H}_{2} \mathrm{O}_{2}$ was only possible when the tyramine units were exposed to the aqueous phase, which was primarily dependent on the PLLA block length. Based on the availability of tyramine groups and aggregation behavior, crosslinking either afforded hydrogels or crosslinked nanoparticles. In Chapter 7 injectable hydrogels intended for cartilage tissue engineering are described, which were prepared by the HRP mediated co-crosslinking of dextran-tyramine (Dex-TA) and hyaluronic acid-tyramine (HA-TA) conjugates. The gelation times of $10 \mathrm{wt} \%$ polysaccharide solutions are less than 20 seconds and their storage moduli can be adjusted by varying the ratio between Dex-TA and HA-TA. Dex-TA/HA-TA hydrogels were fully degradable in the presence of hyaluronidase. Chondrocytes incorporated in $10 \mathrm{wt}$ $\%$ Dex-TA/HA-TA gels showed good viability after 28 days. Chapter 8 reports on in-situ forming hydrogels prepared by HRP-mediated co-crosslinking of Dex-TA, heparin-tyramine (Hep-TA) and/or HA-TA conjugates in different ratios. In general the gelation times of 10 wt \% polysaccharide solutions were below 20 seconds. Dex-TA/Hep-TA/HA-TA hydrogels with different weight ratios showed good mechanical properties and were fully disintegrated in the presence of hyaluronidase. The degradation times decreased with increasing HA-TA content. Dex-TA/Hep-TA/HA-TA (25/50/25 weight ratio) gels containing chondrocytes showed improved production and expression of collagen type II, compared to e.g. Dex-TA chondrocyte containing control hydrogels. These results indicate that these in-situ forming hydrogels are promising injectable and biodegradable materials for cartilage repair.

\section{References}

1. Langer, R.; Vacanti, J. P., Tissue engineering. Science 1993, 260, (5110), 920-926. 


\section{Samenvatting}

Kraakbeen kan beschadigd raken door ziektes zoals artrose of door trauma. Het defect dat in het gewricht ontstaat resulteert in veel pijn en vermoeilijk de normale articulatie. Huidige strategieën voor kraakbeen reparatie, zoals microfractuur, mozaïekplastie en lichaamseigen kraakbeencel implantatie, helpen tijdelijk de pijn te verlichten en articulatie van het gewricht te verbeteren. Echter, de gevormde structuur van het kraakbeenweefsel heeft niet de eigenschappen van het natuurlijk kraakbeen en laat na 1 jaar tekenen van verslechtering zien. Weefsel regeneratie van kraakbeen is daarom een opkomend onderzoeksgebied. Weefsel regeneratie is een multidisciplinair onderzoeksveld dat de principes van technische wetenschappen en biologische wetenschappen combineert om biologische implantaten te maken die het beschadigd weefsel kan herstellen ${ }^{1}$. Een hydrogel is een materiaal dat overeenkomt met kraakbeen en een hydrogel kan daardoor dienen als een tijdelijk construct voor het regenereren van kraakbeen weefsel. Ondanks er veel materialen zijn ontwikkeld die hydrogelen kunnen vormen blijven er nog enkele problemen over om deze materialen toe te kunnen passen voor weefselregeneratie. Een van deze problemen is de adhesie van de hydrogel aan het omliggende weefsel op de plek van het defect. Om de adhesie met de negatief geladen matrix van kraakbeen te verbeteren is in deze thesis fundamenteel onderzocht hoe het inbouwen van positief geladen eenheden in de amfifiele blok copolymeren het aggregatie en geleringsgedrag van deze fysisch gecrosslinkte hydrogelen beïnvloed. Verder, is er onderzocht naar de invloed van de chemische structuur en aggregatiegedrag van tyramine gesubstitueerde synthetische en natuurlijke polymeren ten opzichte van het enzymatisch crosslinken. Dit onderzoek had als doel om injecteerbare en biodegradeerbare hydrogelen te maken met gecontroleerde degradatie tijden die overleving en matrix productie van chondrocyten verbeteren.

In Hoofdstuk 1wordt een algemene achtergrond van het werk in deze thesis beschreven. Hoofdstuk 2 is een literatuur overzicht van injecteerbare hydrogelen voor kraakbeen weefselregeneratie. Het literatuur overzicht bediscussieert huidige methodes voor kraakbeenreparatie en de meest voorkomende problemen. Aan het einde is er een overzicht van injecteerbare hydrogelen die gebruikt kunnen worden voor kraakbeenregeneratie. In Hoofdstuk 3 worden poly(ethylene glycol)-poly(L-lactide) (PEG)-(PLLA) triblock copolymeren beschreven die centraal een actieve N-hydroxie succinimide ester hebben (NHS-(PLLA-mPEG) $)_{2}$. Deze actieve ester kan vervolgens reageren met $\alpha, \omega$-diamines om vierarmige (mPEG-PLLA) $)_{2}$-R-(PLLA-mPEG) $)_{2}$ te krijgen waar in het centrum $(\mathrm{R})$ een $\alpha, \omega-$ 
diamide groep zit. Copolymeren waar R geen secundaire amine groepen bevat lieten volledig thermo-reversibel gel gedrag zien. Copolymeren waarbij de centrale groep $\mathrm{R}$ een secundaire amine bevatte bleven in een vloeibare staat. Het is voorgesteld dat de geprotoneerde amine groepen het liefst in de hydrofiele corona van de micellen zitten en daardoor de verknoping van de PEG ketens bij tempratuurverandering hinderen. In Hoofdstuk 4 worden vierarmige gestereocomplexeerde (mPEG-PLA) $)_{2}$-R-(PLA-mPEG) ${ }_{2}$ copolymeren omschreven. Hydrogelen worden gemaakt door het mixen van tegenovergestelde chiraliteiten. waardoor stereocomplexatie van de PLLA en PDLA blokken voor gel formatie zorgde. Temperatuur gevoelige rheologie experimenten lieten een gel-sol transitie zien bij stereogecomplexeerde hydrogelen waar geen secondaire amine groepen op positie R zitten. Hydrogelen waar wel secundaire amine groepen aanwezig zijn op positie R laten geen gel-sol transitie zien tijdens verwarmen en afkoelen. De verschillen die te zien zijn in het geleringsgedrag komen door stand in de verschillende type micellen die gevormd zijn. Het polymeer waar R een neutrale groep is vormen grotendeels micellen met een hydrofobe kern en een hydrofiele schil, terwijl polymeren met een geladen groep op R micellen vooral een willekeurige distributie hebben van de hydrofobe en hydrofiele blokken door de repulsie van de geladen groepen. Daardoor kan in het systeem met de geladen groepen makkelijker stereocomplexatie plaatsvinden en dit leidt tot kleine domeintjes van stereocomplexen die als crosslinks dienen in het gel netwerk. Hoofdstuk 5 rapporteert over hyperbranched poly(ethyleneimine)-poly(lactide)poly(ethylene glycol) $\left.(\alpha \text {-HPEI- } \gamma \text {-(PLLA-mPEG) })_{2}\right)_{\text {copolymeren. NHS-(PLLA-mPEG) }}$ is gekoppeld aan de primaire amine groepen van de HPEI met verschillende molecuulgewichten van $600,1200,1800,5000$ en $10000 \mathrm{~g} / \mathrm{mol}$. Rheologie metingen bij hoge concentratie $(\geq 25$ wt \%) laten zien dat 1200-HPEI-5.5-(PLLA-mPEG) ${ }_{2}$ en 1800-HPEI-8.2-(PLLA-mPEG) polymeren hydrogelen vormen terwijl alle andere systemen in de vloeibare fase blijven. HR MAS ${ }^{1} \mathrm{H}-\mathrm{NMR}$ bij $25^{\circ} \mathrm{C}$ laat zien dat de lactide eenheden van 1800-HPEI-8.2-(PLLA$\mathrm{mPEG})_{2}$ vooral immobiel zijn en daardoor worden hydrofobe domeinen gevormd. HR MAS ${ }^{1} \mathrm{H}-\mathrm{NMR}$ bij $25{ }^{\circ} \mathrm{C}$ van 10000-HPEI-40.3-(PLLA-mPEG), laat zien dat de lactide groepen vrij mobiel zijn waardoor er een lage efficiëntie is van het pakken van lactide groepen in hydrofobe domeinen.

In het tweede deel van de thesis worden enzymatisch gecrosslinkte hydrogelen gebruikt voor kraakbeenregeneratie. Dit is onderdeel van een doorlopend onderzoek binnen de vakgroep in het veld van injecteerbare in-situ vormende hydrogelen.

In Hoofdstuk 6 worden achtarmige poly(ethylene glycol)-poly(L-lactide)-tyramine (PEG(PLLA-TA $)_{8}$ ) ster blok copolymeren met verschillende PLLA blok lengte gesynthetiseerd. Door de introductie van de functionele tyramine groep word de aggregatie gedrag van de polymeren in een waterige omgeving veranderd. Vergeleken met een PEG-(PLLA) 8 
copolymeren hebben PEG-(PLLA-TA) ${ }_{8}$ copolymeren met een zelfde PLLA blok lengte een lagere kritische aggregatie concentratie waarde en komen fysische hydrogelen met een thermo-reversibel karakter bij een lagere concentratie tot stand. Enzymatisch crosslinken van PEG-(PLLA-TA) met mierikswortelperoxidase (HRP) en $\mathrm{H}_{2} \mathrm{O}_{2}$ was alleen mogelijk wanneer de tyramine groepen in de water fase aanwezig zijn, wat voornamelijk afhing van de PLLA blok lengte. Gebaseerd op de beschikbaarheid van tyramine groepen en aggregatie gedrag van PEG-(PLLA-TA) $)_{8}$ geeft de crosslink reactie gecrosslinkte hydrogelen of gecrosslinkte nanodeeltjes. In Hoofdstuk 7 worden injecteerbare hydrogelen gemaakt voor kraakbeenregeneratie door het crosslinken van dextran-tyramine (Dex-TA) en hyaluron zuur tyramine (HA-TA) conjugaten doormiddel van $\mathrm{HRP}$ en $\mathrm{H}_{2} \mathrm{O}_{2}$. De geleringstijden van 10 wt $\%$ polysacharide oplossingen zijn $<20$ seconden en de opslagmodulus kan worden aangepast door de compositie van Dex-TA en HA-TA te veranderen. In de aanwezigheid van hyaluronidase zijn Dex-TA/HA-TA hydrogelen volledig afbreekbaar. Kraakbeencellen in 10 wt \% Dex-TA/HA-TA hydrogelen laten een goede levensvatbaarheid zien naar 28 dagen. Hoofdstuk 8 rapporteert over in-situ vormende hydrogelen die gebruikt kunnen worden als matrices voor kraakbeenregeneratie. De hydrogelen worden gemaakt door een HRP gemedieerde crosslink reactie van Dex-TA, heparin tyramine (Hep-TA) en/of HATA. In het algemeen zijn de geleringstijden van $10 \mathrm{wt} \%$ polysacharide oplossingen onder de 20 seconden. Verschillende composities van Dex-TA/Hep-TA/HA-TA vertonen goede mechanische eigenschappen en de hydrogelen desintegreeren volledig in de aanwezigheid van hyaluronidase. De degradatietijden werden korter door de HA-TA hoeveelheid in de gel te laten toenemen. Kraakbeencellen die in die in een Dex-TA/Hep-TA/HA-TA (25/50/25 gewicht ratio) waren gezet lieten verbeterde expressie en productie van collageen type II zien in vergelijking met Dex-TA controle hydrogelen. Deze resultaten maken de Dex-TA/ Hep-TA/HA-TA hydrogelen aantrekkelijke kandidaten als injecteerbare biodegradeerbare materialen voor kraakbeen reparatie.

\section{References}

1. Langer, R.; Vacanti, J. P., Tissue engineering. Science 1993, 260, (5110), 920-926. 


\section{Acknowledgements}

Writing a thesis can be compared with participating in a triathlon match. In a triathlon you first swim then you cycle and finally you run towards the finish. The first year of my PhD I was swimming around and hoping not to drown in the world of academia. The second and third year of a $\mathrm{PhD}$ research you need to cycle to make up lost distance during swimming. Finally, in the fourth year you start running and in the end you need to sprint to the finish line. In sports you have coaches and trainers along the sideline that support and guide you to your goal. But when I sit in front of the computer and start looking back at the last four years of my $\mathrm{PhD}$ research at the University of Twente I notice that there are a lot of people that gave support and guidance to me. Without their help, support, coffee breaks, pubquizes etc. the last four years would not have been as memorable and pleasant. In the following section I would like to express my gratitude to them.

First of all, I would like to thank both my promotors, Prof. Dr. Jan Feijen and Prof. Dr. Piet Dijkstra. Dear Jan, I already read about you in the Tubantia (local newspaper) during my first year as a biomedical engineer student and was intrigued by the research that was described in the article. During my $\mathrm{PhD}$ research I got to know you and your research better. I would like to thank you for all your help, suggestions, support and trust. It was an honor to be part of your research and one of your last $\mathrm{PhD}$ students. Dear Piet, I remember the day that you came to the coffee table and said we had to sit down in your office to discuss my future as yesterday. Four years later I do not regret this decision! As my daily supervisor you gave me a lot of freedom to start my research but when I started to swim too far from the edge or drown your office was always open for useful advice to put me back on track. I really appreciate your time spent on reading and commenting the chapters in this thesis. I still have very fond memories of conferences we visited in Italy and China. In Italy you introduced me to the rainy but artistic landscape of Tuscany and good Chianti during dinner. You also showed me the Tower of Pisa which is an impressive feat of Italian engineering. China is an experience I will never forget, your knowledge of Chinese culture and customs was endless and came in handy picking a restaurant or explaining the taxi driver in bu-sh(i) terms where to go.

Besides my two promotors other people played an important role in this thesis. Marcel Karperien in the beginning of the project OAcontrol, financed by BioMedical Material program, you already showed great interest in hydrogels. During the project you were the one that pushed for more biological studies on the hydrogels and I would like 
to thank you for the opportunity, the patience and comments you gave on my studies. I would have never guessed that after four years we were standing in an operating theatre performing cadaver studies on horses with the in-situ forming hydrogels developed in this thesis. Finally thank you for participating in my promotion committee. Dirk Grijpma, although we did not collaborate in the scientific work of this thesis I believe there would not be a thesis, if not for your inspiring bachelor course in polymer chemistry in the spring of 2006. Your course re-ignited the fascination from the newspaper article and let me to pursue a bachelor and master assignment in the field of polymer chemistry and biomaterials! Thank you for all your guidance and tutoring! Francesca Signori or Fra in short, you only spent two months in Enschede and you left me in shock and awe. Two months of anti-Italian working attitude (the shock) and an orange UFO in which you made the best pizzas I ever tasted (the awe). You generated most of the DLS data from chapters 3, 4 and 5. I truly enjoyed your presence in the laboratory and the discussion and appreciate your time spent in correcting chapters 3,4 and 5. Grazie mille! My thanks also to Liliana Moreira Teixeira your help and knowledge were invaluable during the biological studies of chapter 7 and 8 . Thank you for being available every day for small discussions whenever I had trouble with the biological studies.

Also I would like to thank my students that helped me during the research. You were my team of cyclists that kept me out of the wind and handed me refreshments when needed. My three German angels Alexandra, Kerstin and Nadine. I could not have asked for more enthusiastic and motivated students. Alexandra you were my first student and laid the basis for chapter 3. Kerstin you created a protocol for the synthesis of dextran-tyramine evolving around your smoking schedule (currently replaced with coffee breaks). Your hard work let to chapters 7 and 8. Nadine you arrived in September 2013 and continued with the application of in-situ forming hydrogels in horse knees. Although your research is not in this thesis I hope it will be put to good use in the first animal experiments. Vielen Dank für Ihren Beitrag!!! Agnieszka or in short (Lady) Aga. Your work was involved in chapter 6 and 7 . Your search for a synthetic tyramine crosslinkable hydrogel could fill the journal of failed experiments for a decade. Among these problems you always saw some hope and kept smiling and finally you succeeded. I admire your perseverance! Dzięki!!! Freek you continued on the work fromAlexandra and laid the foundation for chapter 5 and started with a synthetic tyramine crosslinkable hydrogel. I enjoyed the months we worked together! Poyan you completed the biological studies of chapter 8 . Your hand on mentality in the biology laboratories was a very good combination with my method of working!

I owe a special thanks to my labmates. Sytze, we shared an office for 2.5 years and became a discussion partner in the afternoon and evenings. I enjoyed the scientific discussions in the 
office and in the lab. Besides scientific discussions we also shared a passion for watching the Tour de France, a pubquiz after a hard day work and if the switch was turned on some alcoholic beverages. You also introduced me to the car pimping scene with your Fiat Bravo 2.0 20V HGT with Xenon lights and tuned exhaust system that silences the $200 \mathrm{bpm}$ of Tiesto! (Zandvoort and a visit to McDonalds Drive will never be the same anymore...). Niels, beside my lab colleague and discussion partner you also became a friend. I enjoyed having a beer or discuss the latest gossip from famous Dutch people at the coffee table. Niels and Sytze thank you for being my paranymphs $27^{\text {th }}$ of March. Marc for your assistance in numerous experiments, ideas and discussions about life. You also kept my entropic ability for generation of mess and misplacement of glassware in check. Thank you! Rong, after Niels and Sytze left you arrived as a new $\mathrm{PhD}$ student that will continue with insitu forming hydrogels. Your Chinese and chopstick lessons were very useful in China and kept me from starvation! I wish you all the best for the future!

A special thanks is in place for Karin and Zlata, you have given me in countless ways always smiling support in ordering chemicals, lab equipment and administrative help or a coffee break when my nerves got the better of me.

I will not mention names anymore else the acknowledgement would become a thesis in its own right. I would like to give many appreciations and cheers for my DBE, BST, BMC, PBM and other colleagues at the university for their support and activities that made the last four years very memorable!

Last but not least, I would like to thank my friends and family, especially my father and brother, Peter, for all their love and support.

Jos

21-2-2013 